\title{
ASSOCIAÇÃO DO CÁLCULO ELÁSTICO COM A TEORIA DAS CHARNEIRAS PLÁSTICAS PARA LAJES RETANGULARES COM UMA BORDA LIVRE
}

PAULA CACOZA AMED

Dissertação apresentada à Escola de Engenharia de São Carlos, da Universidade de São Paulo, como parte dos requisitos para a obtenção do título de "Mestre em Engenharia de Estruturas".

ORIENTADOR: Prof. Dr. Libânio Miranda Pinheiro 
A532a Amed, Paula Cacoza $\quad$ Associação do cálculo elástico com a teoria das charneiras plásticas para lajes retangulares com uma borda livre / Paula Cacoza Amed -- São Carlos, 1995.

$169 \mathrm{p}$.

Dissertação (Mestrado) -- Escola de Engenharia de São CarlosUniversidade de São Paulo, 1995.

Orientador: Prof.Dr. Libânio Miranda Pinheiro

1. Lajes com uma borda livre - Concreto armado. I. Título. 
Aos meus pais, Farid Mamed Amed

e Maria de Lourdes C. Amed e à minha irmã Silvia 


\section{AGRADECIMENTOS}

A DEUS pela oportunidade de trabalhar com pessoas tão maravilhosas.

Ao Professor Libânio Miranda Pinheiro pela excelente orientação que tornou possível a execução deste trabalho, e, especialmente, por sua amizade.

Aos meus pais e à Silvia por estarem presentes em todos os momentos, me incentivando e apoiando.

Às amigas e aos familiares pelo carinho, apoio e compreensão.

Aos professores José Samuel Giongo e João Batista de Paiva pelo incentivo e colaboração que me dispensaram.

Aos funcionários Maria Nadir Minatel, Marta Regina Couto Faria, Rosi A. Jordão Rodrigues, Rui Roberto Casale e Antônio Valdari Carneiro pela paciência e dedicação e ao funcionário Francisco G. de Brito, desenhista eficiente, pelo belo trabalho.

Aos colegas, professores e funcionários do Departamento de Engenharia de Estruturas da EESC/USP.

Ao CNPQ pela bolsa de estudos.

A todos que, de alguma forma contribuíram para a realização deste trabalho. 


\section{SUMÁRIO}

LISTA DE FIGURAS $\ldots \ldots \ldots \ldots \ldots \ldots \ldots \ldots \ldots \ldots \ldots \ldots \ldots \ldots \ldots \ldots$

LISTA DE TABELAS $\ldots \ldots \ldots \ldots \ldots \ldots \ldots \ldots \ldots \ldots \ldots \ldots \ldots \ldots \ldots \ldots \ldots \ldots$

LISTA DE SÍMBOLOS $\ldots \ldots \ldots \ldots \ldots \ldots \ldots \ldots \ldots \ldots \ldots \ldots \ldots$ VI

LISTA DE ABREVIATURAS E SIGLAS $\ldots \ldots \ldots \ldots \ldots \ldots \ldots \ldots \ldots \ldots$

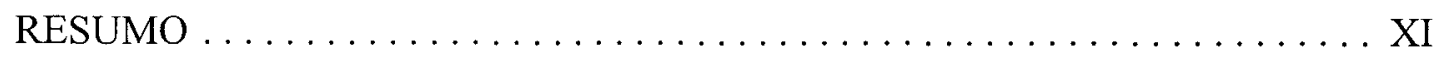

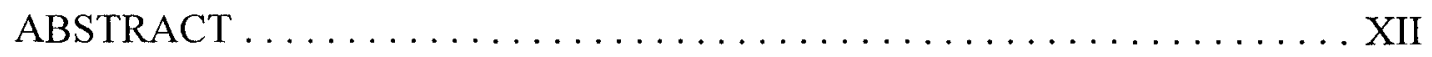

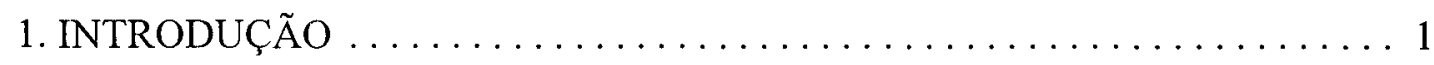

1.1 GENERALIDADES $\ldots \ldots \ldots \ldots \ldots \ldots \ldots \ldots \ldots \ldots \ldots \ldots \ldots$

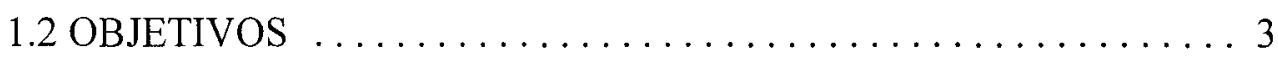

1.3 ETAPAS DO TRABALHO $\ldots \ldots \ldots \ldots \ldots \ldots \ldots \ldots \ldots$

2. MÉTODOS ELÁSTICO E PLÁSTICO $\ldots \ldots \ldots \ldots \ldots \ldots \ldots \ldots \ldots$

2.1 NOÇÕES SOBRE O CÁLCULO ELÁSTICO ............. 5

2.1.1 EQUAÇÃO DIFERENCIAL DAS PLACAS $\ldots \ldots \ldots \ldots 6$

2.1.2 CÁLCULO POR PROCESSOS NUMÉRICOS ...... 9

2.2 NOÇÕES SOBRE O CÁLCULO PLÁSTICO ............ 11

2.2.2 NOÇÕES SOBRE A TEORIA DAS CHARNEIRAS

PLÁSTICAS $\ldots \ldots \ldots \ldots \ldots \ldots \ldots \ldots \ldots \ldots \ldots \ldots \ldots$

2.2.3 TEORIA DO EQUILÍBRIO DE HILLERBORG $\ldots \ldots 14$

3. CÁLCULO ELÁSTICO BASEADO EM TABELAS $\ldots \ldots \ldots \ldots \ldots \ldots$

3.1 GENERALIDADES $\ldots \ldots \ldots \ldots \ldots \ldots \ldots \ldots \ldots \ldots \ldots \ldots \ldots \ldots \ldots$

3.2 CASOS DE VINCULAÇÃO $\ldots \ldots \ldots \ldots \ldots \ldots \ldots \ldots \ldots \ldots$ 


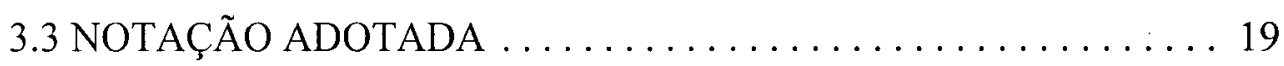

3.4 FUNÇÕES APROXIMADORAS PARA OS MOMENTOS ...... 21

3.4.1 DETERMINAÇÃO DAS FUNÇÕES $\ldots \ldots \ldots \ldots \ldots 21$

3.4.2 EFICIÊNCIA DAS FUNÇÕES ADOTADAS ........ 22

3.5 FUNÇÕES APROXIMADORAS PARA AS FLECHAS ......... 22

4. PRÉ - DIMENSIONAMENTO DAS LAJES $\ldots \ldots \ldots \ldots \ldots \ldots \ldots \ldots \ldots$

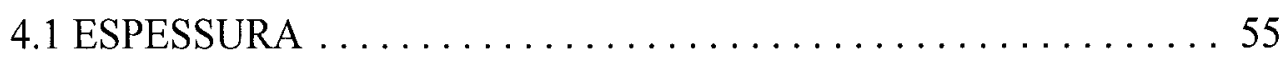

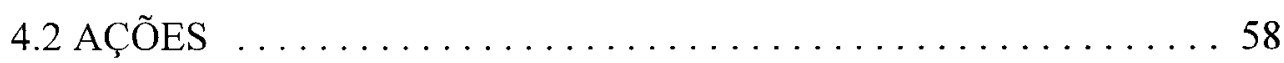

4.2.1 CARGA PERMANENTE $\ldots \ldots \ldots \ldots \ldots \ldots \ldots \ldots 58$

4.2 .2 CARGA DE USO . . . . . . . . . . . . . . . . . 58

4.3 MOMENTOS E COMPATIBILIZAÇÃO $\ldots \ldots \ldots \ldots \ldots \ldots . \ldots 59$

5. A TEORIA DAS CHARNEIRAS PLÁSTICAS $\ldots \ldots \ldots \ldots \ldots \ldots \ldots \ldots$

5.1 FASES DE COMPORTAMENTO $\ldots \ldots \ldots \ldots \ldots \ldots \ldots \ldots . \ldots 1$

5.2 MATERIAIS FRÁGEIS E MATERIAIS DÚCTEIS $\ldots \ldots \ldots \ldots 63$

5.3 MATERIAIS ELASTOPLÁSTICO E RÍGIDO-PLÁSTICO . . . . . 64

5.4 HIPÓTESES DE CÁLCULO $\ldots \ldots \ldots \ldots \ldots \ldots \ldots \ldots \ldots 6$

5.5 REDISTRIBUIÇÃO DOS MOMENTOS $\ldots \ldots \ldots \ldots \ldots \ldots \ldots 6$

5.6 CONFIGURAÇÕES DAS CHARNEIRAS $\ldots \ldots \ldots \ldots \ldots \ldots 67$

5.7 PROCESSO DO EQUILÍBRIO $\ldots \ldots \ldots \ldots \ldots \ldots \ldots \ldots$

5.7.1 DETERMINAÇÃO DAS FORÇAS NODAIS ........ 71

5.7.2 NÓ COM CHARNEIRA DE MESMO SINAL ....... 72

5.7.3 CHARNEIRA CONCORRENTE COM BORDA

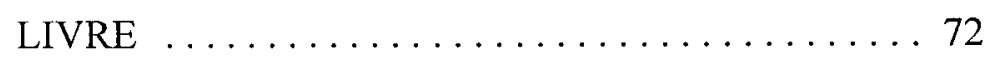

5.7.4 APLICAÇÃO DO PROCESSO DO EQUILÍBRIO . . . . . 74

5.7 .5 EXEMPLO $1 \ldots \ldots \ldots \ldots \ldots \ldots \ldots \ldots \ldots \ldots . \ldots \ldots$

5.8 PROCESSO DA ENERGIA $\ldots \ldots \ldots \ldots \ldots \ldots \ldots \ldots \ldots \ldots$

5.8.1 TRABALHO DAS FORÇAS INTERNAS $\left(\mathrm{T}_{\mathrm{i}}\right) \ldots \ldots \ldots 77$

5.8.2 TRABALHO DAS FORÇAS EXTERNAS .......... 77

5.8 .3 EXEMPLO $2 \ldots \ldots \ldots \ldots \ldots \ldots \ldots \ldots \ldots$ 
5.9 LAJES ISÓTROPAS, ANISÓTROPAS E ORTÓTROPAS

5.10 TRANSFORMAÇÃO DE LAJES ORTÓTROPAS EM

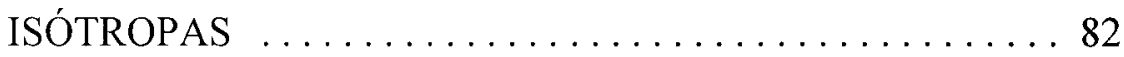

5.11 CARGAS CONCENTRADAS $\ldots \ldots \ldots \ldots \ldots \ldots \ldots \ldots$

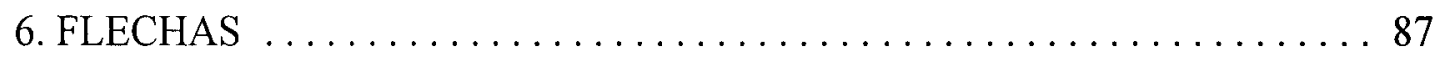

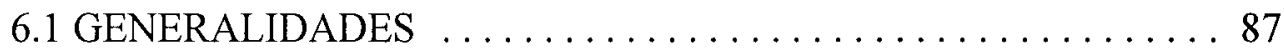

6.2 ESTADOS LIMITES $\ldots \ldots \ldots \ldots \ldots \ldots \ldots \ldots \ldots \ldots \ldots$

6.2.1 ESTADOS LIMITES ÚLTIMOS . . . . . . . . . . . 88

6.2.2 ESTADOS LIMITES DE UTILIZAÇÃO . . . . . . . . . 89

6.3 TIPOS DE DEFORMAÇÕES $\ldots \ldots \ldots \ldots \ldots \ldots \ldots \ldots$

6.4 VALORES LIMITES DAS FLECHAS $\ldots \ldots \ldots \ldots \ldots \ldots . \ldots 90$

6.5 COMBINAÇÕES DAS AÇÕES . . . . . . . . . . . . . . . . . . 91

6.5.1 COMBINAÇÕES QUASE PERMANENTES DE

UTILIZAÇÃO $\ldots \ldots \ldots \ldots \ldots \ldots \ldots \ldots \ldots . \ldots 1$

6.5.2 COMBINAÇÕES FREQUENTES DE UTILIZAÇÃO . . . 91

6.5.3 COMBINAÇÕES RARAS DE UTILIZAÇÃO . ...... 91

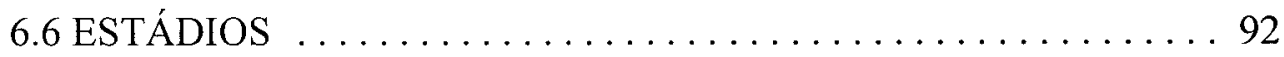

6.7 ROTEIRO DE CÁLCULO ........................... 94

6.7.1 ESPESSURA ........................ 94

6.7.2 CARGAS ........................... 95

6.7.3 MOMENTOS ........................ 95

6.7.4 SITUAÇÕES A CONSIDERAR ............... 96

6.7.5 FLECHA IMEDIATA $\ldots \ldots \ldots \ldots \ldots \ldots \ldots . \ldots 9$

6.7.6 FLECHA DECORRENTE DE AÇÕES

DURADOURAS $\ldots \ldots \ldots \ldots \ldots \ldots \ldots . \ldots 9$

6.7.7 FLECHA IMEDIATA PARA AÇÃO

SUPLEMENTAR ................... 101

6.7.8 FLECHA TOTAL $\ldots \ldots \ldots \ldots \ldots \ldots \ldots \ldots \ldots \ldots$

6.7.9 CRITÉRIO DE ACEITAÇÃO . . ............... 102

6.7 .10 CONTRAFLECHA $\ldots \ldots \ldots \ldots \ldots \ldots \ldots \ldots . \ldots \ldots$ 
7. CÁlCULo dE LAJES RETANGULARES PELA TCP ........... 104

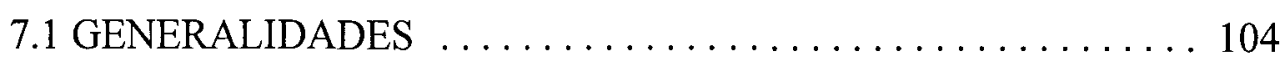

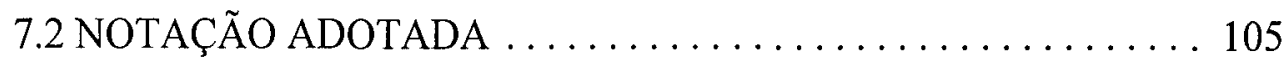

7.3 LAJES RETANGULARES COM UMA BORDA LIVRE ...... 106

7.4 PONTO DE INTERRUPÇÃO DA ARMADURA NEGATIVA . . . 113

7.5 MARCHA DE CÁLCULO ........................ 117

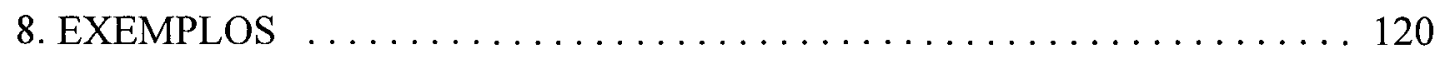

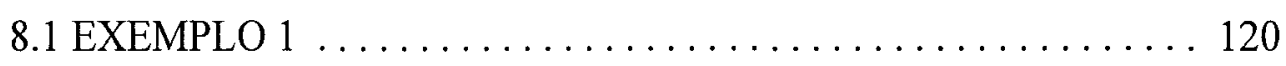

8.1.1 ESPESSURA DAS LAJES $\ldots \ldots \ldots \ldots \ldots \ldots \ldots, 122$

8.1.2 CÁLCULO DOS MOMENTOS ELÁSTICOS …... 123

8.1.3 ARMADURAS PARA CÁLCULO ELÁSTICO ...... 126

8.1.4 COMPRIMENTO DA ARMADURA SUPERIOR

NOS APOIOS ...................... 126

8.1.5 CÁlCULO DOS MOMENTOS PELA TCP ........ 130

8.1.6 ARMADURAS PARA O CÁLCULO PLÁSTICO .... 135

8.1.7 COMPRIMENTO DAS BARRAS SOBRE OS

APOIOS .......................... 139

8.1.8 CÁLCULO DAS FLECHAS : VERIFICAÇÃO

PARA L1 .......................... 142

8.2 EXEMPLO $2 \ldots \ldots \ldots \ldots \ldots \ldots \ldots \ldots \ldots \ldots \ldots \ldots \ldots \ldots \ldots \ldots$

8.2.1 CÁLCULO DOS MOMENTOS ELÁSTICOS ….. 147

8.2 .2 CÁLCULO PELA TCP $\ldots \ldots \ldots \ldots \ldots \ldots \ldots \ldots$

8.2.3 CÁLCULO DAS FLECHAS $\ldots \ldots \ldots \ldots \ldots \ldots \ldots$

9. CONSIDERAÇÕES FINAIS $\ldots \ldots \ldots \ldots \ldots \ldots \ldots \ldots \ldots \ldots \ldots$

9.1 CONTRIBUIÇÕES DO TRABALHO $\ldots \ldots \ldots \ldots \ldots \ldots \ldots$

9.2 ANÁLISE DOS RESULTADOS $\ldots \ldots \ldots \ldots \ldots \ldots \ldots \ldots$

9.3 CONCLUSÕES . . . . . . . . . . . . . . . . . . 162

9.4 SUGESTÕES PARA NOVAS PESQUISAS $\ldots \ldots \ldots \ldots \ldots . \ldots 163$ 


\section{LISTA DE FIGURAS}

FIGURA 2.1 - Esforços em um elemento de placa $\ldots \ldots \ldots \ldots \ldots \ldots \ldots$

FIGURA 2.2- Pontos próximos das bordas . . . . . . . . . . . . 9

FIGURA 3.1- Casos de vinculação com bordas apoiadas ou engastadas . . . . 18

FIGURA 3.2- Casos de vinculação com uma borda livre $\ldots \ldots \ldots \ldots \ldots \ldots$

FIGURA 3.3- Momentos fletores atuantes (caso 8) . . . . . . . . . . . . 19

FIGURA 3.4- Caso $7: \mathrm{m}_{\mathrm{x}} \mathrm{e} \mathrm{m}_{\mathrm{xb}} \ldots \ldots \ldots \ldots \ldots \ldots \ldots \ldots \ldots \ldots \ldots \ldots \ldots \ldots \ldots$

FIGURA 3.5 - Caso $7: \mathrm{m}_{\mathrm{y}}$ e $\mathrm{m}_{\mathrm{ymax}} \ldots \ldots \ldots \ldots \ldots \ldots \ldots \ldots \ldots \ldots \ldots \ldots \ldots \ldots \ldots \ldots$

FIGURA 3.6- Caso $8: \mathrm{m}_{\mathrm{x}} \mathrm{e} \mathrm{m}_{\mathrm{xmax}} \ldots \ldots \ldots \ldots \ldots \ldots \ldots \ldots \ldots \ldots \ldots \ldots \ldots \ldots \ldots$

FIGURA $3.7-$ Caso $8: \mathrm{m}_{\mathrm{y}} \mathrm{e} \mathrm{m}_{\mathrm{ymax}} \ldots \ldots \ldots \ldots \ldots \ldots \ldots \ldots \ldots \ldots \ldots \ldots \ldots \ldots \ldots$

FIGURA 3.8- Caso $8: \mathrm{m}_{\mathrm{y}}^{\prime} \quad \ldots \ldots \ldots \ldots \ldots \ldots \ldots \ldots \ldots \ldots \ldots \ldots \ldots \ldots \ldots \ldots \ldots \ldots$

FIGURA 3.9- Caso $9: \mathrm{m}_{\mathrm{x}}, \mathrm{m}_{\mathrm{xb}} \mathrm{e} \mathrm{m}_{\mathrm{xbmax}} \ldots \ldots \ldots \ldots \ldots \ldots \ldots \ldots \ldots \ldots$

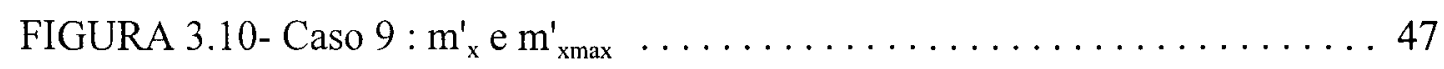

FIGURA $3.11-$ Caso $9: \mathrm{m}_{\mathrm{y}}$ e $\mathrm{m}_{\mathrm{ymax}} \ldots \ldots \ldots \ldots \ldots \ldots \ldots \ldots \ldots \ldots \ldots \ldots \ldots$

FIGURA $3.12-$ Caso $10: \mathrm{m}_{\mathrm{x}} \mathrm{e}_{\mathrm{xb}} \ldots \ldots \ldots \ldots \ldots \ldots \ldots \ldots \ldots \ldots \ldots \ldots \ldots \ldots \ldots \ldots$

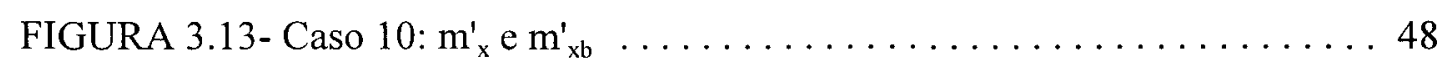

FIGURA $3.14-$ Caso $10: \mathrm{m}_{\mathrm{y}}$ e $\mathrm{m}_{\mathrm{ymax}} \ldots \ldots \ldots \ldots \ldots \ldots \ldots \ldots \ldots \ldots \ldots \ldots \ldots \ldots$

FIGURA 3.15- Caso 11: $\mathrm{m}_{\mathrm{x}}, \mathrm{m}_{\mathrm{xb}} \mathrm{e}_{\mathrm{xbmax}} \ldots \ldots \ldots \ldots \ldots \ldots \ldots \ldots \ldots \ldots \ldots \ldots$

FIGURA 3.16 - Caso $11: \mathrm{m}_{\mathrm{x}}^{\prime}$ e $\mathrm{m}_{\mathrm{x} \max }^{\prime} \ldots \ldots \ldots \ldots \ldots \ldots \ldots \ldots \ldots \ldots \ldots \ldots \ldots \ldots \ldots \ldots$

FIGURA 3.17 - Caso $11: \mathrm{m}_{\mathrm{y}}$ e $\mathrm{m}_{\mathrm{ymax}} \ldots \ldots \ldots \ldots \ldots \ldots \ldots \ldots \ldots \ldots \ldots \ldots \ldots \ldots \ldots \ldots$

FIGURA $3.18-$ Caso $11: m_{y \max }^{\prime} \ldots \ldots \ldots \ldots \ldots \ldots \ldots \ldots \ldots \ldots \ldots \ldots \ldots \ldots \ldots \ldots \ldots$

FIGURA 3.19 - Caso $12: \mathrm{m}_{\mathrm{x}} \mathrm{e} \mathrm{m}_{\mathrm{xb}} \ldots \ldots \ldots \ldots \ldots \ldots \ldots \ldots \ldots \ldots \ldots \ldots \ldots \ldots \ldots$

FIGURA 3.20 - Caso $12: \mathrm{m}_{\mathrm{x}}^{\prime} \mathrm{e}^{\prime} \mathrm{m}_{\mathrm{xb}} \ldots \ldots \ldots \ldots \ldots \ldots \ldots \ldots \ldots \ldots \ldots \ldots \ldots \ldots \ldots \ldots$

FIGURA 3.21 - Caso $12: \mathrm{m}_{\mathrm{y}}$ e $\mathrm{m}_{\mathrm{ymax}} \ldots \ldots \ldots \ldots \ldots \ldots \ldots \ldots \ldots \ldots \ldots \ldots \ldots \ldots \ldots \ldots \ldots$

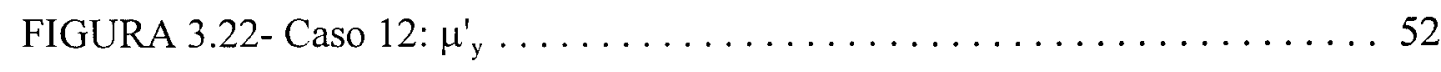

FIGURA 3.23 - Caso $7: \alpha$ e $\alpha_{b} \ldots \ldots \ldots \ldots \ldots \ldots \ldots \ldots \ldots \ldots \ldots \ldots \ldots \ldots \ldots \ldots \ldots \ldots$

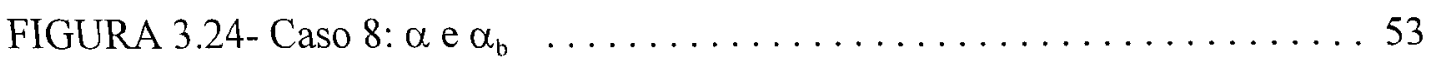




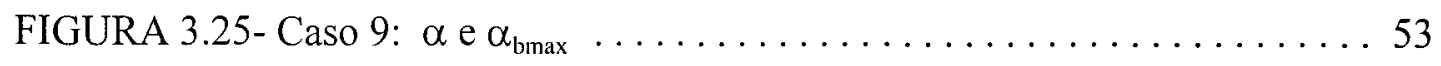

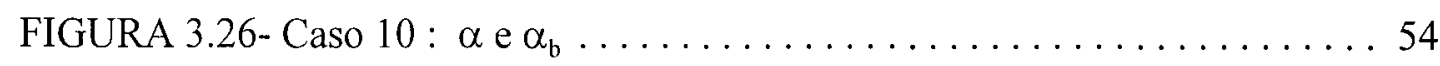

FIGURA 3.27- Caso 11: $\alpha$ e $\alpha_{\text {bmax }} \ldots \ldots \ldots \ldots \ldots \ldots \ldots \ldots \ldots \ldots \ldots \ldots \ldots \ldots \ldots$

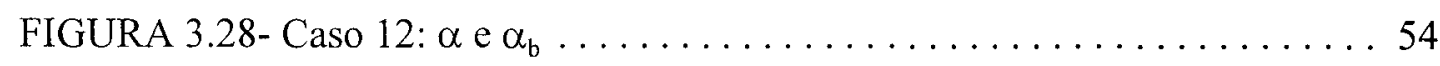

FIGURA 5.1 - Fases de comportamento das lajes subarmadas . . . . . . . . 62

FIGURA 5.2- Diagramas tensão - deformação . . . . . . . . . . . . . 64

FIGURA 5.3-Comportamento dos materiais $\ldots \ldots \ldots \ldots \ldots \ldots \ldots$

FIGURA 5.4- Exemplos de configurações possíveis . . . . . . . . . . 68

FIGURA 5.5- Configurações de ruína de lajes com contorno poligonal

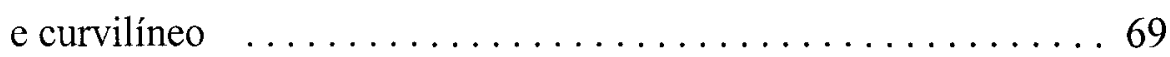

FIGURA $5.6-$ Forças de transmissão $\ldots \ldots \ldots \ldots \ldots \ldots \ldots \ldots \ldots \ldots$

FIGURA 5.7- Nó com duas charneiras positivas e uma negativa . . . . . . . 72

FIGURA 5.8- Charneira concorrente com borda não engastada . . . . . . . 73

FIGURA 5.9- Charneira concorrente com borda não engastada . . . . . . . . 75

FIGURA 5.10- Laje retangular com uma borda livre . . . . . . . . . . . 79

FIGURA 5.11 - Elemento de laje ortótropa $\ldots \ldots \ldots \ldots \ldots \ldots \ldots \ldots \ldots \ldots$

FIGURA 5.12- Obtenção de laje isótropa afim $\ldots \ldots \ldots \ldots \ldots 4$

FIGURA 5.13- Contorno engastado ou apoiado sem armadura superior . . . . . 85

FIGURA 6.1- Diagramas de tensões nos estádios de comportamento . . . . . . 92

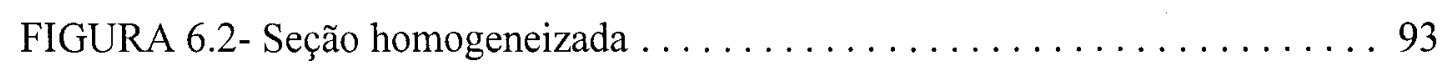

FIGURA 6.3- Diagrama de deformações $\ldots \ldots \ldots \ldots \ldots \ldots \ldots . \ldots . \ldots 9$

FIGURA 6.4 - Diagrama de deformações $\ldots \ldots \ldots \ldots \ldots \ldots \ldots \ldots \ldots \ldots$

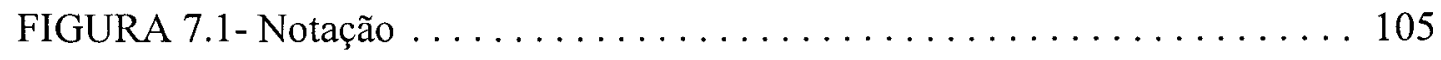

FIGURA 7.2- Laje retangular com uma borda livre $\ldots \ldots \ldots \ldots \ldots \ldots$

FIGURA 7.3- Extensão da armadura negativa $\ldots \ldots \ldots \ldots \ldots \ldots \ldots \ldots$

FIGURA 7.4- Laje retangular com uma borda livre $\ldots \ldots \ldots \ldots \ldots \ldots \ldots$ 
FIGURA 8.1 - Planta de fôrma do exemplo $1 \ldots \ldots \ldots \ldots \ldots \ldots$

FIGURA 8.2- Vínculos das lajes . . . . . . . . . . . . . . . . 122

FIGURA 8.3- Laje retangular com borda livre: LAJE $1=$ LAJE $8 \ldots \ldots \ldots 124$

FIGURA 8.4- Momentos elásticos compatibilizados . . . . . . . . . . . . 125

FIGURA 8.5- Detalhamento da armadura inferior (positiva) . . . . . . . 128

FIGURA 8.6- Detalhamento da armadura superior (negativa) . . . . . . . . . 129

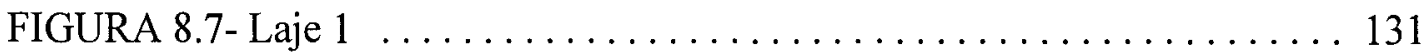

FIGURA 8.8- Momento x Função $\ldots \ldots \ldots \ldots \ldots \ldots \ldots \ldots \ldots \ldots \ldots \ldots \ldots$

FIGURA 8.9- Momentos plásticos $\ldots \ldots \ldots \ldots \ldots \ldots \ldots \ldots \ldots \ldots \ldots$

FIGURA 8.10- Detalhamento da armadura inferior (positiva) . . . . . . . 138

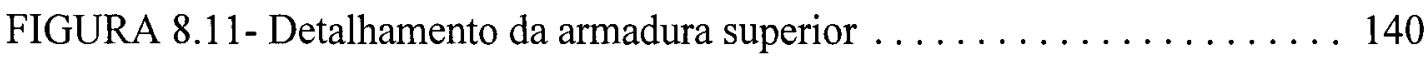

FIGURA 8.12- Planta de fôrma do exemplo $2 \ldots \ldots \ldots \ldots \ldots \ldots \ldots$

FIGURA 8.13- Momentos elásticos compatibilizados $\ldots \ldots \ldots \ldots \ldots \ldots . \ldots 148$

FIGURA 8.14- Detalhamento da armadura inferior $\ldots \ldots \ldots \ldots \ldots \ldots$

FIGURA 8.15- Detalhamento da armadura superior . . . . . . . . . . 151

FIGURA 8.16- Momentos para o cálculo plástico $\ldots \ldots \ldots \ldots \ldots \ldots \ldots$

FIGURA 8.17- Detalhamento da armadura inferior $\ldots \ldots \ldots \ldots \ldots \ldots \ldots$

FIGURA 8.18- Detalhamento da armadura superior $\ldots \ldots \ldots \ldots \ldots \ldots$ 


\section{LISTA DE TABELAS}

TABELA 3.1- CASO 7: Momentos para carga uniforme $\ldots \ldots \ldots \ldots \ldots \ldots 23$

TABELA 3.2- CASO 8: Momentos para carga uniforme .............. 24

TABELA 3.3- CASO 8: Momentos para carga uniforme .............. 25

TABELA 3.4- CASO 9: Momentos para carga uniforme $\ldots \ldots \ldots \ldots \ldots \ldots$

TABELA 3.5- CASO 9: Momentos para carga uniforme $\ldots \ldots \ldots \ldots \ldots 27$

TABELA 3.6- CASO 10: Momentos para carga uniforme $\ldots \ldots \ldots \ldots \ldots 28$

TABELA 3.7- CASO 10: Momentos para carga uniforme . . . . . . . . . . . 29

TABELA 3.8-CASO 11: Momentos para carga uniforme ............ 30

TABELA 3.9- CASO 11: Momentos para carga uniforme ............ 31

TABELA 3.10- CASO 11: Momentos para carga uniforme ............ 32

TABELA 3.11- CASO 12: Momentos para carga uniforme ........... 33

TABELA 3.12- CASO 12: Momentos para carga uniforme ............ 34

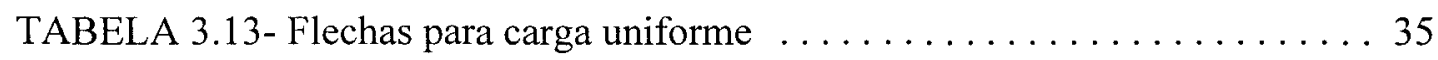

TABELA 3.14- Flechas para carga uniforme $\ldots \ldots \ldots \ldots \ldots \ldots \ldots \ldots \ldots \ldots \ldots \ldots$

TABELA 3.15a- Funções aproximadoras dos momentos fletores $\ldots \ldots \ldots \ldots 37$

TABELA 3.15b- Funções aproximadoras dos momentos fletores $\ldots \ldots \ldots \ldots 38$

TABELA 3.15c- Funções aproximadoras dos momentos fletores $\ldots . \ldots \ldots . . .39$

TABELA 3.15d- Funções aproximadoras dos momentos fletores $\ldots \ldots \ldots \ldots 40$

TABELA 3.15e- Funções aproximadoras dos momentos fletores $\ldots . \ldots \ldots 41$

TABELA 3.15f- Funções aproximadoras dos momentos fletores . . . . . . . . . 42

TABELA 3.16a- Funções aproximadoras para as flechas . . . . . . . . . 43

TABELA 3.16b- Funções aproximadoras para as flechas . . . . . . . . . . . 44

TABELA 4.1 - Valores de $\psi_{2}$ para lajes armadas em uma direção . . . . . . . 56

TABELA 4.2- Valores de $\psi_{2}$ para lajes armadas em cruz ............ 56

TABELA 4.3- Valores de $\Psi_{3}$ para lajes maciças $\ldots \ldots \ldots \ldots \ldots \ldots \ldots \ldots$

TABELA 4.4- Cargas de uso em edifícios (NBR 6120, 1980) . . . . . . . . 59 


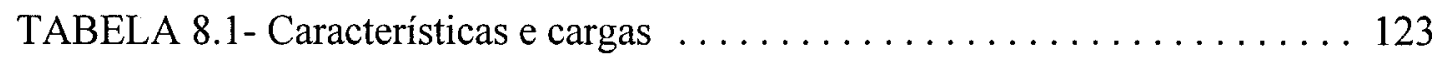

TABELA 8.2- Momentos elásticos adotados $\ldots \ldots \ldots \ldots \ldots \ldots \ldots \ldots \ldots \ldots$

TABELA 8.3- Momentos positivos e respectivas armaduras. ........... 127

TABELA 8.4- Momentos negativos e respectivas armaduras. ........... 127

TABELA 8.5- Quantidade de barras ....................... 130

TABELA 8.6 - Quantidade de aço da armadura .................. 130

TABELA 8.7- Momentos positivos e respectivas armaduras ............ 135

TABELA 8.8- Momentos negativos e respectivas armaduras ............ 136

TABELA 8.9- Quantidade de barras $\ldots \ldots \ldots \ldots \ldots \ldots \ldots \ldots \ldots \ldots . \ldots \ldots$

TABELA 8.10- Massa do aço da armadura $\ldots \ldots \ldots \ldots \ldots \ldots \ldots \ldots \ldots . . \ldots \ldots 14$

TABELA 8.11- Características e cargas ....................... 147

TABELA 8.12- Momentos elásticos adotados $\ldots \ldots \ldots \ldots \ldots \ldots \ldots \ldots . \ldots \ldots$

TABELA 8.13- Momentos positivos e respectivas armaduras ............ 149

TABELA 8.14- Momentos negativos e respectivas armaduras ............ 149

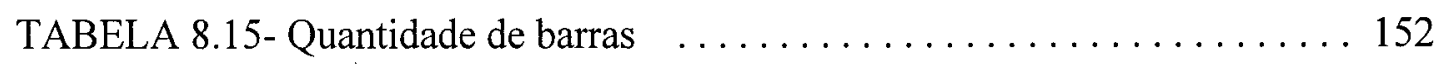

TABELA 8.10- Massa do aço da armadura .................... 152

TABELA 8.17- Momentos positivos e respectivas armaduras ........... 154

TABELA 8.18- Momentos negativos e respectivas armaduras ........... 155

TABELA 8.19- Quantidade de barras $\ldots \ldots \ldots \ldots \ldots \ldots \ldots \ldots \ldots \ldots . \ldots \ldots$

TABELA 8.20 - Massa do aço da armadura $\ldots \ldots \ldots \ldots \ldots \ldots \ldots \ldots \ldots . \ldots \ldots$ 


\section{LISTA DE SÍMBOLOS}

LETRAS ROMANAS MAIÚSCULAS:

A área da seção

$\mathbf{A}^{*}$ área de concreto equivalente à armadura de tração

$\mathbf{A}_{\mathbf{s}}^{\prime} \quad$ área da armadura comprimida

$\mathbf{A}_{\text {cc }}^{*}$ área de concreto equivalente à armadura comprimida

D módulo de rigidez à flexão

E módulo de deformação longitudinal do concreto

$\mathbf{E}_{\mathbf{c}} \quad$ módulo de elasticidade do concreto

$\mathbf{E}_{\mathrm{co}} \quad$ módulo tangente à origem

H distância de um ponto arbitrário até o eixo de rotação

I momento de inércia à flexão da placa

$\mathbf{K}_{\mathbf{i}} \quad$ forças nodais

$\mathbf{M}_{\mathbf{r}} \quad$ momento de fissuração 
$\mathbf{T}_{\mathbf{e}} \quad$ trabalho das forças externas

$\mathbf{T}_{\mathbf{i}} \quad$ trabalho das forças internas

V forças de transmissão

\section{LETRAS ROMANAS MINÚSCULAS:}

a flecha

$\beta \quad$ coeficiente de fluência

h espessura da laje

$\ell_{h} \quad$ comprimento do vão na direção "horizontal"

$\ell_{v} \quad$ comprimento do vão na direção "vertical"

m momento fletor por unidade de comprimento

$\mathbf{m}_{\mathbf{i}} \quad$ momento de plastificação por unidade de comprimento

$\mathbf{m}_{\mathrm{h}}$ momento relativo à armadura "horizontal"

$\mathbf{m}_{\mathbf{v}}$ momento relativo à armadura "vertical"

p carga total uniformemente distribuída 
$\mathbf{p}_{\ell} \quad$ carga linear

r reação de apoio

$(1 / \mathbf{r})_{t}$ curvatura final

$(\mathbf{1} / \mathbf{r})_{\mathrm{i}}$ curvatura inicial

u ângulo entre a carga linear e a seção que resiste ao momento

$\mathbf{x}_{1} \quad$ linha neutra no estádio I

$\mathbf{w}(\mathbf{x}, \mathbf{y})$ função que determina os deslocamentos verticais dos pontos $(\mathrm{x}, \mathrm{y})$ do plano médio da placa 


\section{LETRAS GREGAS:}

v coeficiente de Poisson

$\boldsymbol{\mu} \quad$ coeficiente adimensional para cálculo do momento fletor ou razão dos momentos de vão

$\alpha \quad$ coeficiente adimensional para cálculo da flecha

$\alpha_{\mathrm{e}} \quad$ razão entre os módulos de elasticidade do aço e do concreto

$\rho \quad$ coeficiente adimensional para cálculo da reação de apoio

$\theta \quad$ rotação das charneiras

К razão dos momentos positivos

$\sigma_{\text {st }} \quad$ tensão na armadura de tração

$\sigma_{\text {se }} \quad$ tensão na armadura comprimida

$\phi \quad$ razão entre o momento de plastificação negativo e o positivo 


\section{LISTA DE ABREVIATURAS E SIGLAS}

ACI American Concrete Institute

CEB Comité Euro-International du Béton

EESC Escola de Engenharia de São Carlos

NBR Norma Brasileira Registrada

TCP Teoria das Charneiras Plásticas

USP Universidade de São Paulo 


\section{RESUMO}

AMED, P. C. (1995). Associação do cálculo elástico com a teoria das charneiras plásticas para lajes retangulares com uma borda livre. São Carlos. 168p. Dissertação (Mestrado) -Escola de Engenharia de São Carlos, Universidade de São Paulo.

Este trabalho apresenta uma associação dos cálculos elástico e plástico, para lajes retangulares com carga uniforme e uma borda livre. O cálculo elástico é usado para prédimensionamento, na determinação dos momentos negativos e da razão dos momentos positivos nas duas direções. Esses momentos fletores são obtidos através de funções aproximadoras, determinadas a partir de tabelas. Após compatibilização dos momentos elásticos, são adotados os momentos de plastificação negativos, sendo os positivos obtidos através da teoria das charneiras plásticas, que é utilizada também no cálculo do comprimento das barras sobre os apoios. Conhecidas as armaduras, os momentos elásticos são novamente utilizados na verificação das flechas. Nos exemplos são comparadas as armaduras do cálculo elástico com as obtidas através do cálculo plástico, no qual se pôde constatar a economia deste último em relação ao primeiro.

Palavras-chave: Teoria das Charneiras Plásticas; Lajes com uma borda livre 


\section{ABSTRACT}

AMED, P. C. (1995). The elastic analysis associated with the yield line theory for rectangular slabs with a free edge. São Carlos. 168p. Dissertação (Mestrado) Escola de Engenharia de São Carlos, Universidade de São Paulo.

This work presents an association of elastic and plastic analysis, for rectangular slabs with uniform load and a free edge. The elatic theory is used to estimate the negative moments and the relation between positive moments in the two directions. These bending moments are obtained from approached functions, based on tables. After compatibilization of elastic moments, the negative plastic moments are adoted and the positive moments are obtained from yield line theory, which will be used again in the calculation of the lenght of the bars over the supports. Once the reinforcements are known, the elastic moments are used again for checking the deflexions. In the examples, the results of elastic plate theory are compared with those obtained by plastic analysis, where it is possible to evidence the economy of the later over the former.

Keywords: Yield Line Theory; Slabs with a free edge 


\section{INTRODUÇÃO}

\subsection{GENERALIDADES}

$\mathrm{Na}$ análise de placas, há basicamente dois métodos usuais de cálculo: o elástico linear e o plástico. Sendo o problema fundamental afastar a possibilidade de ruína, o cálculo plástico é o mais indicado, pois nessas situações os materiais se comportam plasticamente.

Porém, o cálculo plástico apresenta restrições: as relações entre momentos em duas direções e entre momentos de apoio e de vão, na mesma direção, devem ser adotados de início e, principalmente, não serve para analisar o comportamento das estruturas em serviço pois, nessas condições, os materiais em geral se comportam elasticamente.

Portanto, para verificar as condições de utilização da estrutura - basicamente fissuração e flechas -, o cálculo elástico é o mais adequado. O cálculo elástico serve também como pré-dimensionamento para o cálculo plástico, fornecendo dados sobre os momentos de apoio e relação entre os momentos de vão, valores estes que são coerentes com o comportamento das estruturas em serviço. Fica evidente, portanto, que os cálculos elástico e plástico se completam.

Os pioneiros do cálculo estrutural já tinham a noção correta de que na ruína os materiais se comportam plasticamente. GALILEI (1638), analisando ensaios de vigas de pedra e de madeira, admitiu que havia a mesma tração em todas as fibras, portanto uma hipótese plástica. Errou por ter considerado que toda compressão se concentrava junto à face mais comprimida, o que levava a resultados contra a segurança em relação aos observados nos ensaios. 
Após a publicacão da lei de Hooke em 1678, o cálculo elástico passou a receber maior atenção. Retomando a pesquisa de Galilei, Mariotte fez a consideração correta de que a compressão se distribuía ao longo de certa altura; admitindo distribuição elástica das tensões de compressão, obteve resultados mais próximos dos observados nos ensaios de Galilei e com destaque para o fato de estarem a favor da segurança.

Como na época o interesse dos pesquisadores estava voltado para o comportamento das peças estruturais em serviço, o cálculo plástico ficou relegado. Por levar a um dimensionamento a favor da segurança e por permitir um elegante tratamento matemático, o cálculo elástico continuou a receber maior atenção até os tempos atuais. Somente no século XX o cálculo plástico começou a recuperar parte do terreno perdido.

Para as lajes, INGERSLEV (1923) deu início à "teoria das charneiras plásticas". Estudou o equilíbrio de cada região, delimitada pelas charneiras, que são linhas de plastificação, assumindo existirem apenas momentos ao longo dessas linhas.

JOHANSEN (1932) fez algumas correções, criando o conceito de forças nodais, que são forças que substituem os efeitos das forças cortantes e dos momentos torsores e que atuam nas interseções das linhas de plastificação. Como ele deu grande desenvolvimento ao processo, foram creditados a ele os méritos de criador da teoria das charneiras plásticas.

Essa teoria foi pouco abordada até 1950, destacando-se os trabalhos de GVOZDEV (1934), (1938), (1939), (1948), (1949), (1949), na União Soviética, os do próprio JOHANSEN (1934), (1949) e de CHAMECKI (1948), este último no Brasil, sendo divulgada após isto com inúmeros trabalhos, destacando-se os de MANSFIELD (1957), WOOD (1961), JONES (1966)e LANGENDONCK (1966), (1970), (1975).

Apesar disso, sua utilização era limitada, pois faltava maior divulgação de processos que permitissem ao engenheiro enfrentar os casos reais da prática, que são as lajes anisótropas contínuas. AMARAL (1964) propôs fórmulas simples e diretas, onde os próprios momentos negativos eram fixados, facilitando o uso da teoria. PINHEIRO (1988) fixou as relações entre os momentos negativos e positivos conduzindo a cálculo iterativo, uma vez que, nos vínculos onde há continuidade das lajes, os momentos são diferentes. SANTOS (1989) aprimorou o trabalho de Amaral e RIOS (1991) seguiu a 
mesma linha de Santos, fixando os momentos negativos e a relação entre os positivos.

Neste trabalho foram incluídas funções aproximadoras e exemplos de lajes com uma borda livre utilizando o método do equilíbrio, sem a consideração de leques das charneiras nos cantos da laje. O cálculo é feito para lajes retangulares sujeitas a carga uniformemente distribuída e carga linear ao longo da borda livre.

\subsection{OBJETIVOS}

Tem-se como objetivo o cálculo de lajes retangulares com carga uniforme e uma borda livre, associando o cálculo elástico ao plástico, podendo haver carga linear ao longo da borda livre.

Utilizar-se-á o cálculo elástico para a determinação dos momentos negativos e da razão dos momentos positivos nas duas direções. Estes valores servirão de base para o cálculo pela teoria das charneiras plásticas, usado para dimensionamento e para determinação do comprimento das barras sobre os apoios.

Obtidas as armaduras e suas distribuições, dever-se-á analisar também os deslocamentos transversais, situações em que o cálculo elástico será novamente utilizado.

\subsection{ETAPAS DO TRABALHO}

Neste primeiro capítulo foram apresentadas considerações gerais sobre o trabalho.

As noções sobre o cálculo elástico, o cálculo plástico e outros procedimentos de cálculo estão apresentados no capítulo 2 . O capítulo 3 apresenta tabelas de momentos 
fletores e de flechas para lajes com uma borda livre, considerando comportamento elástico.

O pré-dimensionamento das lajes é apresentado no capítulo 4.

O capítulo 5 apresenta a teoria das charneiras plásticas, aplicada às lajes retangulares com uma borda livre, onde se encontra a formulação para o cálculo dos momentos de plastificação.

O capítulo 6 apresenta um roteiro para o cálculo das flechas. O cálculo sistematizado de lajes retangulares pela TCP é apresentado no capítulo 7. Exemplos de projetos de lajes com uma borda livre, usando-se o cálculo elástico e a teoria das charneira plásticas, são apresentados no capítulo 8.

O capitulo 9 apresenta uma comparação dos resultados obtidos no capítulo 8, as conclusões e as sugestões para novas pesquisas. 


\section{MÉTOdOS ELÁSTICO E PLÁSTICO}

Neste capítulo serão apresentados os aspectos principais relativos aos métodos elástico e plástico. Eles se completam, pois cada um serve a propósitos distintos.

\subsection{NOÇÕES SOBRE O CÁLCULO ELÁSTICO}

O método elástico, fundado na teoria da elasticidade e portanto mais coerente com os esforços da laje em serviço, neste trabalho admite-se que o material seja homogêneo, isótropo e tenha comportamento linear. Esse método, também conhecido como método clássico, fornece a melhor distribuição das armaduras. Serve, portanto, como base para o cálculo plástico, no qual a razão dos momentos de vão precisa ser adotada.

Com respeito à ruína, o cálculo elástico apresenta limitações. A primeira é que, para certos tipos de estruturas indeterminadas, é difícil encontrar solução precisa, sendo adotadas soluções aproximadas ou apenas estimadas. É o que ocorre com as lajes, pois fora os casos de formas simples e carregamentos padrões, as equações diferenciais e as condições de contorno tornam-se complexas, exigindo o emprego de processos numéricos, que nem sempre são de fácil acesso ao engenheiro comum. 
6

A segunda limitação é que os métodos elásticos não fornecem indicação precisa de segurança, porque por ocasião da ruína o material se comporta plasticamente, contrariando as hipóteses da teoria da elasticidade. Entretanto, o cálculo elástico é indispensável no estudo do comportamento da estrutura durante sua utilização; é útil como pré-dimensionamento para o cálculo plástico, na escolha da proporção entre os momentos positivos nas duas direções e na avaliação dos momentos negativos ou de suas razões com os positivos na mesma direção.

\subsubsection{EQUAÇÃO DIFERENCIAL DAS PLACAS}

Ao submeter uma placa delgada horizontal a ações normais ao seu plano, sua deformada pode ser definida pela função $\mathrm{w}(\mathrm{x}, \mathrm{y})$, que determina os deslocamentos verticais dos pontos $(\mathrm{x}, \mathrm{y})$ do plano médio. Admite-se então que esses pontos sofram apenas deslocamentos verticais, pequenos em relação à espessura, e que as retas normais ao plano médio permaneçam perpendiculares à superfície deformada.

Supõe-se que a placa seja constituída de material homogêneo e isótropo, tenha comportamento linear e que as ações sejam verticais e aplicadas de cima para baixo.

A convenção adotada supõe tensões normais positivas, quando provocam tração na face inferior do elemento, e tensões tangenciais positivas (sempre tomando a face inferior como referência), se coincidem com o sentido positivo dos eixos. Os esforços são considerados positivos quando os momentos fletores provocam tração nas fibras inferiores, os momentos volventes têm seu vetor emergente da face considerada e os esforços cortantes tendem a girar o elemento no sentido horário, olhando o eixo da esquerda para a direita, como mostra a figura 2.1 . 


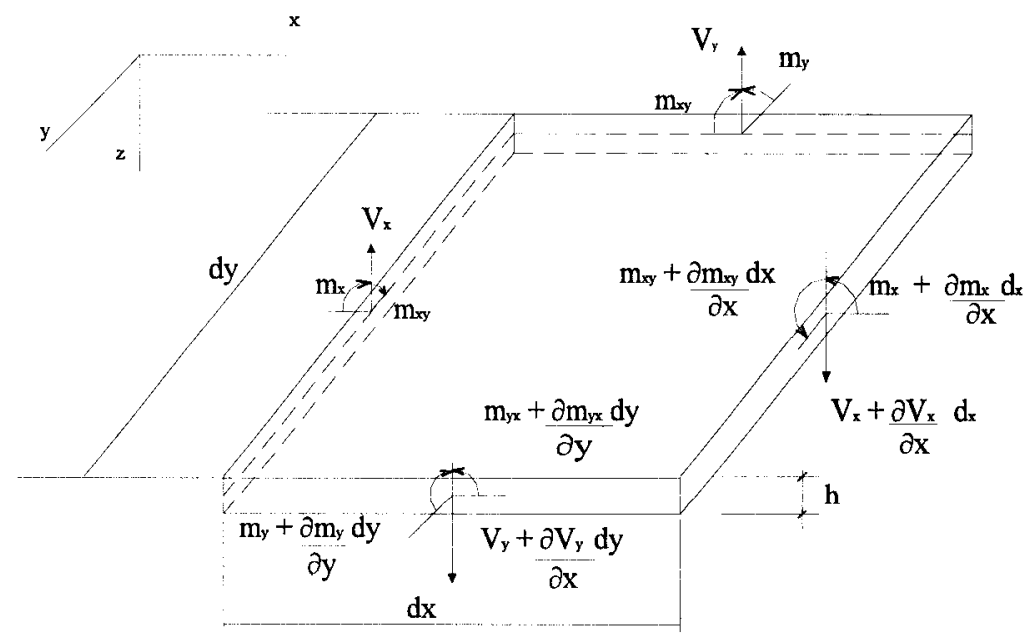

FIGURA 2.1- Esforços em um elemento de placa

A seguir apresentam-se os esforços por unidade de largura:

$$
\begin{array}{ll}
m_{x}=-D\left(\frac{\partial^{2} w}{\partial x^{2}}+v \frac{\partial^{2} w}{\partial y^{2}}\right) & =\text { Momento fletor na direção } \mathrm{x}(\mathrm{em} \text { torno de } \mathrm{y}) \\
m_{y}=-D\left(\frac{\partial^{2} w}{\partial y^{2}}+v \frac{\partial^{2} w}{\partial x^{2}}\right) & =\text { Momento fletor na direção } \mathrm{y}(\text { em torno de } \mathrm{x}) \\
m_{x y}=-D(1-v) \frac{\partial^{2} w}{\partial x \partial y} & =\text { Momento torçor } \\
v_{x}=-D \frac{\partial}{\partial x}\left(\frac{\partial^{2} w}{\partial x^{2}}+\frac{\partial^{2} w}{\partial y^{2}}\right) & =\text { Força cortante na direção } \mathrm{x} \\
v_{y}=-D \frac{\partial}{\partial y}\left(\frac{\partial^{2} w}{\partial x^{2}}+\frac{\partial^{2} w}{\partial y^{2}}\right) & =\text { Força cortante na direção } \mathrm{y}
\end{array}
$$

Fazendo-se o equilíbrio em relação aos eixos x, y e z e utilizando-se as expressões anteriores, obtém-se a conhecida equação das placas elásticas ou de Lagrange: 
$\frac{\partial^{4} w}{\partial x^{4}}+2 \frac{\partial^{4} w}{\partial x^{2} \partial y^{2}}+\frac{\partial^{4} w}{\partial y^{4}}=\frac{p}{D}$

sendo:

$$
D=\frac{E h^{3}}{12\left(1-v^{2}\right)} \quad=\text { rigidez à flexão da placa }
$$

$\mathrm{E}=$ módulo de deformação longitudinal

$\mathrm{h}=$ espessura

$v=$ coeficiente de Poisson

As condições de contorno da equação diferencial (2.1) dependem dos tipos de apoio. Assim, por exemplo, se se trata de uma borda reta paralela ao eixo y, ter-se-á, em função das condições desta borda, as seguintes condições de contorno:

a) borda engastada - deslocamento e rotação nulos

$$
w=0, \frac{\partial w}{\partial x}=0
$$

b) borda simplesmente apoiada - deslocamento e momento nulos

$$
w=0, m_{x}=-D\left(\frac{\partial^{2} w}{\partial x^{2}}+v \frac{\partial^{2} w}{\partial y^{2}}\right)=0
$$

c) borda livre - momento $m_{x}$ e reação na borda nulos

$$
m_{x}=0, \quad v_{x}-\frac{\partial m_{x y}}{\partial y}=0
$$

Obtida a função w, os esforços são calculados pelas expressões fornecidas anteriormente. 


\subsubsection{CÁLCULO POR PROCESSOS NUMÉRICOS}

Normalmente não é fácil encontrar uma função w $(x, y)$ que satisfaça a equação diferencial das placas e atenda às condições de contorno. Para tal, recorre-se a soluções aproximadas, obtendo-se w como uma soma de funções elementares que satisfaçam as condições de contorno.

O processo de integração da Equação de Lagrange só pode ser aplicado a alguns poucos casos de formas de placas e condições de contorno. Uma das alternativas é o uso de diferenças finitas para a integração numérica, conduzindo à resolução de um sistema de equações lineares.

Além de diferenças finitas, o cálculo por processos numéricos abrange elementos de contorno, elementos finitos e analogia de grelha.

No cálculo por diferenças finitas, a placa é dividida por uma malha que se adapte ao seu contorno. Adotam-se como incógnitas os deslocamentos w nos vértices da malha. Em função destes, podem ser expressas suas derivadas e, consequentemente, os esforços e a equação de equilíbrio da placa. Para pontos próximos das bordas, é necessário usar os deslocamentos em pontos fictícios, situados fora da placa, que se obtém empregando as condições de contorno, como se indica na fig. 2.2.

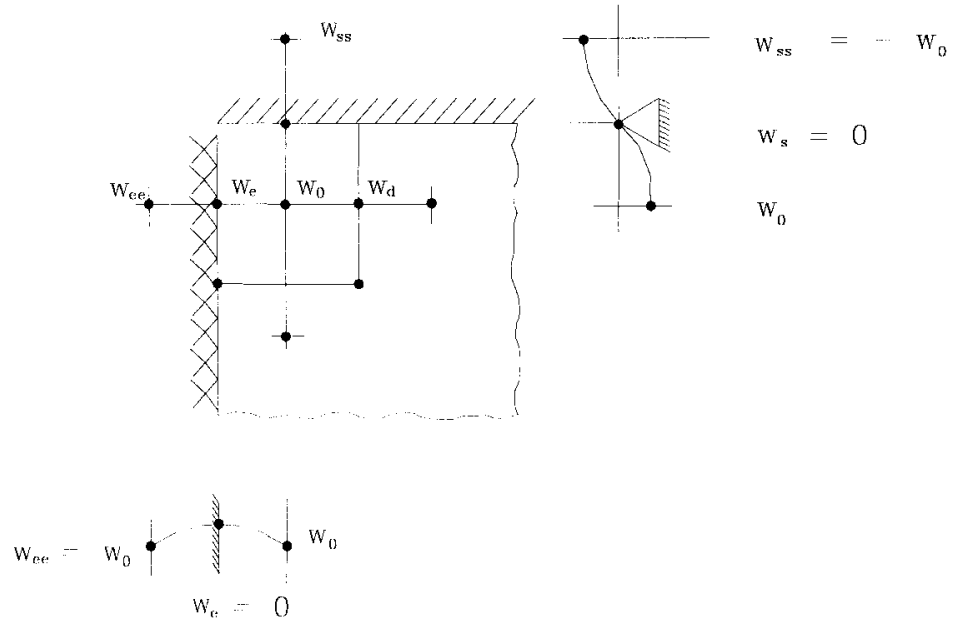

FIGURA 2.2- Pontos próximos das bordas 
Esse processo aplica-se à elaboração de tabelas e é através destas tabelas que se obtém facilmente os esforços em placas com formas e carregamentos mais comuns, submetidas a carregamentos uniformes ou triangulares.

O processo das diferenças finitas é aplicável em casos de placas com forma mais complexa, com aberturas, com regiões de diferentes espessuras, com carregamentos de distribuição mais complexa ou com condições de apoio variadas. Há, porém, outras alternativas, entre as quais o processo dos elementos finitos e a analogia de grelha.

Em ambos os processos a estrutura é tratada de forma discretizada, substituindoa por outra equivalente formada por elementos finitos. A principal diferença, com relação ao processo das diferenças finitas, é que neste último o que se discretiza é a função w. Portanto, no cálculo por diferenças finitas, o problema é tratado rigorosamente dando lugar a um problema matemático complexo, que é resolvido de forma aproximada, enquanto que no cálculo por elementos finitos e analogia de grelha, o problema estrutural é tratado de forma aproximada, para que o problema matemático seja simples e possa ser resolvido exatamente.

Tanto o cálculo por elementos finitos como por analogia de grelha é feito por computadores. Em geral, os referentes à analogia de grelha são mais acessíveis e econônicos que os de elementos finitos, já que estes em geral necessitam de computadores de maior capacidade.

Há outros processos que precisam ser citados, como o processo aproximado de MARCUS (1929), aplicado às lajes retangulares com carga uniforme e bordas apoiadas ou engastadas, pela sua importância histórica, sendo o mais indicado da fase anterior aos computadores eletrônicos. Hoje as tabelas de Marcus (encontradas em ROCHA, 1971, por exemplo) podem ser substituídas com vantagens por outras como as de BARES (1972) ou CZERNY (1976). As tabelas de Czerny são anteriores às de Bares, apesar de aqui citadas em edição mais recente. Ambas apresentam resultados muito bons como demonstram MANZOLI, PINHEIRO, PAIVA (1986).

Às estruturas com apoio simples nos extremos, com presença ou não de apoios intermediários, sendo a ênfase de aplicação os tabuleiros de pontes, usa-se o processo das faixas finitas, de aplicação não tão geral quanto a dos elementos finitos, mas que, 
no seu campo de utilização, permite redução do trabalho computacional com manutenção de versatilidade e de precisão dos resultados. Sobre o processo das faixas finitas, recomenda-se CORREA (1983).

Finalmente, o processo dos elementos de contorno, em fase de desenvolvimento, que compete com o dos elementos finitos na resolução dos casos complexos.

Neste trabalho foram utilizadas funções aproximadoras, para o cálculo de momentos fletores e de flechas, as quais foram baseadas em tabelas elaboradas através do processo dos elementos de contorno (tabelas 3.1 a 3.12).

\subsection{NOÇÕES SOBRE O CÁLCULO PLÁSTICO}

O método plástico, baseado na teoria da plasticidade, supõe que o material tenha comportamento rígido-plástico; permite a obtenção mais racional da carga última na situação de ruína, mas não fornece, por outro lado, informações sobre a melhor distribuição das armaduras. Já que este é um dos pontos de partida, podem ser adotadas as distribuições sugeridas pelo cálculo elástico ou obtidas através de um estudo econômico.

\subsubsection{TEOREMAS FUNDAMENTAIS}

O cálculo pela teoria da plasticidade, para as lajes, em geral não é possível, pelo fato de o grau de indeterminação estática ser infinito. Em vez do valor exato da capacidade de carga, obtém-se dois valores: um limite superior, dado pelo teorema cinemático, e um inferior, dado pelo teorema estático. 


\section{a) Teorema cinemático ou do limite superior}

Denomina-se mecanismo a toda configuração de ruína cinematicamente admissível. O teorema prediz que toda carga correspondente a um mecanismo é igual ou superior à carga que provoca a ruína da peça. A carga obtida com a aplicação do teorema é contra a segurança, pois a carga de ruína pode estar sendo superestimada.

A teoria das charneiras plásticas é uma aplicação desse teorema, que fornece um valor da carga igual ou superior à carga de ruína. Resultados experimentais demonstram que a carga efetiva de ruína é, em geral, maior que a obtida pela teoria das charneiras plásticas. A reserva de resistência decorre dos efeitos de arqueamento e de membrana, que podem não existir para todos os tipos de laje e, mesmo que existam, ruínas secundárias também podem ocorrer antes, provocando o colapso prematuro da laje.

\section{b) Teorema estático ou do limite inferior}

Todo carregamento, com uma distribuição de esforços internos que satisfaça as condições de contorno e que em nenhum ponto ultrapasse a resistência da laje, é denominado estaticamente admissível e é igual ou inferior ao que provoca a ruína. Este teorema permite a obtenção de um limite inferior para a carga de ruína, tendo-se então um cálculo a favor da segurança.

Uma aplicação do teorema estático às lajes é dado pelo processo das faixas de HILLERBORG (1975), que se baseia numa determinação simplificada da distribuição de momentos.

Com a aplicação desses dois teoremas, obtém-se importantes informações a respeito da segurança. 


\subsubsection{NOÇÕES SOBRE A TEORIA DAS CHARNEIRAS PLÁSTICAS}

Estudos de INGERSLEV (1923) deram início à teoria das charneiras plásticas, num trabalho publicado em 1921, em dinamarquês e em inglês dois anos depois. Ingerslev deduziu fórmulas para lajes retangulares livremente apoiadas ou engastadas, baseando-se na hipótese de que elas se rompessem devido ao escoamento da armadura, segundo linhas retas, ao longo das quais o momento fletor era constante e os esforços cortantes não considerados. Por esta razão, sua teoria não era correta em todos os casos.

Em 1931, Johansen retomou a questão, publicando um trabalho onde considerava as forças cortantes ao longo das charneiras plásticas, substituindo seus efeitos por forças nodais. As hipóteses formuladas são aceitas até hoje.

A teoria das charneiras plásticas começou a tomar maior impulso por volta da década de 50, com inúmeros trabalhos publicados por MANSFIELD (1957), WOOD (1961), JONES (1966), LANGENDONCK (1966), (1970), (1975) e outros.

Apesar de ser aceita e bastante difundida nos países desenvolvidos, a teoria das charneiras plásticas se encontra de certa forma relegada, devido a dois aspectos principais: aspectos teóricos e práticos.

Do ponto de vista teórico, sendo uma aplicação do teorema cinemático, ela é contra a segurança. Como os ensaios têm demonstrado que para os casos usuais essa insegurança teórica não se verifica na prática, esse aspecto não impõe restrições à aplicação da teoria das charneiras plásticas às lajes comuns. O mesmo não acontece às lajes com formas, carregamentos e condições de apoio não usuais, para as quais a segurança adicional pode não existir, exigindo investigações suplementares.

É nos aspectos práticos que ainda existem algumas barreiras para a completa aceitação da teoria das charneiras plásticas, para o cálculo das lajes comuns.

A primeira diz respeito à razão dos momentos de vão, que é um dado de partida no cálculo plástico e é resultado do cálculo elástico. Adotando um valor decorrente de um pré-dimensionamento em regime elástico, certamente resultará em uma distribuição de armaduras adequada às condições de utilização.

Adotando índices baseados em critérios econômicos, podem resultar valores que 
se afastem dos verificados com hipóteses elásticas e, até mesmo, das condições decorrentes da quantidade mínima de armadura adotada para a direção menos solicitada. Um índice adotado com base em um critério econômico pode ser inadequado do ponto de vista prático.

Pode acontecer que grandes variações da razão dos momentos tenham pouca influência no consumo total de armaduras, como cita MONTOYA (1973), por exemplo. Nessas condições, a melhor solução é adotar índices próximos dos obtidos em regime elástico e que sejam coerentes, ao mesmo tempo, com a armadura adotada na direção dos menores esforços.

Um outro aspecto prático é o que diz respeito ao grau de engastamento $\phi=\mathrm{m} / \mathrm{m}$ (momento no apoio sobre o momento no vão), que também é um dado de partida; num caso geral, há necessidade de se investigar o valor a ser adotado. No caso de lajes de edifícios com carga uniforme e bordas apoiadas ou engastadas, costumam ser indicados os intervalos de variação $1 \leq \phi \leq 2$ (por exemplo, LANGENDONCK, 1972) ou $1,5 \leq \phi$ $\leq 2,5$ (HILLERBORG, 1975). Os extremos inferiores dos intervalos devem ser mais econômicos, pois possibilitam menores espessuras para as lajes e uma melhor repartição entre as armaduras superiores e inferiores; mas, podem apresentar problemas de fissuração inaceitável, na região dos apoios. Já os extremos superiores são mais próximos dos obtidos em regime elástico, sendo portanto mais adequados às condições de fissuração. Recomenda-se adotar valores obtidos num pré-dimensionamento em regime elástico, analogamente ao que se faz com a razão dos momentos de vão. Porém, os momentos negativos deverão sofrer redução.

\subsubsection{TEORIA DO EQUILÍBRIO DE HILLERBORG}

O único método prático para a análise limite das placas, até 1956, era a teoria das charneiras plásticas, teoricamente contra a segurança. HILLERBORG (1956), procurando um processo de cálculo baseado no teorema estático e que não apresentasse os inconvenientes da insegurança, publicou em Sueco um artigo com os resultados de seus estudos, no qual foram dados os princípios gerais de sua teoria do equilíbrio e a 
expressão "processo das faixas" (strip method) foi introduzida, para os casos em que o momento volvente podia ser considerado nulo. Não foi discutido nesse artigo a questão dos apoios pontuais.

Posteriormente, HILLERBORG(1964) desenvolveu outro processo, inicialmente também publicado em sueco, baseado na teoria do equilíbrio, para o cálculo de lajes sobre pilares, placas com forma de L etc, no qual o problema dos apoios pontuais foi analisado.

Após a publicação em inglês dos princípios da teoria do equilíbrio e do processo das faixas (HILLERBORG, 1960), o assunto ganhou seguidores, entre os quais CRAWFORD (1962), (1964) e BLAKEY, que traduziu para o inglês, em 1964, o "Processo das faixas para cálculo de lajes sobre pilares, placas com forma de L etc" (HILLERBORG, 1964). Desde então, o processo das faixas tem sido referido e discutido por diversos autores, entre os quais ARMER (1968), WOOD \& ARMER (1968), FERNANDO \& KEMP (1975), entre outros. 


\section{CÁLCULO ELÁSTICO BASEADO EM TABELAS}

\subsection{GENERALIDADES}

Este capítulo apresenta o cálculo de lajes retangulares submetidas a cargas uniformes, com bordas apoiadas, engastadas ou livres. Tem-se por base $\mathrm{o}$ comportamento elástico, imprescindível para a verificação das condições de utilização, a partir dos quais pode ser escolhida a distribuição das armaduras.

Através de funções aproximadoras, determinadas a partir de tabelas, são calculados momentos fletores e flechas. Essas tabelas, apresentadas por MELGES (1993), foram baseadas no processo dos elementos de contorno, através de um programa desenvolvido pelo Prof. J. B. Paiva, do Departamento de Engenharia de Estruturas da EESC-USP. Tais tabelas consideram a relação entre os vãos $\lambda=\ell_{\mathrm{y}} / \ell_{\mathrm{x}}$ não superior a cinco.

Para $\lambda>5$, as lajes foram consideradas armadas em uma só direção, ou seja, na direção do menor vão. Na outra direção, consideram-se os mesmos valores relativos às lajes $\operatorname{com} \lambda=5$. 


\subsection{CASOS DE VINCULAÇÃO}

Existem basicamente 12 casos possíveis de vinculação. Os seis primeiros são casos de lajes com bordas apoiadas ou engastadas e os outros seis apresentam borda livre.

Três casos dos seis primeiros precisam ser subdivididos, resultando um total de nove casos, indicados na fig 3.1. Os casos com borda livre são apresentados na fig 3.2 .

Convenções utilizadas:

borda simplesmente apoiada $\quad \rightarrow$ - /IIII/I/III/I

borda engastada $\quad \rightarrow$ XXXXXX

borda livre

caso 1 --> quatro bordas simplesmente apoiadas,

caso 2A --> uma borda menor engastada,

caso 2B --> uma borda maior engastada,

caso 3 --> duas bordas adjacentes engastadas,

caso 4A --> duas bordas menores engastadas,

caso 4B --> duas bordas maiores engastadas,

caso 5A --> uma borda maior apoiada,

caso 5B -.> uma borda menor apoiada,

caso 6 --> quatro bordas engastadas. 

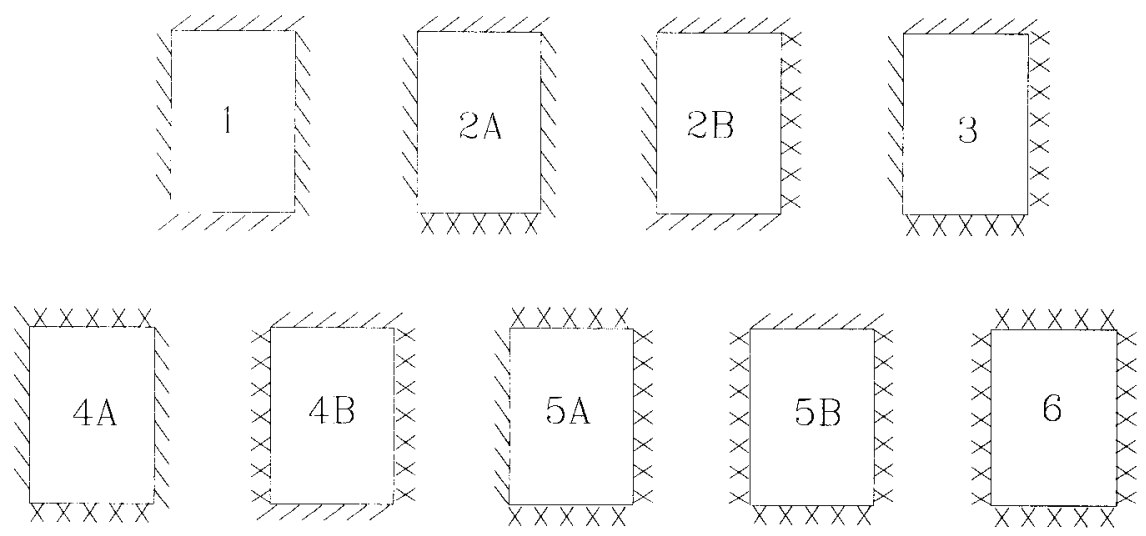

FIGURA 3.1- Casos de vinculação com bordas apoiadas ou engastadas

caso 7 --> três bordas simplesmente apoiadas,

caso 8 --> borda engastada oposta à borda livre,

caso 9 --> uma borda engastada adjacente à borda livre,

caso 10 --> uma borda apoiada oposta à borda livre,

caso 11 --> uma borda apoiada adjacente à borda livre,

caso 12 --> três bordas engastadas.
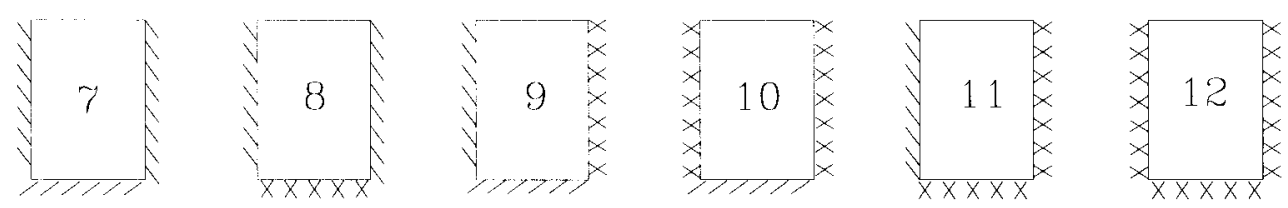

FIGURA 3.2- Casos de vinculação com uma borda livre

O cálculo de lajes com bordas apoiadas ou engastadas, através de funções aproximadoras, está demonstrado em PINHEIRO (1988), onde se considerou $\ell_{x}=$ menor vão e $\ell_{y}=$ maior vão. Neste capítulo serão apresentados os casos com uma borda livre, considerando $\ell_{x}$ paralelo e $\ell_{y}$ perpendicular à borda livre. 


\subsection{NOTAÇÃO ADOTADA}

Considere-se uma laje de concreto armado com uma borda livre, sujeita a cargas uniformemente distribuídas. A princípio, no fator de multiplicação dos coeficientes tabelados, considerou-se $\ell$ sendo o menor lado, como foi feito para os casos 1 até 6 . Isto resultou em valores tabelados muito altos nos trechos de $\lambda$ entre 0,2 e 1,0 , quando comparados com valores de $\lambda$ maiores que 1,0 .

Em vista disto, passou-se a considerar $\ell$ paralelo à borda livre $\left(\ell_{x}\right)$, resultando em valores tabelados em geral crescentes, evitando variações bruscas nas curvas encontradas a partir de tabelas. Os momentos fletores atuantes para o caso 8 são indicados na fig 3.3.

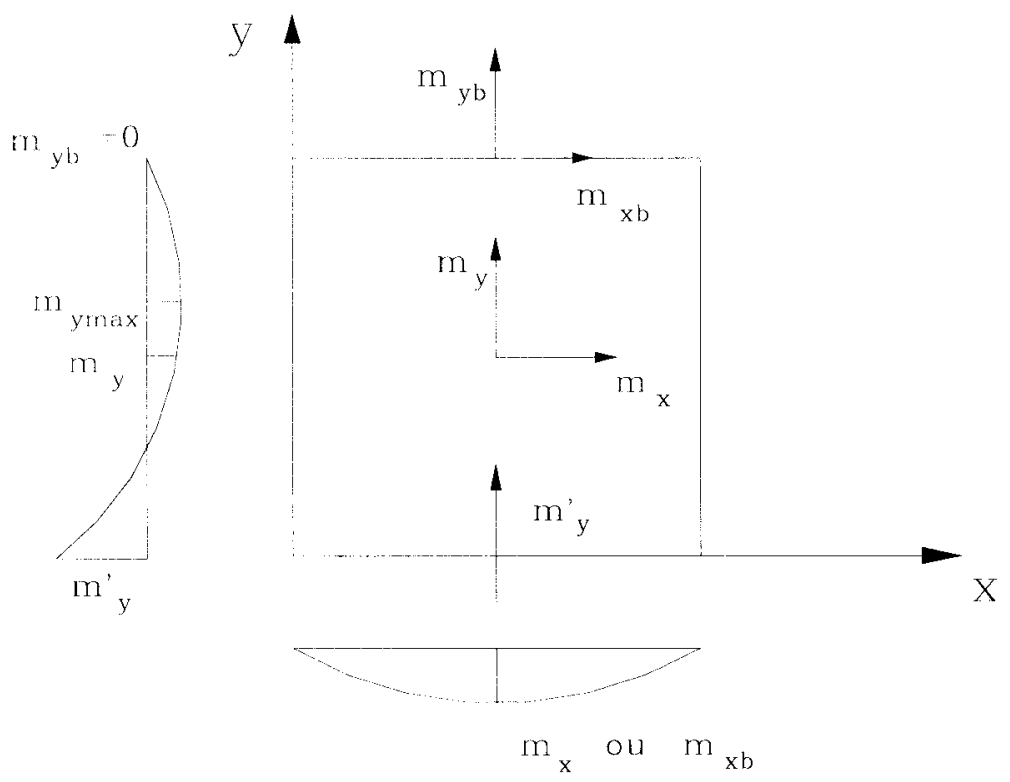

FIGURA 3.3- Momentos fletores atuantes (caso 8)

Com a mesma notação usada por PINHEIRO (1993), calculam-se os momentos fletores, as flechas e as reações de apoio da seguinte forma: 
$m=\mu \frac{p \ell_{x}^{2}}{100}$

$a=\alpha \frac{p l_{x}^{4}}{100 E h^{3}}$

$r=\rho \frac{p \ell_{x}}{10}$

Nos casos 7 a 12, considerou-se $\ell_{\mathrm{x}}$ como o vão paralelo à borda livre e nos casos 1 a $6, \ell_{x}$ é o menor vão. Nestas expressões tem-se:

$\mathrm{m}=$ momento fletor por unidade de largura,

$\mu=$ coeficiente adimensional para cálculo do momento fletor,

$\mathrm{p}=$ carga total uniformemente distribuída,

$\mathrm{a}=$ flecha,

$\alpha=$ coeficiente adimensional para cálculo de flecha,

$\mathrm{E}=$ módulo de deformação longitudinal do concreto,

$\mathrm{h}=$ espessura da laje,

$\mathrm{r}=$ reação de apoio por unidade de comprimento,

$\rho=$ coeficiente adimensional para cálculo da reação de apoio.

Empregam-se ainda os índices x e y, para indicar as direções dos planos de flexão, e plica (') nos momentos negativos (sobre os apoios); utiliza-se plica também para indicar as reações de apoio nas bordas engastadas.

As tabelas encontradas em MELGES (1993) consideram o coeficiente de Poisson igual a 0,20. Os coeficientes de Melges, adaptados para a notação aqui adotada, encontram-se nas tabelas 3.1 a 3.10, para momentos, e 3.11 e 3.12 para as flechas, sendo consideradas as seguintes relações entre os lados:

$$
\lambda=\frac{l_{Y}}{l_{x}}=0,2 ; 0,25 ; 0,3 ; \ldots 1,0 ; 1,1 ; \ldots 2,0 ; 2,5 ; 3,0 ; \ldots 5,0 ; \infty
$$




\subsection{FUNÇÕES APROXIMADORAS PARA OS MOMENTOS}

Serão consideradas a determinação e a eficiência das funções adotadas.

\subsubsection{DETERMINAÇÃO DAS FUNÇÕES}

As funções foram determinadas através de um programa chamado Grapher, o qual fornece gráficos tendo $\lambda=\ell_{y} / \ell_{x}$ em abscissas e $\mu$ em ordenadas, usando as tabelas de MELGES (1993). Inicialmente, adotaram-se funções lineares, do segundo ou do terceiro grau, compatíveis com os gráficos em intervalos adequados, que estimassem com razoável precisão os coeficientes originais, levando-se em conta um erro máximo da ordem de $3 \%$.

Isso não foi possível sem a modificação de alguns dos valores, pois essas tabelas apresentavam alguns pontos muito fora da curva. Essas descontinuidades não tinham justificativa física, sendo provavelmente decorrentes de alguma imprecisão do programa utilizado. Esse tipo de erro ocorreu principalmente para $\lambda=1,0$, sendo feitas as correções utilizando interpolação linear.

Em casos onde havia muitos pontos fora da curva, foi utilizado um método mais rigoroso, ou seja, delimitou-se um trecho o qual continha esses pontos; em seguida, através do programa Grapher, foi encontrada uma equação compatível com a curva dada, que respeitasse o limite de erro de $3 \%$ e, a partir dessa equação, a maioria do terceiro grau, calcularam-se os novos valores.

Cada momento foi analisado individualmente, de modo a satisfazer os valores tabelados.

As funções adotadas encontram-se indicadas nas tabelas 3.13 e as respectivas curvas são mostradas nas figuras 3.1 a 3.19 . 


\subsubsection{EFICIÊNCIA DAS FUNÇÕES ADOTADAS}

Como os pontos adotados para o cálculo das funções aproximadoras não são os mesmos em todos os casos, a relação $\mu_{\mathrm{a}} / \mu_{\mathrm{c}}$ foi determinada para todos os valores de $\lambda$, sendo:

$\mu_{\mathrm{a}}=$ valor de $\mu$ correspondente à função aproximadora, $\mu_{\mathrm{c}}=$ valor obtido por Melges, dado nas tabelas 3.1 a 3.10.

Verificou-se que as funções aproximadoras dão resultados muito bons, ou seja, com erros não superiores a $3 \%$ em quase todos os casos. Houve erros maiores que $3 \%$ para $\lambda$ entre 0,2 a 0,3 , nos casos 8,11 e 12 , devido a valores muito baixos dos momentos fletores para esses casos.

\subsection{FUNÇÕES APROXIMADORAS PARA AS FLECHAS}

Foi adotado o mesmo critério utilizado para os momentos, ou seja, através do programa Grapher, usando as tabelas de Melges referentes às flechas (tabelas $3.11 \mathrm{e}$ 3.12). Também foram adotadas funções lineares, do segundo ou do terceiro grau. Em nenhum caso o erro foi maior que $3 \%$. As funções aproximadoras das flechas encontram-se nas tabelas 3.14 e os respectivos gráficos nas figuras 3.20 a 3.25 . 
TABELA 3.1- CASO 7: MOMENTOS PARA CARGA UNIFORME

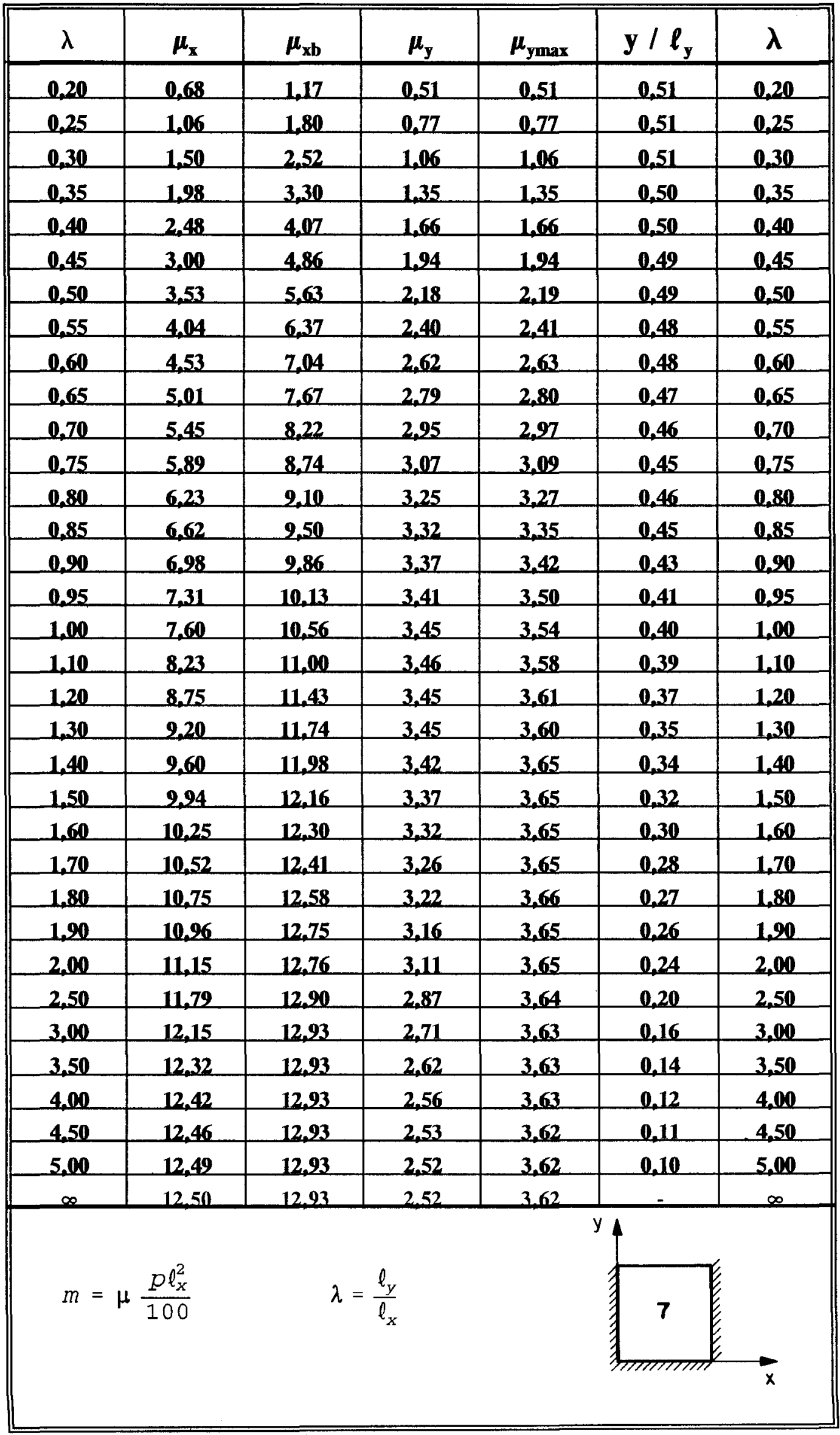


TABELA 3.2- CASO 8: MOMENTOS PARA CARGA UNIFORME

\begin{tabular}{|c|c|c|c|c|}
\hline$\lambda$ & $\boldsymbol{\mu}_{\mathrm{x}}$ & $\boldsymbol{\mu}_{\mathrm{xbmax}}$ & $\mathbf{x} / \ell_{\mathrm{x}}$ & $\lambda$ \\
\hline 0.20 & $-0,06$ & 0.28 & 0,$10 ; 0,90$ & 0,20 \\
\hline 0,25 & -0.04 & 0,47 & 0,$15 ; 0,85$ & 0,25 \\
\hline 0,30 & 0.05 & 0.71 & $0.20 ; 0.80$ & 0.30 \\
\hline 0.35 & 0.21 & 1,04 & $0.25 ; 0.75$ & 0.35 \\
\hline 0,40 & 0,43 & 1,50 & $0.31 ; 0.69$ & 0,40 \\
\hline 0.45 & 0.73 & 2.12 & 0.50 & 0,45 \\
\hline 0,50 & 1.07 & 2,81 & 0,50 & 0,50 \\
\hline 0.55 & 1,46 & 3,55 & 0.50 & 0,55 \\
\hline 0,60 & 1,88 & 4,30 & 0.50 & 0,60 \\
\hline 0,65 & 2,33 & 5,05 & 0,50 & 0,65 \\
\hline 0,70 & 2,78 & 5,75 & 0,50 & 0,70 \\
\hline 0.75 & 3,23 & 6.43 & 0,50 & 0,75 \\
\hline 0,80 & 3,67 & 7,02 & 0,50 & 0,80 \\
\hline 0,85 & 4,10 & 7,60 & 0.50 & 0,85 \\
\hline 0.20 & 4,52 & 8.11 & 0,50 & 0,90 \\
\hline 0.95 & 4,90 & 8,53 & 0,50 & 0.25 \\
\hline 1.00 & 5,17 & 8,87 & 0.50 & 1.00 \\
\hline 1,10 & 6,10 & 2.85 & 0.50 & 1,10 \\
\hline 1,20 & 6,81 & 10,53 & 0.50 & 1,20 \\
\hline 1.30 & 7.45 & 11.04 & 0.50 & 1,30 \\
\hline 1,40 & 8,02 & 11,44 & 0,50 & 1,40 \\
\hline 1.50 & 8,52 & 11,74 & 0,50 & 1,50 \\
\hline 1,60 & 8,97 & 11,98 & 0.50 & 1,60 \\
\hline 1,70 & 9,38 & 12,16 & 0.50 & 1,70 \\
\hline 1,80 & 2,72 & 12.50 & 0,50 & 1,80 \\
\hline 1.90 & 10.04 & 12.61 & 0,50 & 1,20 \\
\hline 2,00 & 10,33 & 12,61 & 0,50 & 2,00 \\
\hline 2,50 & 11,34 & 12,62 & 0,50 & 2,50 \\
\hline 3,00 & 11,90 & 12,63 & 0,50 & 3,00 \\
\hline 3.50 & 12,19 & 12,64 & 0,50 & 3,50 \\
\hline 4,00 & 12,35 & 12,64 & 0,50 & 4,00 \\
\hline 4,50 & 12,43 & 12,65 & 0,50 & 4,50 \\
\hline 5,00 & 12,47 & 12,66 & 0,50 & 5,00 \\
\hline$\infty$ & 12,50 & 12,66 & $\frac{0.50}{y 4}$ & $\infty$ \\
\hline \multicolumn{2}{|c|}{$m=\mu \frac{p l_{x}^{2}}{100}$} & $\frac{\ell_{y}}{\ell_{x}}$ & y 4 & $\notin$ \\
\hline
\end{tabular}


TABELA 3.3- CASO 8: MOMENTOS PARA CARGA UNIFORME

\begin{tabular}{|c|c|c|c|c|c|c|}
\hline$\lambda$ & $\mu_{y}$ & $\boldsymbol{\mu}_{\mathrm{ymax}}$ & $\mathbf{y} / \ell_{\mathrm{y}}$ & $\mathbf{x} / \boldsymbol{\ell}_{\mathbf{x}}$ & $\mu_{y}^{\prime}$ & $\lambda$ \\
\hline 0,20 & $-0,43$ & 0,13 & 1,00 & $0.10 ; 0.90$ & 1,93 & 0,20 \\
\hline 0.25 & $-0,55$ & 0,17 & 1,00 & $0.10: 0.90$ & 2,88 & 0.25 \\
\hline 0,30 & -0.61 & 0,17 & 0.86 & $0.17: 0.83$ & 3,20 & 0,30 \\
\hline 0,35 & -0.59 & 0,23 & 0.83 & $0.22 ; 0.78$ & 4,93 & 0.35 \\
\hline 0.40 & $-0,47$ & 0,37 & 0.80 & 0,$28 ; 0,72$ & 5,91 & 0,40 \\
\hline 0,45 & $-0,29$ & 0,63 & 0,78 & $0,47,0,53$ & 6,84 & 0,45 \\
\hline 0,50 & $-0,07$ & 0,74 & 0.76 & 0,50 & 7,69 & 0,50 \\
\hline 0,55 & 0,19 & 0,96 & 0,73 & 0.50 & 8.45 & 0.55 \\
\hline 0.60 & 0,50 & 1,24 & 0,72 & 0,50 & 2,08 & 0,60 \\
\hline 0.65 & 0,79 & 1,46 & 0,70 & 0,50 & 9,67 & 0,65 \\
\hline 0,70 & 1.11 & 1,72 & 0,69 & 0,50 & 10,14 & 0,70 \\
\hline 0.75 & 1.38 & 1,21 & 0,67 & 0.50 & 10,58 & 0.75 \\
\hline 0,80 & 1.73 & 2.24 & 0,67 & 0.50 & 10,86 & 0.80 \\
\hline 0,85 & 1,96 & 2,40 & 0.65 & 0.50 & 11.19 & 0,85 \\
\hline 0.90 & 2,17 & 2,52 & 0,64 & 0,50 & 11,48 & 0,90 \\
\hline 0.25 & 2,35 & 2,62 & 0.62 & 0.50 & 11,80 & 0.95 \\
\hline 1.00 & 2,50 & 2,78 & 0.59 & 0.50 & 11.99 & 1,00 \\
\hline 1.10 & 2,80 & 2,24 & 0,59 & 0,50 & 12.17 & 1,10 \\
\hline 1.20 & 3,00 & 3,07 & 0,57 & 0,50 & 12.31 & 1,20 \\
\hline 1.30 & 3,17 & 3,21 & 0.55 & 0.50 & 12,37 & 1.30 \\
\hline 1,40 & 3.26 & 3,27 & 0.53 & 0,50 & 12,44 & 1,40 \\
\hline 1.50 & 3,31 & 3,31 & 0.51 & 0.50 & 12.48 & 1.50 \\
\hline 1.60 & 3,33 & 3,33 & 0,48 & 0.50 & 12.52 & 1.60 \\
\hline 1,70 & 3,33 & 3,35 & 0,46 & 0.50 & 12.54 & 1.70 \\
\hline 1,80 & 3,32 & 3,36 & 0,44 & 0,50 & 12,58 & 1,80 \\
\hline 1,90 & 3,29 & 3,36 & 0,42 & 0,50 & 12,59 & 1,90 \\
\hline 2,00 & 3,25 & 3,36 & 0,40 & 0,50 & 12,59 & 2,00 \\
\hline 2,50 & 3,01 & $3, \mathbf{3 5}$ & 0,32 & 0.50 & 12,59 & 2,50 \\
\hline 3.00 & 2,82 & 3,34 & 0,27 & 0,50 & 12.59 & 3,00 \\
\hline 3,50 & 2,68 & 3,34 & 0,23 & 0.50 & 12,62 & 3,50 \\
\hline 4.00 & 2,60 & 3,34 & 0.20 & 0,50 & 12,62 & 4,00 \\
\hline 4,50 & 2,55 & 3,33 & 0,18 & 0,50 & 12,62 & 4,50 \\
\hline 5,00 & 2,53 & 3,33 & 0.16 & 0,50 & 12,62 & 5,00 \\
\hline$\infty$ & 2.53 & 3.33 & & 0.50 & 12.62 & $\infty$ \\
\hline & $\frac{p l_{x}^{2}}{100}$ & & $\frac{\ell_{y}}{\ell_{x}}$ & & 8 & $x$ \\
\hline
\end{tabular}


TABELA 3.4- CASO 9: MOMENTOS PARA CARGA UNIFORME

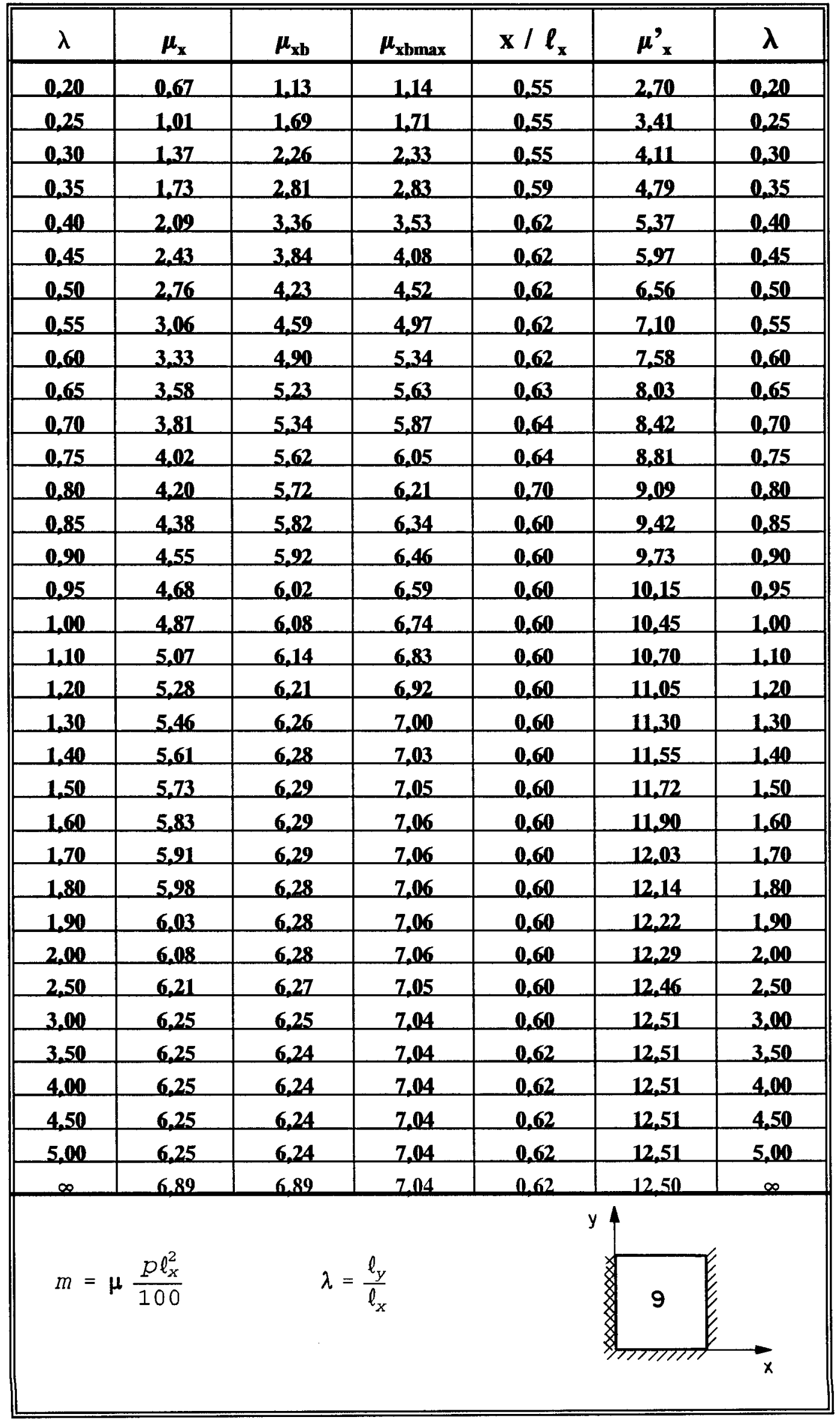


TABELA 3.5- CASO 9: MOMENTOS PARA CARGA UNIFORME

\begin{tabular}{|c|c|c|c|c|c|c|c|}
\hline$\lambda$ & $\mu_{\text {xmax }}^{\prime}$ & $\mathrm{y} / \boldsymbol{l}_{\mathrm{y}}$ & $\mu_{y}$ & $\boldsymbol{\mu}_{\mathrm{ymax}}$ & $x / \ell_{x}$ & $\mathbf{y} / \boldsymbol{\ell}_{\mathrm{y}}$ & $\lambda$ \\
\hline 0.20 & 7.41 & 0.20 & 0,49 & 0.50 & 0.60 & 0,50 & 0,20 \\
\hline 0.25 & 8.07 & 0,20 & 0,73 & 0,74 & 0,60 & 0,50 & 0,25 \\
\hline 0,30 & 2.54 & 1,00 & 0.96 & 0,92 & 0.58 & 0,50 & 0,30 \\
\hline l.35 & 10,63 & 1,00 & 1,18 & 1.22 & 0,58 & 0,50 & 0.35 \\
\hline 0.40 & 11,37 & 1.00 & 1,40 & 1.45 & 0.59 & 0.50 & 0,40 \\
\hline 0,45 & 12,10 & 1,00 & 1.57 & 1,63 & 0.59 & 0.50 & 0,45 \\
\hline 0.50 & 12,76 & 1.00 & 1.72 & 1.79 & 0.59 & 0.50 & 0.50 \\
\hline 0,55 & 12,99 & 1,00 & 1.84 & 1,22 & 0.58 & 0,45 & 0.55 \\
\hline 0.60 & 13,18 & 1.00 & 1.94 & 2,05 & 0.58 & 0.45 & 0.60 \\
\hline 0,65 & 13,34 & 1.00 & 2.02 & 2.13 & 0.58 & 0,45 & 0,65 \\
\hline 0.70 & 13,47 & 1,00 & 2.08 & 2.21 & 0.55 & 0.45 & 0.70 \\
\hline 0.75 & 13.57 & 0.90 & 2.11 & 2.25 & 0.60 & 0,40 & 0.75 \\
\hline 0,80 & 13,64 & 0.20 & 2.18 & 2.34 & 0.60 & 0,40 & 0.80 \\
\hline 0.85 & 13,70 & 0.90 & 2.16 & 2,37 & 0.59 & 0,40 & 0.85 \\
\hline 0.90 & 13.73 & 0,90 & 2.14 & 2,39 & 0,60 & 0,40 & 0,90 \\
\hline 0.95 & 13,74 & 1,00 & 2,13 & 2,41 & 0.60 & 0.35 & 0.25 \\
\hline 1.00 & 13,75 & 1,00 & 2,11 & 2,42 & 0.60 & 0.30 & 1.00 \\
\hline 1.10 & 13,75 & 1,00 & 2,08 & 2,43 & 0.60 & 0,30 & 1.10 \\
\hline 1.20 & 13,76 & 0.22 & 2.01 & 2.43 & 0.60 & 0.29 & 1.20 \\
\hline 1,30 & 13,72 & 0.92 & 1,25 & 2,43 & 0,60 & 0.27 & 1,30 \\
\hline 1,40 & 13,70 & 0.23 & 1.87 & 2,43 & 0,60 & 0,25 & 1,40 \\
\hline 1.50 & 13,71 & 0.24 & 1,80 & 2,43 & 0,60 & 0,24 & 1.50 \\
\hline 1,60 & 13,71 & 0.94 & 1,74 & 2,43 & 0.60 & 0.22 & 1,60 \\
\hline 1.70 & 13.71 & 0.94 & 1,67 & 2,43 & 0,60 & 0,20 & $\mathbf{1 , 7 0}$ \\
\hline 1.80 & 13,68 & 0.22 & 1,62 & 2,43 & 0.60 & 0.19 & 1.80 \\
\hline 1,90 & 13,65 & 0,92 & 1.57 & 2,43 & 0,60 & 0,18 & 1,90 \\
\hline 2,00 & 13,63 & 0.92 & 1.52 & 2,43 & 0.60 & 0.17 & 2.00 \\
\hline 2.50 & 13,49 & 0.24 & 1,37 & 2,42 & 0,60 & 0.15 & 2.50 \\
\hline 3,00 & 13.35 & 0.25 & 1.29 & 2.42 & 0.60 & 0.12 & 3,00 \\
\hline 3,50 & 13,26 & 0,96 & 1,27 & 2,42 & 0,60 & 0,11 & 3,50 \\
\hline 4,00 & 13,21 & 0.97 & 1,25 & 2,42 & 0,60 & 0,09 & 4,00 \\
\hline 4,50 & 13,16 & 0,97 & 1.25 & 2,42 & 0,60 & 0,08 & 4,50 \\
\hline 5.00 & 13.12 & 0,98 & 1,25 & 2,42 & 0,60 & 0.07 & 5,00 \\
\hline$\infty$ & 13.12 & & 125 & 2.42 & & 0.07 & $\infty$ \\
\hline & $\frac{p l_{x}^{2}}{100}$ & & $=\frac{\ell_{y}}{\ell_{x}}$ & & $y$ & 9 & $x$ \\
\hline
\end{tabular}


TABELA 3.6- CASO 10: MOMENTOS PARA CARGA UNIFORME

\begin{tabular}{|c|c|c|c|c|c|}
\hline$\lambda$ & $\mu_{x}$ & $\mu_{\mathbf{x b}}$ & $\mu_{x}^{\prime}$ & $\mu_{\text {sb }}^{\prime}$ & $\lambda$ \\
\hline 0,20 & 0,66 & 1,11 & 2.46 & 6,51 & 0.20 \\
\hline 0.25 & 0,97 & 1,60 & 3,04 & 7.07 & 0,25 \\
\hline 0.30 & 1,28 & 2,09 & 3,59 & 7.26 & 0,30 \\
\hline 0.35 & 1.58 & 2,54 & 4,10 & 8.70 & 0.35 \\
\hline 0,40 & 1,85 & 2,20 & 4,53 & 9,01 & 0,40 \\
\hline 0,45 & 2,05 & 3,22 & $-4,96$ & 2.28 & 0,45 \\
\hline 0.50 & 2,32 & 3,49 & 5,35 & 2,44 & 0.50 \\
\hline 0,55 & 2,52 & $\mathbf{3 , 7 0}$ & 5,71 & 2,53 & 0.55 \\
\hline 0.60 & 2,70 & 3,86 & 6,02 & 9.56 & 0,60 \\
\hline 0.65 & 2,86 & 3,29 & 6,31 & 2,54 & 0,65 \\
\hline 0.70 & 3,01 & 4,07 & 6,55 & 2,48 & 0,70 \\
\hline 0.75 & 3,14 & 4,14 & 6,78 & 2,40 & 0.75 \\
\hline 0.80 & 3,25 & 4,15 & 6,97 & 2.31 & 0.80 \\
\hline 0,85 & 3,36 & $-4,17$ & 7.15 & 2,23 & 0,85 \\
\hline 0,90 & 3,46 & 4,19 & 7.32 & 2,17 & 0.90 \\
\hline 0.25 & 3,54 & 4,21 & 7,47 & 2,15 & 0,25 \\
\hline 1,00 & 3,65 & 4,22 & 7,65 & 2,13 & 1,00 \\
\hline 1.10 & 3,76 & $-4,22$ & 7.82 & 2,10 & 1.10 \\
\hline 1.20 & 3,87 & 4,22 & 7.92 & 2,08 & 1,20 \\
\hline 1,30 & 3,95 & 4,22 & 8,17 & 2.06 & 1,30 \\
\hline 1,40 & 4,02 & 4,22 & 8,19 & 2,05 & 1,40 \\
\hline 1,50 & 4,07 & 4,222 & 8.29 & 2.03 & 1.50 \\
\hline 1,60 & 4,11 & $-4,22$ & 8,30 & 2,01 & 1,60 \\
\hline 1,70 & $-4,13$ & 4,22 & 8,35 & 8,99 & 1,70 \\
\hline 1,80 & 4,15 & 4,22 & 8,36 & 8,98 & 1,80 \\
\hline 1,90 & 4,17 & 4,21 & 8.37 & 8,96 & 1,90 \\
\hline 2.00 & 4,18 & $-4,21$ & 8.38 & 8.94 & 2,00 \\
\hline 2,50 & 4,18 & 4,21 & 8,37 & 8.85 & 2,50 \\
\hline 3,00 & 4,18 & 4,21 & 8.35 & 8,76 & 3,00 \\
\hline $\mathbf{3}, 50$ & 4,17 & 4,21 & 8.34 & 8.69 & 3,50 \\
\hline 4,00 & 4,17 & 4,21 & 8.33 & 8,66 & 4,00 \\
\hline 4,50 & 4,17 & 4,21 & 8,33 & 8,63 & 4,50 \\
\hline 5,00 & 4,17 & 4,21 & 8,33 & 8,61 & 5,00 \\
\hline$\infty$ & 4.17 & $-4,21$ & 8.33 & 8.61 & $\infty$ \\
\hline \multicolumn{2}{|c|}{$m=\mu \frac{p \ell_{x}^{2}}{100}$} & $\lambda=\frac{\ell_{y}}{\ell_{x}}$ & & 10 & \\
\hline
\end{tabular}


TABELA 3.7- CASO 10: MOMENTOS PARA CARGA UNIFORME

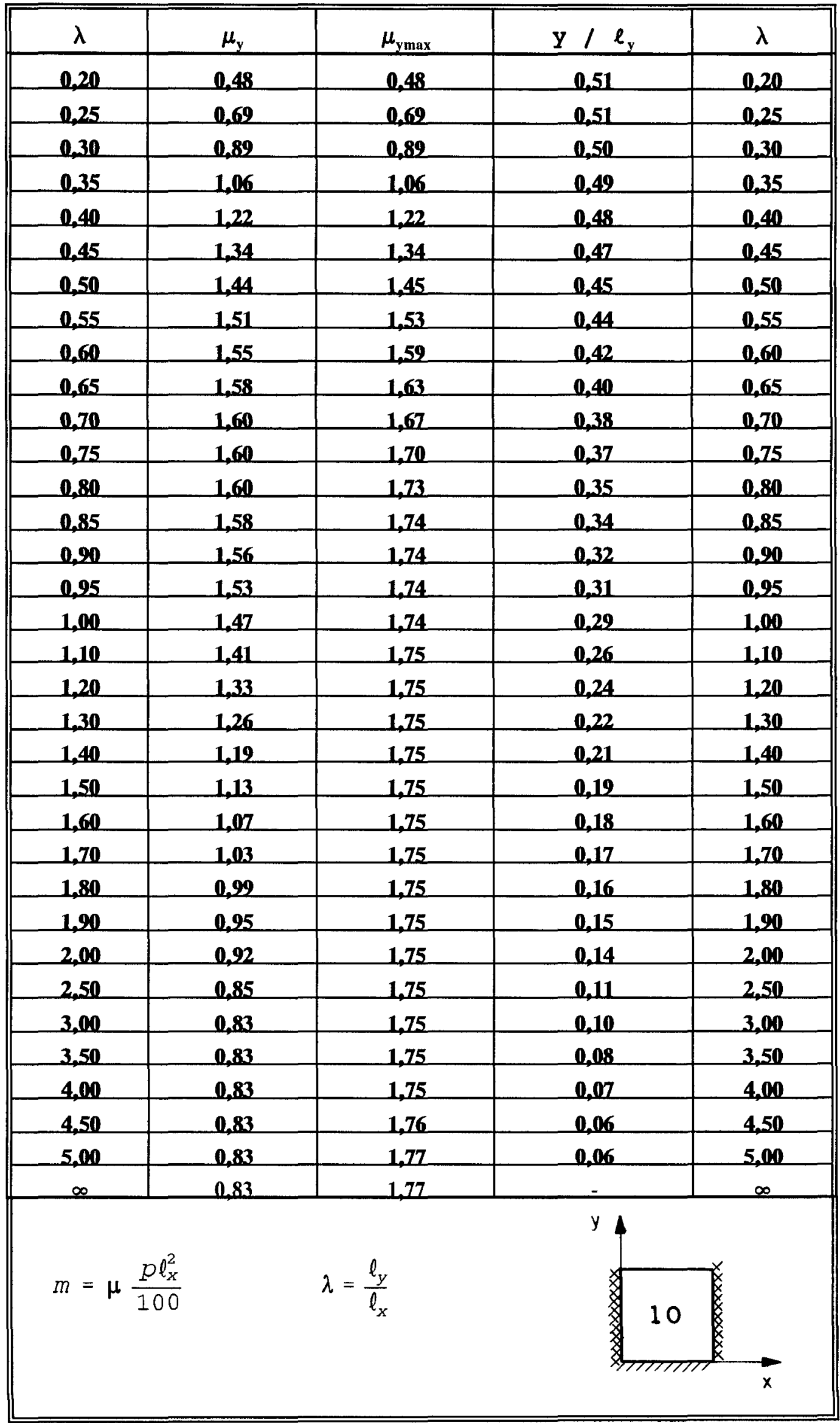


TABELA 3.8- CASO 11: MOMENTOS PARA CARGA UNIFORME

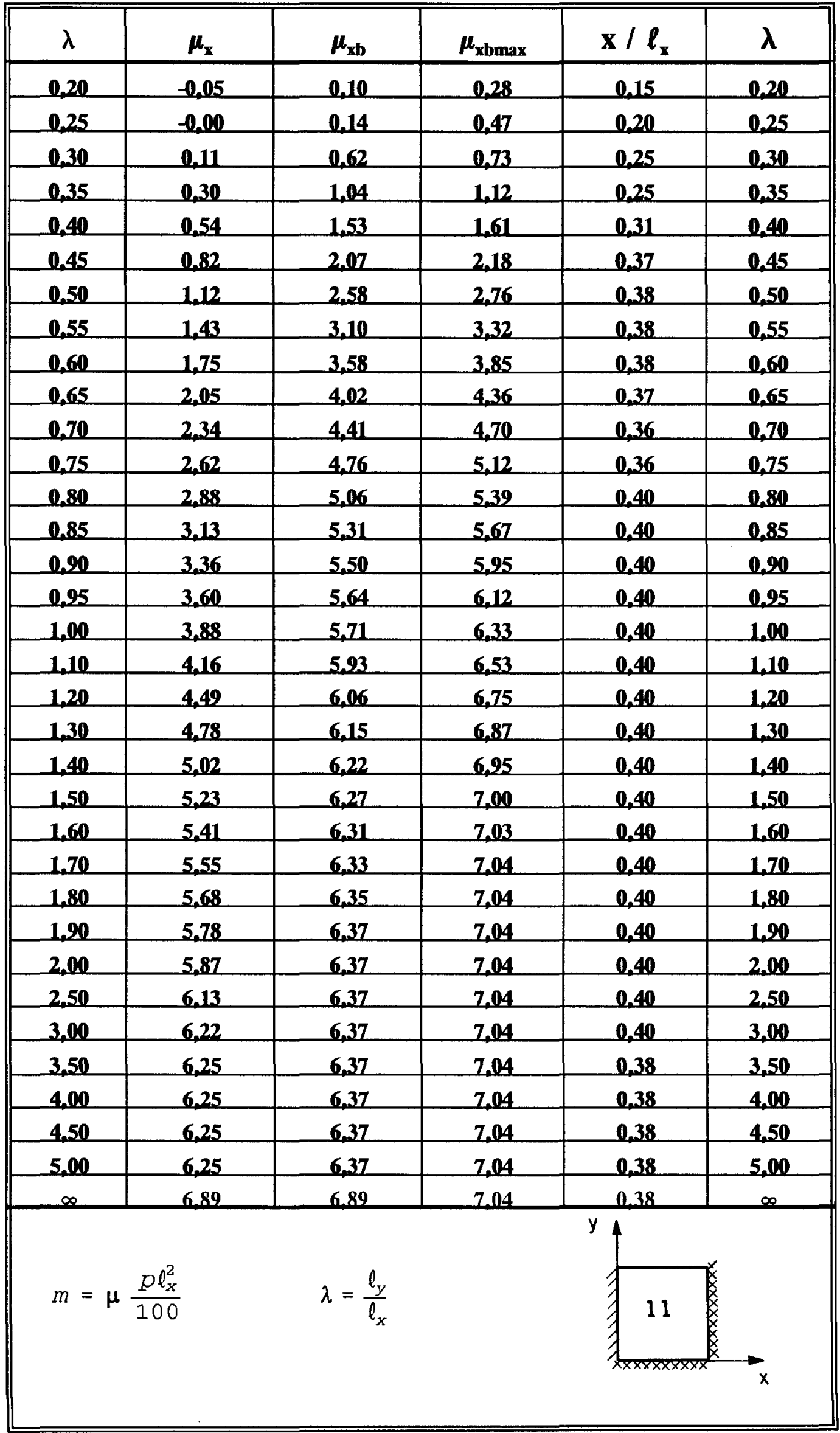


TABELA 3.9- CASO 11: MOMENTOS PARA CARGA UNIFORME

\begin{tabular}{|c|c|c|c|c|c|}
\hline$\lambda$ & $\mu_{x}^{\prime}$ & $\mu_{\operatorname{xmax}}^{\prime}$ & $y / \ell_{y}$ & $\mu_{y}$ & $\lambda$ \\
\hline 0,20 & 0,58 & 1,93 & 0,87 & $-0,41$ & 0.20 \\
\hline 0,25 & 0.92 & 3,00 & 1,00 & $-0,49$ & 0.25 \\
\hline 0,30 & 1,32 & 4,37 & 1,00 & -0.49 & 0.30 \\
\hline 0,35 & 1.79 & 5,80 & 1,00 & $-0,40$ & 0,35 \\
\hline 0.40 & 2.33 & 7.08 & 1,00 & -0.23 & 0,40 \\
\hline 0,45 & 2,84 & 8.39 & 1,00 & $-0,03$ & 0,45 \\
\hline 0,50 & 3,41 & 2,54 & 1,00 & 0,21 & 0.50 \\
\hline 0,55 & 3,98 & 10,49 & 1,00 & 0,45 & 0.55 \\
\hline 0,60 & 4,55 & 11,25 & 1,00 & 0,70 & 0,60 \\
\hline 0,65 & 5,12 & 11.83 & 1,00 & 0,92 & 0.65 \\
\hline 0,70 & 5,65 & 12,27 & 1.00 & 1.13 & 0,70 \\
\hline 0,75 & 6,17 & 12,59 & 1,00 & 1.31 & 0.75 \\
\hline 0,80 & 6,61 & 12,79 & 1,00 & 1,50 & 0,80 \\
\hline 0,85 & 7,08 & 12,98 & 1.00 & 1.63 & 0,85 \\
\hline 0,90 & 7,52 & 13,02 & 1,00 & 1,72 & 0,20 \\
\hline 0,95 & 8,20 & 13,08 & 1,00 & 1,80 & 0.25 \\
\hline 1,00 & 8,50 & 13,14 & 1,00 & 1.86 & 1,00 \\
\hline 1,10 & 2,05 & 13,26 & 1,00 & 1,97 & 1.10 \\
\hline 1,20 & 9,65 & 13,36 & 1.00 & 2.00 & 1,20 \\
\hline 1,30 & 10,08 & 13,38 & 0.92 & 2.01 & 1.30 \\
\hline 1,40 & 10,54 & 13,36 & 0,93 & 1,99 & 1,40 \\
\hline 1,50 & 10,87 & 13,34 & 0,93 & 1,95 & 1.50 \\
\hline 1,60 & 11,20 & 13,34 & 0,24 & 1,89 & 1.60 \\
\hline 1,70 & 11,42 & 13.33 & 0,94 & 1.84 & 1,70 \\
\hline 1.80 & 11,65 & 13,33 & 0,92 & 1,78 & 1,80 \\
\hline 1,90 & 11,82 & 13,32 & 0,92 & 1,72 & 1,90 \\
\hline 2,00 & 11,26 & 13,31 & 0,92 & 1,67 & 2,00 \\
\hline 2,50 & 12,36 & 13,28 & 0,24 & 1,46 & 2,50 \\
\hline 3,00 & 12,48 & 13,25 & 0,95 & 1.33 & 3.00 \\
\hline 3,50 & 12,50 & 13,22 & 0,96 & 1,30 & 3,50 \\
\hline 4,00 & 12,50 & 13,18 & 0.97 & 1,26 & 4,00 \\
\hline 4,50 & 12,50 & 13,15 & 0,97 & 1,26 & 4,50 \\
\hline 5,00 & 12,50 & 13,12 & 0,97 & 1.25 & 5,00 \\
\hline$\infty$ & 12,50 & 13.12 & & 1.25 & $\infty$ \\
\hline$m=$ & & $\lambda=\frac{\ell_{y}}{\ell_{x}}$ & & $y_{y} 11$ & $x$ \\
\hline
\end{tabular}


TABELA 3.10- CASO 11: MOMENTOS PARA CARGA UNIFORME

\begin{tabular}{|c|c|c|c|c|c|c|}
\hline$\lambda$ & $\mu_{\mathrm{ymax}}$ & $\mathrm{x} / \boldsymbol{\ell}_{\mathrm{x}}$ & $\mathrm{y} / \boldsymbol{l}_{\mathrm{y}}$ & $\mu_{\text {ymax }}^{\prime}$ & $\mathbf{x} / \boldsymbol{l}_{\mathrm{x}}$ & $\lambda$ \\
\hline 0.20 & 0,21 & 0.26 & 0,90 & 1,20 & 0,45 & 0.20 \\
\hline 0,25 & 0,25 & 0,23 & 0,20 & 2,79 & 0,45 & 0.25 \\
\hline 0,30 & 0,28 & 0.23 & 0,85 & 3,69 & 0.45 & e.30 \\
\hline 0.35 & 0.30 & 0.23 & 0.80 & 4,53 & 0,45 & 0.35 \\
\hline 0,40 & 0,43 & 0.23 & 0,75 & 5,26 & 0,44 & 0,40 \\
\hline 0,45 & 0,61 & 0,28 & 0,75 & 5,88 & 0,44 & 0.45 \\
\hline 0,50 & e.80 & 0.38 & 0,75 & 6,38 & 0,44 & 0.50 \\
\hline 0.55 & 0,92 & 0,40 & 0,70 & 6,78 & 0,44 & 0,55 \\
\hline 0,60 & 1.18 & 0,39 & 0,70 & 7.09 & 0,44 & 0,60 \\
\hline 0,65 & 1.34 & 0,39 & 0,65 & 7,33 & 0,44 & 0.65 \\
\hline 0.70 & 1.50 & 0.39 & 0,65 & 7,53 & 0,43 & 0,70 \\
\hline 0.75 & 1,62 & 0,40 & 0,65 & 7,68 & 0,43 & 0,75 \\
\hline 0.80 & 1.80 & 0,40 & 0,65 & 7,79 & 0,40 & 0,80 \\
\hline 0.85 & 1.86 & 0,40 & 0,60 & 7,90 & 0,40 & 0.85 \\
\hline 0,90 & 1.22 & 0,40 & 0,60 & 7,92 & 0,40 & 0,20 \\
\hline 0,95 & 1.26 & 0,40 & 0,55 & 8,02 & 0,40 & 0,25 \\
\hline 1.00 & 2,00 & 0,40 & 0,50 & 8,05 & 0,50 & 1,00 \\
\hline 1,10 & 2,06 & 0,40 & 0,50 & 8,10 & 0,40 & 1.10 \\
\hline 1.20 & 2.10 & 0,40 & 0.50 & 8,13 & 0,40 & 1,20 \\
\hline 1,30 & 2.12 & 0,40 & 0,46 & 8.16 & 0,40 & 1.30 \\
\hline 1,40 & 2.13 & 0,40 & 0,43 & 8,18 & 0,40 & 1,40 \\
\hline 1.50 & 2,14 & 0.40 & 0,40 & 8,18 & 0,40 & 1,50 \\
\hline 1,60 & 2,15 & 0,40 & 0.37 & 8.19 & 0,40 & 1,60 \\
\hline 1,70 & 2.15 & 0,40 & 0.35 & 8,20 & 0,40 & 1,70 \\
\hline 1.80 & 2,15 & 0,40 & 0.33 & 8,21 & 0,40 & 1.80 \\
\hline 1.20 & 2,15 & 0,40 & 0.32 & 8,22 & 0,40 & 1,90 \\
\hline 2.00 & 2,15 & 0,40 & 0,30 & 8,22 & 0,40 & 2,00 \\
\hline 2,50 & 2.14 & 0,40 & 0.24 & 8.22 & 0,40 & 2,50 \\
\hline 3,00 & 2.14 & 0,40 & 0,20 & 8.22 & 0,40 & 3,00 \\
\hline 3,50 & 2,14 & 0,40 & 0,17 & 8,22 & 0,38 & 3,50 \\
\hline 4,00 & 2,14 & 0,40 & 0,15 & 8,22 & 0.38 & 4,00 \\
\hline 4.50 & 2.14 & 0,40 & 0,12 & 8,22 & 0.38 & 4,50 \\
\hline 5,00 & 2.14 & 0,40 & 0,12 & 8,22 & 0,38 & 5,00 \\
\hline$\infty$ & 2.14 & 0,40 & & 8.22 & 0.38 & $\infty$ \\
\hline \multicolumn{2}{|c|}{$\begin{array}{c}m=\mu \frac{p \ell_{x}^{2}}{100} \\
\text { Obs: } \mu_{y}^{\prime}=\mu_{y \max }^{\prime}\end{array}$} & 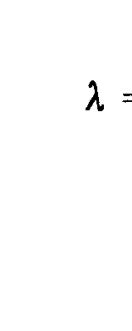 & & & 11 & x \\
\hline
\end{tabular}


TABELA 3.11- CASO 12: MOMENTOS PARA CARGA UNIFORME

\begin{tabular}{|c|c|c|c|c|c|c|}
\hline$\lambda$ & $\mu_{x}$ & $\boldsymbol{\mu}_{\text {xhmax }}$ & $\mathrm{x} / \boldsymbol{l}_{\mathrm{x}}$ & $\mu_{x}^{\prime}$ & $\mu_{\mathbf{x b}}^{\prime}$ & $\lambda$ \\
\hline 0.20 & $-0,04$ & 0.22 & $0.25 ; 0.75$ & 0.58 & 1,76 & 0,20 \\
\hline 0.25 & 0,03 & 0.39 & 0,$30 ; 0,70$ & 0.21 & 2,23 & 0.25 \\
\hline 0,30 & 0.17 & 0.69 & 0,$45 ; 0,55$ & 1.31 & 4,20 & 0.30 \\
\hline 0.35 & 0.38 & 1.14 & 0.50 & 1.75 & 5,47 & 0.35 \\
\hline 0,40 & 0,63 & 1,59 & 0,50 & 2,21 & 6,43 & 0,40 \\
\hline 0,45 & 0,89 & 2,05 & 0,50 & 2,69 & 7,38 & 0,45 \\
\hline 0.50 & 1.16 & 2.47 & 0,50 & 3,17 & 8.12 & 0,50 \\
\hline 0.55 & 1,42 & 2,84 & 0.50 & 3.64 & 8.57 & 0.55 \\
\hline 0.60 & 1,66 & 3.15 & 0,50 & 4,07 & 8,89 & 0.60 \\
\hline 0.65 & 1,89 & 3.41 & 0.50 & 4,49 & 2.10 & 0.65 \\
\hline 0.70 & 2,09 & 3,61 & 0,50 & 4,71 & 2,23 & 0,70 \\
\hline 0.75 & 2.29 & 3.78 & 0.50 & 5,22 & 2.28 & 0.75 \\
\hline 0.80 & 2.46 & 3.86 & 0,50 & 5.53 & 2.27 & 0,80 \\
\hline 0.85 & 2.63 & 3,26 & 0.50 & 5,84 & 2.24 & 0,85 \\
\hline 0.20 & 2.79 & 4,03 & 0.50 & 6,12 & 2.18 & 0,20 \\
\hline 0.95 & 2.92 & 4,10 & 0,50 & 6,38 & 2.14 & 0.25 \\
\hline 1.00 & 3,08 & 4,14 & 0.50 & 6,66 & 2.11 & 1.00 \\
\hline 1,10 & 3.28 & 4,18 & 0.50 & 7.01 & 2,03 & 1.10 \\
\hline 1,20 & 3,47 & 4,20 & 0,50 & 7.33 & 8.94 & 1.20 \\
\hline 1.30 & 3,63 & 4,20 & 0.50 & 7.76 & 8.74 & 1.30 \\
\hline 1,40 & 3.76 & 4.19 & 0,50 & 7.78 & 8.67 & 1,40 \\
\hline 1,50 & 3.86 & 4.19 & 0.50 & 7.92 & 8,63 & 1.50 \\
\hline 1.60 & 3.24 & 4,18 & 0.50 & 8.06 & 8.54 & 1,60 \\
\hline 1,70 & 4,00 & 4,18 & 0.50 & 8.21 & 8,46 & $\mathbf{1 . 7 0}$ \\
\hline 1,80 & 4.05 & 4,18 & 0.50 & 8.22 & 8.37 & 1.80 \\
\hline 1.90 & 4.09 & 4,18 & 0.50 & 8,27 & 8.36 & 1,90 \\
\hline 2,00 & 4.12 & 4,18 & 0,50 & 8.31 & 8,36 & 2,00 \\
\hline 2,50 & 4,17 & 4.18 & 0.50 & 8.37 & 8,36 & 2.50 \\
\hline 3,00 & 4.17 & 4,18 & 0.50 & 8,36 & 8,36 & 3,00 \\
\hline 3,50 & 4.17 & 4,18 & 0.50 & 8.34 & 8.34 & 3,50 \\
\hline 4,00 & 4,17 & 4,18 & 0,50 & 8,34 & 8,34 & 4,00 \\
\hline 4,50 & 4.17 & 4,18 & 0.50 & 8.33 & 8,33 & 4.50 \\
\hline 5,00 & 4.17 & 4,18 & 0.50 & 8.33 & 8,33 & 5,00 \\
\hline$\infty$ & 4,17 & 4.17 & 0.50 & 8.33 & 8.33 & $\infty$ \\
\hline \multicolumn{2}{|c|}{$m=\mu \frac{p \ell_{x}^{2}}{100}$} & & $\frac{\ell_{y}}{\ell_{x}}$ & & 12 & $x$ \\
\hline
\end{tabular}


TABELA 3.12- CASO 12: MOMENTOS PARA CARGA UNIFORME

\begin{tabular}{|c|c|c|c|c|c|}
\hline$\lambda$ & $\boldsymbol{\mu}_{\mathbf{y}}$ & $\boldsymbol{\mu}_{\mathrm{ymax}}$ & $\mathbf{y} / \boldsymbol{\ell}_{\mathbf{y}}$ & $\mu_{y}^{\prime}$ & $\lambda$ \\
\hline 0.20 & $-0,38$ & $-0,06$ & 1,00 & 1,88 & 0.20 \\
\hline 0.25 & $-0,43$ & 0.09 & 1,00 & 2,68 & 0,25 \\
\hline 0,30 & $-0,37$ & 0.12 & 1.00 & 3,43 & 0.30 \\
\hline 0.35 & -0.24 & 0,28 & 0.79 & 4,05 & 0,35 \\
\hline 0,40 & $-0,02$ & 0,45 & 0,76 & 4,52 & 0,40 \\
\hline 0,45 & 0,19 & 0.62 & 0.73 & 4.86 & 0.45 \\
\hline 0,50 & 0.41 & 0,77 & 0,71 & 5,10 & 0,50 \\
\hline 0.55 & 0.62 & 0.92 & 0.69 & 5.27 & 0,55 \\
\hline 0,60 & 0,81 & 1,04 & 0,66 & 5.39 & 0,60 \\
\hline 0,65 & 0.97 & 1.15 & 0,64 & 5,46 & 0,65 \\
\hline 0.70 & 1.11 & 1.24 & 0.61 & 5,53 & 0.70 \\
\hline 0,75 & 1.22 & 1,31 & 0,60 & 5,57 & 0,75 \\
\hline 0.80 & 1.32 & 1,37 & 0.57 & 5,63 & 0,80 \\
\hline 0.85 & 1.38 & 1,41 & 0.55 & 5,66 & 0.85 \\
\hline 0,90 & 1,43 & 1.43 & 0.53 & 5,67 & 0,90 \\
\hline 0,95 & 1.46 & 1.46 & 0.51 & 5,67 & 0.95 \\
\hline 1,00 & 1.49 & 1,48 & 0.51 & 5.69 & 1,00 \\
\hline 1,10 & 1.47 & 1,49 & 0,45 & 5.71 & 1,10 \\
\hline 1,20 & 1,44 & 1,49 & 0,42 & 5.73 & 1,20 \\
\hline 1,30 & 1.39 & 1,49 & 0.39 & 5.74 & 1,30 \\
\hline 1,40 & 1,33 & 1,49 & 0,36 & 5,75 & 1,40 \\
\hline 1.50 & 1,27 & 1,49 & 0,34 & 5,75 & 1,50 \\
\hline 1,60 & 1.21 & 1,49 & 0,32 & 5,75 & 1,60 \\
\hline 1,70 & 1,15 & 1,49 & 0,30 & 5,75 & 1,70 \\
\hline 1.80 & 1,10 & 1,49 & 0,28 & 5,75 & 1,80 \\
\hline 1.20 & 1.06 & 1,49 & 0.27 & 5,76 & 1,90 \\
\hline 2,00 & 1,01 & 1,49 & 0,25 & 5,76 & 2,00 \\
\hline 2,50 & 0.89 & 1,49 & 0.20 & 5,76 & 2,50 \\
\hline 3,60 & 0.84 & 1,49 & 0.17 & 5.76 & 3,00 \\
\hline 3,50 & 0.83 & 1,49 & 0.14 & 5.76 & 3.50 \\
\hline 4,00 & 0,83 & 1,49 & 0.13 & 5,76 & 4,00 \\
\hline 4,50 & 0.83 & 1,49 & 0,11 & 5,76 & 4.50 \\
\hline 5,00 & 0,83 & 1,49 & 0,10 & 5,76 & 5,00 \\
\hline$\infty$ & 0.83 & 1.49 & & 5,76 & $\infty$ \\
\hline \multicolumn{2}{|c|}{$m=\mu \frac{p \ell_{x}^{2}}{100}$} & $\lambda=\frac{\ell_{y}}{\ell_{x}}$ & & 12 & $x$ \\
\hline
\end{tabular}


TABELA 3.13 - FLECHAS PARA CARGA UNIFORME

\begin{tabular}{|c|c|c|c|c|c|c|c|}
\hline \multirow{2}{*}{$\lambda$} & \multicolumn{2}{|c|}{7} & \multicolumn{2}{|c|}{8} & \multicolumn{2}{|c|}{9} & \multirow{2}{*}{$\lambda$} \\
\hline & $\alpha$ & $\alpha_{\text {bmax }}$ & $\alpha$ & $\alpha_{\text {bmax }}$ & $\alpha$ & $\alpha_{b \max }$ & \\
\hline 0.20 & 0.82 & 1,61 & 0,08 & 0,21 & 0,68 & 1,33 & 0,20 \\
\hline 0.25 & 1,26 & 2,44 & 0,18 & 0,48 & 0,98 & 1,92 & 0,25 \\
\hline 0,30 & 1,76 & 3,37 & 0,33 & 0,89 & 1,31 & 2,51 & 0,30 \\
\hline 0,35 & 2,32 & 4,36 & 0,55 & 1,45 & 1,63 & 3,09 & 0,35 \\
\hline 0,40 & 2,87 & 5,31 & 0,84 & 2,13 & 1,94 & 3,58 & 0,40 \\
\hline 0,45 & 3,46 & 6.30 & 1,18 & 2.23 & 2,24 & 4,06 & 0,45 \\
\hline 0.50 & 4,06 & 7.26 & 1,57 & 3,74 & 2,53 & 4,49 & 0,50 \\
\hline 0,55 & 4,65 & 8,18 & 2,01 & 4,73 & 2,81 & 4,86 & 0,55 \\
\hline 0,60 & 5,20 & 8,25 & 2,46 & 5,62 & 3,05 & 5,15 & 0,60 \\
\hline 0,65 & 5,76 & 9,75 & 2,95 & 6,55 & 3,29 & 5,42 & 0,65 \\
\hline 0.70 & 6,26 & 10,37 & 3,43 & 7,39 & 3,50 & 5,60 & 0,70 \\
\hline 0,75 & 6,77 & 11,04 & 3,23 & 8,25 & 3,70 & 5,69 & 0,75 \\
\hline $\mathbf{0}, 80$ & 7,16 & 11,25 & 4,39 & 8,78 & 3,86 & 5,79 & 0,80 \\
\hline 0.85 & 7,62 & 11,77 & 4,88 & 2.51 & 4,04 & 5.90 & 0,85 \\
\hline 0.90 & 8.05 & 12,24 & 5,34 & 10.16 & 4.20 & 6.01 & 0.90 \\
\hline 0,95 & 8,45 & 12,62 & 5,76 & 10,71 & 4.31 & 6,06 & 0,25 \\
\hline 1,00 & 8,78 & 12,86 & 6,05 & 11,03 & 4,52 & 6,12 & 1,00 \\
\hline 1,10 & 9,56 & 13,72 & 7.13 & 12,35 & 4,72 & 6,22 & 1.10 \\
\hline 1,20 & 10,20 & 14,29 & 7,95 & 13,21 & 4,23 & 6.29 & 1,20 \\
\hline 1,30 & 10,75 & 14,50 & 8,70 & 13,67 & 5,12 & 6,32 & 1,30 \\
\hline 1,40 & 11,25 & 14,78 & 2.36 & 14,13 & 5,27 & 6,34 & 1,40 \\
\hline 1.50 & 11.68 & 14,99 & 2,97 & 14,49 & 5,40 & 6,35 & $\mathbf{1 . 5 0}$ \\
\hline 1,60 & 12,07 & 15,15 & 10,51 & 14,77 & 5,51 & 6,35 & 1,60 \\
\hline 1,70 & 12,41 & 15,16 & 11,00 & 14,88 & 5,60 & 6,35 & 1,70 \\
\hline 1,80 & 12,70 & 15,17 & 11,43 & 14,94 & 5,67 & 6,28 & 1,80 \\
\hline 1,90 & 12.97 & 15,24 & 11.83 & 15,07 & 5,74 & 6,27 & 1,90 \\
\hline 2,00 & 13,21 & 15,29 & 12,18 & 15,16 & 5,79 & 6,27 & 2,00 \\
\hline 2,50 & 14,07 & 15,41 & 13,48 & 15,38 & 5,94 & 6,27 & 2,50 \\
\hline 3,00 & 14,53 & 15,45 & 14,21 & 15,44 & 6,00 & 6,27 & 3,00 \\
\hline 3,50 & 14,77 & 15,47 & 14,60 & 15,47 & 6,01 & 6,27 & 3,50 \\
\hline 4,00 & 14,90 & 15,47 & 14,81 & 15,47 & 6,02 & 6,27 & 4,00 \\
\hline 4,50 & 14,97 & 15,47 & 14,92 & 15,47 & 6,02 & 6,27 & 4,50 \\
\hline 5,00 & 15,01 & 15,47 & 14,98 & 15,47 & 6,03 & 6,27 & 5,00 \\
\hline$\infty$ & 15,63 & 15,63 & 15,63 & 15,63 & 6,50 & 6,50 & $\infty$ \\
\hline & $\frac{\ell_{y}}{\ell_{x}}$ & & $\frac{p l_{x}^{4}}{100 E h^{3}}$ & & $\begin{aligned} & \text { carga } \\
&= \text { vão } \\
&= \text { mód } \\
& \text { espes }\end{aligned}$ & $\begin{array}{l}\text { orme } \\
\text { ela à bo } \\
\text { elastic } \\
\text { da laje }\end{array}$ & \\
\hline
\end{tabular}


TABELA 3.14 - FLECHAS PARA CARGA UNIFORME

\begin{tabular}{|c|c|c|c|c|c|c|c|}
\hline \multirow{2}{*}{$\lambda$} & \multicolumn{2}{|c|}{10} & \multicolumn{2}{|c|}{11} & \multicolumn{2}{|c|}{12} & \multirow{2}{*}{$\lambda$} \\
\hline & $\alpha$ & $\alpha_{\mathrm{bmax}}$ & $\alpha$ & $\alpha_{b \max }$ & $\alpha$ & $\alpha_{\text {bmax }}$ & \\
\hline 0,20 & 0,56 & 1,09 & 0,08 & 0,21 & 0,07 & 0,20 & 0,20 \\
\hline 0,25 & 0,77 & 1,48 & 0,17 & 0,46 & 0,16 & 0,43 & 0,25 \\
\hline 0,30 & 0,98 & 1,83 & 0,31 & 0,82 & 0,28 & 0,73 & 0,30 \\
\hline 0,35 & 1,17 & 2,13 & 0,49 & 1,27 & 0,43 & 1,07 & 0,35 \\
\hline 0,40 & 1,34 & 2,36 & 0,70 & 1,78 & 0,59 & 1,42 & 0,40 \\
\hline 0,45 & 1.51 & 2.57 & 0.95 & 2,32 & 0.76 & 1.75 & 0,45 \\
\hline 0.50 & 1.66 & 2.73 & 1,20 & 2,86 & 0,92 & 2,02 & 0,50 \\
\hline 0,55 & 1,79 & 2,85 & 1,47 & 3.38 & 1,08 & 2,28 & 0.55 \\
\hline 0,60 & 1,21 & 2,94 & 1,73 & 3,84 & 1,24 & 2,49 & 0,60 \\
\hline 0,65 & 2,03 & 3,00 & 1,99 & 4,27 & 1,38 & 2,65 & 0,65 \\
\hline 0,70 & 2,13 & 3,03 & 2,28 & 4,62 & 1,52 & 2,76 & 0,70 \\
\hline 0,75 & 2,22 & 3,06 & 2,48 & 4,95 & 1,65 & 2,86 & 0,75 \\
\hline 0,80 & 2,30 & 3,05 & 2,70 & 5,14 & 1,76 & 2,88 & 0,80 \\
\hline 0,85 & 2.38 & 3,04 & 2,93 & 5,32 & 1,87 & 2,93 & 0,85 \\
\hline 0,90 & 2.45 & 3,04 & 3,13 & 5,45 & 1,98 & 2.97 & 0,90 \\
\hline 0,95 & 2,52 & 3,02 & 3,40 & 5,65 & 2,08 & 2,99 & 0,95 \\
\hline 1,00 & 2,57 & 3,02 & 3,57 & 5,81 & 2,19 & 3,01 & 1,00 \\
\hline 1,10 & 2,68 & 3,01 & 3,86 & 6,03 & 2,33 & 3,02 & 1,10 \\
\hline 1,20 & 2,73 & 3,01 & 4,17 & 6,16 & 2,47 & 3,02 & 1,20 \\
\hline 1,30 & 2,83 & 3,00 & 4,46 & 6,22 & 2,59 & 3,02 & 1,30 \\
\hline 1,40 & 2,88 & 2,92 & 4,69 & 6,25 & 2,68 & 3,01 & 1,40 \\
\hline 1.50 & 2.92 & 2,92 & 4.90 & 6.27 & 2.76 & 3,01 & 1,50 \\
\hline 1.60 & 2.95 & 2.98 & 5.08 & 6.27 & 2.82 & 3,00 & 1,60 \\
\hline 1,70 & 2,97 & 2,98 & 5,23 & 6,27 & 2,87 & 3,00 & 1,70 \\
\hline 1,80 & 2,98 & 2,97 & 5,36 & 6,27 & 2,91 & 2,97 & 1,80 \\
\hline 1,90 & 2,29 & 2,97 & 5,47 & 6,27 & 2,94 & 2,97 & 1,90 \\
\hline 2,00 & 3,00 & 2,97 & 5,56 & 6,27 & 2,96 & 2,27 & 2,00 \\
\hline 2,50 & 3,02 & 2,97 & 5,85 & 6,27 & 3,02 & 2,97 & 2,50 \\
\hline 3,00 & 3,02 & 2,95 & 5,97 & 6,27 & 3,02 & 2,96 & 3,00 \\
\hline 3,50 & 3,02 & 2,95 & 6,00 & 6,27 & 3,02 & 2.95 & 3,50 \\
\hline 4,00 & 3,02 & 2,95 & 6,01 & 6,27 & 3,02 & 2,95 & 4,00 \\
\hline 4,50 & 3,02 & 2,95 & 6,02 & 6,27 & 3,02 & 2,95 & 4,50 \\
\hline 5,00 & 3,03 & 2,95 & 6,03 & 6,27 & 3,03 & 2,95 & 5,00 \\
\hline$\infty$ & 3,13 & 3,13 & 6,50 & 6,50 & 3,13 & 3,13 & $\infty$ \\
\hline & & & $\frac{p \ell_{x}^{4}}{100 E}$ & & $\begin{array}{l}\mathbf{p}=\text { carg } \\
\ell_{\mathbf{x}}=\mathbf{v a ̃ o} \\
\mathbf{E}=\mathbf{m} \delta 0 \\
\mathbf{h}=\text { espe }\end{array}$ & $\begin{array}{l}\text { forme } \\
\text { elo a b } \\
\text { e elasti } \\
\text { da laje }\end{array}$ & \\
\hline
\end{tabular}


TABELA 3.15a - FUNÇÕES APROXIMADORAS DOS MOMENTOS FLETORES

\begin{tabular}{|c|c|c|c|}
\hline CASO & $\mu$ & $\lambda=\ell_{\mathrm{y}} / \ell_{\mathrm{x}}$ & $\mu=\mathbf{f}(\lambda)$ \\
\hline \multirow{18}{*}{7} & \multirow{5}{*}{$\mu_{\mathrm{x}}$} & $0,2 \leq \lambda \leq 0,5$ & $5,69 \lambda^{2}+5,57 \lambda-0,67$ \\
\hline & & $0,5<\lambda \leq 1,0$ & $-4,80 \lambda^{2}+15,35 \lambda-2,95$ \\
\hline & & $1,0<\lambda \leq 2,0$ & $-2,29 \lambda^{2}+10,34 \lambda-0,40$ \\
\hline & & $2,0<\lambda \leq 3,0$ & $-0,62 \lambda^{2}+4,08 \lambda+5,47$ \\
\hline & & $\lambda>\mathbf{3 , 0}$ & 12,50 \\
\hline & \multirow{5}{*}{$\mu_{\mathrm{xb}}$} & $0,2 \leq \lambda \leq 0,5$ & $4,77 \lambda^{2}+11,71 \lambda-1,40$ \\
\hline & & $0,5<\lambda \leq 1,0$ & $-9,95 \lambda^{2}+24,51 \lambda-4,10$ \\
\hline & & $1,0<\lambda \leq 2,0$ & $-2,07 \lambda^{2}+8,31 \lambda+4,38$ \\
\hline & & $2,0<\lambda \leq 4,0$ & $-0,08 \lambda^{2}+0,55 \lambda+12,03$ \\
\hline & & $\lambda>4,0$ & 12,93 \\
\hline & \multirow{5}{*}{$\mu_{y}$} & $0,2 \leq \lambda \leq 0,5$ & $-0,62 \lambda^{2}+6,13 \lambda-0,71$ \\
\hline & & $0,5<\lambda \leq 1,0$ & $-4,54 \lambda^{2}+9,36 \lambda-1,37$ \\
\hline & & $1,0<\lambda \leq 1,4$ & $-0,34 \lambda^{2}+0,73 \lambda+3,06$ \\
\hline & & $1,4<\lambda \leq 4,0$ & $0,10 \lambda^{2}-0,85 \lambda+4,43$ \\
\hline & & $\lambda>4,0$ & 2,52 \\
\hline & \multirow{3}{*}{$\mu_{\text {ymax }}$} & $0,2 \leq \lambda \leq 0,5$ & $-0,57 \lambda^{2}+6,1 \lambda-0,71$ \\
\hline & & $0,5<\lambda \leq 1,0$ & $-4,03 \lambda^{2}+8,76 \lambda-1,19$ \\
\hline & & $\lambda>\mathbf{1 , 0}$ & 3,62 \\
\hline \multirow{9}{*}{8} & \multirow{5}{*}{$\mu_{\mathrm{x}}$} & $0,2 \leq \lambda \leq 0,5$ & $13,22 \lambda^{2}-5,46 \lambda+0,50$ \\
\hline & & $0,5<\lambda \leq 1,0$ & $-1,59 \lambda^{2}+10,86 \lambda-3,99$ \\
\hline & & $1,0<\lambda \leq 2,0$ & $-3,04 \lambda^{2}+14,16 \lambda-5,86$ \\
\hline & & $2,0<\lambda \leq 4,0$ & $-0,56 \lambda^{2}+4,31 \lambda+4,02$ \\
\hline & & $\lambda>4,0$ & 12,50 \\
\hline & \multirow{4}{*}{$\mu_{\mathrm{xmax}}$} & $0,2 \leq \lambda \leq 0,5$ & $21,78 \lambda^{3}-0,61 \lambda^{2}+0,39 \lambda+0,058$ \\
\hline & & $0,5<\lambda \leq 1,0$ & $-9,18 \lambda^{2}+26,14 \lambda-8,03$ \\
\hline & & $1,0<\lambda \leq 2,0$ & $-3,81 \lambda^{2}+15,00 \lambda-2,15$ \\
\hline & & $\lambda>\mathbf{2 , 0}$ & 12,66 \\
\hline \multicolumn{3}{|c|}{$m=\mu \frac{p \ell_{x}^{2}}{100}$} & $\begin{array}{l}\mathrm{p}=\text { carga uniforme } \\
\ell_{\mathrm{x}}=\text { vão paralelo à borda livre }\end{array}$ \\
\hline
\end{tabular}


TABELA 3.15b - FUNÇÕES APROXIMADORAS DOS MOMENTOS FLETORES

\begin{tabular}{|c|c|c|c|}
\hline CASO & $\mu$ & $\lambda=\ell_{\mathrm{Y}} / \ell_{\mathrm{X}}$ & $\mu=\mathbf{f}(\lambda)$ \\
\hline \multirow{13}{*}{8} & \multirow{5}{*}{$\mu_{\mathrm{y}}$} & $0,20 \leq \lambda \leq 0,45$ & $-0,74 \lambda^{3}+16,49 \lambda^{2}-9,94 \lambda+0,90$ \\
\hline & & $0,45<\lambda \leq 1,0$ & $-12,87 \lambda^{3}+25,79 \lambda^{2}-11,04 \lambda+0,61$ \\
\hline & & $1,0<\lambda \leq 2,0$ & $1,38 \lambda^{3}-7,93 \lambda^{2}+14,93 \lambda-5,87$ \\
\hline & & $2,0<\lambda \leq 4,0$ & $0,11 \lambda^{2}-0,97 \lambda+4,77$ \\
\hline & & $\lambda>4,0$ & 2,53 \\
\hline & \multirow{4}{*}{$\mu_{\text {ymax }}$} & $0,2 \leq \lambda \leq 0,3$ & $0,72 \lambda-0,03$ \\
\hline & & $0,3<\lambda \leq 1,0$ & $-11,01 \lambda^{3}+21,38 \lambda^{2}-8,79 \lambda+1,17$ \\
\hline & & $1,0<\lambda \leq 5,0$ & $-0,06 \lambda^{2}+0,40 \lambda+2,73$ \\
\hline & & $\lambda>\mathbf{5 , 0}$ & 3,33 \\
\hline & \multirow{4}{*}{$\mu_{y}^{\prime}$} & $0,2 \leq \lambda \leq 0,5$ & $-5,10 \lambda^{2}+23,01 \lambda-2,51$ \\
\hline & & $0,5<\lambda \leq 1,0$ & $-11,13 \lambda^{2}+25,03 \lambda-1,97$ \\
\hline & & $1,0<\lambda \leq 1,5$ & $0,97 \lambda+11,06$ \\
\hline & & $\lambda>1,5$ & 12,62 \\
\hline \multirow{12}{*}{9} & \multirow{4}{*}{$\mu_{x}$} & $0,2 \leq \lambda \leq 0,5$ & $-0,74 \lambda^{2}+7,54 \lambda-0,82$ \\
\hline & & $0,5<\lambda \leq 1,0$ & $-3,30 \lambda^{2}+9,08 \lambda-0,94$ \\
\hline & & $1,0<\lambda \leq 3,0$ & $-0,53 \lambda^{2}+2,72 \lambda+2,77$ \\
\hline & & $\lambda>\mathbf{3 , 0}$ & 6,25 \\
\hline & \multirow{4}{*}{$\mu_{\mathrm{xb}}$} & $0,2 \leq \lambda \leq 0,5$ & $-6,3 \lambda^{2}+14,90 \lambda-1,62$ \\
\hline & & $0,5<\lambda \leq 1,0$ & $-6,77 \lambda^{2}+13,72 \lambda-0,91$ \\
\hline & & $1,0<\lambda \leq 2,0$ & $-0,44 \lambda^{2}+1,50 \lambda+5,03$ \\
\hline & & $\lambda>\mathbf{2 , 0}$ & 6,28 \\
\hline & \multirow{4}{*}{$\mu_{\mathrm{xbmax}}$} & $0,2 \leq \lambda \leq 0,5$ & $-2,77 \lambda^{2}+13,41 \lambda-1,45$ \\
\hline & & $0,5<\lambda \leq 1,0$ & $-6,82 \lambda^{2}+14,37 \lambda-0,89$ \\
\hline & & $1,0<\lambda \leq 2,0$ & $-0,60 \lambda^{2}+2,10 \lambda+5,26$ \\
\hline & & $\lambda>2,0$ & 7,05 \\
\hline \multicolumn{3}{|c|}{$m=\mu \frac{p \ell_{x}^{2}}{100}$} & $\begin{array}{l}\mathrm{p}=\text { carga uniforme } \\
\ell_{\mathrm{x}}=\text { vão paralelo à borda livre }\end{array}$ \\
\hline
\end{tabular}


TABELA 3.15c - FUNÇÕES APROXIMADORAS DOS MOMENTOS FLETORES

\begin{tabular}{|c|c|c|c|}
\hline CASO & $\mu$ & $\lambda=\ell_{\mathrm{y}} / \ell_{\mathrm{x}}$ & $\mu=\mathbf{f}(\lambda)$ \\
\hline \multirow{16}{*}{9} & \multirow{4}{*}{$\mu_{\mathrm{x}}^{\prime}$} & $0,2 \leq \lambda \leq 0,5$ & $-6,37 \lambda^{2}+17,30 \lambda-0,51$ \\
\hline & & $0,5<\lambda \leq 1,0$ & $-4,14 \lambda^{2}+17,79 \lambda+0,76$ \\
\hline & & $1,0<\lambda \leq 2,0$ & $-1,45 \lambda^{2}+6,18 \lambda+5,72$ \\
\hline & & $\lambda>2,0$ & 12,50 \\
\hline & \multirow{5}{*}{$\mu_{\mathrm{xmax}}^{\prime}$} & $0,2 \leq \lambda \leq 0,5$ & $-20,86 \lambda^{2}+33,14 \lambda+1,43$ \\
\hline & & $0,5<\lambda \leq 1,0$ & $-5,06 \lambda^{2}+9,49 \lambda+9,29$ \\
\hline & & $1,0<\lambda \leq 2,0$ & $-0,08 \lambda^{2}+0,14 \lambda+13,69$ \\
\hline & & $2,0<\lambda \leq 3,0$ & $-0,28 \lambda+14,19$ \\
\hline & & $\lambda>3,0$ & 13,12 \\
\hline & \multirow{4}{*}{$\mu_{\mathrm{y}}$} & $0,2 \leq \lambda \leq 0,5$ & $-3,43 \lambda^{2}+6,55 \lambda-0,69$ \\
\hline & & $0,5<\lambda \leq 1,0$ & $-3,38 \lambda^{2}+5,82 \lambda-0,34$ \\
\hline & & $1,0<\lambda \leq 3,2$ & $0,19 \lambda^{2}-1,17 \lambda+3,13$ \\
\hline & & $\lambda>3,2$ & 1,25 \\
\hline & \multirow{3}{*}{$\mu_{\text {ymax }}$} & $0,2 \leq \lambda \leq 0,5$ & $-3,51 \lambda^{2}+6,83 \lambda-0,74$ \\
\hline & & $0,5<\lambda \leq 1,0$ & $-2,66 \lambda^{2}+5,22 \lambda-0,14$ \\
\hline & & $\lambda>1,0$ & 2,42 \\
\hline \multirow{11}{*}{10} & \multirow{4}{*}{$\mu_{x}$} & $0,2 \leq \lambda \leq 0,5$ & $-3,85 \lambda^{2}+8,20 \lambda-0,83$ \\
\hline & & $0,5<\lambda \leq 1,0$ & $-2,42 \lambda^{2}+6,22 \lambda-0,17$ \\
\hline & & $1,0<\lambda \leq 3,0$ & $-0,27 \lambda^{2}+1,27 \lambda+2,72$ \\
\hline & & $\lambda \geq \mathbf{3 , 0}$ & 4,17 \\
\hline & \multirow{3}{*}{$\mu_{\mathrm{xb}}$} & $0,2 \leq \lambda \leq 0,5$ & $-10,19 \lambda^{2}+15,13 \lambda-1,53$ \\
\hline & & $0,5<\lambda \leq 1,0$ & $-4,33 \lambda^{2}+7,79 \lambda+0,72$ \\
\hline & & $\lambda>1,0$ & 4,21 \\
\hline & \multirow{4}{*}{$\mu_{\mathrm{x}}^{\prime}$} & $0,2 \leq \lambda \leq 0,5$ & $-8,06 \lambda^{2}+15,24 \lambda-0,26$ \\
\hline & & $0,5<\lambda \leq 1,0$ & $-4,46 \lambda^{2}+11,16 \lambda+0,92$ \\
\hline & & $1,0<\lambda \leq 2,0$ & $-0,99 \lambda^{2}+3,66 \lambda+4,99$ \\
\hline & & $\lambda>2,0$ & 8,33 \\
\hline & & $\mu \frac{p l_{x}^{2}}{100}$ & $\begin{array}{l}\mathbf{p}=\text { carga uniforme } \\
\ell_{\mathrm{x}}=\text { vão paralelo à borda livre }\end{array}$ \\
\hline
\end{tabular}


TABELA 3.15d - FUNÇÕES APROXIMADORAS DOS MOMENTOS FLETORES

\begin{tabular}{|c|c|c|c|}
\hline CASO & $\mu$ & $\lambda=\ell_{\mathbf{Y}} \backslash \ell_{\mathrm{X}}$ & $\mu=\mathbf{f}(\lambda)$ \\
\hline \multirow{12}{*}{10} & \multirow{4}{*}{$\mu_{\mathrm{xb}}^{\prime}$} & $0,2 \leq \lambda \leq 0,5$ & $-28,30 \lambda^{2}+30,01 \lambda+1,53$ \\
\hline & & $0,5<\lambda \leq 1,0$ & $-1,77 \lambda^{2}+1,73 \lambda+9,10$ \\
\hline & & $1,0<\lambda \leq 3,0$ & $-0,18 \lambda+9,30$ \\
\hline & & $\lambda>\mathbf{3 , 0}$ & 8,61 \\
\hline & \multirow{5}{*}{$\mu_{\mathrm{y}}$} & $0,2 \leq \lambda \leq 0,5$ & $-4,55 \lambda^{2}+6,38 \lambda-0,61$ \\
\hline & & $0,5<\lambda \leq 1,0$ & $-2,40 \lambda^{2}+3,65 \lambda+0,22$ \\
\hline & & $1,0<\lambda \leq 2,0$ & $0,28 \lambda^{2}-1,41 \lambda+2,61$ \\
\hline & & $2,0<\lambda \leq 3,0$ & $0,10 \lambda^{2}-0,61 \lambda+1,72$ \\
\hline & & $\lambda>\mathbf{3 , 0}$ & $\mathbf{0 , 8 3}$ \\
\hline & \multirow{3}{*}{$\mu_{\operatorname{ymax}}$} & $0,2 \leq \lambda \leq 0,5$ & $-4,42 \lambda^{2}+6,33 \lambda-0,61$ \\
\hline & & $0,5<\lambda \leq 1,0$ & $-1,72 \lambda^{2}+3,14 \lambda+0,31$ \\
\hline & & $\lambda>1,0$ & 1,77 \\
\hline \multirow{13}{*}{11} & \multirow{5}{*}{$\mu_{\mathrm{x}}$} & $0,2 \leq \lambda \leq 0,5$ & $10,54 \lambda^{2}-3,40 \lambda+0,20$ \\
\hline & & $0,5<\lambda \leq 1,0$ & $-1,95 \lambda^{2}+8,38 \lambda-2,58$ \\
\hline & & $1,0<\lambda \leq 2,0$ & $-1,41 \lambda^{2}+6,22 \lambda-0,93$ \\
\hline & & $2,0<\lambda \leq 3,0$ & $-0,36 \lambda^{2}+2,13 \lambda+3,05$ \\
\hline & & $\lambda>\mathbf{3 , 0}$ & 6,25 \\
\hline & \multirow{4}{*}{$\mu_{\mathrm{xb}}$} & $0,2 \leq \lambda \leq 0,5$ & $13,26 \lambda^{2}-0,54 \lambda-0,41$ \\
\hline & & $0,5<\lambda \leq 1,0$ & $-9,86 \lambda^{2}+21,11 \lambda-5,53$ \\
\hline & & $1,0<\lambda \leq 2,0$ & $-0,93 \lambda^{2}+3,41 \lambda+3,26$ \\
\hline & & $\lambda>\mathbf{2 , 0}$ & 6,37 \\
\hline & \multirow{4}{*}{$\mu_{\mathrm{xbmax}}$} & $0,2 \leq \lambda \leq 0,5$ & $17,73 \lambda^{2}-4,01 \lambda+0,36$ \\
\hline & & $0,5<\lambda \leq 1,0$ & $-8,91 \lambda^{2}+20,40 \lambda-5,19$ \\
\hline & & $1,0<\lambda \leq 2,0$ & $-1,28 \lambda^{2}+4,48 \lambda+3,16$ \\
\hline & & $\lambda>\mathbf{2 , 0}$ & 7,04 \\
\hline \multicolumn{4}{|r|}{ paralelo à borda livre } \\
\hline
\end{tabular}


TABELA 3.15e - FUNÇÕES APROXIMADORAS DOS MOMENTOS FLETORES

\begin{tabular}{|c|c|c|c|}
\hline CASO & $\mu$ & $\lambda=\ell_{\mathrm{y}} \backslash \ell_{\mathrm{x}}$ & $\mu=\mathbf{f}(\lambda)$ \\
\hline \multirow{22}{*}{11} & \multirow{4}{*}{$\mu_{x}^{\prime}$} & $0,2 \leq \lambda \leq 0,5$ & $8,68 \lambda^{2}+3,44 \lambda-0,47$ \\
\hline & & $0,5<\lambda \leq 1,0$ & $-2,59 \lambda^{2}+14,10 \lambda-2,98$ \\
\hline & & $1,0<\lambda \leq 2,0$ & $-2,66 \lambda^{2}+11,41 \lambda-0,25$ \\
\hline & & $\lambda>\mathbf{2 , 0}$ & 12,50 \\
\hline & \multirow{5}{*}{$\mu_{x \max }^{\prime}$} & $0,2 \leq \lambda \leq 0,5$ & $-1,05 \lambda^{2}+26,67 \lambda-3,47$ \\
\hline & & $0,5<\lambda \leq 1,0$ & $32,97 \lambda^{3}-94,02 \lambda^{2}+90,55 \lambda-16,35$ \\
\hline & & $1,0<\lambda<2,0$ & $-0,47 \lambda^{2}+1,51 \lambda+12,15$ \\
\hline & & $2,0<\lambda \leq 3,0$ & $-0,06 \lambda+13,44$ \\
\hline & & $\lambda>\mathbf{3 , 0}$ & 13,12 \\
\hline & \multirow{5}{*}{$\mu_{y}$} & $0,2 \leq \lambda \leq 0,5$ & $-22,22 \lambda^{3}+36,48 \lambda^{2}-14,81 \lambda+1,27$ \\
\hline & & $0,5<\lambda \leq 1,0$ & $-3,96 \lambda^{3}+4,28 \lambda^{2}+3,80 \lambda-2,27$ \\
\hline & & $1,0<\lambda \leq 2,0$ & $1,15 \lambda^{3}-5,89 \lambda^{2}+9,46 \lambda-2,86$ \\
\hline & & $2,0<\lambda \leq 4,0$ & $0,076 \lambda^{2}-0,66 \lambda+2,64$ \\
\hline & & $\lambda>4,0$ & 1,25 \\
\hline & \multirow{4}{*}{$\mu_{\text {ymax }}$} & $0,2 \leq \lambda \leq 0,4$ & $0,60 \lambda+0,14$ \\
\hline & & $0,4<\lambda \leq 1,0$ & $-4,36 \lambda^{3}+5,89 \lambda^{2}+1,16 \lambda-0,70$ \\
\hline & & $1,0<\lambda \leq 1,4$ & $-0,25 \lambda^{2}+0,85 \lambda+1,43$ \\
\hline & & $\lambda>1,4$ & 2,14 \\
\hline & \multirow{4}{*}{$\mu_{y \max }^{\prime}$} & $0,2 \leq \lambda \leq 0,5$ & $-16,75 \lambda^{2}+26,74 \lambda-2,79$ \\
\hline & & $0,5<\lambda \leq 1,0$ & $-7,52 \lambda^{2}+14,51 \lambda+1,04$ \\
\hline & & $1,0<\lambda \leq 2,0$ & $0,16 \lambda+7,93$ \\
\hline & & $\lambda>\mathbf{2 , 0}$ & 8,22 \\
\hline \multirow{4}{*}{12} & \multirow{4}{*}{$\mu_{\mathrm{x}}$} & $0,2 \leq \lambda \leq 0,4$ & $13,80 \lambda^{2}-4,78 \lambda+0,36$ \\
\hline & & $0,4<\lambda<1,0$ & $-2,70 \lambda^{2}+7,85 \lambda-2,08$ \\
\hline & & $1,0<\lambda \leq 2,0$ & $-1,04 \lambda^{2}+4,12 \lambda+0,01$ \\
\hline & & $\lambda>2,0$ & 4,17 \\
\hline \multicolumn{3}{|c|}{$m=\mu \frac{p \ell_{x}^{2}}{100}$} & $\begin{array}{l}\mathrm{p}=\text { carga uniforme } \\
\ell_{\mathrm{x}}=\text { vão paralelo à borda livre }\end{array}$ \\
\hline
\end{tabular}


TABELA 3.15f - FUNÇÕES APROXIMADORAS DOS MOMENTOS FLETORES

\begin{tabular}{|c|c|c|c|}
\hline CASO & $\mu$ & $\lambda=\ell_{\mathrm{Y}} / \ell_{\mathrm{X}}$ & $\mu=\mathbf{f}(\lambda)$ \\
\hline \multirow{22}{*}{12} & \multirow{3}{*}{$\mu_{\mathrm{xbmax}}$} & $0,2 \leq \lambda \leq 0,5$ & $-67,11 \lambda^{3}+80,45 \lambda^{2}-22,63 \lambda+2,06$ \\
\hline & & $0,5<\lambda \leq 1,0$ & $-7,29 \lambda^{2}+14,08 \lambda-2,70$ \\
\hline & & $\lambda>1,0$ & 4,17 \\
\hline & \multirow{4}{*}{$\mu_{x}^{\prime}$} & $0,2 \leq \lambda \leq 0,5$ & $5,64 \lambda^{2}+4,80 \lambda-0,62$ \\
\hline & & $0,5<\lambda \leq 1,0$ & $-4,18 \lambda^{2}+13,19 \lambda-2,36$ \\
\hline & & $1,0<\lambda \leq 2,0$ & $-1,79 \lambda^{2}+6,96 \lambda+1,51$ \\
\hline & & $\lambda>\mathbf{2 , 0}$ & 8,33 \\
\hline & \multirow{4}{*}{$\mu^{\prime}{ }_{x b}^{\prime}$} & $0,2 \leq \lambda \leq 0,5$ & $-21,03 \lambda^{2}+36,28 \lambda-4,70$ \\
\hline & & $0,5<\lambda \leq 1,0$ & $25,11 \lambda^{3}-67,05 \lambda^{2}+58,62 \lambda-7,57$ \\
\hline & & $1,0<\lambda \leq 2,0$ & $0,51 \lambda^{2}-2,32 \lambda+10,96$ \\
\hline & & $\lambda>\mathbf{2 , 0}$ & 8,33 \\
\hline & \multirow{5}{*}{$\mu_{\mathrm{y}}$} & $0,2 \leq \lambda \leq 0,5$ & $-36,22 \lambda^{3}+49,00 \lambda^{2}-17,52 \lambda+1,45$ \\
\hline & & $0,5<\lambda \leq 1,0$ & $-4,34 \lambda^{2}+8,63 \lambda-2,81$ \\
\hline & & $1,0<\lambda \leq 2,0$ & $-0,08 \lambda^{2}-0,27 \lambda+1,86$ \\
\hline & & $2,0<\lambda \leq 3,2$ & $0,15 \lambda^{2}-0,90 \lambda+2,20$ \\
\hline & & $\lambda>3,2$ & $\mathbf{0 , 8 3}$ \\
\hline & \multirow{3}{*}{$\mu_{y \max }$} & $0,2 \leq \lambda \leq 0,5$ & $2,80 \lambda-0,65$ \\
\hline & & $0,5<\lambda \leq 1,0$ & $-2,91 \lambda^{2}+5,74 \lambda-1,36$ \\
\hline & & $\lambda>1,0$ & 1,49 \\
\hline & \multirow{3}{*}{$\mu_{y}^{\prime}$} & $0,2 \leq \lambda \leq 0,5$ & $-24,59 \lambda^{2}+28,00 \lambda-2,76$ \\
\hline & & $0,5<\lambda \leq 1,0$ & $-3,01 \lambda^{2}+5,58 \lambda+3,09$ \\
\hline & & $\lambda>\mathbf{1 , 0}$ & 5,76 \\
\hline \multicolumn{3}{|c|}{$m=\mu \frac{p \ell_{x}^{2}}{100}$} & $\begin{array}{l}\mathrm{p}=\text { carga uniforme } \\
\ell_{\mathrm{x}}=\text { vão paralelo à borda livre }\end{array}$ \\
\hline
\end{tabular}


TABELA 3.16a - FUNÇÕES APROXIMADORAS PARA AS FLECHAS

\begin{tabular}{|c|c|c|c|}
\hline CASO & $\alpha$ & $\lambda=\ell_{\mathrm{y}} / \ell_{\mathrm{x}}$ & $\alpha=\mathbf{f}(\lambda)$ \\
\hline \multirow{9}{*}{7} & \multirow{5}{*}{$\alpha$} & $0,2 \leq \lambda \leq 0,5$ & $6,25 \lambda^{2}+6,45 \lambda-0,72$ \\
\hline & & $0,5<\lambda \leq 1,0$ & $-4,88 \lambda^{2}+16,76 \lambda-3,10$ \\
\hline & & $1,0<\lambda \leq 2,0$ & $-2,75 \lambda^{2}+12,61 \lambda-1,03$ \\
\hline & & $2,0<\lambda \leq 5,0$ & $-0,29 \lambda^{2}+2,58 \lambda+9,37$ \\
\hline & & $\lambda>\mathbf{5 , 0}$ & 15,53 \\
\hline & \multirow{4}{*}{$\alpha_{b}$} & $0,2 \leq \lambda \leq 0,5$ & $4,75 \lambda^{2}+15,57 \lambda-1,70$ \\
\hline & & $0,5<\lambda \leq 1,0$ & $-12,63 \lambda^{2}+30,01 \lambda-4,52$ \\
\hline & & $1,0<\lambda<2,0$ & $-3,71 \lambda^{2}+13,29 \lambda+3,43$ \\
\hline & & $\lambda>\mathbf{2 , 0}$ & 15,63 \\
\hline \multirow{9}{*}{8} & \multirow{5}{*}{$\alpha$} & $0,2 \leq \lambda \leq 0,5$ & $12,00 \lambda^{2}-3,42 \lambda+0,28$ \\
\hline & & $0,5<\lambda \leq 1,0$ & $-1,75 \lambda^{2}+11,77 \lambda-3,92$ \\
\hline & & $1,0<\lambda \leq 2,0$ & $-3,43 \lambda^{2}+16,31 \lambda-6,78$ \\
\hline & & $2,0<\lambda \leq 4,0$ & $-0,71 \lambda^{2}+5,52 \lambda+4,08$ \\
\hline & & $\lambda>\mathbf{4 , 0}$ & 15,63 \\
\hline & \multirow{4}{*}{$\alpha_{b}$} & $0,2 \leq \lambda \leq 0,5$ & $-31,67 \lambda^{3}+56,50 \lambda^{2}-15,43 \lambda+1,29$ \\
\hline & & $0,5<\lambda \leq 1,0$ & $-11,80 \lambda^{2}+32,41 \lambda-9,54$ \\
\hline & & $1,0<\lambda \leq 1,8$ & $-7,39 \lambda^{2}+25,36 \lambda-6,83$ \\
\hline & & $\lambda>1,8$ & 15,63 \\
\hline \multirow{7}{*}{9} & \multirow{4}{*}{$\alpha$} & $0,2 \leq \lambda \leq 0,5$ & $-1,05 \lambda^{2}+6,95 \lambda-0,68$ \\
\hline & & $0,5<\lambda \leq 1,0$ & $-2,57 \lambda^{2}+7,79 \lambda-0,71$ \\
\hline & & $1,0<\lambda \leq 2,0$ & $-0,99 \lambda^{2}+4,22 \lambda+1,28$ \\
\hline & & $\lambda>\mathbf{2 , 0}$ & 6,50 \\
\hline & \multirow{3}{*}{$\alpha_{\text {bmax }}$} & $0,2 \leq \lambda \leq 0,5$ & $-6,75 \lambda^{2}+15,28 \lambda-1,46$ \\
\hline & & $0,5<\lambda \leq 1,0$ & $-6,55 \lambda^{2}+12,95 \lambda-0,31$ \\
\hline & & $\lambda>1,0$ & 6,50 \\
\hline & \multicolumn{2}{|c|}{$a=\alpha \frac{p l_{x}^{4}}{100 E h^{3}}$} & $\begin{array}{l}\mathrm{p}=\text { carga uniforme } \\
\ell_{\mathrm{x}}=\text { vão paralelo à borda livre } \\
\mathrm{E}=\text { módulo de elasticidade } \\
\mathrm{h}=\text { espessura }\end{array}$ \\
\hline
\end{tabular}


TABELA 3.16b - FUNÇÕES APROXIMADORAS PARA AS FLECHAS

\begin{tabular}{|c|c|c|c|}
\hline CASO & $\alpha$ & $\lambda=\ell_{\mathrm{y}} / \ell_{\mathrm{x}}$ & $\alpha=\mathbf{f}(\lambda)$ \\
\hline \multirow{7}{*}{10} & \multirow{4}{*}{$\alpha$} & $0,2 \leq \lambda \leq 0,5$ & $-2,50 \lambda^{2}+5,41 \lambda-0,42$ \\
\hline & & $0,5<\lambda \leq 1,0$ & $-1,65 \lambda^{2}+4,29 \lambda-0,07$ \\
\hline & & $1,0<\lambda \leq 2,0$ & $-0,52 \lambda^{2}+1,96 \lambda+1,14$ \\
\hline & & $\lambda>\mathbf{2 , 0}$ & 3,13 \\
\hline & \multirow{3}{*}{$\alpha_{\mathrm{b}}$} & $0,2 \leq \lambda \leq 0,5$ & $-9,25 \lambda^{2}+11,93 \lambda-0,92$ \\
\hline & & $0,5<\lambda \leq 1,0$ & $-2,81 \lambda^{2}+4,70 \lambda+1,10$ \\
\hline & & $\lambda>1,0$ & 3,13 \\
\hline \multirow{9}{*}{11} & \multirow{5}{*}{$\alpha$} & $0,2 \leq \lambda \leq 0,5$ & $6,75 \lambda^{2}-0,98 \lambda+0,01$ \\
\hline & & $0,5<\lambda \leq 1,0$ & $-1,66 \lambda^{2}+7,20 \lambda-1,98$ \\
\hline & & $1,0<\lambda \leq 2,0$ & $-1,33 \lambda^{2}+5,98 \lambda-1,08$ \\
\hline & & $2,0<\lambda \leq 3,0$ & $-0,36 \lambda^{2}+2,19 \lambda+2,62$ \\
\hline & & $\lambda>\mathbf{3 , 0}$ & $\mathbf{6 , 5 0}$ \\
\hline & \multirow{4}{*}{$\alpha_{\text {bmax }}$} & $0,2 \leq \lambda \leq 0,5$ & $-38,33 \lambda^{3}+52,00 \lambda^{2}-12,62 \lambda+0,96$ \\
\hline & & $0,5<\lambda \leq 1,0$ & $-8,94 \lambda^{2}+19,13 \lambda-4,44$ \\
\hline & & $1,0<\lambda \leq 2,0$ & $-0,90 \lambda^{2}+3,04 \lambda+3,73$ \\
\hline & & $\lambda>\mathbf{2 , 0}$ & 6,50 \\
\hline \multirow{7}{*}{12} & \multirow{4}{*}{$\alpha$} & $0,2 \leq \lambda \leq 0,5$ & $3,00 \lambda^{2}+0,76 \lambda-0,21$ \\
\hline & & $0,5<\lambda \leq 1,0$ & $-1,41 \lambda^{2}+4,63 \lambda-1,04$ \\
\hline & & $1,0<\lambda \leq 2,5$ & $0,28 \lambda^{3}-2,00 \lambda^{2}+4,80 \lambda-0,89$ \\
\hline & & $\lambda>2,5$ & 3,13 \\
\hline & \multirow{3}{*}{$\alpha_{b}$} & $0,2 \leq \lambda \leq 0,5$ & $-42,22 \lambda^{3}+46,10 \lambda^{2}-9,73 \lambda+0,64$ \\
\hline & & $0,5<\lambda \leq 1,0$ & $10,51 \lambda^{3}-28,87 \lambda^{2}+26,91 \lambda-5,53$ \\
\hline & & $\lambda>1,0$ & 3,13 \\
\hline & \multicolumn{2}{|c|}{$a=\alpha \frac{p \ell_{x}^{4}}{100 E h^{3}}$} & $\begin{array}{l}\mathrm{p}=\text { carga uniforme } \\
\ell_{\mathrm{x}}=\text { vão paralelo à borda livre } \\
\mathbf{E}=\text { módulo de elasticidade } \\
\mathrm{h}=\text { espessura }\end{array}$ \\
\hline
\end{tabular}




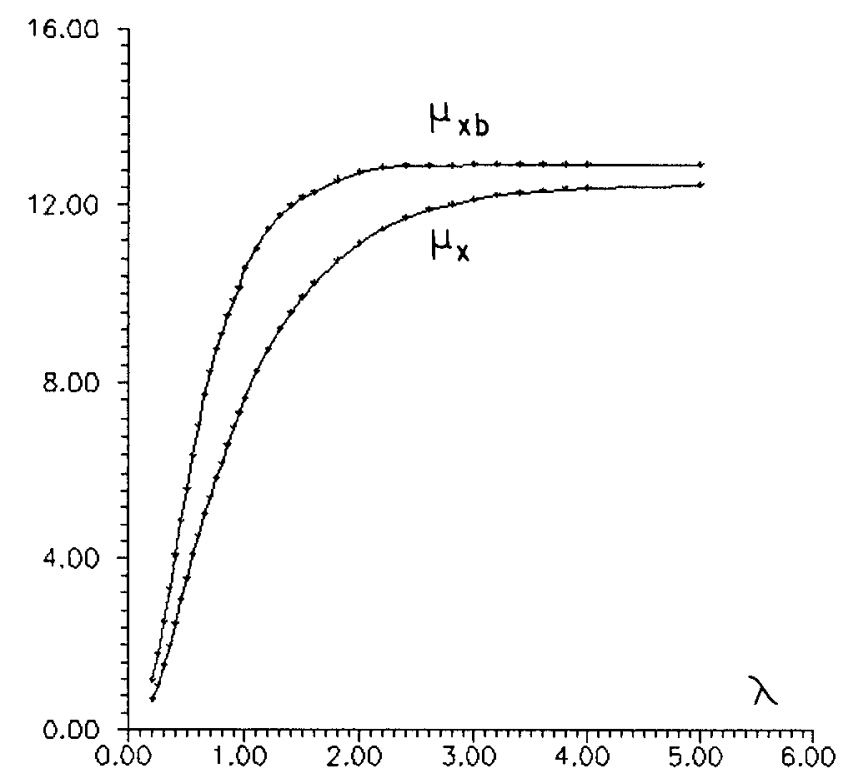

Fig. 3.4

Caso $7: \mu_{x}$ e $\mu_{x b}$

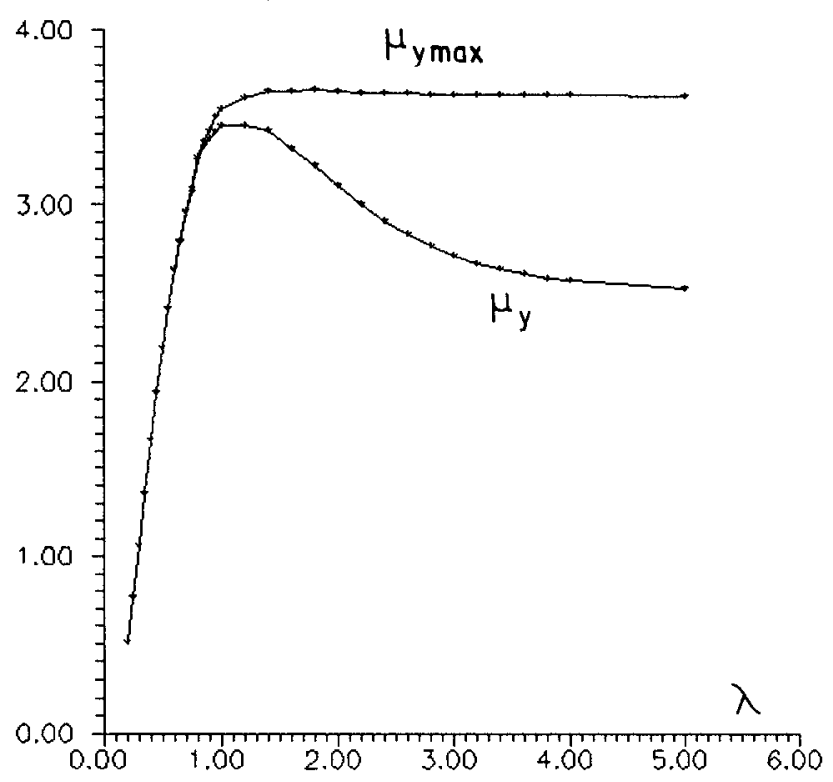

Fig. 3.5

Caso $7: \mu_{y}$ e $\mu_{y \max }$ 


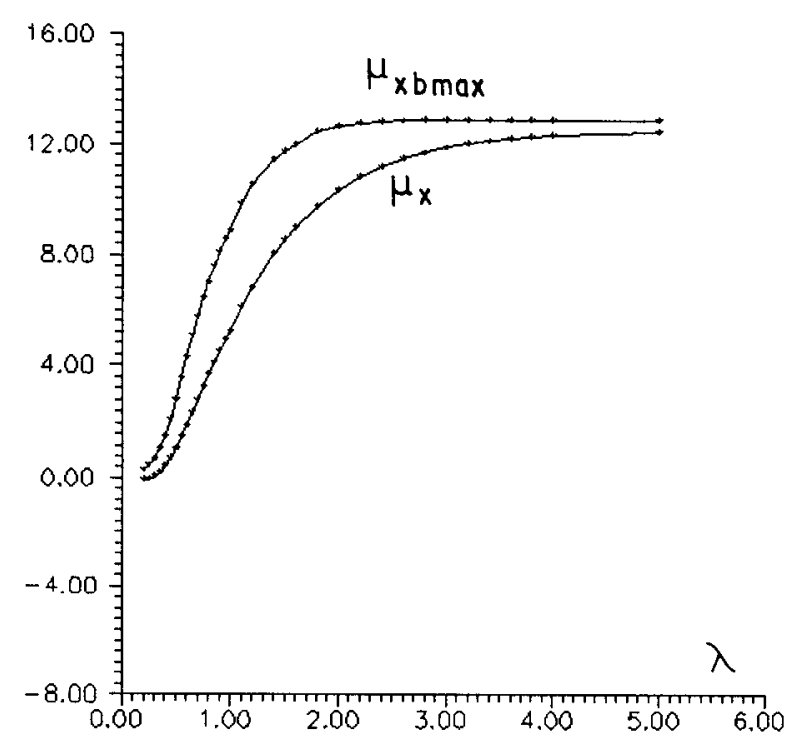

Fig. 3.6

Caso $8: \mu_{x}$ e $\mu_{x b \max }$

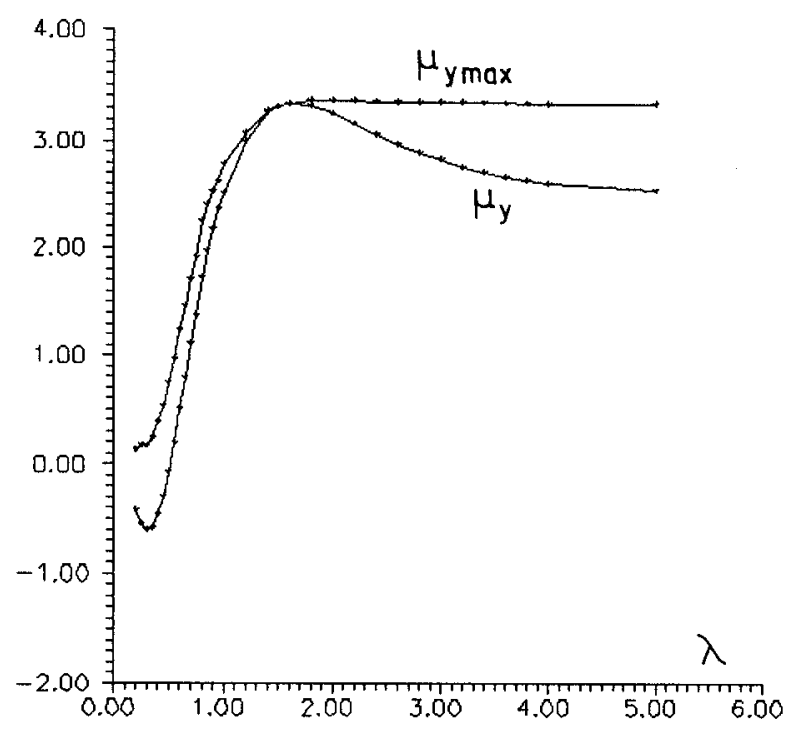

Fig. 3.7

Caso $8: \mu_{y}$ e $\mu_{y \max }$

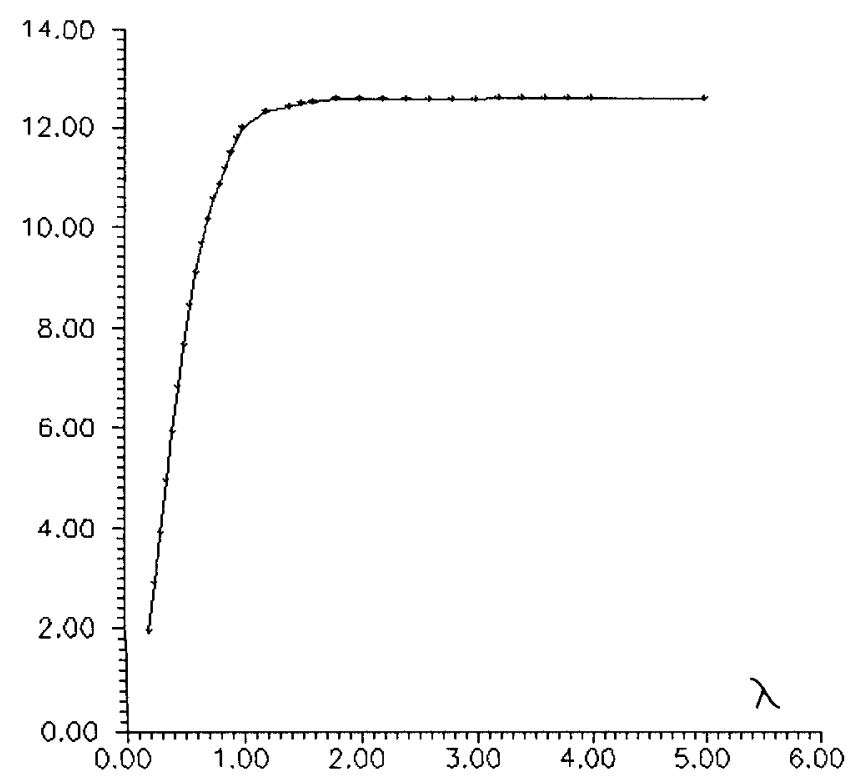

Fig. 3.8

Caso $8: \mu^{\prime} y$ 


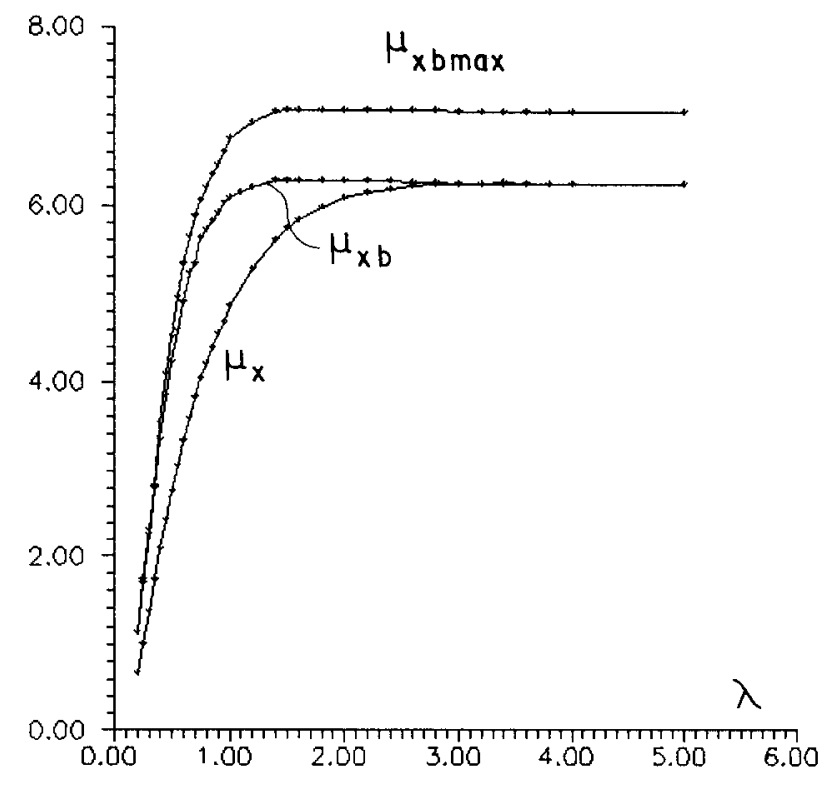

Fig. 3.9

Caso $9: \mu_{x}, \mu_{x b}$ e $\mu_{x b \max }$

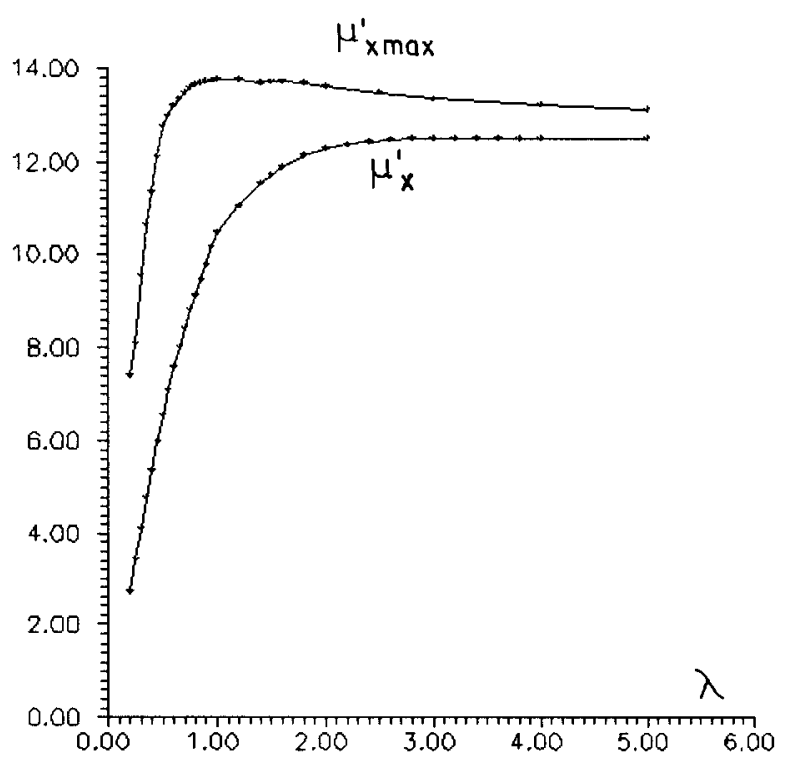

Fig. 3.10

Caso 9 : $\mu^{\prime}{ }_{x}$ e $\mu^{\prime}{ }_{x \max }$

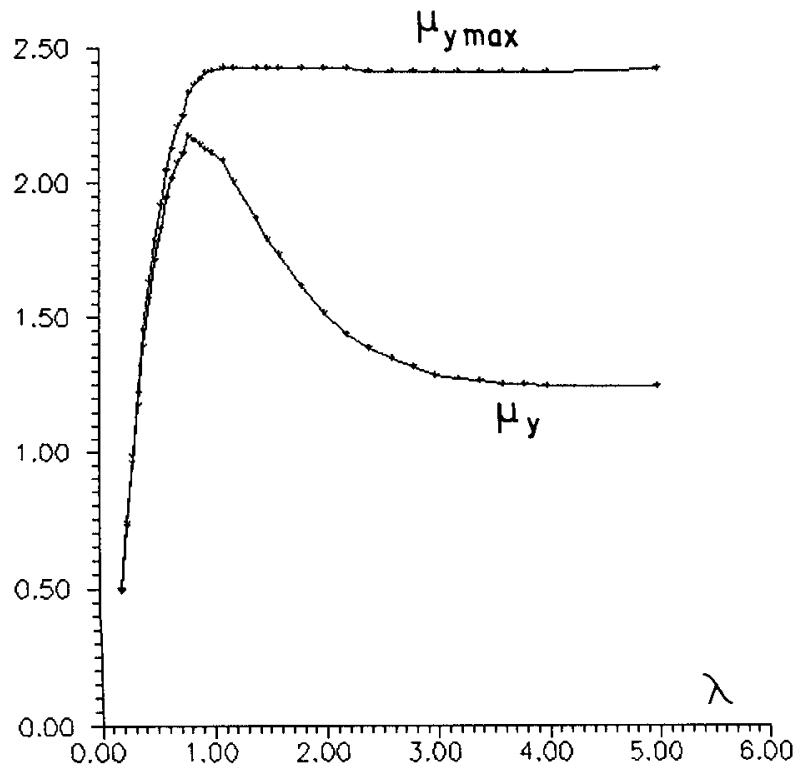

Fig. 3.11

Caso $9: \mu_{\mathrm{y}}$ e $\mu_{\mathrm{ymax}}$ 


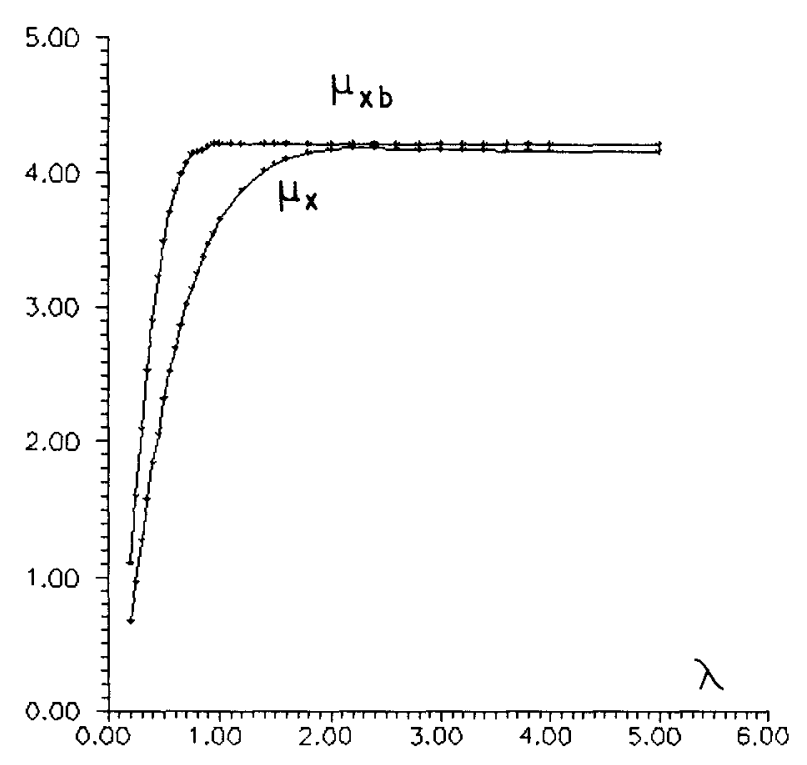

Fig. 3.12

Caso 10: $\mu_{\mathrm{x}}$ e $\mu_{\mathrm{xb}}$

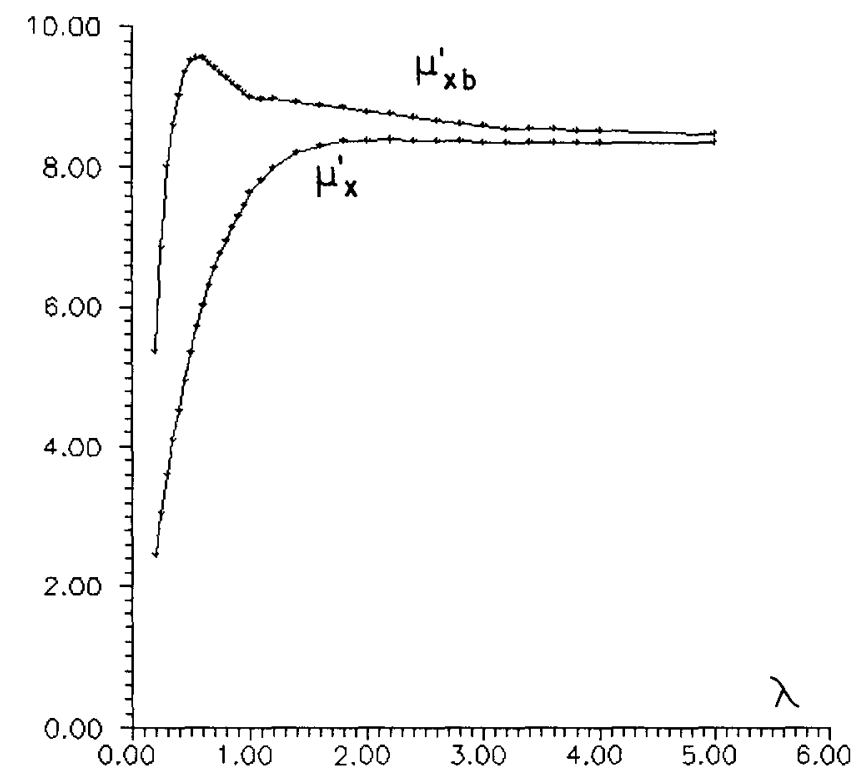

Fig. 3.13

Caso 10: $\mu^{\prime}{ }_{x}$ e $\mu^{\prime}{ }_{x b}$

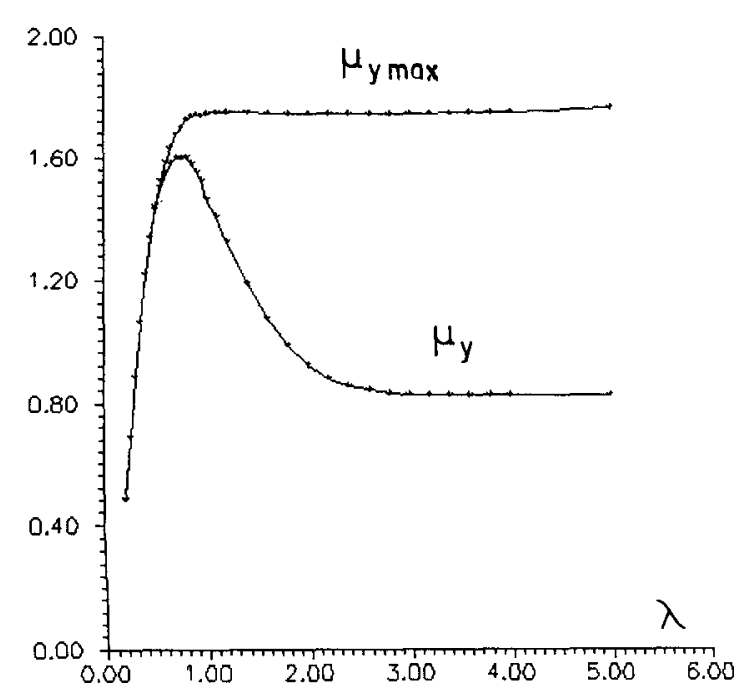

Fig. 3.14

Caso $10: \mu_{y}$ e $\mu_{y m a x}$ 


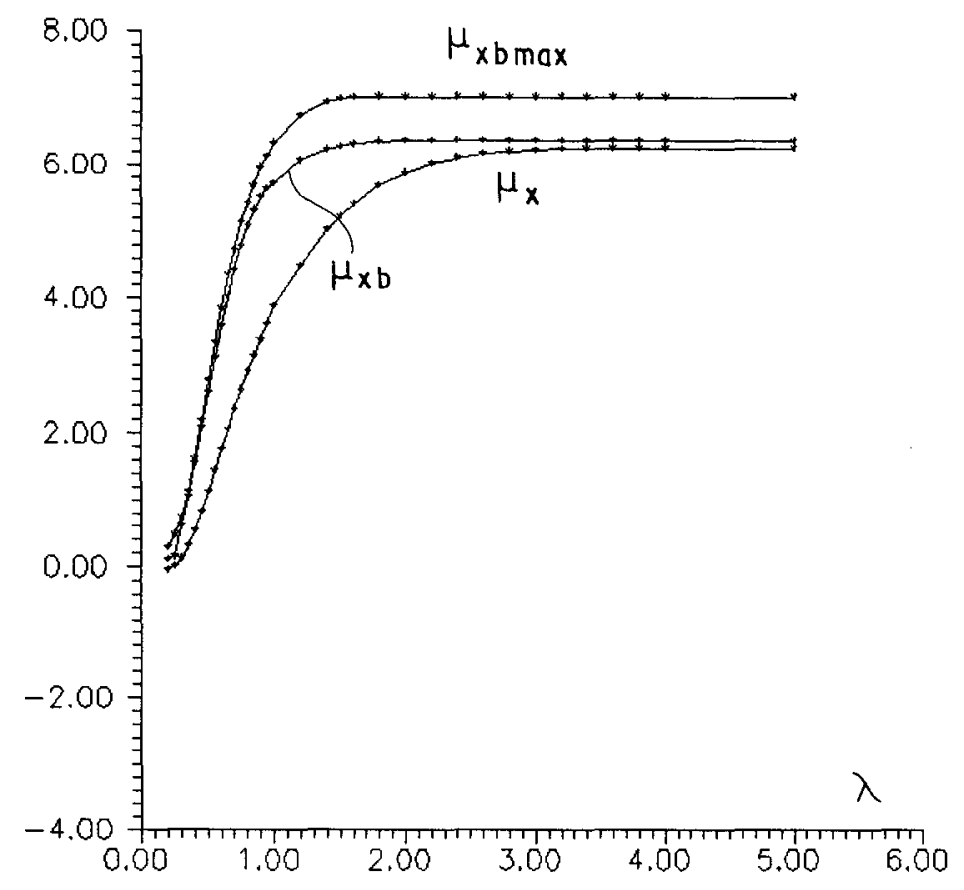

Fig. 3.15

Caso 11: $\mu_{\mathrm{x}}, \mu_{\mathrm{xb}} \mathrm{e}$

$\mu_{\mathrm{xbmax}}$

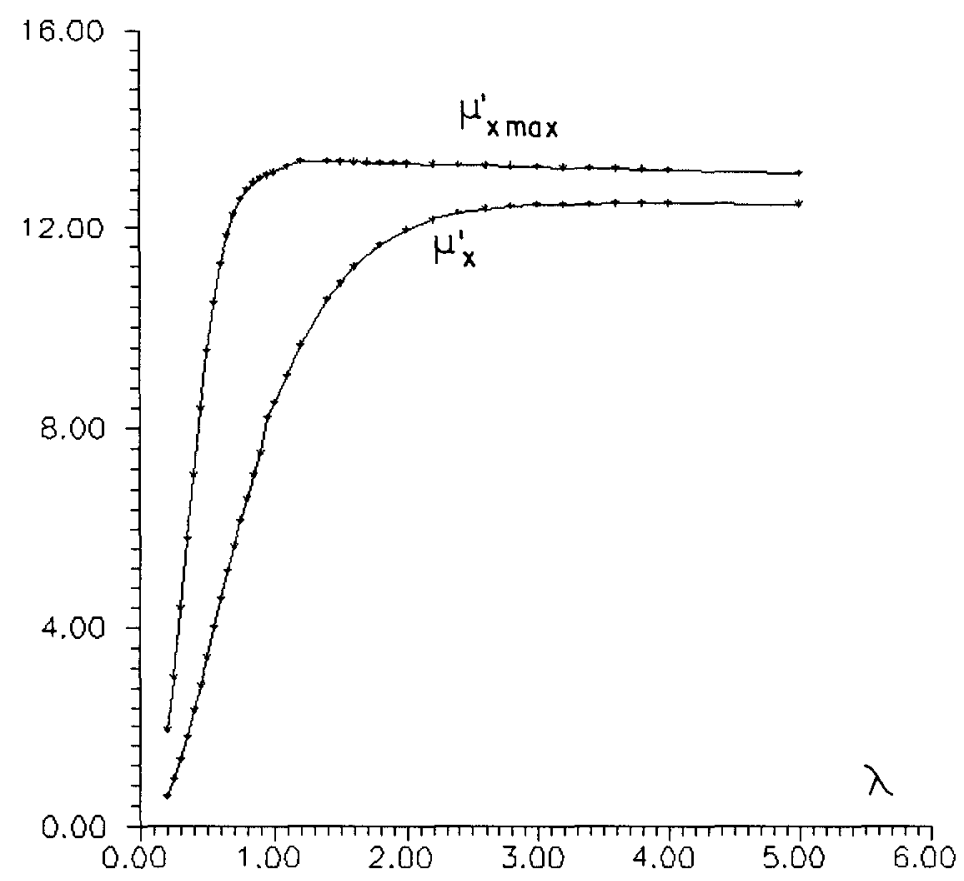

Fig. 3. 16

Caso 11 : $\mu^{\prime}{ }_{x}, \mu^{\prime}{ }_{x \max }$ 


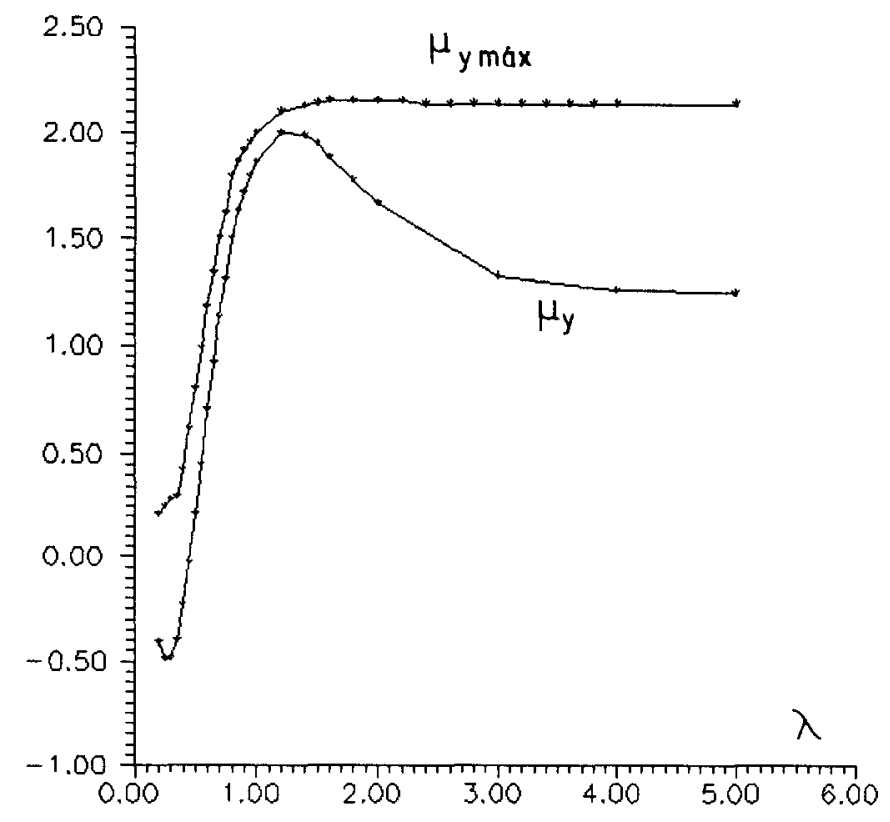

Fig. 3.17

Caso 11 : $\mu_{\mathrm{y}}$ e $\mu_{\mathrm{ymax}}$

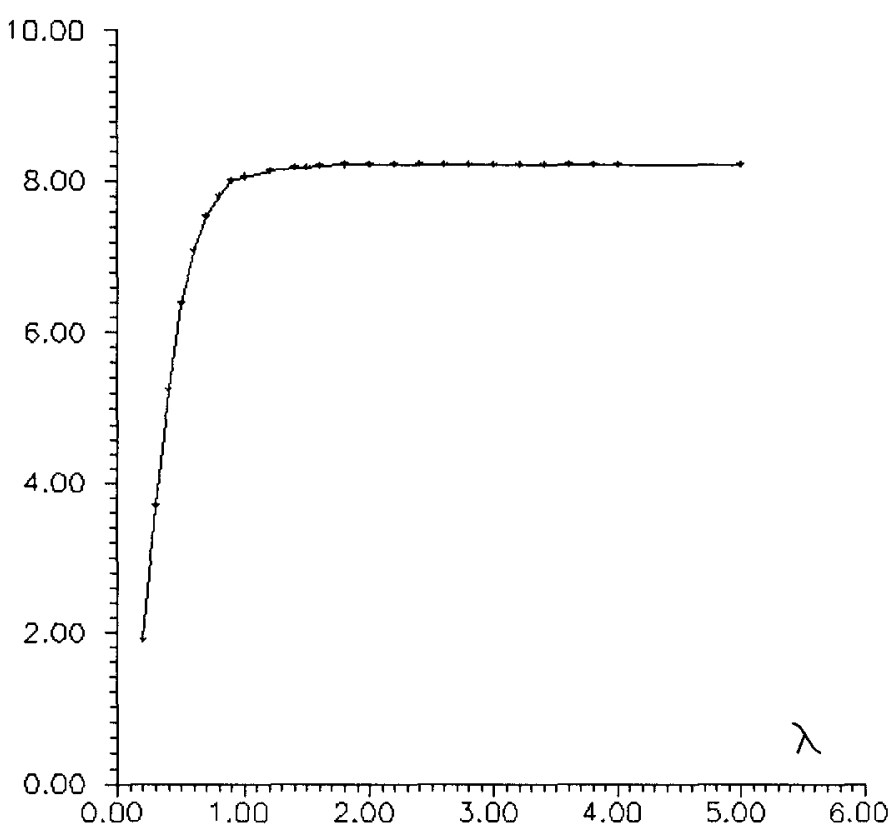

Fig. 3.18

Caso 11 : $\mu^{\prime}{ }_{y \max }$ 


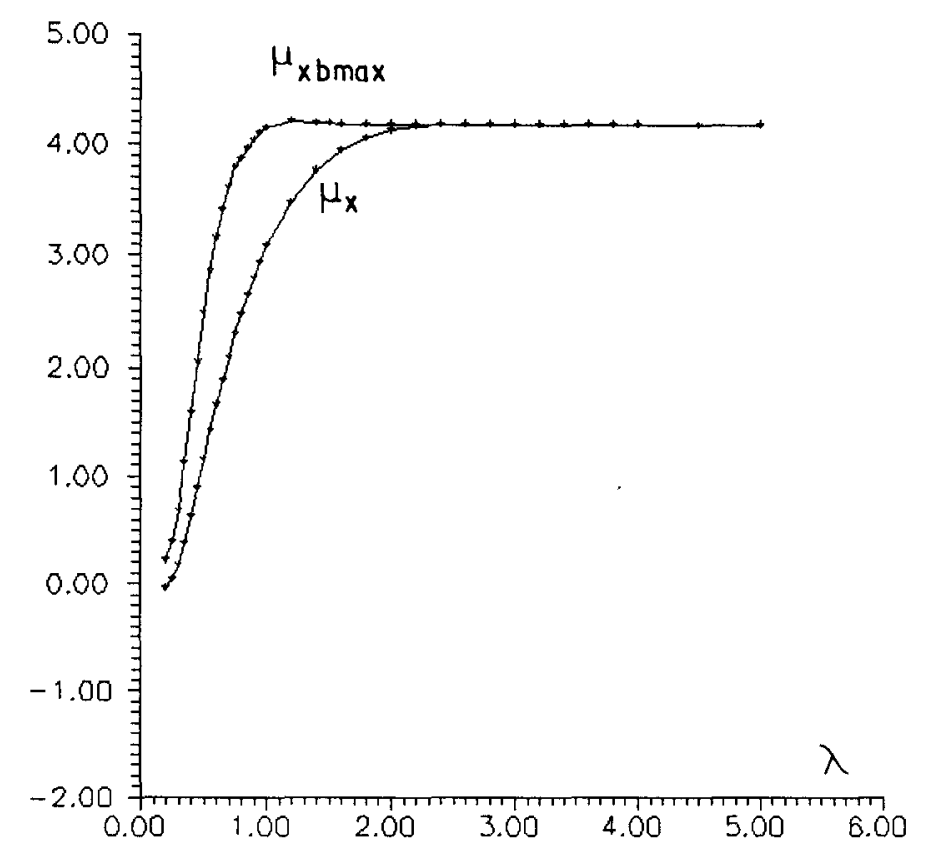

Fig. 3.19

Caso $12: \mu_{x}$ e $\mu_{\text {xbmáx }}$

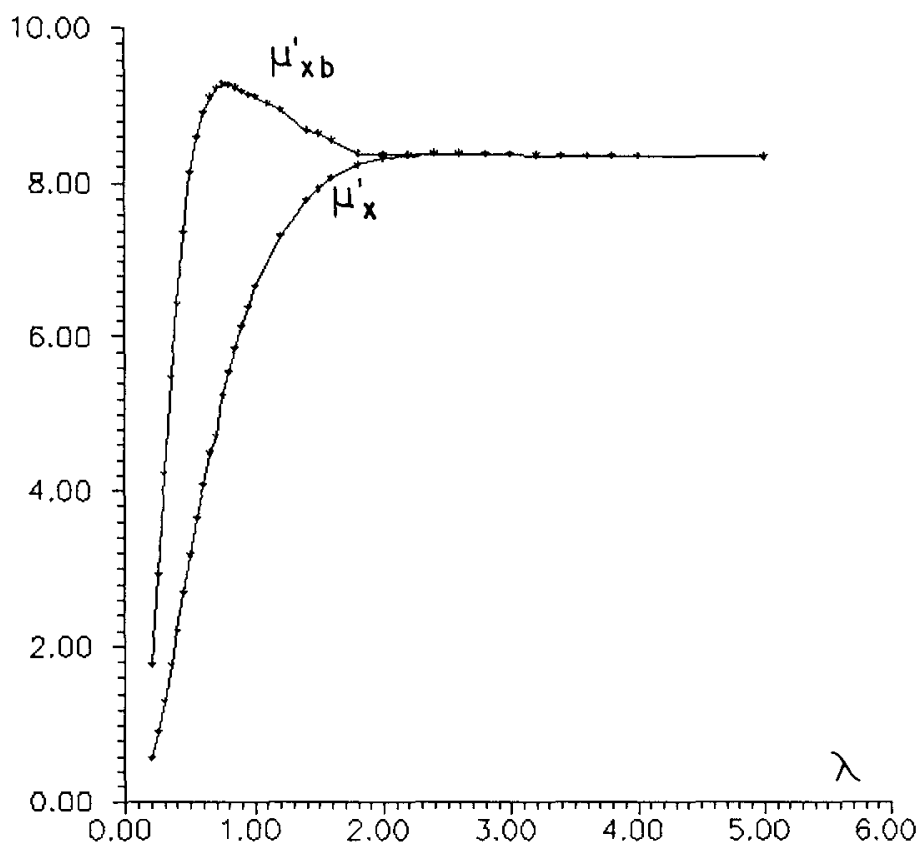

Fig. 3.20

Caso $12: \mu^{\prime}{ }_{x}$ e $\mu^{\prime}{ }_{x b}$ 


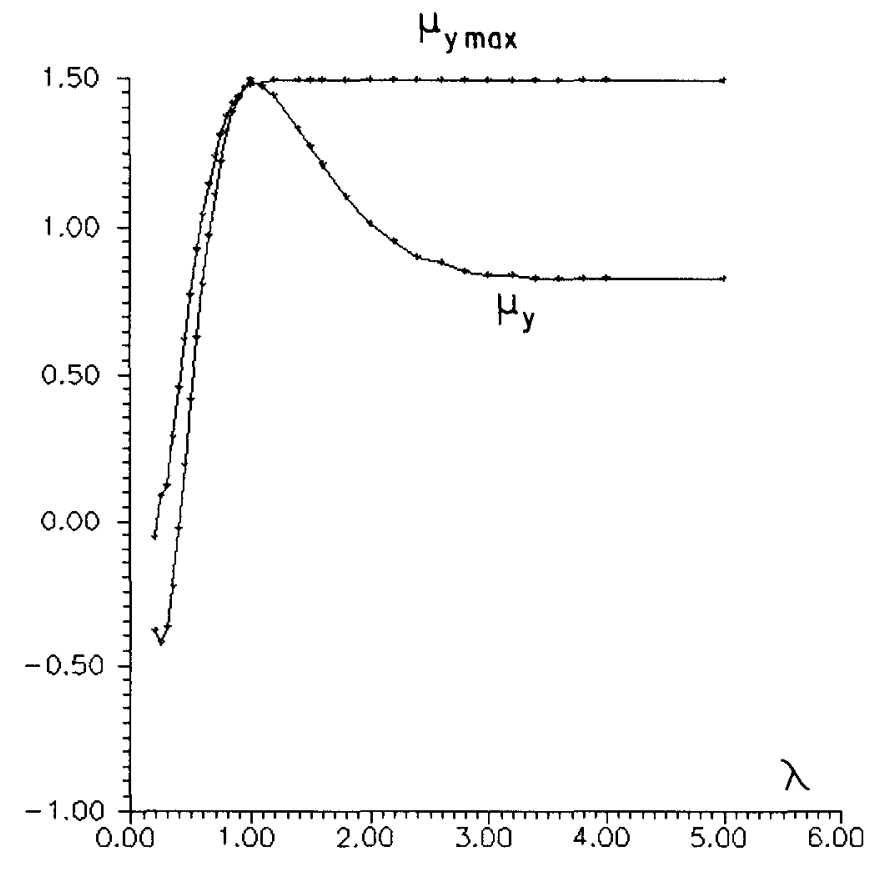

Fig. 3.21

Caso $12: \mu_{\mathrm{y}}$ e $\mu_{\mathrm{ymax}}$

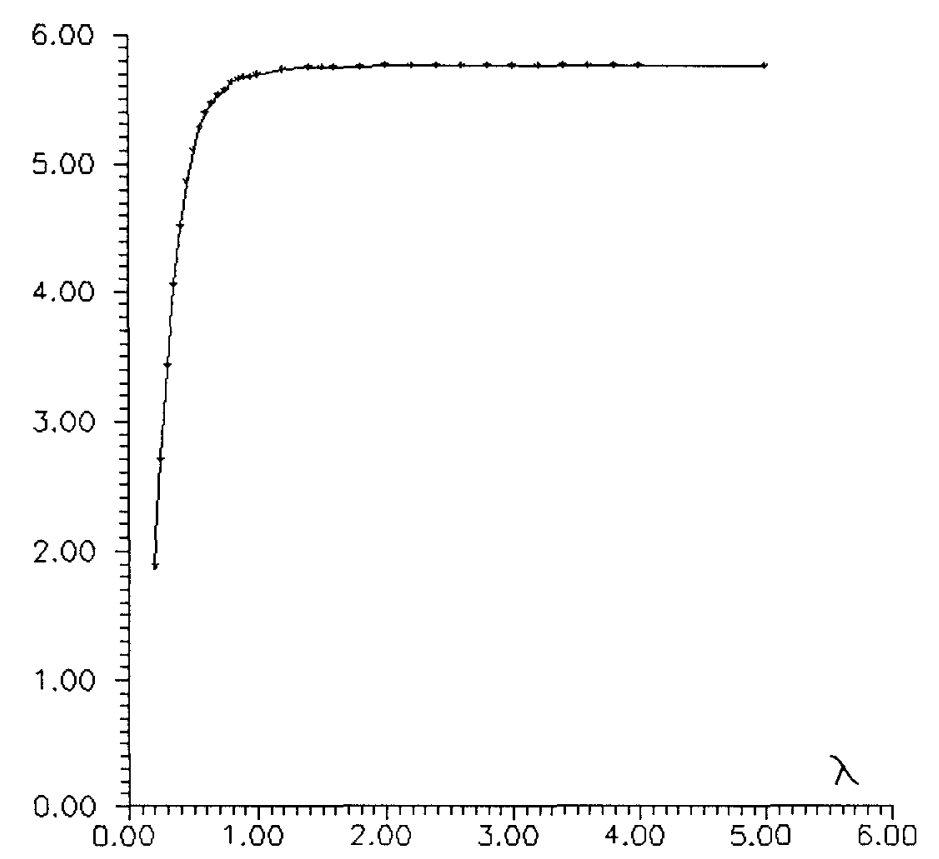

Fig. 3.22

Caso $12: \mu^{\prime}$ 


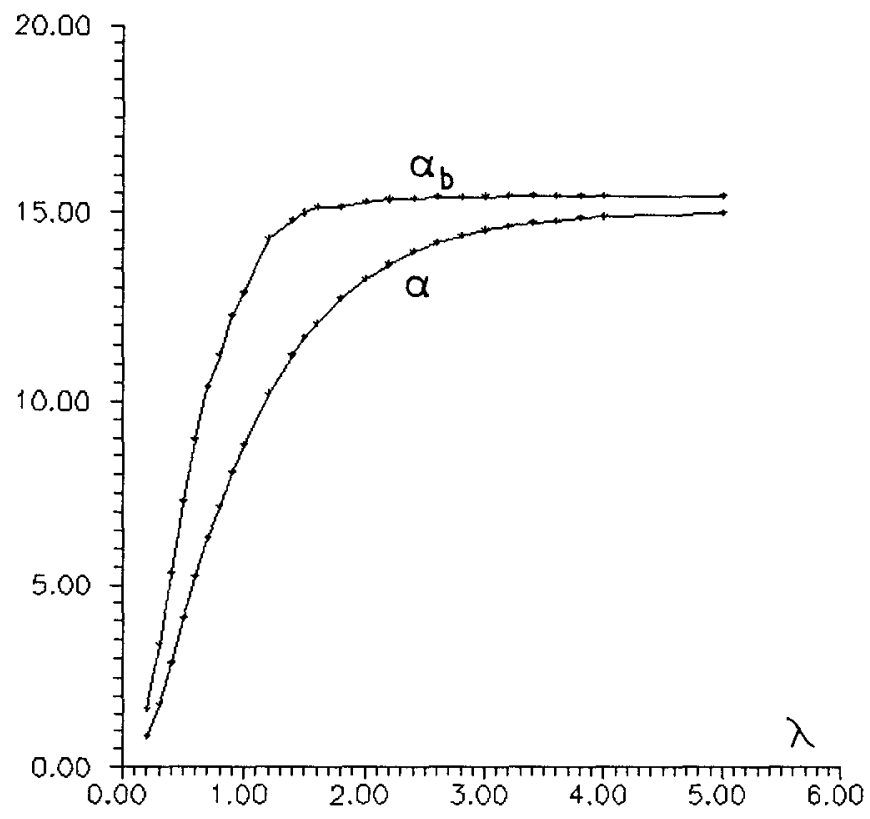

Fig. 3.23

Caso $7: \alpha$ e $\alpha_{b}$

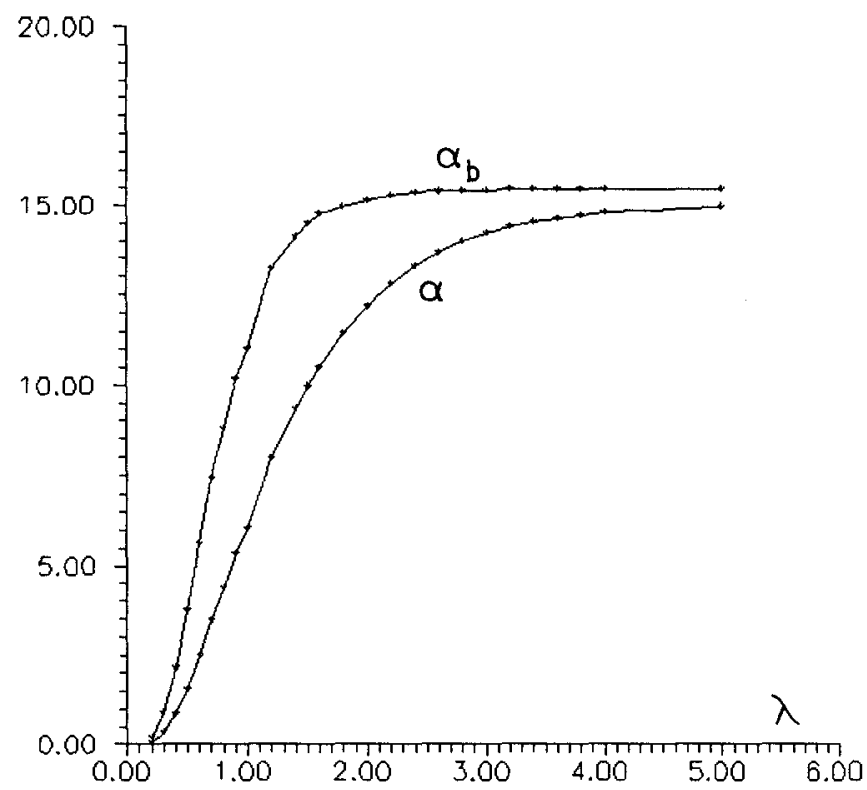

Fig. 3.24

Caso $8: \alpha$ e $\alpha_{b}$

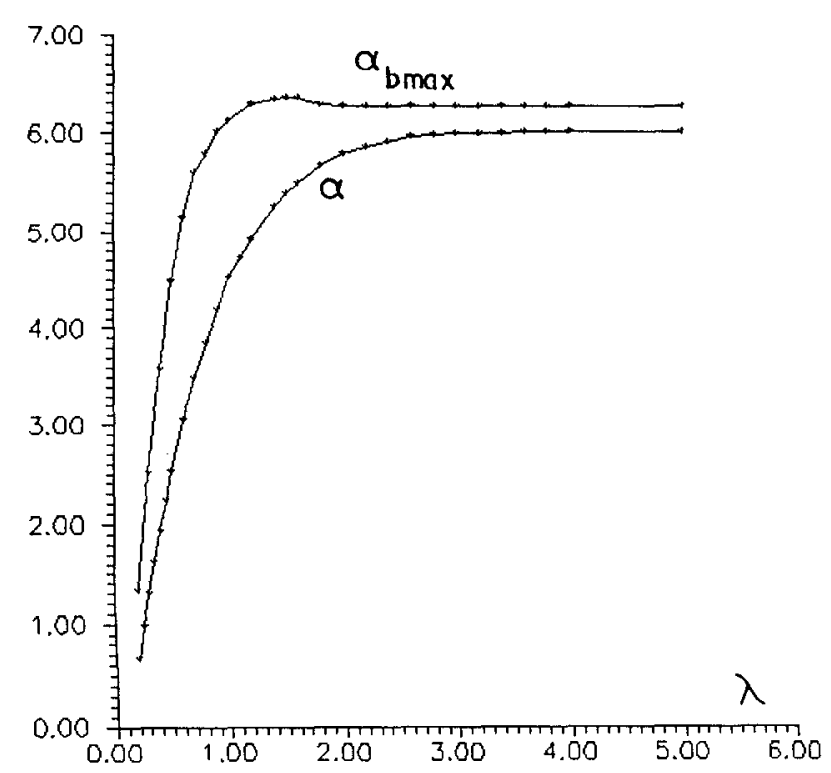

Fig. 3.25

Caso $9: \alpha$ e $\alpha_{b \max }$ 


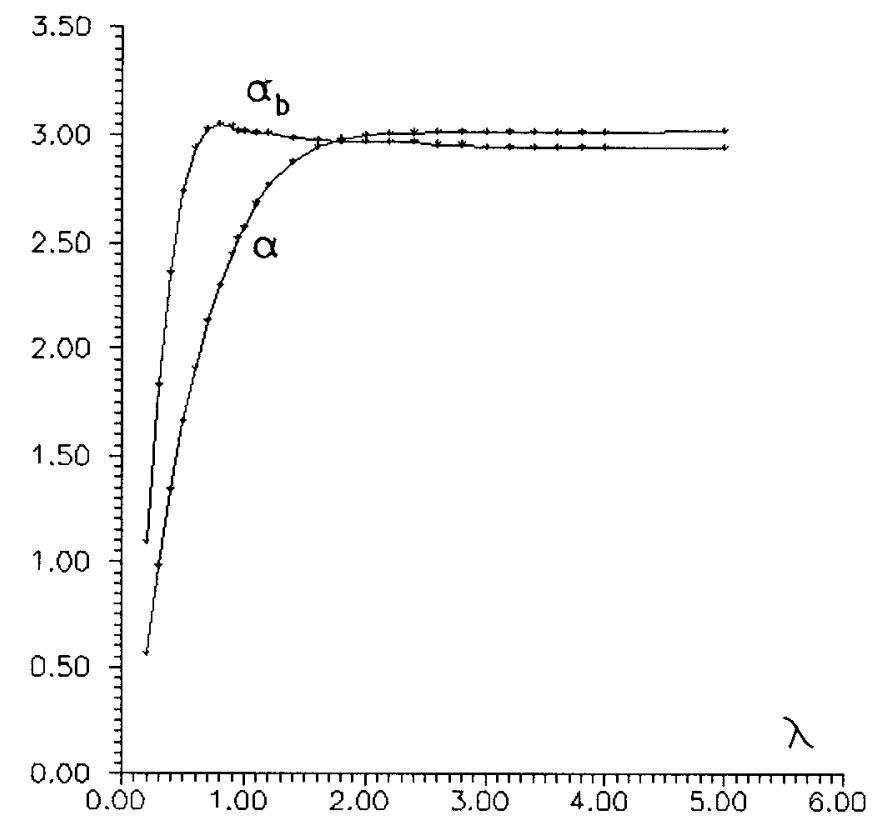

Fig. 3.26

Caso 10: $\alpha$ e $\alpha_{b}$

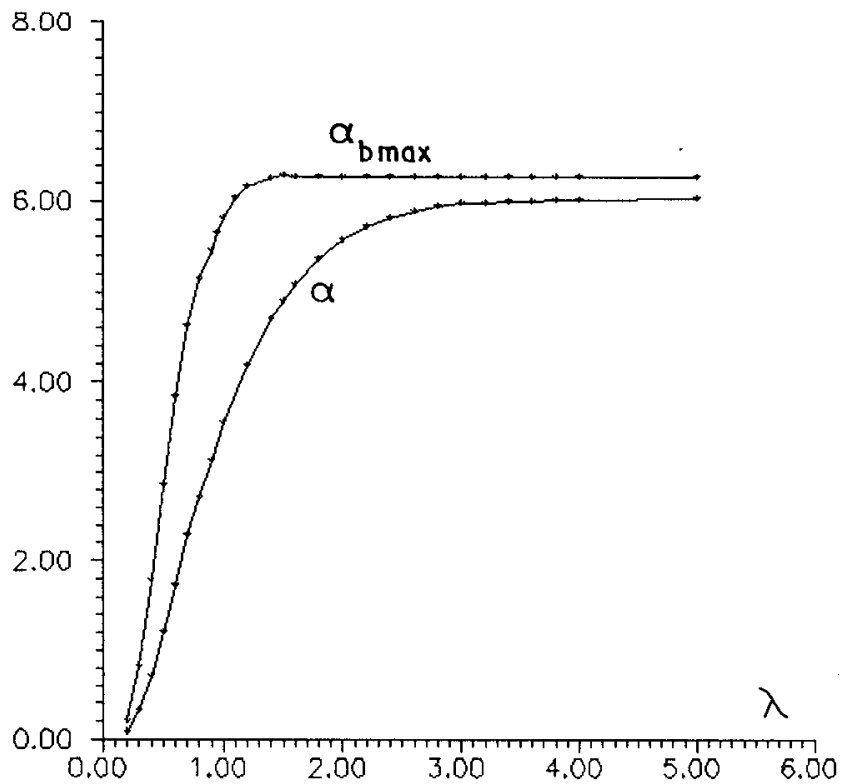

Fig. 3.27

Caso 11 : $\alpha$ e $\alpha_{\text {bmax }}$

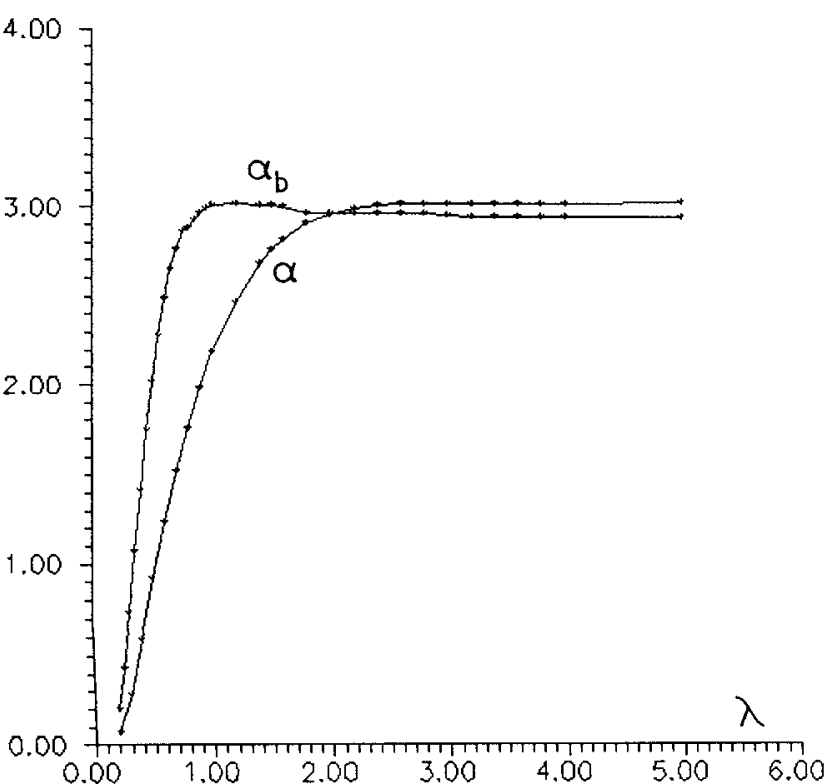

Fig. 3.28

Caso 12 : $\alpha$ e $\alpha_{b}$ 


\section{PRÉ - DIMENSIONAMENTO DAS LAJES}

A espessura das lajes pode ser avaliada por processo sugerido pela NBR 6118(1978). Após o cálculo das ações, os momentos negativos do cálculo plástico e a razão dos momentos de vão são adotados com base no cálculo elástico.

\subsection{ESPESSURA}

Para a determinação da espessura das lajes, podem ser adotados valores seguindo recomendações da Norma Brasileira NBR 6118. Poderia ser feita adaptação do processo de MACHADO (1989), considerando a laje simétrica com o dobro da dimensão na direção perpendicular à borda livre. Esta consideração, porém, também conduziria a espessuras exageradas.

Nas vigas e lajes das estruturas de edifícios, deverão ser obedecidas as seguintes condições:

- as flechas medidas a partir do plano que contém os apoios, quando atuarem todas as ações, não ultrapassarão $1 / 300$ do vão teórico, exceto nos balanços para os quais não ultrapassarão 1/150 do seu comprimento teórico.

- o deslocamento causado pelas cargas acidentais não será superior a 1/500 do vão teórico e 1/250 do comprimento teórico dos balanços.

Segundo a NBR 6118, em vigas de seção retangular e em lajes maciças retangulares de edifícios, serão consideradas atendidas as condições descritas e dispensar-se-á o cálculo das flechas quando a altura útil d não for inferior ao valor $\ell /\left(\Psi_{2} \Psi_{3}\right)$, sendo $\ell$ o menor vão. 
Os valores de $\psi_{2}$ são indicados nas tabelas 4.1 e 4.2, respectivamente, para lajes armadas em uma direção e em cruz. Os valores de $\psi_{3}$ são indicados na tabela 4.3.

TABELA 4.1- Valores de $\psi_{2}$ para lajes armadas em uma direção

\begin{tabular}{||l|c|}
\hline \multicolumn{1}{|c|}{ Condições dos apoios } & $\Psi_{2}$ \\
\hline Simplesmente apoiadas & 1,0 \\
Contínuas & 1,2 \\
Duplamente engastadas & 1,7 \\
Em balanço & 0,5 \\
\hline
\end{tabular}

TABELA 4.2- Valores de $\psi_{2}$ para lajes armadas em cruz

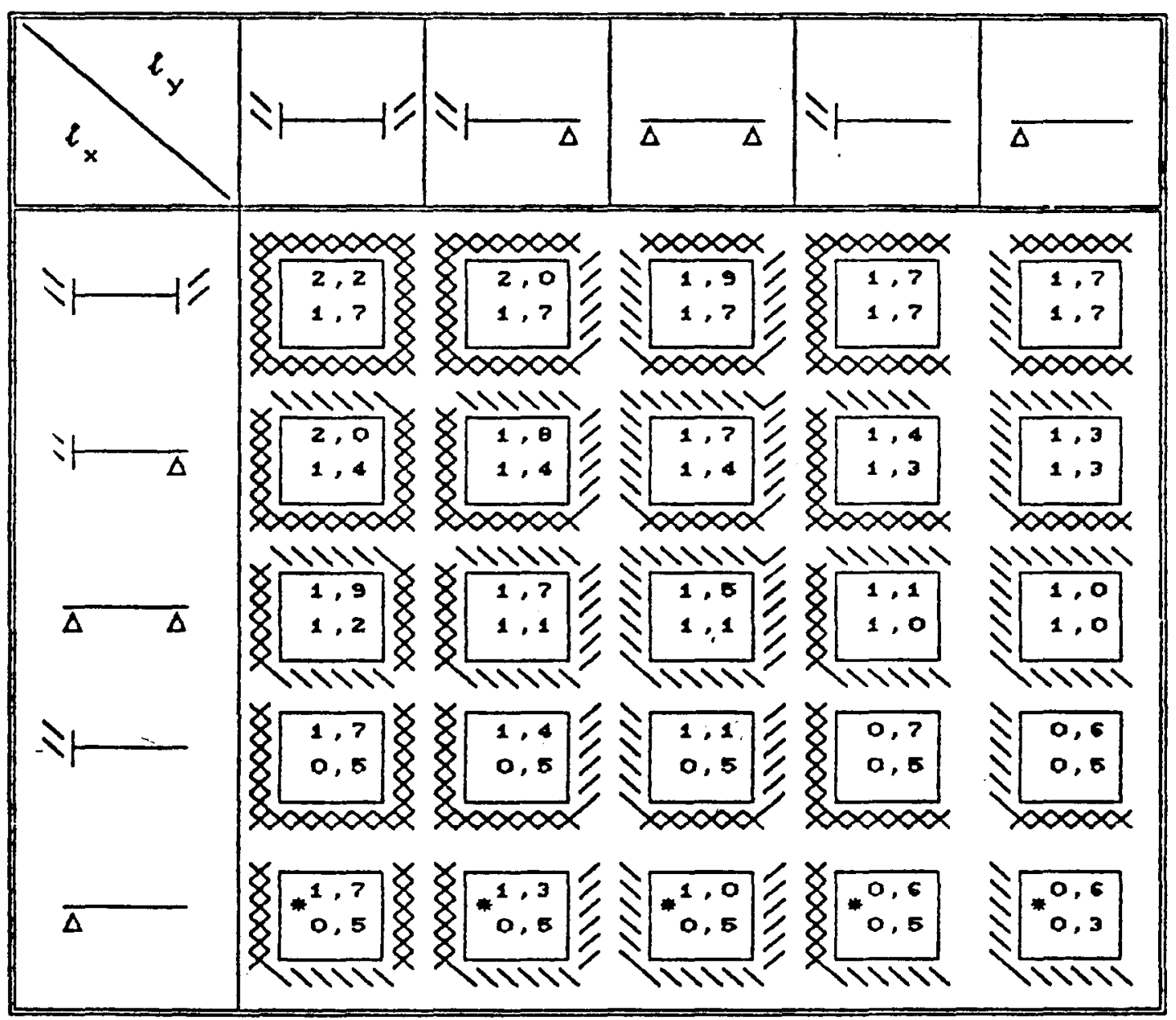


Na tabela 4.2 tem-se:

$\ell_{x}=$ menor vão

$\ell_{y}=$ maior vão

Número superior : $\psi_{2}$ para $\ell_{y} / \ell_{x}=1$,

Número inferior : $\Psi_{2}$ para $\ell_{\mathrm{y}} / \ell_{\mathrm{x}}=2$, podendo usar-se, para razão entre os lados maior que 2, exceto nos casos assinalados com asterisco.

Para $1<\ell_{\mathrm{y}} / \ell_{\mathrm{x}}<2$ : interpolar linearmente.

TABELA 4.3- Valores de $\psi_{3}$ para lajes maciças

\begin{tabular}{||c|c|c||}
\hline AÇOS & $\begin{array}{c}\text { Tensão na armadura para solicitação de } \\
\text { cáculo }\left(\sigma_{\text {sd }}\right)\end{array}$ & $\psi_{3}$ \\
\hline CA-25 & $215 \mathrm{MPA}$ & 35 \\
CA-32 & $280 \mathrm{MPA}$ & 33 \\
CA-40 & $350 \mathrm{MPA}$ & 30 \\
CA-50 & $435 \mathrm{MPA}$ & 25 \\
CA-60 & $520 \mathrm{MPA}$ & 20 \\
\hline
\end{tabular}

Esses valores de $\sigma_{\mathrm{sd}}$ correspondem aos valores aproximados de $f_{\mathrm{yd}}$, considerando $\gamma_{\mathrm{s}}=1,15$

Para as lajes com mais de $4 \mathrm{~m}$ de vão teórico, que suportarem paredes, na direção do vão, susceptíveis de fissuração, as alturas úteis mínimas calculadas por este item deverão ser multiplicadas por $\ell / 4$ ( $\ell$ em metros).

Os valores mínimos fixados pela NBR 6118 que devem ser adotados para a espessura das lajes são:

lajes de cobertura não em balanço $5 \mathrm{~cm}$

lajes de piso e lajes em balanço $7 \mathrm{~cm}$

lajes destinadas a passagem de veículos $12 \mathrm{~cm}$ 


\subsection{AÇÕES}

No cálculo dos esforços solicitantes, deverá ser considerada a influência das cargas permanentes e das acidentais e de todas as ações que possam produzir esforços importantes. Estas ações serão consideradas de acordo com as normas e condições peculiares a cada obra.

\subsubsection{CARGA PERMANENTE}

É constituída pelo peso próprio da estrutura e por todas as sobrecargas fixas e instalações permanentes, como revestimento, pavimentação, enchimento e peso de paredes. Na avaliação do peso próprio, admite-se o peso específico de $25 \mathrm{kN} / \mathrm{m}^{3}$ para o concreto armado, como prescrito na NBR 6118(1978).

De acordo com a NBR 6120(1980), para paredes divisórias, cuja posição não esteja definida no projeto, o cálculo de pisos com suficiente capacidade de distribuição transversal da carga, quando não for feito por processo exato, pode ser feito admitindo, além dos demais carregamentos, uma carga uniformemente distribuída por metro quadrado, maior que $1 / 3$ do peso por metro linear de parede, observado o valor mínimo de $1 \mathrm{kN} / \mathrm{m}^{2}$. Ou seja, a carga das paredes é uma carga linear mas, em muitos casos pode ser suposta uniformemente distribuída.

\subsubsection{CARGA DE USO}

É toda carga que pode atuar sobre a estrutura em função do seu uso, como pessoas, móveis, materiais diversos, veículos, etc. São ações verticais supostas uniformemente distribuídas, com os valores mínimos indicados na tabela 4.4, de acordo com a NBR 6120. 
TABELA 4.4- Cargas de uso em edifícios (NBR 6120, 1980)

\begin{tabular}{||l|l||}
\hline \hline 1.Edifícios residenciais & \\
- dormitório, sala, copa, cozinha e banheiro & $1,5 \mathrm{kN} / \mathrm{m}^{2}$ \\
- dispensa, área de serviço e lavanderia & $2,0 \mathrm{kN} / \mathrm{m}^{2}$ \\
\hline $\begin{array}{l}\text { 2. Escadas } \\
\text { - com acesso público } \\
\text { - sem acesso público }\end{array}$ & $3,0 \mathrm{kN} / \mathrm{m}^{2}$ \\
\hline $\begin{array}{l}\text { 3. Escritórios } \\
\text { - salas de uso geral e banheiros }\end{array}$ & $2,5 \mathrm{kN} / \mathrm{m}^{2}$ \\
\hline $\begin{array}{l}\text { 4. Forros } \\
\text { - sem acesso de pessoas }\end{array}$ & $2,0 \mathrm{kN} / \mathrm{m}^{2}$ \\
\hline 5. Garagens e estacionamentos & $0,5 \mathrm{kN} / \mathrm{m}^{2}$ \\
\hline $\begin{array}{l}\text { - para veículos de passageiros ou semelhantes com carga máxima de } \\
25 \mathrm{kN} \text { por veículo }\end{array}$ & $3,0 \mathrm{kN} / \mathrm{m}^{2}$ \\
\hline
\end{tabular}

\subsection{MOMENTOS E COMPATIBILIZAÇÃO}

Ao se analisar um pavimento composto por várias lajes, dependendo do processo podem surgir dificuldades no estudo das lajes contínuas, devido ao engastamento nos apoios internos, onde há continuidade, porque nesses apoios ocorrem engastamentos parciais, ou seja, o engaste não é perfeito.

Na maioria dos casos, supõe-se as lajes contínuas perfeitamente engastadas nas lajes adjacentes.

Como em geral as lajes de um pavimento diferem nas condições de apoio, nos vãos ou nos carregamentos, resultando em momentos negativos diferentes em um mesmo vínculo, faz-se a compatibilização dos momentos. Um critério usual consiste em 
considerar, para esse momento negativo, o maior valor entre a média dos dois momentos ou $80 \%$ do maior. Esse critério é razoável quando os momentos negativos, entre lajes vizinhas, são de mesma ordem de grandeza. Quando não o forem, a laje com menor momento pode ser considerada engastada, sendo a outra considerada apoiada nesse vínculo.

Após a compatibilização dos momentos negativos, deve-se corrigir os momentos positivos relativos à mesma direção. A correção é feita subtraindo do maior momento negativo o momento compatibilizado, dividindo por dois este resultado e somando ao positivo na direção considerada, ou seja, os momentos no centro da laje devem ser aumentados adequadamente de acordo com a variação do respectivo momento negativo após a compatibilização. A diminuição do momento positivo não é recomendada.

Os momentos resultantes do cálculo elástico servem de base para o cálculo plástico. Como os momentos positivos encontrados a partir do cálculo plástico são geralmente bem menores que os do elástico, os momentos nos vãos resultam muito pequenos. Para o cálculo plástico, recomenda-se que haja uma redução no valor desses momentos negativos já compatibilizados. Para as lajes com bordas apoiadas ou engastadas, recomenda-se adotar, para o cálculo plástico, momentos no apoio igual à metade dos momentos compatibilizados, obtidos em regime elástico. Para lajes com uma borda livre, recomenda-se adotar de $50 \%$ a $60 \%$ dos momentos elásticos compatibilizados.

Com essa redução dos momentos nos apoios, pretende-se obter momentos de plastificação, nos apoios e nos vãos, da mesma ordem de grandeza. A razão dos momentos de vão é obtida através do cálculo elástico. Se os valores obtidos no cálculo plástico não forem adequados, novos valores devem ser adotados para os momentos de apoio, calculando-se novamente os correspondentes momentos de vão. 


\section{A TEORIA DAS CHARNEIRAS PLÁSTICAS}

A teoria das charneiras plásticas consiste em uma aplicação às placas do teorema do limite superior do cálculo plástico. Tem como principal objetivo estudar o comportamento das lajes de concreto armado com relação à ruína.

Quando uma laje atinge a ruína por ruptura do concreto à compressão, sem que haja escoamento do aço, é denominada superarmada. Nessas peças a ruína ocorre de maneira súbita, sem que a estrutura apresente sintomas visíveis de sua iminência. Nesse tipo de laje predomina o uso excessivo de aço, tornando-a antieconômica.

Portanto as lajes usuais são subarmadas, isto é, as taxas de armadura devem ser pequenas o suficiente para que não ocorra ruptura do concreto comprimido antes do escoamento das armaduras, permitindo o completo desenvolvimento das linhas de plastificação e, consequentemente, do mecanismo de colapso.

\subsection{FASES DE COMPORTAMENTO}

O diagrama da figura 5.1 demonstra as diversas fases de comportamento de lajes subarmadas, submetidas à ação de um carregamento proporcional F. A princípio, com o crescimento de $\mathrm{F}$, tem-se a Fase Elástica, onde atuam pequenas forças, o concreto resiste à tração e o material deforma-se proporcionalmente à carga. A laje comporta-se de acordo com a teoria das placas em regime elástico (trecho OA na figura 5.1). 


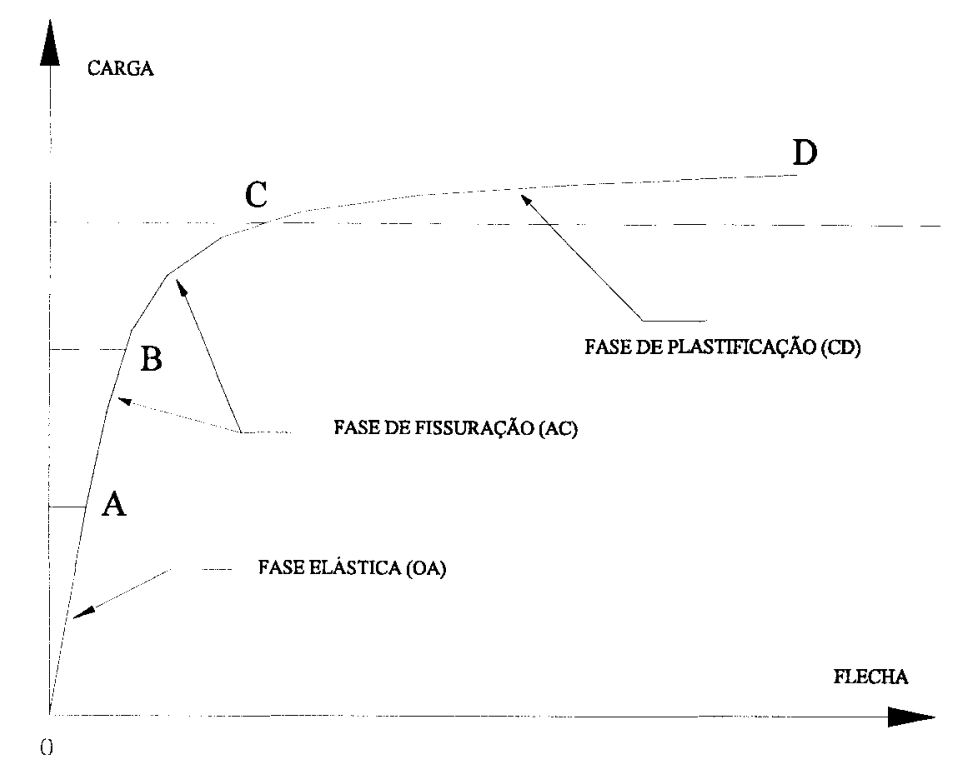

FIGURA 5.1- Fases de comportamento das lajes subarmadas

Com o aumento do carregamento o material atinge a Fase de Fissuração, onde a resistência do concreto à tração é ultrapassada nas regiões de maiores momentos (trecho AC). A formação de fissuras faz com que haja um crescimento dos momentos nas seções não fissuradas, provocando novas fissuras. Nesta fase a laje comporta-se de acordo com a teoria das placas em regime elástico, enquanto as armaduras permanecem em regime elástico linear (trecho $\mathrm{AB}$ ), sendo o crescimento dos deslocamentos mais acentuado que na fase anterior. No instante em que as armaduras ultrapassam o regime elástico linear (trecho BC da figura 5.1), a placa deixa de se comportar de acordo com a teoria das placas em regime elástico, sendo o crescimento dos deslocamentos mais acentuado ainda. 
Com o crescimento dos momentos fletores nas seções mais solicitadas, a armadura entra em escoamento, dando início à Fase de Plastificação (trecho CD). Esta fase caracteriza-se por grandes deformações, havendo uma redistribuição de esforços bem mais acentuada que na fase anterior; nas seções plastificadas os momentos permanecem constantes, crescendo nas seções vizinhas até que estas se plastifiquem e assim sucessivamente, até o total desenvolvimento das linhas de plastificação.

Obtido o mecanismo, torna-se impossível qualquer acréscimo de carga; os deslocamentos podem aumentar mesmo com a diminuição da carga aplicada. O colapso da laje ocorre quando a superfície neutra desloca-se em direção à face comprimida, nas regiões mais solicitadas, quando há diminuição das seções resistentes, causando a ruptura do concreto. Diz-se que a laje atingiu a ruína, sendo a máxima carga atuante denominada carga limite ou carga de ruína. Geralmente a carga efetiva de ruína é superior à prevista pela teoria das charneiras plásticas. Mesmo após completamente desenvolvida a configuração de ruína, com deformações plásticas excessivas, o colapso pode ser alcançado somente após esgotada uma reserva de resistência da laje, que provém do endurecimento do aço da armadura ou dos efeitos de membrana (ver PINHEIRO, 1988).

\subsection{MATERIAIS FRÁGEIS E MATERIAIS DÚCTEIS}

O concreto simples e as lajes superarmadas são consideradas frágeis, por se romperem com pequenas deformações, não apresentando comportamento plástico (ver fig.5.2a).

Para a aplicação da teoria da plasticidade, o material tem necessariamente que ser dúctil, ou seja, romper após grandes deformações. Tem-se nesses casos o aço e as lajes de concreto subarmadas (ver fig.5.2b). 


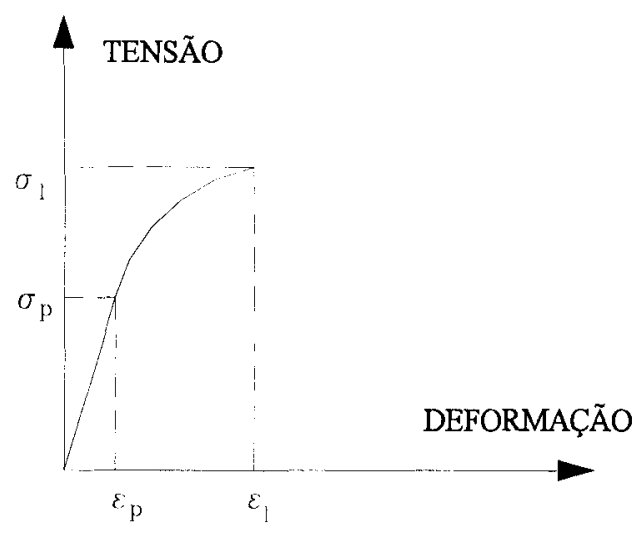

a) Materiais frágeis

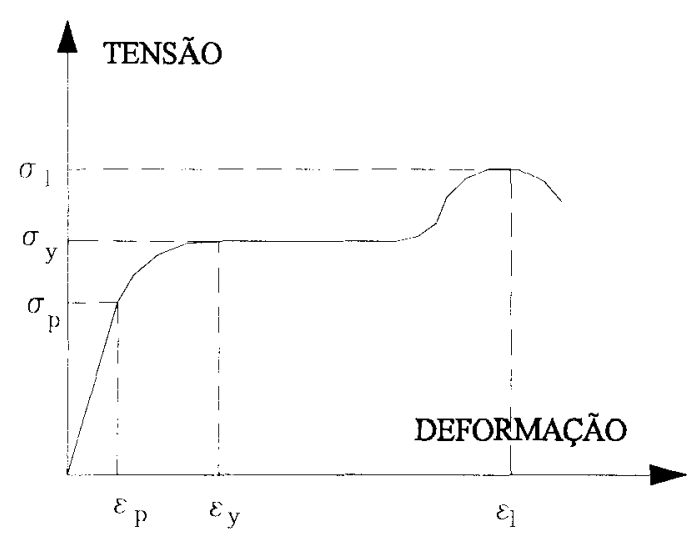

b) Materiais dúcteis

FIGURA 5.2- Diagrama tensão-deformação

\subsection{MATERIAIS ELASTOPLÁSTICO E RÍGIDO-PLÁSTICO}

Considerando-se uma peça constituída de material elastoplástico, submetida a cargas proporcionais, tem-se a princípio a fase elástica, quando o deslocamento de um de seus pontos é proporcional à carga; depois a fase elastoplástica, situação em que o acréscimo da deformação é mais acentuado que o da carga, e finalmente a fase plástica, quando a deformação cresce sob carga constante (ver fig.5.3a).

Numa peça constituída de material rígido-plástico, despreza-se a parte elástica das suas deformações, ou seja, toda deformação é impedida até o início da plastificação (fig 5.3b). 


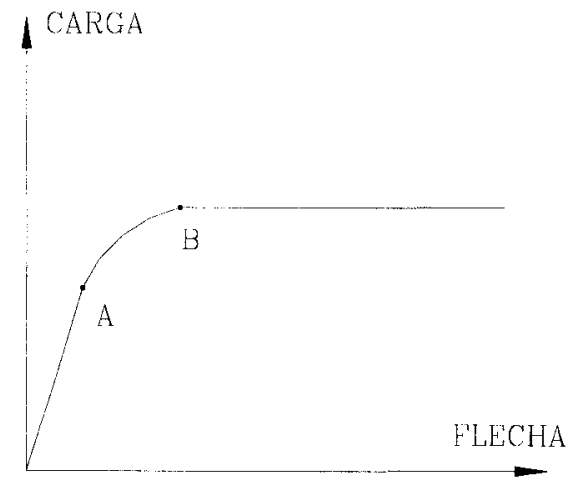

a) Materiais elastoplásticos

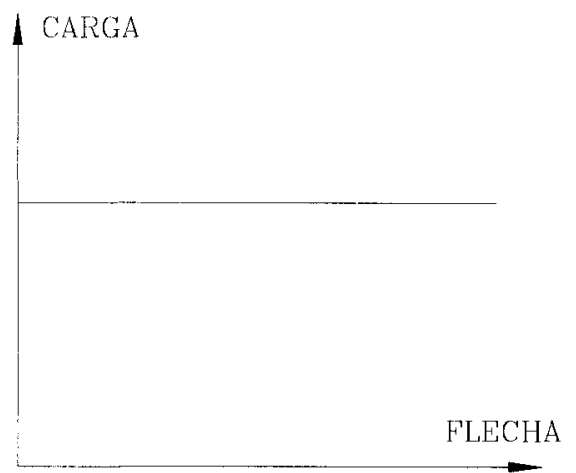

b) Materiais rígido-plásticos

FIGURA 5.3- Comportamento dos materiais

As cargas de ruína calculadas pelos teoremas fundamentais da teoria da plasticidade são válidas tanto para peças elastoplásticas como para rígido-plásticas. Sendo iguais as cargas de ruína para os dois materiais, conclui-se que a consideração elastoplástica não é melhor que a rígido-plástica.

A primeira parte da hipótese de que as deformações até a fase elastoplástica permanecem muito pequenas, a fim de estudar a peça na sua forma inicial conhecida; quando isso ocorre, no instante em que se inicia a fase plástica, a forma da peça resulta muito próxima da inicial e portanto comporta-se como se fosse rígida até este momento. Por outro lado, se as deformações reais antes da fase plástica não são despreziveis, as duas considerações são igualmente deficientes; a primeira porque a hipótese referente às deformações não se verifica, e a segunda porque representa de maneira grosseira a peça real. A melhor alternativa é considerar o material como rígido-plástico, pois o objetivo é a determinação da carga de ruína. 


\subsection{HIPÓTESES DE CÁLCULO}

As hipóteses de cálculo que constituem as bases da teoria das charneiras plásticas são:

a) as peças utilizadas são compostas de materiais dúcteis, ou seja, a ruína ocorre após grandes deformações; suas seções devem ser subarmadas, de modo que, no estado de ruína, a armadura atinja o escoamento nas linhas de plastificação;

b) o material utilizado é rígido-plástico;

c) os momentos de plastificação são constantes ao longo das charneiras e também nas suas proximidades, segundo o fenômeno da redistribuição dos momentos (ver item 5.5);

d) não deverá ocorrer ruína prematura do concreto por cisalhamento ou punção; a ruína da estrutura ocorrerá quando, pelo efeito da plastificação, ela se tornar hipostática, ou seja, quando se formar um mecanismo livremente deformável;

e) despreza-se a influência dos efeitos de membrana, provenientes das restrições para os deslocamentos no plano da laje (decorrentes da rigidez lateral das vigas de borda ou da continuidade com as lajes vizinhas).

\subsection{REDISTRIBUIÇÃO DOS MOMENTOS}

Quando a região mais solicitada da laje atinge o estado plástico, deixa de receber tensões adicionais mesmo continuando a se deformar (foi alcançado o momento máximo que a laje poderia resistir nesse ponto). 
Continuando a crescer a solicitação, as regiões vizinhas passam a receber os acréscimos de tensões até entrarem por sua vez em estado plástico.

A propagação do estado plástico repete-se de região para região até que se formem as linhas de plastificação. Quando é atingido o estado plástico, em cada ponto de uma linha de plastificação, o momento fletor máximo é desenvolvido e, nesse ponto, esse valor não é mais ultrapassado, permanecendo aproximadamente constante em toda a extensão dessa linha.

\subsection{CONFIGURAÇÕES DAS CHARNEIRAS}

Para a determinação da configuração de ruína há necessidade de se analisarem todas as possíveis configurações. Tais configurações irão depender, principalmente, da natureza, distribuição das cargas, disposição das armaduras e condições de apoio da laje.

A obtenção das configurações de ruína depende das seguintes regras:

a) ao longo de contornos engastados, formam-se charneiras negativas (figuras $5.4 \mathrm{~b}$ e 5.4d);

b) os eixos de rotação das diversas regiões divididas pelas charneiras coincidem com os lados simplesmente apoiados (5.4a e 5.4c), com os lados engastados (5.4b e 5.4d) ou passam por apoios isolados $(5.4 \mathrm{c}$ e $5.4 \mathrm{~d})$;

c) cada charneira passa pelo ponto de intersecção dos eixos de rotação das regiões delimitadas pela charneira;

d) cargas distribuídas geralmente dão origem a charneiras retilíneas. 
Convenções utilizadas:

$\sim \sim \sim \sim \sim \sim \quad$ charneira

$\underline{\operatorname{xxxxxxxx} \quad \text { borda engastada }}$

|IIIIIIIII apoio simples

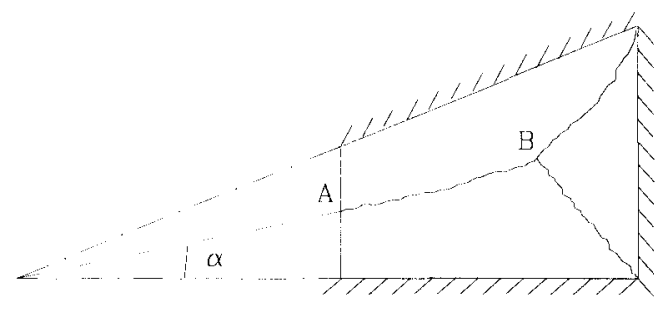

(a)

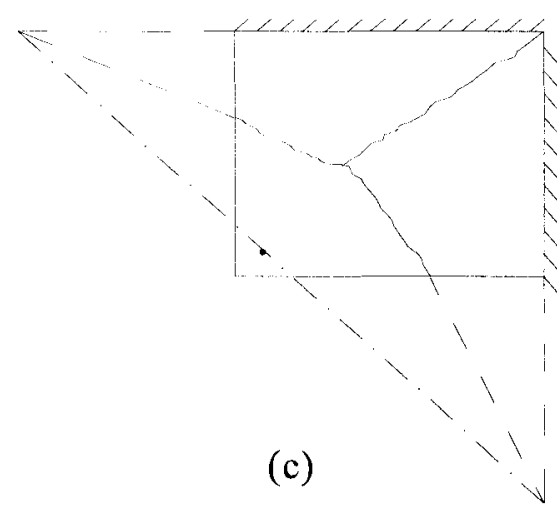

borda livre

eixo de rotação

apoio pontual

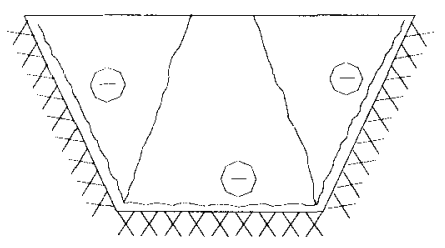

(b)

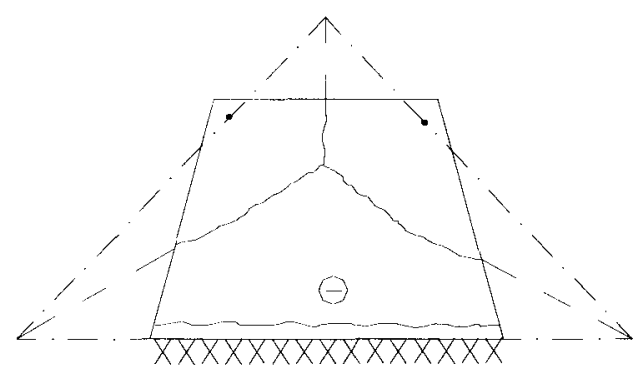

(d)

FIGURA 5.4- Exemplos de configurações possíveis

Quando houver contorno curvilíneo, como na figura 5.5, este pode ser considerado como o limite para o qual tende um contorno poligonal, com lados cujos comprimentos tendem a zero. As charneiras, que deveriam convergir para os vértices do polígono, ficarão encostadas umas às outras, formando uma superfície regrada, mas não plana, que se admite ser possível. 


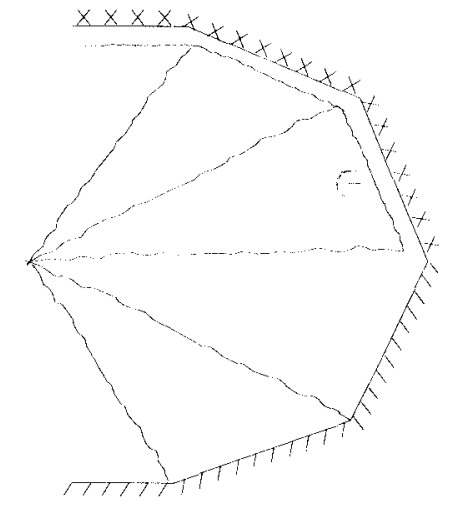

a) Superfície poliédrica

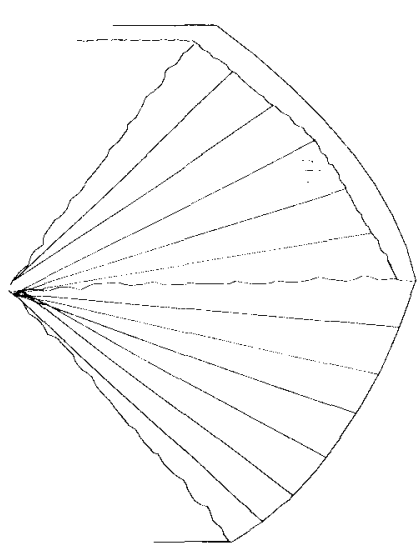

b) Superfície regrada

FIGURA 5.5- Configurações de ruína de lajes com contorno poligonal e curvilíneo

\subsection{PROCESSO DO EQUILÍBRIO}

Existem dois processos de cálculo. O primeiro, denominado processo do equilíbrio ou processo das forças nodais, vem sendo empregado desde o trabalho original de JOHANSEN (1932). O segundo, mais recente, é denominado processo da energia e será apresentado no item subsequente.

Nas lajes isótropas, o momento de plastificação, além de ser constante ao longo de cada charneira, é também igual para qualquer direção, ou seja, constante ao longo de todas as linhas de plastificação da laje.

Ao longo de uma linha de plastificação de uma laje isótropa, atua um momento $\mathrm{m}$ por unidade de comprimento, assim o momento total ao longo da linha de plastificação resulta igual ao produto de seu comprimento pelo valor de $\mathrm{m}$.

Para que o equilíbrio da região seja satisfeito é necessário que se conheçam as forças cortantes e os momentos torçores. Esses esforços são substituídos por forças concentradas, que são pares de forças de transmissão estaticamente equivalentes, formados por duas forças iguais e de sentidos opostos (figura 5.6). 
Esta substituição é válida uma vez que, para o estabelecimento das equações de equilíbrio, não é necessário o conhecimento da distribuição exata dos esforços ao longo das linhas de plastificação, bastando que os esforços internos equilibrem as forças externas (ver PINHEIRO, 1988, e RIOS, 1991).

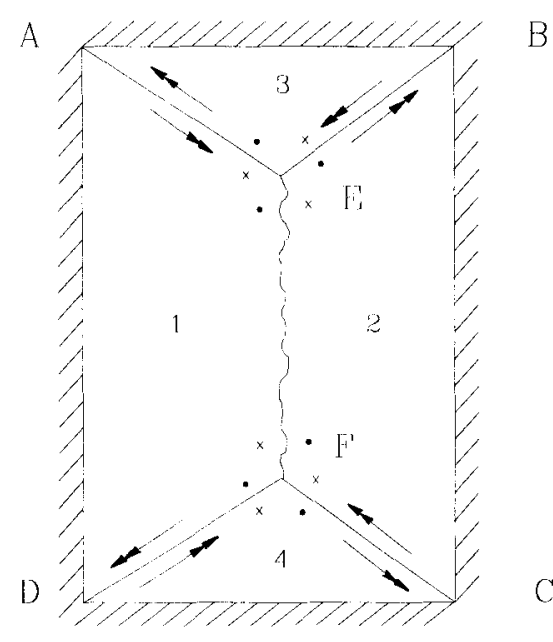

(a)

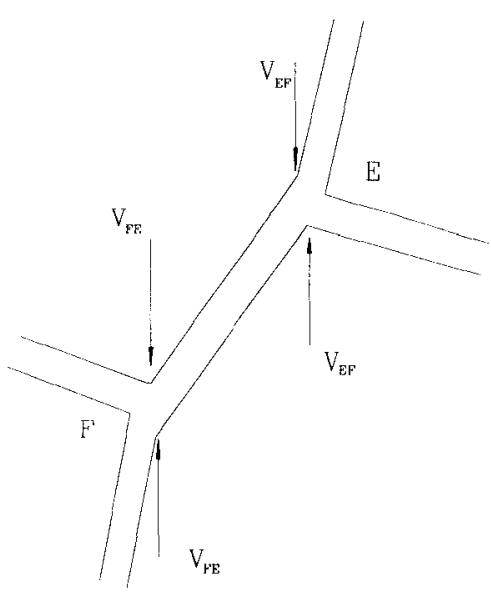

(b)

FIGURA 5.6- Forças de transmissão

Portanto, para o nó E da figura 5.6 pode-se escrever, respectivamente para as partes 1, 2 e 3 da laje, as seguintes equações:

$$
\begin{aligned}
& K_{E 1}=V_{E F}-V_{E A} \\
& K_{E 2}=V_{E B}-V_{E F} \\
& K_{E 3}=V_{E A}-V_{E B}
\end{aligned}
$$

Para o nó $\mathrm{F}$, para as partes 1,2 e 4, resulta:

$$
\begin{aligned}
& K_{F 1}=V_{F D}-V_{F E} \\
& K_{F 2}=V_{F E}-V_{F C} \\
& K_{F 4}=V_{F C}-V_{F D}
\end{aligned}
$$


As forças $\mathrm{K}_{\mathrm{E} 1}, \mathrm{~K}_{\mathrm{E} 2}, \mathrm{~K}_{\mathrm{E} 3}, \mathrm{~K}_{\mathrm{F} 1}, \mathrm{~K}_{\mathrm{F} 2}, \mathrm{~K}_{\mathrm{F} 4}$ são denominadas forças nodais, para as quais se tem:

$$
\begin{aligned}
& K_{E 1}+K_{E 2}+K_{E 3}=V_{E E}-V_{E A}+V_{E B}-V_{E F}+V_{E A}+V_{E B}=0 \\
& K_{F 1}+K_{F 2}+K_{F 3}=V_{E D}-V_{F E}+V_{F E}-V_{F C}+V_{F C}-V_{F D}=0
\end{aligned}
$$

Resumindo:

"A soma algébrica das forças nodais, em um nó qualquer, é igual a zero".

Este resultado independe da convenção de sinais e do sentido adotado para as forças de transmissão.

\subsubsection{DETERMINAÇÃO DAS FORÇAS NODAIS}

As forças nodais podem ser determinadas a partir da hipótese de que nas proximidades das linhas de plastificação o momento fletor é o mesmo que o existente ao longo dessas linhas.

Por exemplo, suponha-se uma laje isótropa, com momentos de plastificação positivos m e negativos m', e um nó onde concorram duas charneiras positivas e uma negativa, como indica a fig 5.7 .

As expressões finais são dadas por PINHEIRO (1988), e conclui-se que:

$$
\begin{aligned}
& K_{01}=-\left(m+m^{\prime}\right) \operatorname{cotg} \beta \\
& K_{02}=-\left(m+m^{\prime}\right) \operatorname{cotg} \beta \\
& K_{03}=\left(m+m^{\prime}\right)(\operatorname{cotg} \quad \alpha+\operatorname{cotg} \quad \beta)
\end{aligned}
$$

Nota-se que a soma algébrica das forças nodais é igual a zero, como já foi visto. 


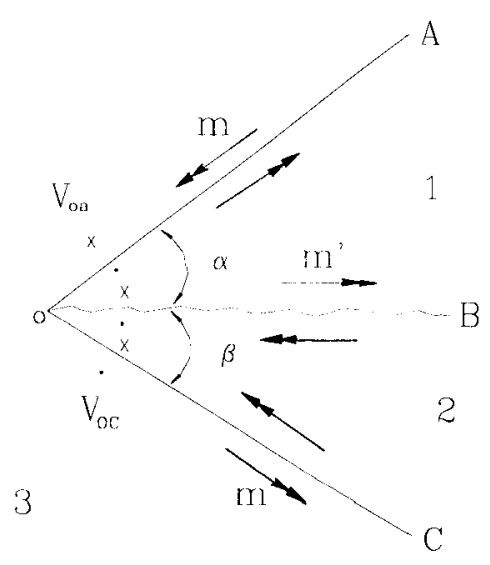

FIGURA 5.7- Nó com duas charneiras positivas e uma negativa

\subsubsection{NÓ COM CHARNEIRA DE MESMO SINAL}

Supondo que para o nó 0 da figura $5.7 f$ concorram três charneiras positivas, substituindo-se m' por -m nas expressões (5.4) resulta:

$K_{01}=0, \quad K_{02}=0, \quad K_{03}=0$

O mesmo seria obtido se as três charneiras fossem negativas, substituindo-se m por $-\mathrm{m}^{\prime}$.

Pode-se enunciar:

"Em um nó para o qual convergem somente charneiras de mesmo sinal, todas as forças nodais são nulas".

\subsubsection{CHARNEIRA CONCORRENTE COM BORDA LIVRE}

Uma charneira negativa encontrando uma borda livre (figura 5.8a) pode ser analisada como uma linha de plastificação interceptando duas outras linhas de momentos 
nulos, ou seja, as forças nodais podem ser obtidas com as expressões (5.4) fazendo-se $\mathrm{m}=0$ na borda e $\alpha+\beta=180^{\circ}$, supondo-se $\alpha \leq \beta$, resultando:

$\mathrm{K}_{01}=-\mathrm{m}^{\prime} \operatorname{cotg} \beta=\mathrm{m}^{\prime} \operatorname{cotg} \alpha$

$\mathrm{K}_{02}=-\mathrm{m}^{\prime} \operatorname{cotg} \alpha$

$\mathrm{K}_{03}=0$

Se a charneira for positiva (figura $5.8 \mathrm{~b}$ ), substitui-se $\mathrm{m}^{\prime}$ por $-\mathrm{m}$ nas equações (5.6), obtendo-se:

$\mathrm{K}_{01}=-\mathrm{m} \operatorname{cotg} \alpha$

$\mathrm{K}_{02}=\mathrm{m} \operatorname{cotg} \alpha$

$\mathrm{K}_{03}=0$

BORDA LIVRE OU SIMPLESMENTE

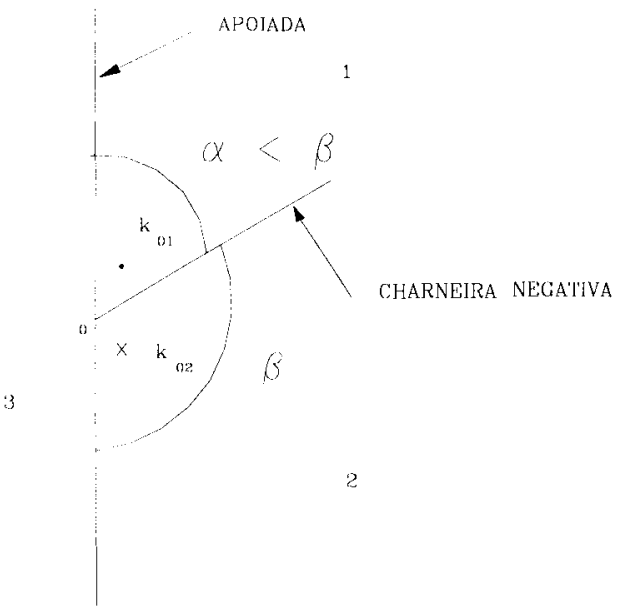

(a)

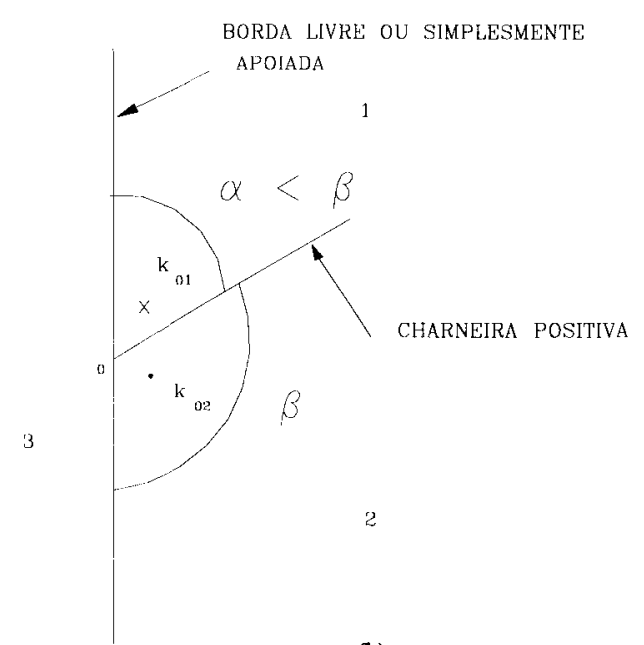

(b)

FIGURA 5.8- Charneira concorrente com borda não engastada

Conclui-se então que:

"Em um nó formado por uma borda livre ou simplesmente apoiada e uma charneira plástica, tem-se duas forças iguais e contrárias, com valor igual ao produto do momento 
de plastificação pela cotangente do ângulo agudo, sendo a deste dirigida para baixo no caso da charneira ser positiva e para cima no caso contrário".

\subsubsection{APLICAÇÃO DO PROCESSO DO EQUILÍBRIO}

O emprego do processo do equilíbrio consiste em estabelecer as equações de equilíbrio de cada região da laje, delimitada pelas linhas de plastificação. Cada região considerada está em equilíbrio sob a ação das forças nodais, dos momentos fletores ao longo das charneiras e das forças externas.

Conhecida a configuração das charneiras, determinam-se as forças nodais e em seguida, a carga de ruína. Para cada parte da laje, tem-se três equações de equilíbrio estático; por exemplo, duas equações de momentos em torno de eixos situados no plano da laje e uma de equilíbrio de forças verticais. Se a laje possuir $n$ regiões, tem-se $3 n$ equações e 3n incógnitas. As incógnitas são:

. o momento de plastificação, para o caso no qual a carga é dada, ou a carga de ruína, se o momento de plastificação é conhecido;

. n-1 relações entre os ângulos de rotação;

. 2n incógnitas provenientes dos eixos de rotação e das reações de apoio.

Apresenta-se, a seguir, um exemplo do processo do equilíbrio no cálculo de lajes usuais.

\subsubsection{EXEMPLO 1}

Laje retangular isótropa com bordas menores apoiadas, uma maior engastada e outra livre, com carga uniforme $\mathrm{p}, \phi=\mathrm{m}^{1} / \mathrm{m}=2$ (fig.5.9). 


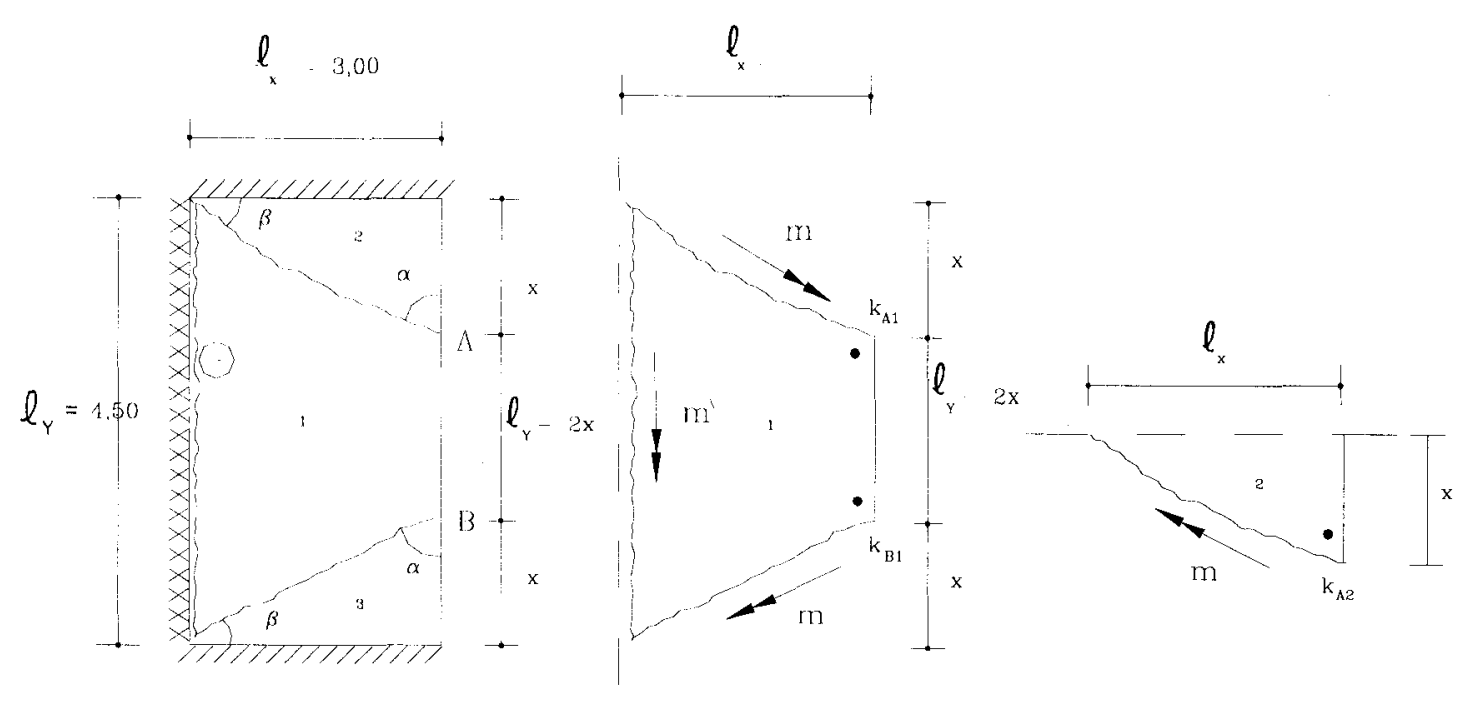

(a)

(b)

(c)

FIGURA 5.8- Charneira concorrente com borda não engastada

Como o ângulo entre as charneiras e a borda livre é diferente de $90^{\circ}$, as forças nodais não se anulam, devendo ser calculadas de acordo com as expressões (5.7):

$$
\begin{aligned}
& K_{A 1}=K_{B 1}=m \operatorname{cotg} \alpha=\frac{m_{x}}{\ell_{x}} \\
& K_{A 2}=-m \operatorname{cotg} \alpha=-\frac{m_{x}}{\ell_{x}}
\end{aligned}
$$

Fazendo-se o equilíbrio da região 1 (figura 5.9b), resulta:

$$
\begin{aligned}
& m \cdot 2 x+m^{\prime} l_{y}+\left(K_{A 1}+K_{B 1}\right) \ell_{x}=p\left[x \cdot \frac{\ell_{x}}{2} \cdot \frac{\ell_{x}}{3} \cdot 2+\left(\ell_{y}-2 x\right) \ell_{x} \cdot \frac{\ell_{x}}{2}\right] \\
& m=p \frac{20,25-6 x}{9+4 x}
\end{aligned}
$$


Fazendo-se o equilíbrio da região 2 (figura 5.9c), resulta:

$m \cdot 2 x+m^{\prime} l_{y}+\left(K_{A 1}+K_{B 1}\right) l_{x}=p\left[x \cdot \frac{\ell_{x}}{2} \cdot \frac{\ell_{x}}{3} \cdot 2+\left(l_{y}-2 x\right) l_{x} \cdot \frac{\ell_{x}}{2}\right]$

$m=p \frac{3 x^{2}}{18-2 x^{2}}$

Igualando (5.10) a (5.11) e resolvendo a equação do segundo grau, obtém-se:

$x=1,66$ metros

Substituindo este valor nas equações (5.10) ou (5.11), obtém-se:

$m=0,659 p$

\subsection{PROCESSO DA ENERGIA}

O processo da energia, também conhecido como processo do trabalho, nada mais é do que uma aplicação do princípio dos trabalhos virtuais, permitindo que as equações de equilíbrio sejam escritas de forma concisa, resultando num cálculo rápido e prático. O princípio dos trabalhos virtuais consiste no deslocamento de um ponto da laje na direção perpendicular ao seu plano médio; considera-se esse deslocamento unitário. Calculam-se os ângulos $\theta_{i}$ e $\theta_{i}^{\prime}$ de rotação das charneiras positivas e negativas, considerando $\ell$ e $\ell^{\prime}$ os comprimentos das charneiras positivas e negativas e $\mathrm{m}$ e $\mathrm{m}^{\prime}$ os momentos de plastificação por unidade de comprimento. Assume-se que na ruína não há perda de energia, enquanto a laje se deforma. 
Como demonstrado em PINHEIRO (1988), se a configuração de ruína depender de alguns parâmetros, a equação do momento se apresenta sob a forma:

$$
m=F(x, y, \ldots)
$$

Como, pelo teorema cinemático da teoria da plasticidade, o momento de plastificação é o maior entre aqueles correspondentes às diversas configurações possíveis, os valores dos parâmetros $\mathrm{x}, \mathrm{y}$, etc são determinados pelas condições de máximo:

$$
\frac{\partial F}{\partial x}=0, \quad \frac{\partial F}{\partial y}=0, \quad \ldots
$$

\subsubsection{TRABALHO DAS FORÇAS INTERNAS $\left(\mathbf{T}_{\mathrm{i}}\right)$}

A equação da energia absorvida pelas charneiras ao se deformarem será:

$$
T_{i}=m_{i} \ell_{i} \theta_{i}+m_{i}^{\prime} \ell_{i}^{\prime} \theta_{i}^{\prime}
$$

sendo

$\boldsymbol{m}_{\boldsymbol{i}}$ e $\boldsymbol{m}_{\boldsymbol{i}}{ }^{\prime}=$ momentos de plastificação por unidade de comprimento $\theta_{i}$ e $\theta_{i}^{\prime}=$ ângulos de rotação de todas as charneiras positivas e negativas respectivamente

$\ell_{i}$ e $\ell_{i}^{\prime}=$ comprimentos das charneiras positivas e negativas respectivamente

\subsubsection{TRABALHO DAS FORÇAS EXTERNAS}

Considerando-se uma região da laje, a energia fornecida pela carga externa, num elemento dA da área da laje, ao sofrer um deslocamento f referente à carga distribuída 
é pfdA, e a energia devida à deformação em toda região é obtida fazendo-se a integral sobre toda essa região:

$\iint p f d A$

Uma vez que a laje é composta de várias regiões, o trabalho total das forças externas é o somatório das integrais calculadas para cada região:

$T_{\mathrm{e}}=\sum\left[\iint p f d A\right]_{\text {região }}$

Supondo que neste elemento dA, além das cargas distribuídas, atuem cargas concentradas, os deslocamentos causados por essas cargas são denominados $\mathbf{f}_{\mathbf{j}}$. $\mathrm{O}$ trabalho total desenvolvido por essas cargas será:

$T_{\mathrm{e}}=\sum\left[p_{j} f_{j}+\int_{A} p f d A\right]_{\text {região }}$

No caso da carga p ser uniformemente distribuída, o último termo desta equação pode ser substituído por $\mathrm{pV}$, sendo $\mathrm{V}$ o volume desenvolvido pela superfície deformada. No caso de cargas lineares $\mathrm{p}_{\ell}$, o deslocamento $\mathrm{f}_{2}$ será função do elemento ds sob a carga linear. Resulta:

$$
T_{e}=\sum\left[p_{j} f_{j}+p V+\int p_{l} f_{l} d s\right]_{\text {região }}
$$

\subsubsection{EXEMPLO 2}

Laje retangular isótropa com borda maior engastada e a outra livre, as duas menores apoiadas, submetida a carga uniforme $\mathrm{p} \mathrm{e} \phi=\mathrm{m}^{1} / \mathrm{m}=2$ (figura 5.10)

Exemplo análogo ao anterior, ora resolvido pelo processo da energia. 


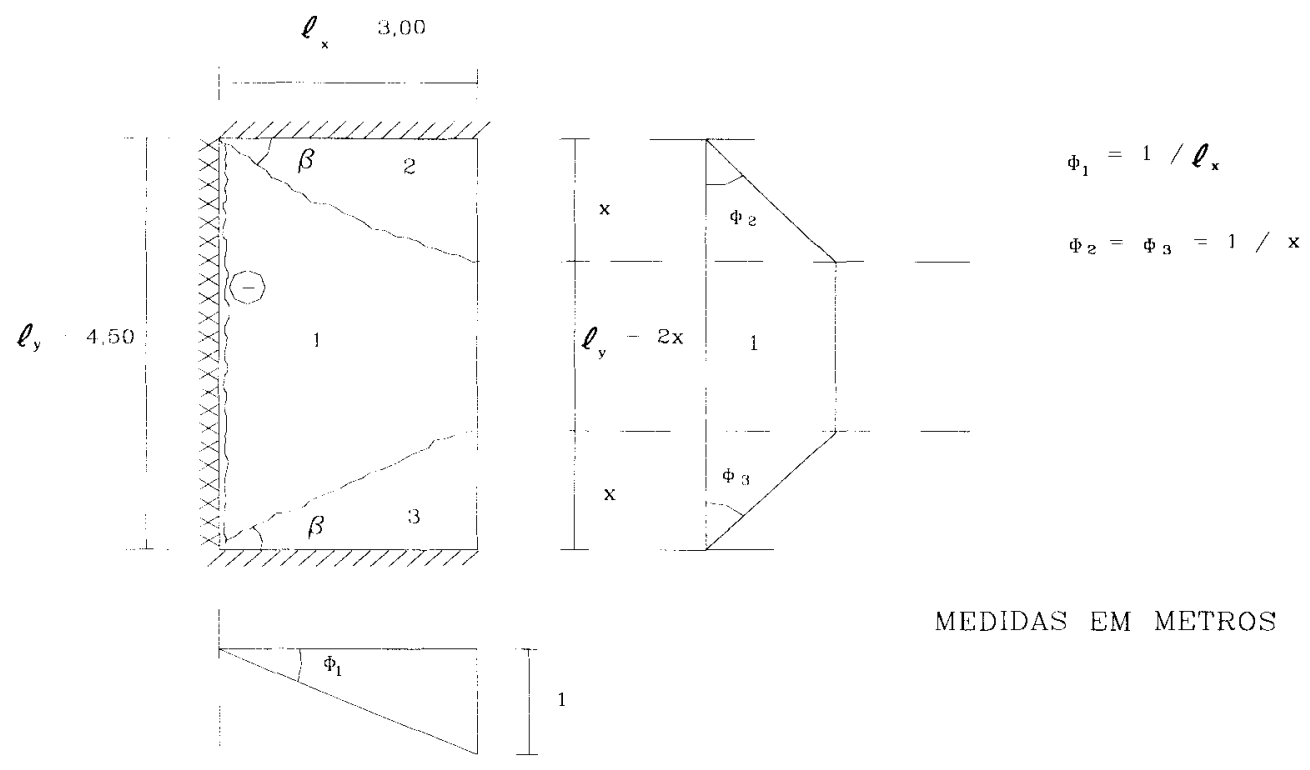

FIGURA 5.10- Laje retangular com uma borda livre

Para a região 1, tem-se:

$$
\begin{aligned}
& T_{i}=m \cdot 2 x \cdot \theta_{1}+m^{\prime} \cdot \ell_{y} \cdot \theta_{1}=2 m\left(x+\ell_{y}\right) \frac{1}{\ell_{x}}=\frac{2}{3} m(x+4,5) \\
& T_{e}=p\left[x \cdot \frac{\ell_{x}}{2} \cdot \frac{1}{3} \cdot 2+\left(\ell_{y}-2 x\right) \cdot \ell_{x} \cdot \frac{1}{2}\right]=p(6,75-2 x)
\end{aligned}
$$

Para as regiões 2 e 3, tem-se:

$$
\begin{aligned}
& T_{i}=m \cdot \ell_{x} \cdot \theta_{2}=\frac{3 m}{x} \\
& T_{e}=p \cdot \ell_{x} \cdot \frac{x}{2} \cdot \frac{1}{3}=\frac{p x}{2}
\end{aligned}
$$


Para a laje toda obtém-se, respectivamente:

$$
\begin{aligned}
& T_{i}=\frac{2}{3} m(x+4,5)+\frac{3 m}{x}+\frac{3 m}{x}=m\left(\frac{2}{3} x+3+\frac{6}{x}\right) \\
& T_{e}=p\left(6,75-2 x+\frac{x}{2}+\frac{x}{2}\right)=p(6,75-x)
\end{aligned}
$$

Igualando-se a equação (5.23) a (5.24) obtém-se:

$$
m=3 p \frac{6,75 x-x^{2}}{2 x^{2}+9 x+18}
$$

O valor de x é obtido derivando a equação (5.25) em relação a x e igualando a zero.

$$
\begin{aligned}
& \frac{d m}{d x}=3 p \frac{\left(2 x^{2}+9 x+18\right)(6,75-2 x)-\left(6,75 x-x^{2}\right)(4 x+9)}{\left(2 x^{2}+9 x+18\right)^{2}}=0 \\
& \left(2 x^{2}+9 x+18\right)(6,75-2 x)-\left(6,75 x-x^{2}\right)(4 x+9)=0 \\
& x^{2}+1,6 x-5,4=0 \\
& x^{\prime}=-3,2576 \\
& x^{\prime \prime}=1,6576
\end{aligned}
$$$$
\text { Adota-se o valor positivo. Portanto: }
$$$$
x=1,66 \text { metros }
$$

Substituindo este valor na (5.25) obtém-se, como esperado, o mesmo valor obtido através do processo do equilíbrio, ou seja: 


\subsection{LAJES ISÓTROPAS, ANISÓTROPAS E ORTÓTROPAS}

Na teouia das charneiras plásticas, uma laje é considerada isótropa se apresenta a mesma resistência à flexão, qualquer que seja a seção considerada. Para que uma laje com armaduras dispostas ortogonalmente seja isótropa, basta que sejam iguais os momentos de plastificação nestas duas direções, o que é válido tanto para os momentos positivos quanto para os negativos (ver PINHEIRO, 1988 e RIOS, 1991).

Anisótropas são as lajes que não apresentam a mesma resistência à flexão qualquer direção considerada. Neste caso, geralmente se admite que, mesmo sendo variáveis os momentos de plastificação conforme a direção considerada, numa mesma direção eles sejam sempre os mesmos.

Se a laje anisotrópa possuir armaduras dispostas em direções ortogonais que ofereçam momentos de plastificação positivos e negativos e se os momentos positivos guardarem entre si uma relação idêntica à relação entre os momentos de plastificação negativos correspondentes, a laje será considerada ortótropa, ou seja, uma laje com armaduras ortogonais, que ofereçam momentos de plastificação positivos $m_{1}$ e $m_{2}$ e negativos $\mathrm{m}_{1}{ }^{\prime}$ e $\mathrm{m}_{2}{ }^{\prime}$, será considerada ortótropa se:

$$
m_{2}=\mathrm{K} m_{1} \quad m_{2}^{\prime}=\mathrm{K} m_{1}^{\prime}
$$

Uma laje anisótropa com armaduras ortogonais que ofereça somente momentos de plastificação positivos, sempre poderá ser considerada ortótropa. A relação $\kappa$ é denominada índice de ortotropia.

Uma laje isótropa afim é aquela obtida modificando-se a forma e a carga da laje ortótropa, de acordo com algumas regras, de maneira a resistir aos mesmos esforços. A vantagem da transformação é conduzir a uma análise mais simples. 


\subsection{TRANSFORMAÇÃO DE LAJES ORTÓTROPAS EM ISÓTROPAS}

As lajes ortótropas podem ser calculadas como se fossem isótropas, modificando-se suas dimensões. Considere-se um elemento de laje ortótropa, como o indicado na figura 5.11, com charneiras resistindo a $m$ e m' na direção $x$ e a km e km' na direção y.

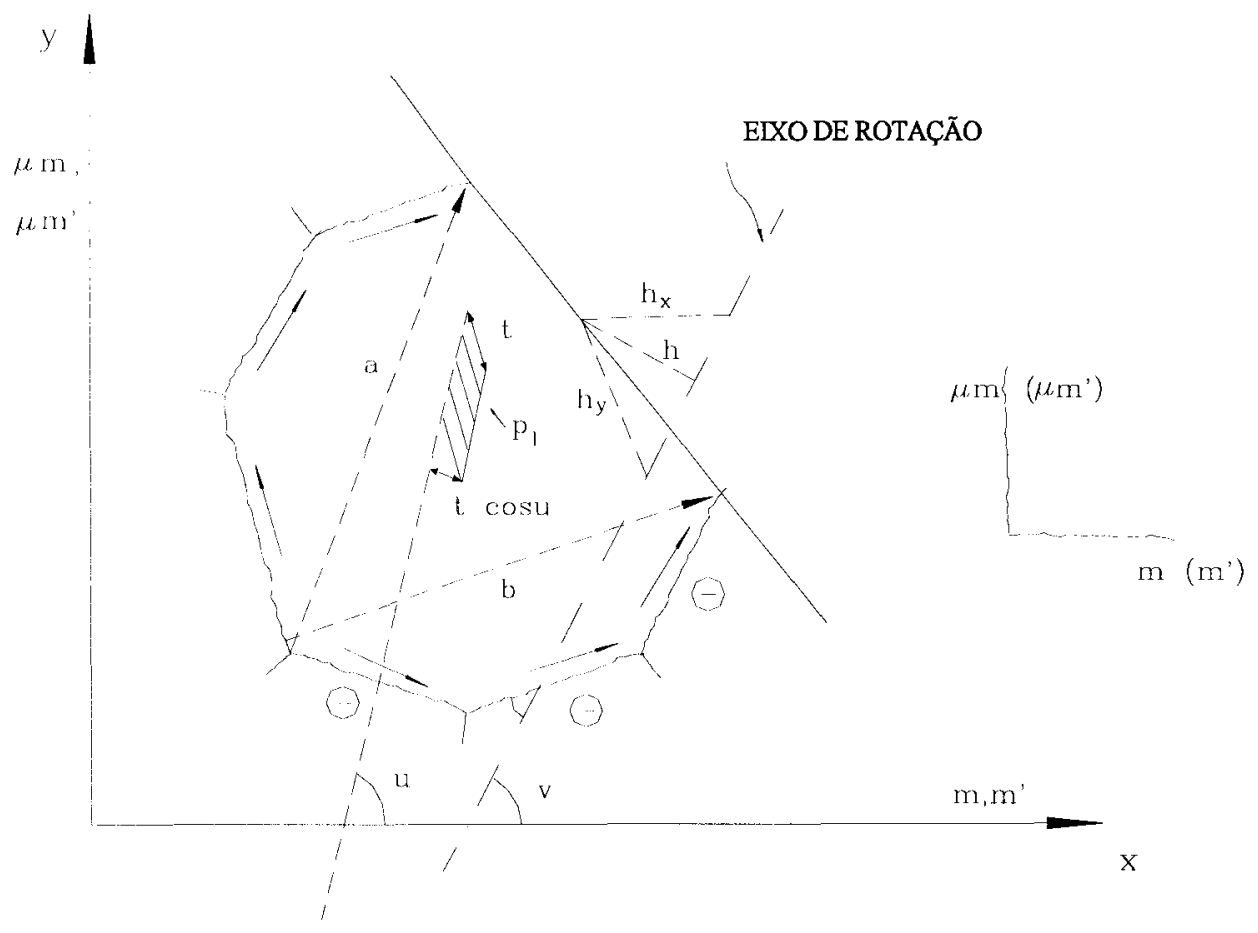

FIGURA 5.11- Elemento de laje ortótropa

Sendo o vetor $\mathbf{a}$ a resultante dos momentos positivos e $\mathbf{a}_{\mathbf{x}}$ e $\mathbf{a}_{\mathbf{y}}$ as projeções de $\mathbf{a}$ segundo esses eixos, as componentes segundo os eixos coordenados são:

$$
M_{x}=m a_{x} \quad M_{Y}=\mathrm{Kma} a_{Y}
$$


Analogamente, para a resultante $\mathbf{b}$ dos momentos negativos obtém-se:

$$
M_{x}^{\prime}=m^{\prime} b_{x} \quad M_{y}^{\prime}=\mathrm{K}^{\prime} b_{y}
$$

Sendo $\delta$ o abaixamento de um ponto arbitrário, $\mathrm{H}$ a distância desse ponto até $\mathrm{o}$ eixo de rotação e $\theta$ o giro em torno do eixo de rotação, tem-se:

$\theta=\delta / H$

sendo as componentes:

$$
\theta_{x}=\theta \cos v=\frac{\delta}{H_{y}} \quad \theta_{y}=\theta \operatorname{sen} v=\frac{\delta}{H_{x}}
$$

A contribuição do elemento de placa à equação dos trabalhos virtuais é dada por:

$$
\left(m a_{x}+m^{\prime} b_{x}\right) \frac{\delta}{H_{y}}+\left(k m a_{y}+k m^{\prime} b_{y}\right) \frac{\delta}{H_{x}}+\iint p_{z} d_{x} d_{y}=0
$$

A equação correspondente à (5.31) para a placa isótropa, admitindo-se que a carga p por unidade de superfície seja a mesma para placa ortótropa e isótropa (ver PINHEIRO, 1988), será:

$$
\left(m \lambda a_{x}+m^{\prime} \lambda b_{x}\right) \frac{\delta}{H_{y}}+\left(m a_{y}+m^{\prime} b_{y}\right) \frac{\delta}{\lambda H_{x}}+\iint p_{z} \lambda d_{x} d_{y}=0
$$

Dividindo-se por $\lambda$ e admitindo $\mathrm{\kappa}=1 / \lambda^{2}$, isto é $\lambda=1 / \sqrt{\kappa}$, tem-se uma expressão análoga à (5.31), ou seja, uma placa ortótropa pode ser calculada como isótropa, afim à ortótropa, multiplicando-se as dimensões nas direções de $\mathrm{m}$ e $\mathrm{m}^{\prime}$ por $1 / \sqrt{\kappa}$, mantendo inalterada a carga p uniformemente distribuída. Este procedimento foi proposto por JOHANSEN (1932) e é ilustrado pela figura 5.12. 

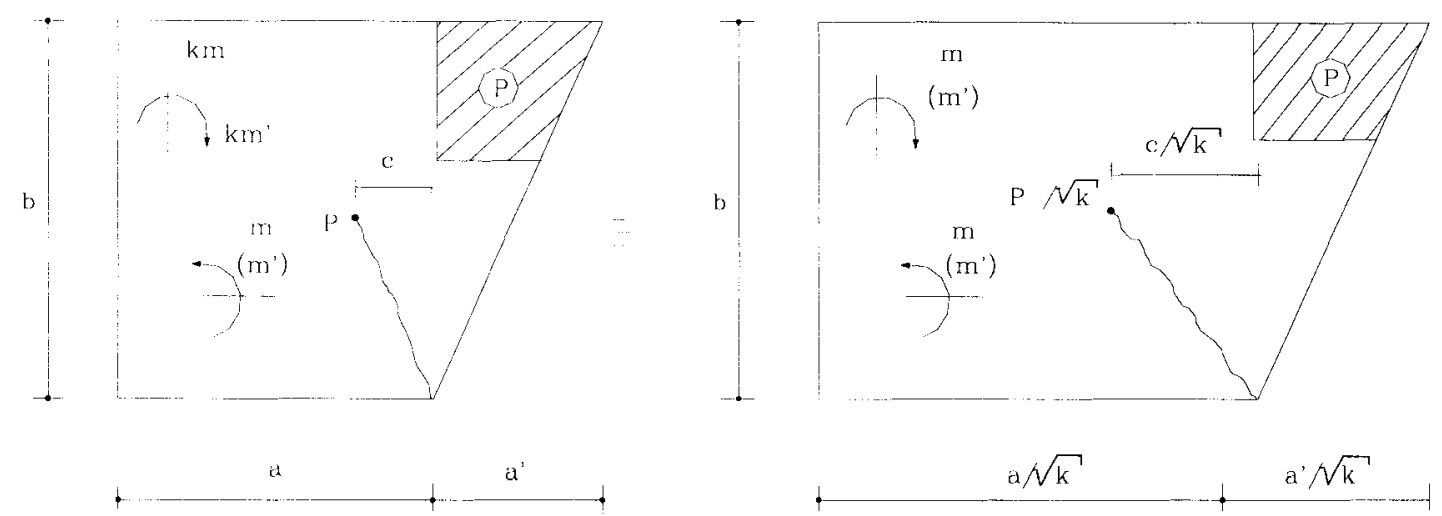

FIGURA 5.12- Obtenção de laje isótropa afim

Uma força concentrada $F$ pode ser encarada como uma carga distribuída sobre uma área muito pequena $\mathrm{A}$. Passando-se à laje isótropa, a área correspondente será $\mathrm{A} / \sqrt{\kappa}$ e a carga $F / \sqrt{\kappa}$.

Uma carga linear $\mathrm{p}_{\ell}$ pode ser encarada como uma carga distribuída $\mathrm{p}$ segundo uma dimensão t na direção $y$, de modo que

$p_{l}=p t \cos u$

sendo u o ângulo entre a carga linear e a seção que resiste ao momento m.

Na placa isótropa tem-se o mesmo p e o mesmo t, porém um outro ângulo $u^{\prime}$ tal que:

$\operatorname{tg} u^{\prime}=\frac{\operatorname{sen} u}{\frac{1}{\sqrt{u}} \cos u}$

Substituindo em $\mathrm{p}_{\ell}^{\prime}=$ ptcos u' obtém-se:

$p_{\ell}^{\prime}=\frac{p_{\ell}}{\sqrt{k \operatorname{sen}^{2} u+\cos ^{2} u}}$ 
No caso de lajes com armaduras não ortogonais, JOHANSEN (1932) demonstra que podem ser transformadas em ortótropas afins e, em seguida, em lajes isótropas equivalentes.

\subsection{CARGAS CONCENTRADAS}

Cargas concentradas ou cargas pontuais não existem na prática; elas distribuemse em pequenas áreas. Com a diminuição dessas áreas, os resultados se aproximam dos valores teóricos, que podem ser considerados como valores limites.

Uma carga pontual pode fazer com que todas as charneiras concorram para ela, formando um número limitado de elementos triangulares, que constituem os leques de charneiras (conforme demonstra PINHEIRO, 1988), limitados por charneiras circulares, no caso de lajes isótropas, como na figura 5.13.

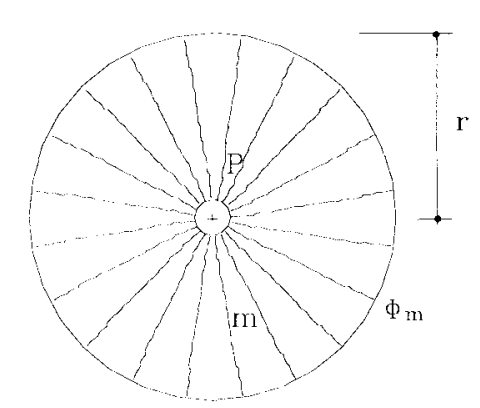

FIGURA 5.13- Contorno engastado ou apoiado sem armadura superior

No caso de lajes ortótropas, formam-se leques elípticos. Como as configurações de ruína para cargas concentradas em geral diferem das relativas a cargas distribuídas, o cálculo torna-se trabalhoso. Portanto, pode-se calcular separando cada tipo de carga e, em seguida, considerando a superposição dos efeitos (ver PINHEIRO, 1988), obtendo resultados próximos do correto e a favor da segurança. 
Exemplos de cargas pontuais atuando em lajes isótropas e ortótropas são encontrados em PINHEIRO (1988), que trata também da superposição dos efeitos e da formação de leques. 


\section{FLECHAS}

\subsection{GENERALIDADES}

De acordo com o item 4.1, quando se adota a espessura de uma laje para que esta atenda às exigências das normas, quanto à espessura mínima e quanto ao limite de deformabilidade, geralmente se chega a valores excessivos.

Procurando trabalhar com lajes mais esbeltas, pois o cálculo pela teoria das charneiras plásticas conduz a momentos fletores menores que os provenientes do cálculo elástico, permitindo a utilização de espessuras menores, torna-se necessária a verificação da flecha.

O cálculo das flechas é dificultado pelo fato de que devem ser consideradas várias influências de difícil avaliação. Portanto determina-se um valor estimado da flecha. Estas influências são comentadas a seguir:

- A colaboração parcial do concreto na tração. A zona tracionada do concreto só não é totalmente eficaz nas regiões de momentos máximos. Na passagem ao estádio II, a rigidez à flexão EI diminui consideravelmente. Portanto, a curvatura aumenta.

- A fluência do concreto aumenta principalmente nas partes que permanecem no estádio I. No estádio II, com zona de tração fissurada, cresce apenas a deformação da zona comprimida. Isto faz com que a linha neutra se desloque para a região tracionada, o que acarreta um aumento da seção transversal da zona comprimida. Com isso, a tensão no bordo diminuiu e o aumento de deformação da zona comprimida é restringido. 
- A retração produz também uma redistribuição dos esforços internos, porque a armadura impede o encurtamento do concreto.

Autores como LEONHARDT (1959), MEHMEL (1959) e MAYER (1967) desenvolveram fórmulas para o cálculo das flechas. O processo desenvolvido por Mayer, no qual as influências podem ser consideradas por meio de coeficientes, é muito adequado. Entretanto, apenas em casos excepcionais se desejará calcular com tanta precisão.

\subsection{ESTADOS LIMITES}

Uma estrutura de concreto, de modo geral, deve ter a sua segurança verificada contra diferentes estados limites, nos quais ela deixa de cumprir as suas finalidades.

De acordo com a NBR 6118 (1978), os estados limites são classificados como estados limites últimos e estados limites de utilização.

\subsubsection{ESTADOS LIMITES ÚLTIMOS}

Um estado limite último ocorre quando se esgota a capacidade de suporte de uma estrutura, surgindo uma deficiência estrutural ou seja, o colapso da estrutura. O colapso surge quando pelo menos parte da estrutura se torna hipostática.

As principais causas que levam uma estrutura de concreto a um estado limite último são:

- perda de estabilidade de uma parte ou do conjunto da estrutura assimilada a um corpo rígido;

- ruptura de seções críticas da estrutura;

- transformação da estrutura em um mecanismo; 
- instabilidade por deformação;

- deteriorização por efeito de fadiga;

- deformações elásticas ou plásticas, deformação lenta e fissuração, que provoquem uma mudança de geometria que exija uma substituição da estrutura;

- e outras, em função de peculiaridades da obra.

Também pode decorrer de causas como: ação do fogo, explosões, etc. Essas causas devem ser consideradas por ocasião da concepção da estrutura.

A segurança contra o colapso não é verificada diretamente. Em lugar do colapso, consideram-se os estados de ruína das seções críticas da estrutura.

\subsubsection{ESTADOS LIMITES DE UTILIZAÇÃO}

Para que uma construção seja considerada segura, além dos estados limites últimos, devem ser considerados também os estados limites de utilização.

Um estado limite de utilização ocorre quando estiver comprometida a durabilidade da estrutura ou quando ficar prejudicada a utilização funcional da contrução. Não há, nesse caso, danos estruturais que comprometam de imediato a integridade da estrutura, mas desempenhos inadmissíveis para a manutenção da própria estrutura ou para a utilização normal da contrução.

Apresentam-se a seguir algumas causas que podem levar a estrutura de concreto a um estado limite de utilização:

- deformações excessivas para uma utilização normal da estrutura;

- fissuração prematura ou excessiva;

- danos indesejáveis (corrosão);

- deslocamentos excessivos sem perda de equilíbrio;

- vibrações excessivas;

- outras, em função das peculiaridades da obra. 


\subsection{TIPOS DE DEFORMAÇÕES}

As deformações do concreto podem ser classificadas como:

- deformações que dependem do carregamento, destacando-se a deformação elástica imediata e deformação lenta (fluência).

- deformações independentes do carregamento, ou seja, dependentes da variação de volume (retração e deformação térmica).

\subsection{VALORES LIMITES DAS FLECHAS}

A NBR 6118(1978) (item 4.2.3.1-c) limita as flechas a 1/300 do vão teórico, exceto no caso de balanços, para os quais o limite é $1 / 150$ do seu comprimento teórico. Além disso, o deslocamento causado pelas cargas acidentais não deve ser superior a 1/500 do vão teórico e 1/250 do comprimento teórico dos balanços.

Os limites definidos pelo Comité Euro-Internacional du Béton, CEB 158E, e pelo American Concrete Institute, ACI-318M(1983), estão relatados na dissertação de RIOS (1991), assim como a determinação da flecha, flecha elástica inicial, flecha decorrente da deformação lenta e flecha decorrente da retração.

\subsection{COMBINAÇÕES DAS AÇÕES}

De acordo com a NBR 8681(1984), nas combinações de utilização são consideradas todas as ações permanentes, inclusive as deformações impostas 
permanentes, e as ações variáveis correspondentes a cada um dos tipos de combinações, como é indicado a seguir.

\subsubsection{COMBINAÇÕES QUASE PERMANENTES DE UTILIZAÇÃO}

Nas combinações quase permanentes de utilização (50\% da vida útil), todas as ações variáveis são consideradas com seus valores quase permanentes $\psi_{2} F_{\mathrm{qk}}\left(\psi_{2}=0,2\right.$ para edifícios, em geral):

$$
F_{d, u t i}=\sum_{i=1}^{m} F_{g i, k}+\sum_{i=1}^{m} \Psi_{2 j} F_{q j, k}
$$

\subsubsection{COMBINAÇÕES FREQUENTES DE UTILIZAÇÃO}

Nas combinações frequentes de utilização ( $5 \%$ da vida útil), a ação variável principal $F_{\mathrm{q} l}$ é tomada com seu valor frequente $\psi_{1} F_{\mathrm{q} 1, \mathrm{k}}$ e todas as demais ações variáveis são tomadas com seus valores quase permanentes $\psi_{2} \mathrm{~F}_{\mathrm{qk}}\left(\psi_{1}=0,3\right.$ para edifícios, em geral):

$$
F_{d, u t i}=\sum_{i=1}^{m} F_{g i, k}+\psi_{1} F_{q 1, k}+\sum_{j=2}^{n} \psi_{2 j} F_{q j, k}
$$

\subsubsection{COMBINAÇÕES RARAS DE UTILIZAÇÃO}

Nas combinações raras de utilização (máximo algumas horas), a ação variável principal $F_{q 1}$ é tomada com seu valor característico $F_{q 1, k}$ e todas as demais ações são tomadas com seus valores frequentes $\psi_{1} \mathrm{~F}_{\mathrm{qk}}$ :

$$
F_{d, u t i}=\sum_{i=1}^{m} E_{g i, k}+F_{q 1, k}+\sum_{j=2}^{n} \psi_{1 j} E_{q 1, k}
$$




\subsection{ESTÁDIOS}

Uma peça de concreto armado submetida a um carregamento que varia de zero até a ruptura, passa por diversos estádios de comportamento. A figura 6.1 apresenta esses estádios de comportamento de uma peça ensaiada à flexão, sob a ação de carga gradativamente crescente.

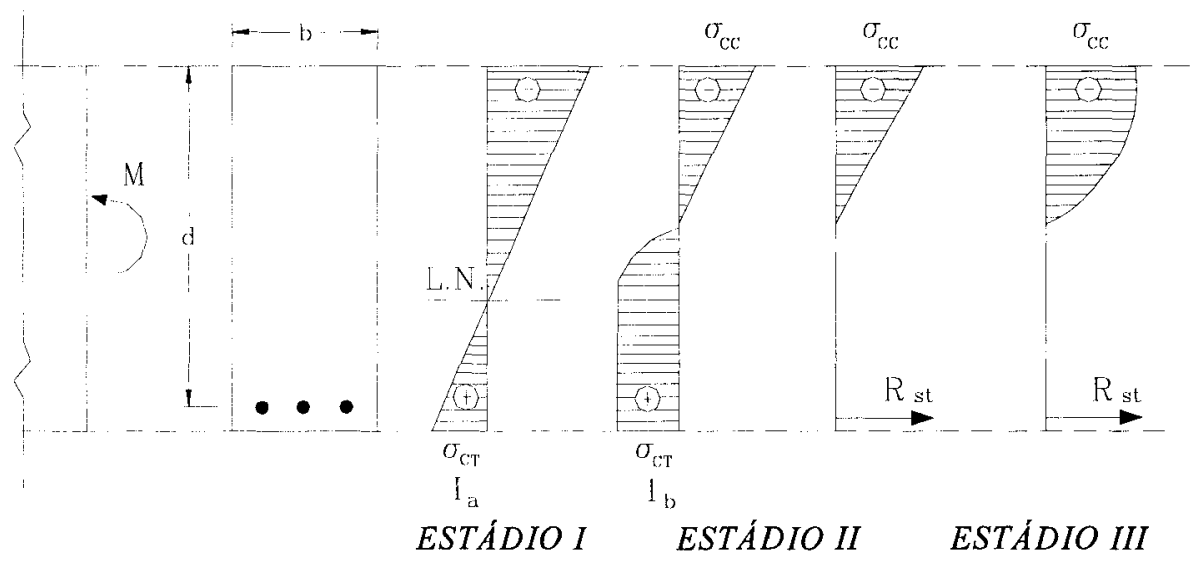

FIGURA 6.1- Diagramas de tensões nos estádios de comportamento

No estádio I, quando as solicitações são pequenas, o concreto resiste às tensões de tração. No estádio Ia o concreto resiste à tração em regime elástico linear e no estádio $\mathrm{Ib}$, em regime plástico ou seja, na iminência da ruptura do concreto à tração.

No estádio II o concreto está fissurado na zona tracionada e as forças de tração são totalmente absorvidas pela armadura, desprezando-se a colaboração do concreto nesta zona.

$\mathrm{M}<\mathrm{M}_{\mathrm{r}}->$ estádio I (todas as seções)

$\mathrm{M}>\mathrm{M}_{\mathrm{r}} \rightarrow>$ estádio II (parte no estádio I)

$\mathrm{M}_{\mathrm{r}} \rightarrow>$ momento de fissuração. 
No estádio III, denominado estádio de ruptura, corresponde à iminência de ruptura do concreto à compressão.

Nos estádios I e II faz-se a homogeinização da seção, ou seja, a armadura de tração de área $A_{s}$ com tensão $\sigma_{s t}$ é transformada numa seção de concreto equivalente $\mathrm{A}^{*}{ }_{\mathrm{ct}}=\alpha_{\mathrm{e}} \mathrm{A}_{\mathrm{s}}$ com tensão $\sigma_{\mathrm{st}} / \alpha_{\mathrm{e}}$, como demonstra a fig. 6.2, na qual se tem:

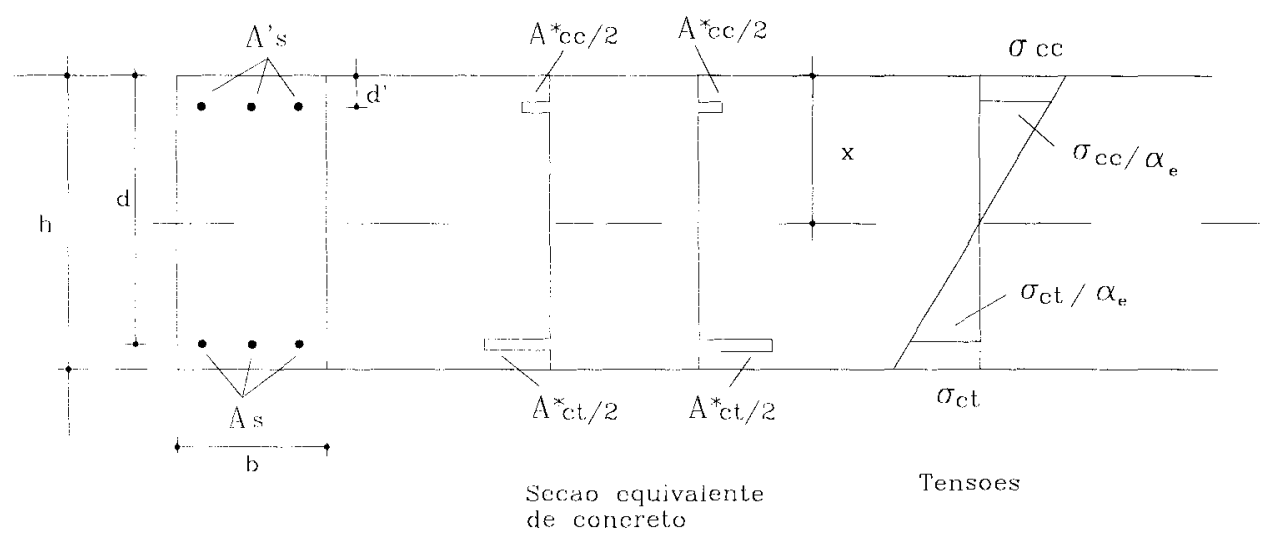

FIGURA 6.2- Seção homogeneizada

seção homogeneizada: $\quad \mathrm{A}_{\mathrm{h}}=\mathrm{bh}+\alpha_{\mathrm{e}} \mathrm{A}_{\mathrm{s}}+\alpha_{\mathrm{e}} \mathrm{A}_{\mathrm{s}}^{\prime}$

linha neutra: $\quad \mathrm{x}_{1}$ ou $\mathrm{x}_{2}$

momento de inércia: $\quad \mathrm{I}_{1}$ ou $\mathrm{I}_{2}$

$\mathrm{A}_{\mathrm{s}}=$ área da armadura de tração;

$\sigma_{\mathrm{st}}=$ tensão na armadura de tração;

$\mathrm{A}^{*}{ }_{\mathrm{ct}}=$ área de concreto equivalente à armadura de tração;

$\alpha_{e}=$ razão estre os módulos de deformação do aço e do concreto;

$\mathrm{A}_{\mathrm{s}}^{\prime}=$ área da armadura comprimida;

$\sigma_{\mathrm{sc}}=$ tensão na armadura comprimida;

$\mathrm{A}^{*}{ }_{\mathrm{cc}}=$ área de concreto equivalente à armadura comprimida. 
De acordo com os diagramas de deformações e de tensões da figura 6.3, tem-se:
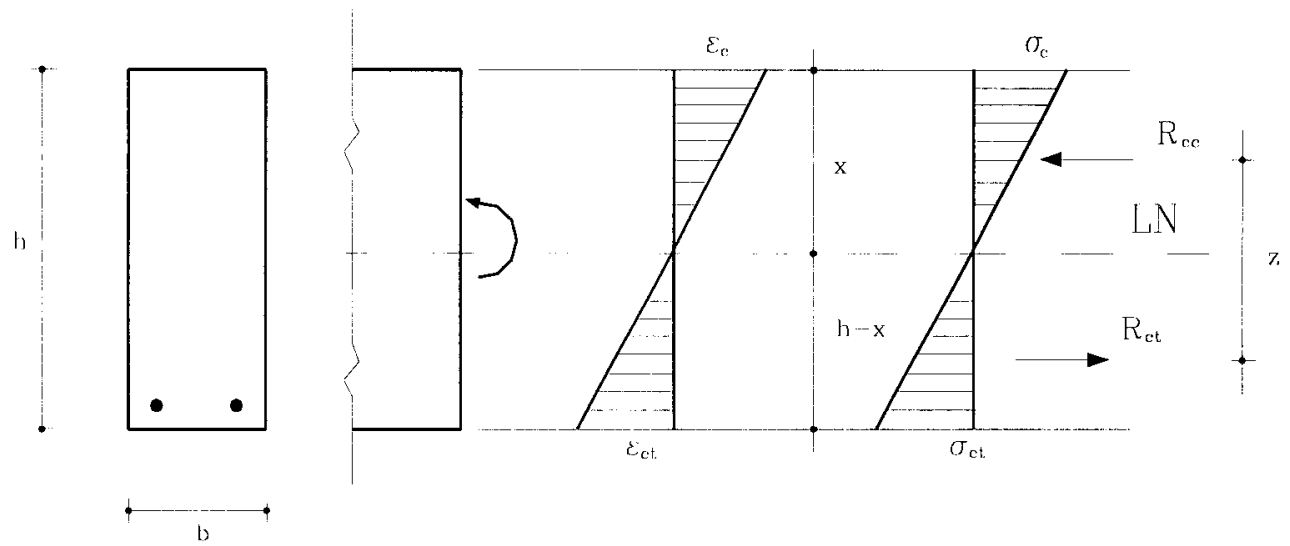

FIGURA 6.3- Diagrama de deformações

tensões:

$\sigma=(M / I) \cdot y$

deformações:

$\epsilon=\sigma / \mathrm{E}$

peças com $M>M_{r}$ :

$\mathrm{x}_{\mathrm{e}}$ e $\mathrm{I}_{\mathrm{e}}$ (fórmulas de Branson, item 6.7.4-b).

\subsection{ROTEIRO DE CÁLCULO}

Apresenta-se a seguir um roteiro para o cálculo das flechas.

\subsubsection{ESPESSURA}

De acordo com a NB 1/78(NBR 6118), para que não haja necessidade de verificação da flecha, deve-se ter:

$$
d>\frac{\ell}{\psi_{2} \psi_{3}}
$$


sendo:

$\ell=$ menor lado

$\psi_{2}$ e $\psi_{3} \Rightarrow>$ valores encontrados nas tabelas 4.1 e 4.2 .

\subsubsection{CARGAS}

Conforme a NBR 7197(1989), para verificar se a seção está ou não fissurada, através da comparação do momento máximo em serviço com $M_{r}$, deve ser considerada combinação rara de utilização. Em geral, em edifícios basta considerar, para combinação rara:

$\mathrm{p}_{\mathrm{d}, \mathrm{uti}}=\mathrm{g}_{\mathrm{k}}+\mathrm{q}_{\mathrm{k}}$

Para cálculo da flecha, devem ser admitidas as combinações quase permanentes de utilização, sendo:

$\mathrm{p}_{\mathrm{d}, \mathrm{uti}}=\mathrm{g}_{\mathrm{k}}+\psi_{2} \mathrm{q}_{\mathrm{k}}$

ou seja, toda a parcela da carga permanente mais $\psi_{2}$ da carga de uso. Os valores de $\psi_{2}$ são definidos pela NBR 8681(1984) ou por normas específicas, referentes ao tipo de construção considerada, ou seja, para edifícios $\psi_{2}=0,2$.

\subsubsection{MOMENTOS}

Desprezando-se a contribuição da armadura, o momento de fissuração da laje é dado por:

$\mathrm{M}_{\mathrm{r}}=0,25 \mathrm{bh}^{2} \mathrm{f}_{\mathrm{tk}}$ 
sendo:

$\mathrm{f}_{\mathrm{tk}}=\mathrm{f}_{\mathrm{ck}} / 10$ para $\mathrm{f}_{\mathrm{ck}} \leq 18 \mathrm{MPa}$

$\mathrm{f}_{\mathrm{tk}}=0,06 \mathrm{f}_{\mathrm{ck}}+0,7 \mathrm{MPa}$ para $\mathrm{f}_{\mathrm{ck}}>18 \mathrm{MPa}$

Os momentos de serviço da laje para carga de utilização são os calculados em regime elástico.

\subsubsection{SITUAÇÕES A CONSIDERAR}

Como já foi visto, para a verificação da segurança em relação ao estado limite de formação de fissuras, deve ser considerada a combinação rara de utilização, na qual a ação variável principal é tomada com seu valor característico $q_{k}$. $O$ momento de inércia a ser adotado é o da seção homogeneizada.

a) Seções não fissuradas $\left(M_{d, \text { uti }} \leq M_{r}\right)$

O momento de serviço é menor que o momento de fissuração, ou seja, a seção está no estádio I. Para seção retangular tem-se:

$$
\begin{aligned}
& x_{1}=\frac{0,5 b h^{2}+\alpha_{e}\left(A_{s} d+A_{s}^{\prime} d^{\prime}\right)}{b h+\alpha_{e}\left(A_{s}+A_{s}^{\prime}\right)} \\
& I_{1}=\frac{b h^{3}}{12}+b h\left(x_{1}-\frac{h}{2}\right)^{2}+\alpha_{e} A_{s}\left(d-x_{1}\right)^{2}+\alpha_{e} A_{s}^{\prime}\left(x-d^{\prime}\right)^{2}
\end{aligned}
$$

com,

$\alpha_{e}=\frac{E_{s}}{E_{c}}$

$E_{C}=E_{C O}=6600 \sqrt{\left(f_{c k}+3,5\right)}$ 
sendo:

$\mathrm{I}_{1}=$ momento de inércia no estádio I

$\mathrm{x}_{1}=$ linha neutra no estádio I

$\mathrm{E}_{\mathrm{c}}=$ módulo de elasticidade do concreto

$\mathrm{E}_{\mathrm{co}}=$ módulo tangente na origem

Para se levar em conta a fluência, o anexo da NBR 7197(1989) permite considerar $\alpha_{\mathrm{e}}=15$, sendo $\alpha_{\mathrm{e}}$ a razão entre os módulos de elasticidade do aço e do concreto. Neste trabalho a fluência será considerada majorando-se a flecha imediata através do coeficiente de fluência $\beta$ (item 6.7.6). Portanto adota-se $\alpha_{\mathrm{e}}=\mathrm{E}_{\mathrm{s}} / \mathrm{E}_{\mathrm{c}}$.

b)Seções fissuradas $\left(M_{d, \text { uti }}>M_{r}\right)$

O momento de serviço é igual ou superior ao momento de fissuração, ou seja, parte das seções está no estádio I e parte no estádio II.

No estádio II, a linha neutra e o momento de inércia são dados por:

$$
\begin{aligned}
& x_{2}^{2}+2 \cdot \frac{\alpha_{e}}{b}\left(A_{s}+A_{s}^{\prime}\right) x_{2}-2 \cdot \frac{\alpha_{e}}{b}\left(A_{s} d+A_{s}^{\prime} d^{\prime}\right)=0 \\
& I_{2}=\frac{b x_{2}^{3}}{3}+\alpha_{e} A_{s}\left(d-x_{2}\right)^{2}+\alpha_{e} A_{s}^{\prime}\left(x-d^{\prime}\right)^{2}
\end{aligned}
$$

Como existem também seções não fissuradas, pode ser considerada a situação equivalente dada pelas fórmulas de Branson:

$$
\begin{aligned}
& x_{e}=\left(\frac{M_{r}}{M}\right)^{2,5} \cdot x_{1}+\left[1-\left(\frac{M_{r}}{M}\right)^{2,5}\right] \cdot x_{2} \leq x_{1} \\
& I_{e}=\left(\frac{M_{r}}{M}\right)^{3} \cdot I_{1}+\left[1-\left(\frac{M_{r}}{M}\right)^{3}\right] \cdot I_{2} \leq I_{1}
\end{aligned}
$$

sendo:

$\mathrm{M}=\mathrm{M}_{\mathrm{d}, \mathrm{uti}}$ 
Se a taxa de armadura $\rho$ for menor que $0,5 \%$, para seção retangular, pode-se adotar:

$x_{0}=h / 2$ em vez de $x_{1}$

$\mathrm{I}_{0}=\mathrm{bh}^{3} / 12$ em vez de $\mathrm{I}_{1}$

De acordo com a NBR 6118(1978), item 4.2.3.1-A, o módulo de deformação longitudinal do concreto é:

$$
E_{C}=0,9.6600 \sqrt{f_{c k}+3,5}
$$

\subsubsection{FLECHA IMEDIATA}

A flecha imediata pode ser obtida através da equação de Lagrange, também chamada equação diferencial da elástica.

$$
\frac{\partial^{4} \omega}{\partial x^{4}}+2 \frac{\partial^{4} \omega}{\partial x^{2} \partial y^{2}}+\frac{\partial^{4} \omega}{\partial y^{4}}=\frac{p}{D}
$$

onde $\mathrm{D}$ é o módulo de rigidez à flexão, cuja expressão é:

$$
D=\frac{E I}{1-\nu^{2}}
$$

sendo:

$\mathrm{I}=$ momento de inércia à flexão da placa,

$\mathrm{E}=$ módulo de deformação longitudinal,

$v=$ coeficiente de Poisson.

A NBR 6118(1978) especifica o coeficiente de Poisson (v) igual a 0,2. 
A solução da equação de Lagrange é complexa, recorrendo-se então a processos numéricos que são utilizados na confecção de tabelas. As flechas são dadas, então, pelas seguintes expressões [ver Pinheiro(1993)]:

$$
\begin{aligned}
& a_{i}=\frac{\alpha}{100} \frac{p \ell_{x}^{4}}{E h^{3}} \\
& a_{i}=\frac{\alpha b}{1200} \frac{p \ell_{x}^{4}}{E I}
\end{aligned}
$$

sendo

$$
\begin{gathered}
I=\frac{b h^{3}}{12} \Leftrightarrow \Rightarrow h^{3}=\frac{12 I}{b} \\
h=\text { espessura da laje }
\end{gathered}
$$

\subsubsection{FLECHA DECORRENTE DE AÇÕES DURADOURAS}

A flecha $a_{1}$ decorrente de ações duradouras compõe-se de duas partes, uma rápida e outra lenta.

As ações duradouras são provenientes da soma da carga permanente a uma parcela da carga acidental, tendo-se:

$$
p_{d, u t i}=p_{1}=g_{k}+\Psi_{2} q_{k}
$$

A flecha $a_{1}$ é a soma da flecha imediata (ações duradouras) com a flecha decorrente da fluência, ou seja, o coeficiente $\beta$ vezes a flecha imediata.

$$
a_{1}=a_{i d}+a_{C}=\beta a_{i d}
$$

Para levar em conta o efeito da deformação lenta, a NBR 6118(1978) permite avaliar a flecha final, devida às ações de longa duração, como o produto do valor da 
flecha imediata respectiva, pela relação das curvaturas final e inicial da seção de maior momento em valor absoluto. Sendo assim, define-se o coeficiente $\beta$ :

$$
\beta=\frac{(1 / r)_{t}}{(1 / r)_{i}}
$$

$(1 / \mathrm{r})_{\mathrm{t}}=$ curvatura final

$(1 / \mathrm{r})_{\mathrm{i}}=$ curvatura inicial

De acordo com a notação da fig.6.4, o valor da curvatura, segundo essa norma, deve ser calculado através da expressão:

$$
\frac{1}{r}=\frac{\left|\varepsilon_{c}\right|+\varepsilon_{s}}{d}
$$

fazendo-se $\varepsilon_{\mathrm{c}}$ final igual a três vezes o valor de $\varepsilon_{\mathrm{c}}$ inicial e $\varepsilon_{\mathrm{s}}$ constante e igual ao seu valor inicial. Portanto, tem-se:

$$
\beta=\frac{\frac{3 \varepsilon_{c}+\varepsilon_{s}}{d}}{\frac{\varepsilon_{c}+\varepsilon_{s}}{d}}=\frac{3 \varepsilon_{c}+\varepsilon_{s}}{\varepsilon_{c}+\varepsilon_{s}}
$$

Baseado no diagrama de deformações (fig.6.4), tem-se uma condição de compatibilidade:

$$
\frac{\varepsilon_{c}}{x}=\frac{\varepsilon_{s}}{d-x} \quad \Leftrightarrow \quad \varepsilon_{c}=\frac{x \varepsilon_{s}}{d-x}
$$

Substituindo na equação (6.15), obtém-se:

$$
\beta=\frac{\frac{3 x \varepsilon_{s}}{d-x}+\varepsilon_{s}}{\frac{x \varepsilon_{s}}{d-x}+\varepsilon_{s}} \quad \Leftrightarrow \quad \beta=\frac{2 x}{d}+1
$$



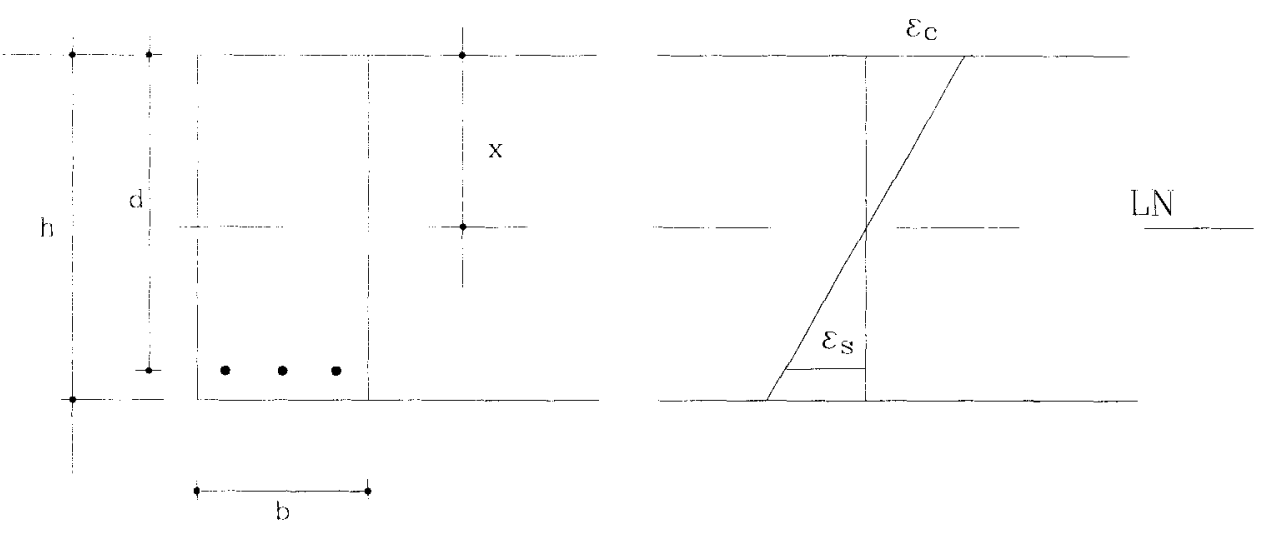

FIGURA 6.4- Diagrama de deformações

\subsubsection{FLECHA IMEDIATA PARA AÇÃO SUPLEMENTAR}

Ação suplementar é a parcela da carga total que não é duradoura:

$$
p_{2}=\left(1-\psi_{2}\right) q_{k}
$$

Esta parcela de carga não provoca fluência. A flecha imediata $a_{2}$ decorrente da ação suplementar é dada por:

$$
a_{2}=\frac{p_{2}}{p_{1}} a_{i d}
$$

\subsubsection{FLECHA TOTAL}

Denomina-se flecha total à soma das parcelas relativas às ações duradouras e à suplementar:

$$
a_{t}=a_{1}+a_{2}=a_{i d}+a_{c}+a_{2}
$$

Poderia ser considerada também uma parcela relativa à retração, que por ser pequena será desprezada (ver RIOS, 1991, por exemplo). 


\subsubsection{CRITÉRIO DE ACEITAÇÃO}

Duas condições devem ser verificadas, uma relativa à deformabilidade da laje após aplicação das ações duradouras e outra relativa à necessidade ou não de contraflecha.

a) Primeira condição : $\quad a_{t}-a_{i d}=a_{c}+a_{2} \leq a_{1 i m}$

Considera-se $\mathrm{a}_{\lim }=\ell / 300$ ou $\mathrm{a}_{\lim }=\ell / 150$, sendo este último valor relativo a balanços.

Se esta condição não for satisfeita, deve-se enrijecer a laje, por exemplo aumentando sua espessura.

A NBR 6118(1978) exige também que $a_{2}$ seja inferior a $\ell / 500$ ou $\ell / 250$, este último no caso de balanços. Porém, em edifícios, em geral a primeira condição é mais rigorosa que esta.

b) Segunda condição: $\quad a_{t} \leq a_{1 \text { im }}$

Se esta condição não for satisfeita, é obrigatório a adoção de uma contraflecha.

\subsubsection{CONTRAFLECHA}

Sempre pode ser adotada uma contraflecha $\mathrm{a}_{\mathrm{cf}}$, sendo ela obrigatória quando a segunda condição não for satisfeita. Seu valor deverá estar entre a flecha imediata para ações de longa duração $\left(\mathrm{a}_{\mathrm{id}}\right)$ e este valor mais metade da flecha devido à fluência $\left(\mathrm{a}_{\mathrm{id}}+\right.$ $a_{c} / 2$ ). É mais adequada uma contraflecha próxima deste último valor.

De acordo com a equação (6.12), tem-se:

$a_{c}=a_{1}-a_{i d}=\beta a_{i d}-a_{i d}=a_{i d}(\beta-1)$ 
Portanto:

$$
\begin{aligned}
& a_{i d}+\frac{a_{c}}{2}=a_{i d}+a_{i d} \frac{(\beta-1)}{2}=a_{i d}\left(\frac{1+\beta}{2}\right) \\
& a_{i d}<a_{c f}<\left(\frac{1+\beta}{2}\right) a_{i d}
\end{aligned}
$$

Então, um valor de $a_{\mathrm{cf}}$ próximo de $[(1+\beta) / 2] \mathrm{a}_{\mathrm{id}}$ é mais adequado. Costuma-se adotar valores múltiplos de $0,5 \mathrm{~cm}$. 


\section{CÁlCULO DE LAJES RETANGULARES PELA TCP}

\subsection{GENERALIDADES}

O cálculo pela Teoria das Charneiras Plásticas não é mais amplamente utilizado devido à falta de divulgação de processos que permitam ao engenheiro enfrentar os casos mais comuns da prática, que são as lajes anisótropas contínuas.

PINHEIRO (1988) apresenta uma formulação em caso de lajes retangulares simplesmente apoiadas ou engastadas no contorno ou de lajes retangulares contínuas sem borda livre, onde devem ser fixadas relações entre os momentos negativos e positivos e uma relação entre os dois momentos positivos. Para o caso de lajes contínuas, há necessidade de compatibilização dos momentos negativos, conduzindo a um cálculo iterativo.

AMARAL (1964), propôs uma solução que conduz a fórmulas simples e diretas, abordando o problema do emprego das relações entre os momentos negativos e positivos. Nessa mesma linha, SANTOS (1989) propôs um processo iterativo, conduzindo a uma solução prática para as lajes retangulares contínuas de edifícios, sem borda livre.

RIOS (1991) apresenta o roteiro de cálculo para laje engastada, simplesmente apoiada, com uma ou duas bordas livres. Neste trabalho foram incluídas funções aproximadoras e exemplos de lajes com uma borda livre utilizando o método do 
equilibrio, sem a consideração de leques das charneiras nos cantos da laje. $O$ cálculo é feito para lajes retangulares sujeitas a carga uniformemente distribuída e carga linear ao longo da borda livre.

\subsection{NOTAÇÃO ADOTADA}

A figura 7.1 apresenta a notação a ser utilizada. Os termos horizontal e vertical se referem a uma maneira intuitiva de representar os vãos e os momentos.

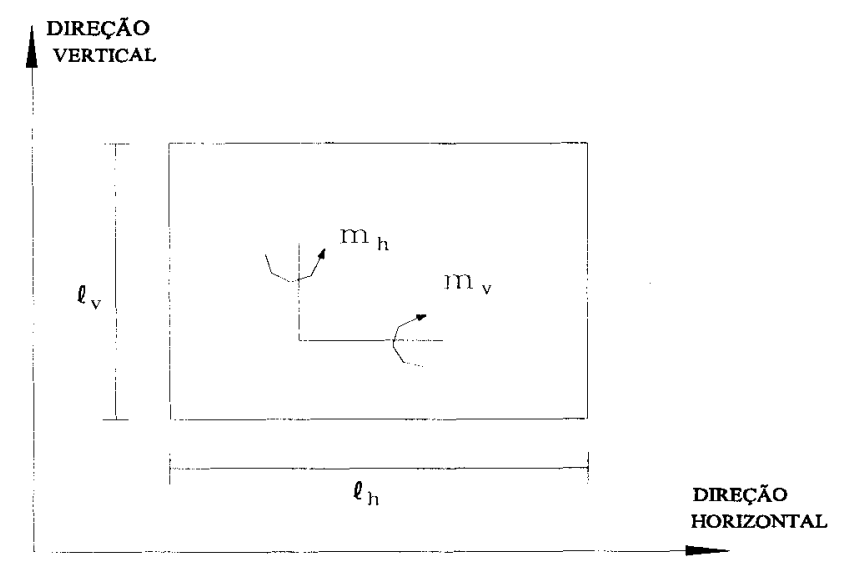

FIGURA 7.1- Notação

$\ell_{\mathrm{h}}=$ vão na direção "horizontal"

$\ell_{v}=$ vão na direção "vertical"

$\mathrm{m}_{\mathrm{h}}=$ momento relativo à armadura horizontal

$\mathrm{m}_{\mathrm{v}}=$ momento relativo à armadura vertical

O índice indica a direção da armadura determinada pelo momento. 


\subsection{LAJES RETANGULARES COM UMA BORDA LIVRE}

A figura 7.2 apresenta a notação adotada no caso 12 , onde a e m são a dimensão e o momento que determina a armadura perpendicular à borda livre, b e $\mu \mathrm{m}$ correspondem à direção paralela a essa borda e $\mathrm{m}_{\mathrm{i}}$ são os momentos negativos. A carga $\mathrm{p}$ é uniformemente distribuída e $\mathrm{p}_{\ell}$ é uma carga linear ao longo da borda livre.

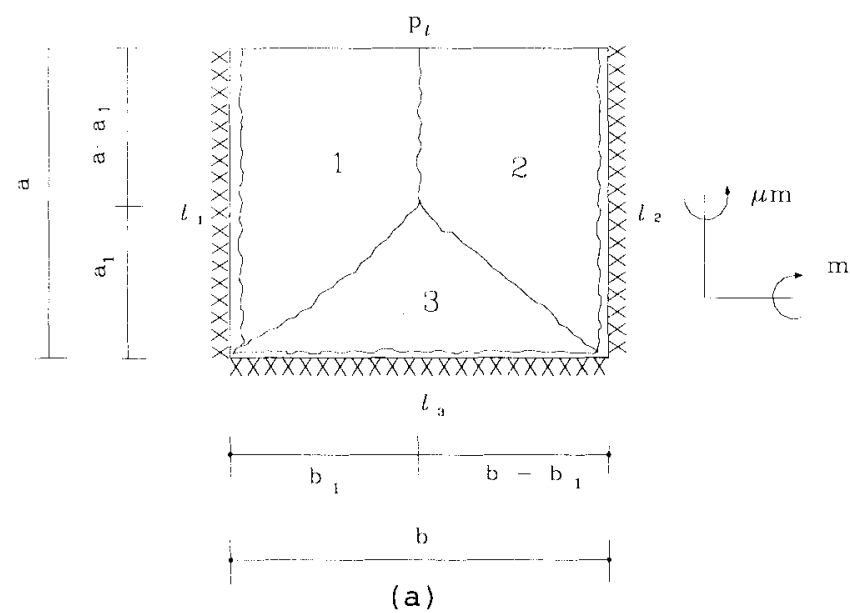

(a)

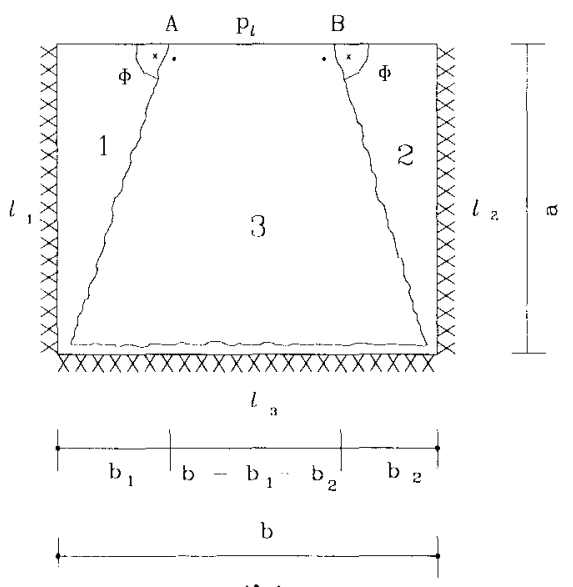

(b)

FIGURA 7.2- Laje retangular com uma borda livre

Será considerado o equilíbrio de momentos para cada região, em torno das bordas adjacentes, supondo a configuração de ruína mostrada na fig. 7.2-a.

Região 1:

$$
\mu m a+m_{1} a=p\left[\frac{b_{1} a_{1}}{2} \frac{b_{1}}{3}+b_{1}\left(a-a_{1}\right) \frac{b_{1}}{2}\right]+p_{\ell} b_{1} \frac{b_{1}}{2}
$$


$\mu m+m_{1}=\frac{b_{1}^{2}}{6 a}\left[p\left(3 a-2 a_{1}\right)+3 p_{\ell}\right]$

Região 2:

$\mu m a+m_{2} a=p\left[\frac{\left(b-b_{1}\right) a_{1}}{2} \cdot \frac{\left(b-b_{1}\right)}{3}+\left(b-b_{1}\right)\left(a-a_{1}\right) \frac{\left(b-b_{1}\right)}{2}\right]+$
$+p_{\ell}\left(b-b_{1}\right) \frac{\left(b-b_{1}\right)}{2}$

$\mu m+m_{2}=\frac{\left(b-b_{1}\right)^{2}}{6 a}\left[p\left(3 a-2 a_{1}\right)+3 p_{l}\right]$

Região 3:

$m b+m_{3} b=p \frac{a_{1} b}{2} \frac{a_{1}}{3}$

$m+m_{3}=p \frac{a_{1}^{2}}{6}$

$O$ valor de $b_{1}$ em função de m é determinado através das equações (7.1) e (7.2), resultando:

$$
\begin{aligned}
& \frac{b_{1}^{2}}{\mu m+m_{1}}=\frac{\left(b-b_{1}\right)^{2}}{\mu m+m_{2}} \\
& \sqrt{\mu m+m_{2}} \cdot b_{1}=\sqrt{\mu m+m_{1}} \cdot b-\sqrt{\mu m+m_{1}} \cdot b_{1} \\
& b_{1}=\frac{\sqrt{\mu m+m_{1}}}{\sqrt{\mu m+m_{1}}+\sqrt{\mu m+m_{2}}} \cdot b
\end{aligned}
$$


$a_{1}=\sqrt{\frac{6\left(m+m_{3}\right)}{p}}$

Substituindo-se estes valores de $a_{1}$ e $b_{1}$ na equação (7.1), obtém-se:

$$
\begin{aligned}
& \mu m+m_{1}=\frac{\left(\mu m+m_{1}\right) \cdot b^{2}}{6 a\left(\sqrt{\mu m+m_{1}}+\sqrt{\mu m+m_{2}}\right)^{2}}\left[p\left(3 a-2 \sqrt{\frac{6\left(m+m_{3}\right)}{p}}\right)+3 p_{\ell}\right] \\
& \sqrt{\mu m+m_{1}}+\sqrt{\mu m+m_{2}}=\sqrt{\frac{b^{2}}{6 a} \cdot\left[3\left(p a+p_{\ell}\right)-2 p \sqrt{\frac{6\left(m+m_{3}\right)}{p}}\right]}
\end{aligned}
$$

Adotam-se $\mathrm{f}_{1}$ e $\mathrm{f}_{2}$ como sendo iguais a cada um dos membros da expressão 7.6, resultando:

$$
\begin{aligned}
& f_{1}(m)=\sqrt{\mu m+m_{1}}+\sqrt{\mu m+m_{2}} \\
& f_{2}(m)=\sqrt{\frac{b^{2}}{6 a} \cdot\left[3\left(p a+p_{\ell}\right)-2 p \sqrt{\frac{6\left(m+m_{3}\right)}{p}}\right]}
\end{aligned}
$$

Observa-se que $f_{1}(m)$ é uma função crescente e $f_{2}(m)$ é decrescente. Desta forma, para que exista um valor de $\mathrm{m}$ positivo que satisfaça a igualdade, deve-se ter:

$$
\begin{aligned}
& \mathrm{f}_{1} \leq \mathrm{f}_{2} \text { para } \mathrm{m}=0 \\
& \mathrm{f}_{1} \geq \mathrm{f}_{2} \text { para } \mathrm{m}=\ell_{\mathrm{s}}
\end{aligned}
$$

O limite superior $\left(\ell_{\mathrm{s}}\right)$ de m é calculado a partir de duas condições:

$1^{\text {a }}$ condição : para atender ao domínio de validade

$$
3\left(p a+p_{l}\right)-2 p \sqrt{\frac{6\left(m+m_{3}\right)}{p}} \geq 0
$$




$$
\begin{aligned}
& 24 p\left(m+m_{3}\right) \leq 9\left(p a+p_{\ell}\right)^{2} \\
& m \leq \frac{3\left(p a+p_{\ell} \ell\right)^{2}}{8 p}-m_{3}
\end{aligned}
$$

$2^{\mathrm{a}}$ condição $: \mathrm{a}_{1} \leq \mathrm{a}$

$$
\begin{aligned}
& \sqrt{\frac{6\left(m+m_{3}\right)}{p}} \leq a \\
& m \leq \frac{p a^{2}}{6}-m_{3}
\end{aligned}
$$

A segunda condição é mais restrita que a primeira. Portanto:

$$
\ell_{s}=\frac{p a^{2}}{6}-m_{3}
$$

Verifica-se que é necessário que a segunda condição seja atendida. A inequação (7.8) deve ser satisfeita para $m=0$, resultando:

$$
m_{3} \leq \frac{p a^{2}}{6}
$$

Se a condição dada pela expressão (7.8) não for satisfeita, deve ser verificada a configuração de ruína dada pela figura 7.2-b. As forças nodais podem ser calculadas com o auxílio das equações dadas no capítulo 5 .

$$
\begin{aligned}
& \mathrm{K}_{01}=\mathrm{m} \cdot \operatorname{cotg} \theta \\
& \mathrm{K}_{02}=-\mathrm{m} \cdot \operatorname{cotg} \theta
\end{aligned}
$$

Então se deve fazer o equilíbrio de momentos para cada região novamente.

$$
K_{A 1}=-m \frac{b_{1}}{a} \quad \text { e } \quad K_{A 3}=m \frac{b_{1}}{a}
$$




$$
\begin{aligned}
& K_{A 1}=-m \cdot \operatorname{cotg} \phi_{1} \\
& K_{B 2}=-m \cdot \operatorname{cotg} \phi_{2} \\
& K_{B 2}=-m \frac{b_{2}}{a} \quad \text { e } \quad K_{B 3}=m \frac{b_{2}}{a}
\end{aligned}
$$

\section{Região 1:}

$$
\begin{aligned}
& \mu m a+m_{1} a-m \cdot \frac{b_{1}}{a} \cdot b_{1}=p \cdot \frac{a b_{1}}{2} \cdot \frac{b_{1}}{3}+p_{\ell} \cdot b_{1} \cdot \frac{b_{1}}{2} \\
& a\left(\mu m+m_{1}\right)-m \frac{b_{1}^{2}}{a}=\frac{b_{1}^{2}}{6}\left(p a+3 p_{\ell}\right)
\end{aligned}
$$

\section{Região 2:}

$$
\begin{aligned}
& \mu m a+m_{2} a-m \cdot \frac{b_{2}}{a} \cdot b_{2}=p \cdot \frac{a b_{2}}{2} \cdot \frac{b_{2}}{3}+p_{\ell} \cdot b_{2} \cdot \frac{b_{2}}{2} \\
& a\left(\mu m+m_{2}\right)-m \frac{b_{2}^{2}}{a}=\frac{b_{2}^{2}}{6}\left(p a+3 p_{\ell}\right)
\end{aligned}
$$

\section{Região 3:}

$$
\begin{aligned}
& m b_{1}+m b_{2}+m_{3} b+m \cdot \frac{b_{1}}{a} \cdot a+m \cdot \frac{b_{2}}{a} \cdot a=p\left[\frac{a b_{1}}{2} \cdot \frac{a}{3}+\right. \\
& \left.+a \frac{b_{2}}{2} \cdot \frac{a}{3}+a \cdot\left(b-b_{1}-b_{2}\right) \cdot \frac{a}{2}\right]+p_{\ell} \cdot\left(b-b_{1}-b_{2}\right) \cdot a \\
& 2 m\left(b_{1}+b_{2}\right)+m_{3} b=p \frac{a^{2}}{6}\left[3 b-2\left(b_{1}+b_{2}\right)\right]+p_{l} a\left[b-\left(b_{1}+b_{2}\right)\right]
\end{aligned}
$$


Das equações (7.9) e (7.10) obtém-se, respectivamente:

$$
\begin{aligned}
& {\left[\frac{p a+3 p_{l}}{6}+\frac{m}{a}\right] b_{1}^{2}=a\left(\mu m+m_{1}\right)} \\
& b_{1}=\sqrt{\frac{6 a^{2}\left(\mu m+m_{1}\right)}{p a^{2}+3 p_{\ell} a+6 m}} \\
& {\left[\frac{p a+3 p_{\ell}}{6}+\frac{m}{a}\right] b_{2}^{2}=a\left(\mu m+m_{2}\right)} \\
& b_{2}=\sqrt{\frac{6 a^{2}\left(\mu m+m_{2}\right)}{p a^{2}+3 p_{\ell} a+6 m}}
\end{aligned}
$$

Substituindo-se os valores da $b_{1}$ e $b_{2}$, dados pelas expressões (7.12) e (7.13), na equação (7.11), resulta:

$$
\begin{aligned}
& 2 m a \cdot \sqrt{\frac{6}{p a^{2}+3 p_{\ell} a+6 m} \cdot\left(\sqrt{\mu m+m_{1}}+\sqrt{\mu m+m_{2}}\right)+m_{3} b=} \\
& =\frac{p a^{2}}{6} \cdot\left[3 b-2 a \cdot \sqrt{\frac{6}{p a^{2}+3 p_{\ell} a+6 m}} \cdot\left(\sqrt{\mu m+m_{1}}+\sqrt{\mu m+m_{2}}\right)\right]+ \\
& +p_{\ell} a\left[b-a \sqrt{\frac{6 a^{2}+3 p_{\ell} a+6 m}{3}} \cdot\left(\sqrt{\mu m+m_{1}}+\sqrt{\mu m+m_{2}}\right)\right] \\
& \left(\sqrt{\mu m+m_{1}}+\sqrt{\mu m+m_{2}}\right) \cdot\left(2 m a+\frac{p a^{3}}{3}+p_{\ell} a^{2}\right)= \\
& =\left(\frac{p a^{2} b}{2}+p_{\ell} a b-m_{3} b\right) \cdot \sqrt{\frac{p a^{2}+3 p_{\ell} a+6 m}{6}}
\end{aligned}
$$




$$
\begin{array}{r}
\sqrt{\mu m+m_{1}}+\sqrt{\mu m+m_{2}}=a \cdot\left(\frac{p a b}{2}+p_{\ell} b-\frac{m_{3} b}{a}\right) . \\
\cdot \sqrt{\frac{p a^{2}+3 p_{\ell} a+6 m}{6}} \cdot \frac{3}{a\left(p a^{2}+3 p_{\ell} a+6 m\right)} \\
\sqrt{\mu m+m_{1}}+\sqrt{\mu m+m_{2}}=\left(\frac{p a b}{2}+p_{\ell} b-\frac{m_{3} b}{a}\right) \sqrt{\frac{3\left(p a^{2}+3 p_{l} a+6 m\right)}{2(3)}}
\end{array}
$$

Adotando-se

$$
\begin{aligned}
& f_{1}=\sqrt{\mu m+m_{1}}+\sqrt{\mu m+m_{2}} \\
& f_{3}=\left(\frac{p a b}{2}+p_{\ell} b-\frac{m_{3} b}{a}\right) \sqrt{\frac{3}{2\left(p a^{2}+3 p_{\ell} a+6 m\right)}}
\end{aligned}
$$

calcula-se o valor de $m$ por iteração, uma vez que $f_{1}(m)$ é crescente e $f_{3}(m)$ é decrescente.

Porém, deve-se estar atento para algumas restrições que devem ser respeitadas:

$1^{\mathrm{a}}$ restrição: $\mathrm{f}_{1} \leq \mathrm{f}_{3}$ para $\mathrm{m}=0$

$$
\sqrt{m_{1}}+\sqrt{m_{2}} \leq\left(\frac{p a b}{2}+p_{l} b-\frac{m_{3} b}{a}\right) \sqrt{\frac{3}{2\left(p a^{2}+3 p_{l} a\right)}}
$$

$2^{\mathrm{a}}$ restrição: $\mathrm{f}_{3} \geq 0$

$$
\left(\frac{p a b}{2}+p_{l} b-\frac{m_{3} b}{a}\right) \geq 0
$$


$m_{3} \leq \frac{p a^{2}}{2}+p_{\ell} a$

$3^{\mathrm{a}}$ restrição: $b_{1}+b_{2} \leq b$

$$
\sqrt{\frac{6 a^{2}}{p a^{2}+3 p_{l} a+6 m}} \cdot\left(\sqrt{\mu m+m_{1}}+\sqrt{\mu m+m_{2}}\right) \leq b
$$

\subsection{PONTO DE INTERRUPÇÃO DA ARMADURA NEGATIVA}

Os pontos de interrupção da armadura negativa devem ser determinados a partir dos pontos de momento nulo, ou seja, se a armadura negativa da laje não tiver comprimento adequado, um tipo de ruína pode ocorrer, formando uma linha de plastificação negativa, como está mostrado na fig. 7.3 ; não havendo armadura e desprezando a resistência do concreto à tração, o momento de plastificação é nulo.

Para a determinação teórica do ponto de interrupção da armadura negativa, define-se uma linha ao longo dos pontos onde a armadura será interrompida. Esta linha delimita uma nova laje (fig.7.3), suposta apoiada ao longo da mesma e que deve resistir aos mesmos esforços que a laje original, pois, do contrário, se produzirá a ruína da placa, formando-se uma charneira negativa ao longo dos pontos onde a armadura foi interrompida. 


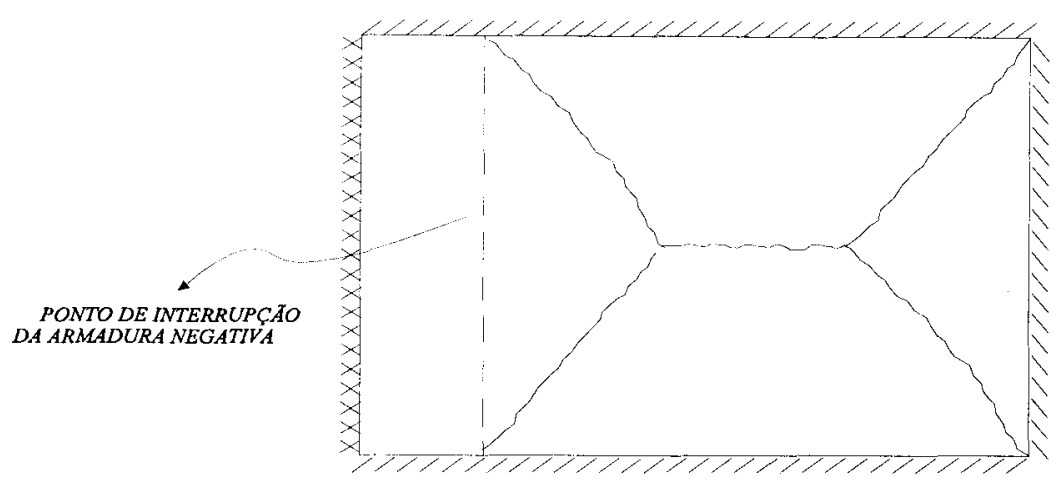

FIGURA 7.3- Extensão da armadura negativa

Conforme as configurações de ruína mostradas nas figs. 7.4-a e 7.4-b para laje retangular com uma borda livre, calculam-se os valores de $\mathrm{b}^{*} \mathrm{e} \mathrm{a}^{*}$, para as armaduras ao longo dos lados perpendiculares à borda livre e ao longo do lado oposto à mesma.

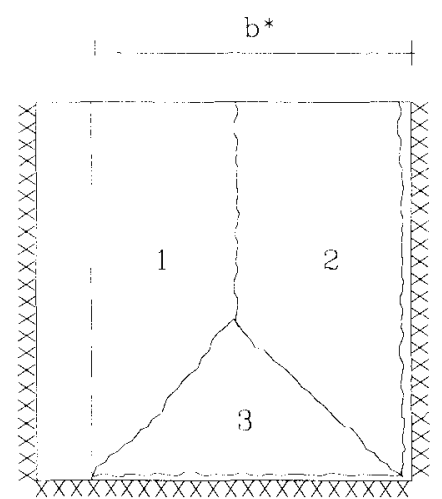

(a)

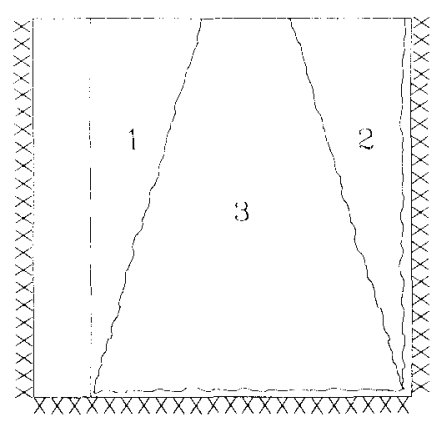

(c)

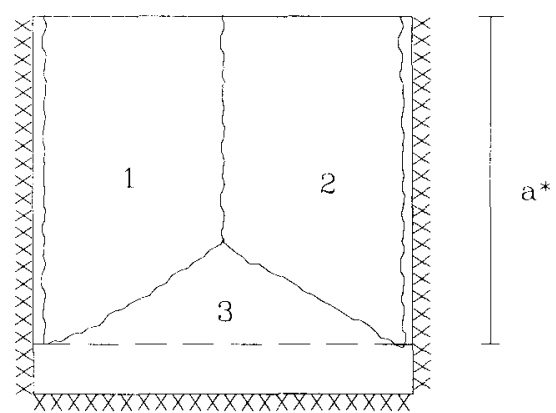

(b)

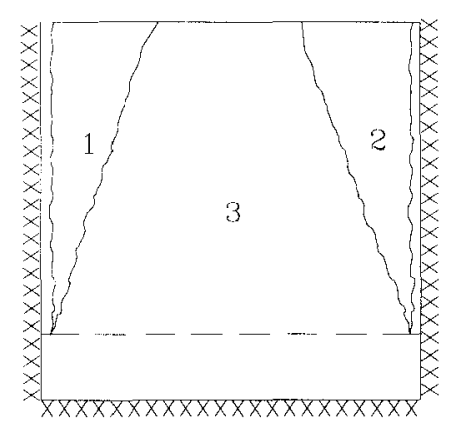

(d)

FIGURA 7.4- Laje retangular com uma borda livre 
O cálculo para a determinação de $b^{*}$ é feito a partir da equação (7.6), adotando-se $\mathrm{m}_{1}=0$ ou $\mathrm{m}_{2}=0$ :

$$
\begin{aligned}
& \sqrt{\mu m+m_{1}}+\sqrt{\mu m+m_{2}}=\sqrt{\frac{b^{*^{2}}}{6 a} \cdot\left[3\left(p a+p_{\ell}\right)-2 p \sqrt{\frac{6\left(m+m_{3}\right)}{p}}\right]} \\
& b^{*}=\frac{\sqrt{6 a} \cdot\left(\sqrt{\mu m+m_{1}}+\sqrt{\mu m+m_{2}}\right)}{\sqrt{3\left(p a+p_{\ell}\right)-2 p \sqrt{\frac{6\left(m+m_{3}\right)}{p}}}}
\end{aligned}
$$

Para determinar $a^{*}$, deve-se fazer $m_{3}=0$ na equação $(7.6)$ :

$$
\begin{aligned}
& \sqrt{\mu m+m_{1}}+\sqrt{\mu m+m_{2}}=\sqrt{\frac{b^{2}}{6 a} \cdot\left[3\left(p a^{*}+p_{\ell}\right)-2 p \sqrt{\frac{6\left(m+m_{3}\right)}{p}}\right]} \\
& {\left[6 \cdot\left(\sqrt{\mu m+m_{1}}+\sqrt{\mu m+m_{2}}\right)^{2}-3 p b^{2}\right] \cdot a^{*}=3 p_{\ell} b^{2}-2 p b^{2} \cdot \sqrt{\frac{6 m}{p}}} \\
& a^{*}=\frac{3 p_{\ell} b^{2}-2 p b^{2} \cdot \sqrt{\frac{6 m}{p}}}{6 \cdot\left(\sqrt{\mu m+m_{1}}+\sqrt{\mu m+m_{2}}\right)^{2}-3 p b^{2}}
\end{aligned}
$$

Se a configuração de ruína for a apresentada nas figuras 7.4-c e 7.4-d, utiliza-se a equação (7.14). Para o cálculo de $b^{*}$ faz-se $m_{1}=0$ ou $m_{2}=0$ :

$$
\begin{aligned}
& \sqrt{\mu m+m_{1}}+\sqrt{\mu m+m_{2}}=\left(\frac{p a b^{*}}{2}+p_{\ell} b^{*}-\frac{m_{3} b^{*}}{a}\right) \sqrt{\frac{3}{2\left(p a^{2}+3 p_{\ell} a+6 m\right)}} \\
& \left(\frac{p a}{2}+p_{\ell}-\frac{m_{3}}{a}\right) \cdot b^{*}=\left(\sqrt{\mu m+m_{1}}+\sqrt{\mu m+m_{2}}\right) \cdot \sqrt{\frac{2\left(p a^{2}+3 p_{\ell} a+6 m\right)}{3}}
\end{aligned}
$$




$$
b^{=}=\frac{\sqrt{\mu m+m_{1}}+\sqrt{\mu m+m_{2}}}{\frac{p a}{2}+p_{l}-\frac{m_{3}}{a}} \sqrt{\frac{2\left(p a^{2}+3 p_{\ell} a+6 m\right)}{3}}
$$

Com a mesma equação (7.14), calcula-se o valor de $\mathrm{a}^{*}$, onde $\mathrm{m}_{3}=0$.

$$
\sqrt{\mu m+m_{1}}+\sqrt{\mu m+m_{2}}=\left(\frac{p a \cdot b}{2}+p_{\ell} b\right) \sqrt{\frac{3}{2\left(p a^{a^{2}}+3 p_{\ell} a^{\cdot}+6 m\right)}}
$$

\section{Sendo}

$$
f_{1}=\sqrt{\mu m+m_{1}}+\sqrt{\mu m+m_{2}}
$$

resulta:

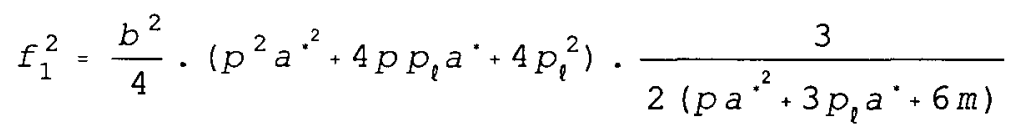

$$
\begin{aligned}
& 8 p a^{*} f_{1}^{2}+24 p_{\ell} a^{*} f_{1}^{2}+48 m f_{1}^{2}=3 p^{2} a^{*^{2}} b^{2}+12 p p_{\ell} a^{*} b^{2}+12 p_{\ell}^{2} b^{2} \\
& \left(8 p f_{1}^{2}-3 p^{2} b^{2}\right) a^{*^{2}}+\left(24 p_{\ell} f_{1}^{2}-12 p p_{\ell} b^{2}\right) a^{*}+48 m f_{1}^{2}-12 p_{\ell}^{2} b^{2}=0 \\
& a^{*}=\frac{12 p p_{\ell} b^{2}-24 p_{\ell} f_{1}^{2} \pm 8 f_{1} \sqrt{3 p_{\ell}^{2}\left(3 f_{1}^{2}-p b^{2}\right)-3 m p\left(8 f_{1}^{2}-3 p b^{2}\right)}}{2 p \cdot\left(8 f_{1}^{2}-3 p b^{2}\right)} \\
& a^{\cdot}=\frac{6 p_{\ell}\left(p b^{2}-2 f_{1}^{2}\right) \pm 4 f_{1} \sqrt{3 p_{\ell}^{2}\left(3 f_{1}^{2}-p b^{2}\right)-3 m p\left(8 f_{1}^{2}-3 p b^{2}\right)}}{p \cdot\left(8 f_{1}^{2}-3 p b^{2}\right)}
\end{aligned}
$$


Considerando $\mathrm{x}_{1}$ e $\mathrm{x}_{2}$ os pontos de interrupção das armaduras ao longo dos lados perpendiculares à borda livre e $\mathrm{x}_{3}$ do lado paralelo à mesma, obtém-se:

$$
\begin{aligned}
& \mathrm{x}_{1}=\mathrm{b}-\mathrm{b}^{*}, \text { para } \mathrm{m}_{1}=0 \\
& \mathrm{x}_{2}=\mathrm{b}-\mathrm{b}^{*}, \text { para } \mathrm{m}_{2}=0 \\
& \mathrm{x}_{3}=\mathrm{a}-\mathrm{a}^{*}, \text { para } \mathrm{m}_{3}=0
\end{aligned}
$$

\subsection{MARCHA DE CÁLCULO}

Supondo conhecidas as cargas permanentes e acidentais, apresenta-se a marcha de cálculo para a determinação dos momentos nas lajes e dos comprimentos das armaduras negativas, pela teoria das charneiras plásticas.

A notação a ser adotada relaciona-se à posição da borda livre. Se a borda livre for horizontal tem-se:
$a=\ell_{v}$
$\mathrm{b}=\ell_{\mathrm{h}}$
$\mu=m_{h} / m_{v}$
$\mathrm{m}_{\mathrm{l}}=\mathrm{m}_{\mathrm{e}}$
$\mathrm{m}_{2}=\mathrm{m}_{\mathrm{d}}$
$\mathrm{m}_{3}=\mathrm{m}_{\mathrm{s}}$ ou $\mathrm{m}_{\mathrm{i}}$
$\mathrm{x}_{1}=\mathrm{x}_{\mathrm{e}}$
$\mathrm{x}_{2}=\mathrm{x}_{\mathrm{d}}$
$\mathrm{x}_{3}=\mathrm{x}_{\mathrm{s}}$ ou $\mathrm{x}_{\mathrm{i}}$

Se a borda livre for vertical, resulta
$a=\ell_{h}$
$\mathrm{b}=\ell_{\mathrm{y}}$
$\mu=m_{v} / m_{h}$
$\mathrm{m}_{1}=\mathrm{m}_{\mathrm{s}}$
$\mathrm{m}_{2}=\mathrm{m}_{\mathrm{i}}$
$\mathrm{m}_{3}=\mathrm{m}_{\mathrm{e}}$ ou $\mathrm{m}_{\mathrm{d}}$
$\mathrm{x}_{1}=\mathrm{x}_{\mathrm{s}}$
$\mathrm{x}_{2}=\mathrm{x}_{\mathrm{i}}$
$x_{3}=x_{e}$ ou $x_{d}$

Verificando-se, inicialmente, a configuração de ruína da figura 7.2-a, sendo:

$$
f_{1}=\sqrt{\mu m+m_{1}}+\sqrt{\mu m+m_{2}}
$$




$$
f_{2}(m)=\sqrt{\frac{b^{2}}{6 a} \cdot\left[3\left(p a+p_{l}\right)-2 p \sqrt{\frac{6\left(m+m_{3}\right)}{p}}\right]}
$$

deve-se ter:

$$
\begin{aligned}
& m_{3} \leq \frac{p a^{2}}{6} \\
& f_{1} \leq f_{2} \text { para } m=0 \\
& f_{1} \geq f_{2} \text { para } m=\ell_{s} \\
& \ell_{s}=\frac{p a^{2}}{6}-m_{3}
\end{aligned}
$$

Se uma dessas condições não se verificar, considera-se a configuração de ruína da figura 7.2-b, resultando novas funções:

$$
\begin{aligned}
& f_{1}=\sqrt{\mu m+m_{1}}+\sqrt{\mu m+m_{2}} \\
& f_{2}(m)=\left(\frac{p a b}{2}+p_{l} b-\frac{m_{3} b}{a}\right) \sqrt{\frac{3}{2\left(p a^{2}+3 p_{l} a+6 m\right)}}
\end{aligned}
$$

Para este caso, devem ser satisfeitas as condições:

$$
\begin{aligned}
& \sqrt{m_{1}}+\sqrt{m_{2}} \leq\left(\frac{p a b}{2}+p_{\ell} b-\frac{m_{3} b}{a}\right) \sqrt{\frac{3}{2\left(p a^{2}+3 p_{\ell} a\right)}} \\
& m_{3} \leq \frac{p a^{2}}{2}+p_{l} a
\end{aligned}
$$

Calcula-se o valor de m por iteração, obtendo-se:

$$
\begin{aligned}
& m_{v}=m \text { e } m_{h}=\mu m \text { se a borda livre for horizontal } \\
& m_{h}=m \text { e } m_{v}=\mu m \text { se a borda livre for vertical }
\end{aligned}
$$


Deve-se verificar ainda se $b_{1}+b_{2} \leq b$ :

$$
\sqrt{\frac{6 a^{2}}{p a^{2}+3 p_{\ell} a+6 m}} \cdot\left(\sqrt{\mu m+m_{1}}+\sqrt{\mu m+m_{2}}\right) \leq b
$$

Os pontos de interrupção das armaduras negativas são:

$$
\begin{aligned}
& \mathrm{x}_{1}=\mathrm{b}-\mathrm{b}^{*}, \text { para } \mathrm{m}_{1}=0 \\
& \mathrm{x}_{2}=\mathrm{b}-\mathrm{b}^{*}, \text { para } \mathrm{m}_{2}=0 \\
& \mathrm{x}_{3}=\mathrm{a}-\mathrm{a}^{*}, \text { para } \mathrm{m}_{3}=0
\end{aligned}
$$

com $\mathrm{b}^{*} \mathrm{e} \mathrm{a}^{*}$ os menores valores entre os seguintes:

$$
\begin{aligned}
& b^{*}=\frac{\sqrt{6 a} \cdot\left(\sqrt{\mu m+m_{1}}+\sqrt{\mu m+m_{2}}\right)}{\sqrt{3\left(p a+p_{\ell}\right)-2 p \sqrt{\frac{6\left(m+m_{3}\right)}{p}}}} \\
& b^{*}=\frac{\sqrt{\mu m+m_{1}}+\sqrt{\mu m+m_{2}}}{\frac{p a}{2}+p_{\ell}-\frac{m_{3}}{a}} \sqrt{\frac{2\left(p a^{2}+3 p_{\ell} a+6 m\right)}{3}} \\
& a^{*}=\frac{3 p_{\ell} b^{2}-2 p b^{2} \cdot \sqrt{\frac{6 m}{p}}}{6 \cdot\left(\sqrt{\mu m+m_{1}}+\sqrt{\mu m+m_{2}}\right)^{2}-3 p b^{2}} \\
& a^{*}=\frac{6 p_{\ell}\left(p b^{2}-2 f_{1}^{2}\right) \pm 4 f_{1} \sqrt{3 p_{\ell}^{2}\left(3 f_{1}^{2}-p b^{2}\right)-3 m p\left(8 f_{1}^{2}-3 p b^{2}\right)}}{p \cdot\left(8 f_{1}^{2}-3 p b^{2}\right)}
\end{aligned}
$$




\section{EXEMPLOS}

Este capítulo apresenta alguns exemplos de lajes retangulares com uma borda livre, associando o cálculo elástico ao plástico. É feita a comparação, mostrando a economia que o cálculo pela Teoria das Charneiras Plásticas pode trazer.

O cálculo elástico é utilizado para a determinação dos momentos negativos e da razão dos momentos positivos nas duas direções. Estes valores servirão de base para o cálculo pela Teoria das Charneiras Plásticas, usado para dimensionamento.

\subsection{EXEMPLO 1}

Apresenta-se um tabuleiro constituído por 8 lajes. A figura 8.1 mostra a planta de fôrma, onde as dimensões encontram-se em metros. Os vínculos das lajes estão indicados na figura 8.2. 


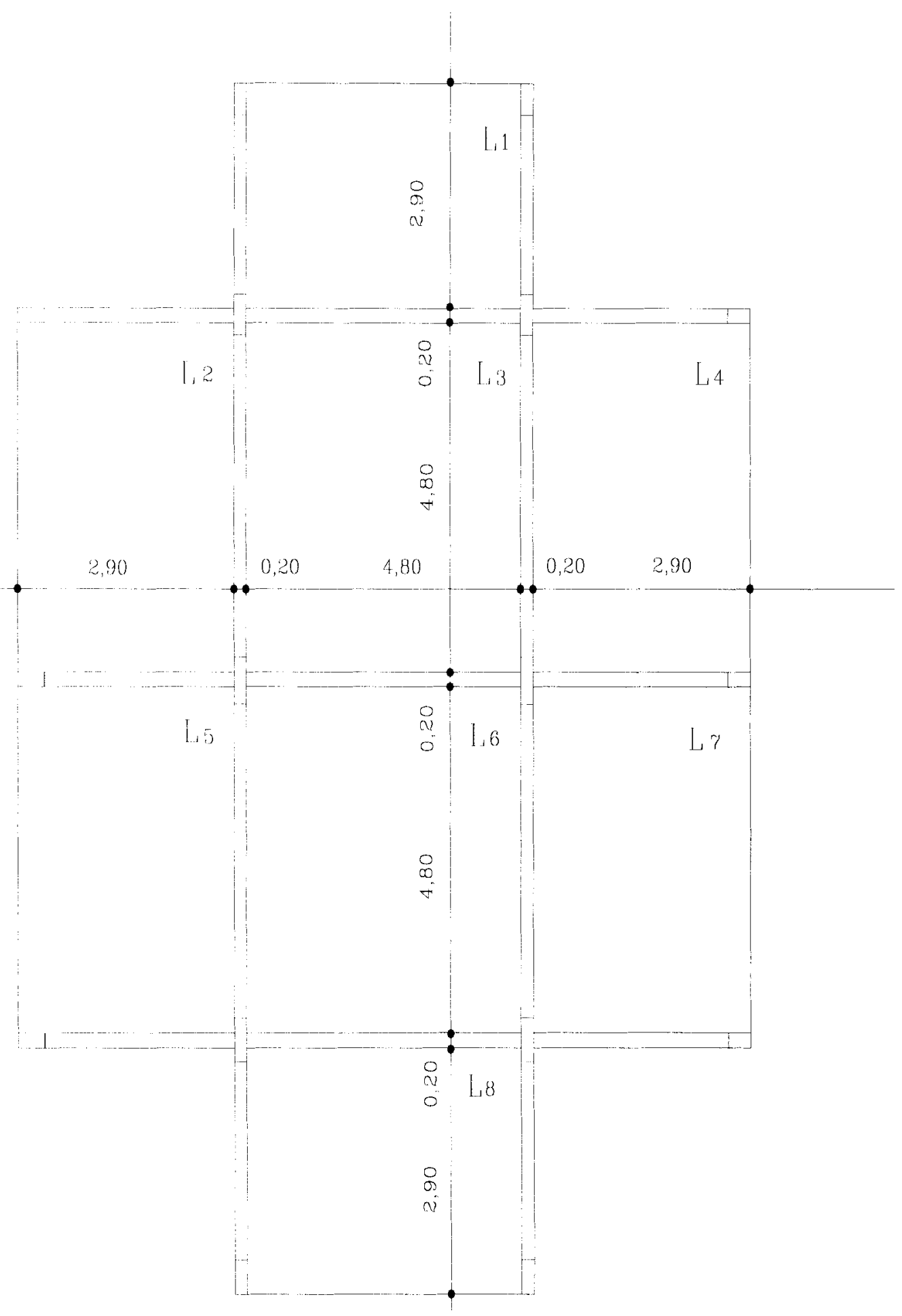

FIGURA 8.1- Planta de fôrma 

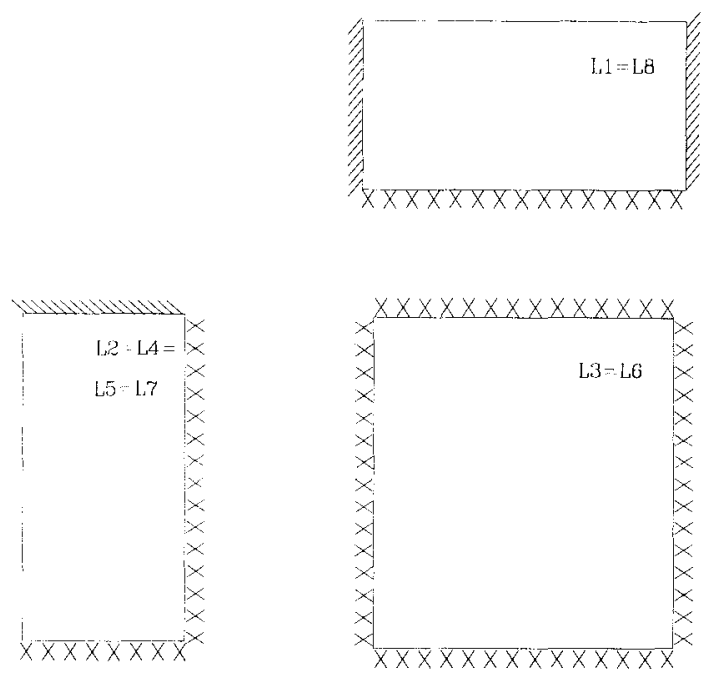

FIGURA 8.2- Vínculos das lajes

\subsubsection{ESPESSURA DAS LAJES}

O cálculo para a determinação da espessura das lajes pode ser baseado na NBR 6118(1978); os valores de $\psi_{2}$ e $\psi_{3}$ estão tabelados em PINHEIRO (1993).

Para obtenção da espessura faz-se:

$$
\begin{aligned}
& d_{0}=\frac{l}{\psi_{2} \cdot \psi_{3}} \quad, \quad l=\text { menor vão } \\
& h-d_{0} \geq 1,0
\end{aligned}
$$

Com este procedimento, as espessuras das lajes $\mathrm{L}_{1}, \mathrm{~L}_{2}$ e $\mathrm{L}_{3}$ deveriam ser, respectivamente: $17,57 \mathrm{~cm} ; 15,50 \mathrm{~cm}$ e $12,29 \mathrm{~cm}$.

Os vãos, as espessuras adotadas e as cargas encontram-se indicados na tabela 8.1. Como foram adotadas espessuras bem menores que as sugeridas pela NBR 6118, é necessária a verificação das flechas. 
TABELA 8.1 - Características e cargas

\begin{tabular}{|c|c|c|c|c|}
\hline \multicolumn{2}{|c|}{ LAJES } & $\mathrm{L}_{1}=\mathrm{L}_{8}$ & $\mathrm{~L}_{2}=\mathrm{L}_{4}=\mathrm{L}_{5}=\mathrm{L}_{7}$ & $\mathrm{~L}_{3}=\mathrm{L}_{6}$ \\
\hline \multirow{3}{*}{$\begin{array}{l}\text { CARACTE- } \\
\text { RÍSTICAS }\end{array}$} & $l_{\mathrm{l}}(\mathrm{m})$ & 5,00 & 3,00 & 5,00 \\
\hline & $\ell_{v}(\mathrm{~m})$ & 3,00 & 5,00 & 5,00 \\
\hline & $\mathrm{h}(\mathrm{cm})$ & 12,00 & 12,00 & 12,00 \\
\hline \multirow{6}{*}{$\begin{array}{l}\text { CARGAS } \\
\left(\mathrm{kN} / \mathrm{m}^{2}\right)\end{array}$} & p.p. & 3,00 & 3,00 & 3,00 \\
\hline & piso + revest. & 1,50 & 1,50 & 1,50 \\
\hline & divisórias & 1,00 & 1,00 & 1,00 \\
\hline & $\mathrm{g}$ & 5,50 & 5,50 & 5,50 \\
\hline & $q$ & 2,00 & 2,00 & 2,00 \\
\hline & $p=g+q$ & 7,50 & 7,50 & 7,50 \\
\hline
\end{tabular}

\subsubsection{CÁLCULO DOS MOMENTOS ELÁSTICOS}

O cálculo elástico é baseado em tabelas. O critério de compatibilização dos momentos negativos é o maior valor entre a média e $80 \%$ do maior momento. Para os momentos positivos a correção é feita considerando cada vínculo e subtraindo do maior momento negativo o momento compatibilizado, dividindo por 2 este resultado e somando ao positivo na direção considerada.

Os valores dos momentos e das flechas foram retirados das tabelas 3.1 a 3.12 apresentadas no capítulo 3. Considerou-se $\ell_{y}$ como sendo o lado perpendicular à borda livre.

Os momentos elásticos adotados encontram-se na tabela 8.2, sendo feito um roteiro de cálculo somente para a laje 1(ver figura 8.3).

Os valores dos momentos elásticos e dos compatibilizados (em evidência) estão indicados na figura 8.4 .

Aqui é apresentado o esquema de cálculo somente para a Laje 1 = Laje 8; os momentos destas e das outras lajes estão indicados na tabela 8.2. 


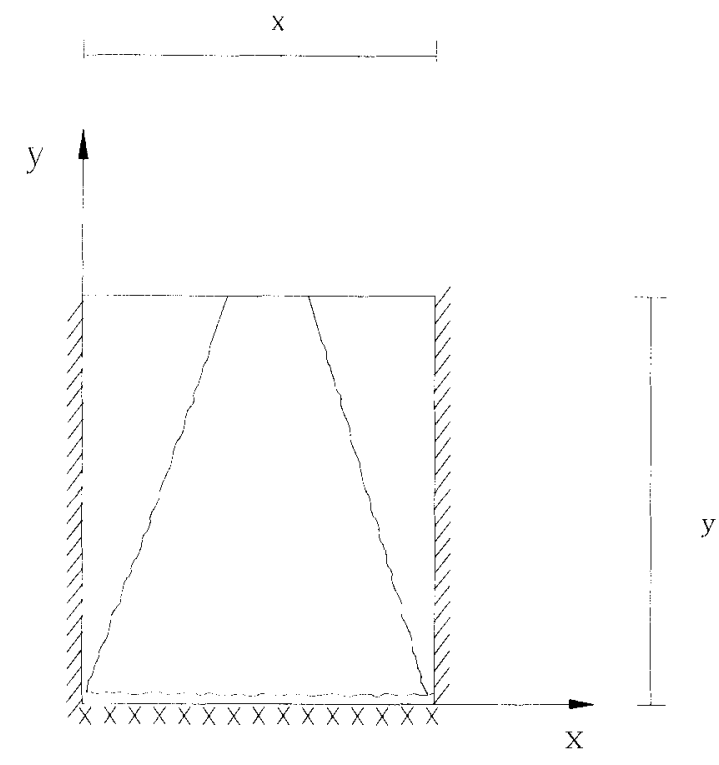

FIGURA 8.3- Laje retangular com borda livre LAJE1=LAJE8

$Y=\frac{l_{y}}{l_{x}}=0,60$

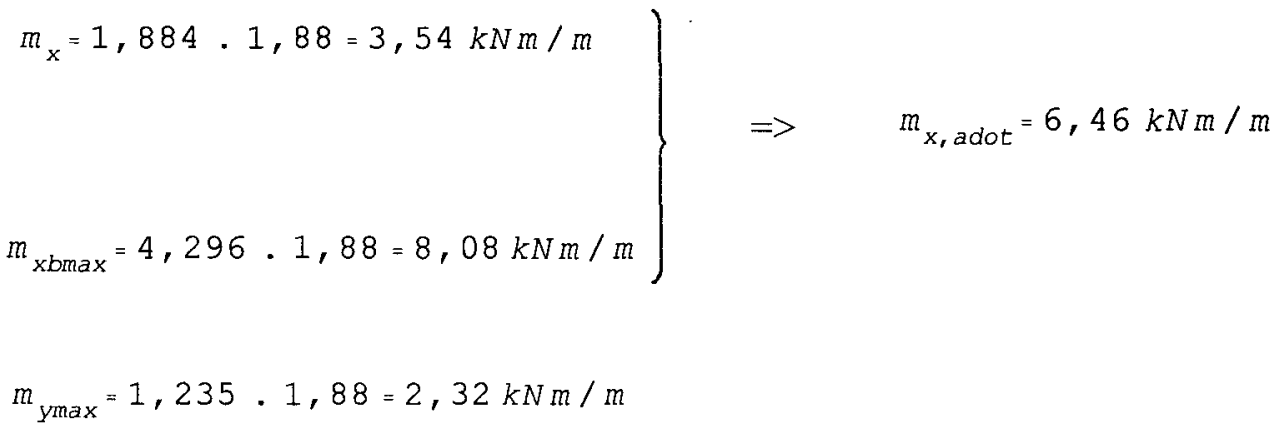

$m_{y}^{\prime}=9,083 \cdot 1,88=17,08 \mathrm{kNm} / \mathrm{m}$

O momento $\mathrm{m}_{\mathrm{x}, \mathrm{adot}}$ refere-se ao maior valor entre a média de $\mathrm{m}_{\mathrm{x}}$ e $\mathrm{m}_{\mathrm{xbmax}}$ e $0,8 \mathrm{de}$ $\mathrm{m}_{\mathrm{xbmax}}$. 
TABELA 8.2- Momentos elásticos adotados

\begin{tabular}{|c|c|c|c||}
\hline Coef. & $\mathrm{L}_{1}=\mathrm{L}_{8}$ & $\mathrm{~L}_{2}=\mathrm{L}_{4}=\mathrm{L}_{5}=\mathrm{L}_{7}$ & $\mathrm{~L}_{3}=\mathrm{L}_{6}$ \\
\hline $\mathrm{m}_{\mathrm{x}}$ & 6,46 & 5,78 & 3,80 \\
\hline $\mathrm{m}_{\mathrm{x}}{ }^{\prime}$ & - & 16,92 & 9,68 \\
\hline $\mathrm{m}_{\mathrm{y}}$ & 2,32 & 2,22 & 3,80 \\
\hline $\mathrm{m}_{\mathrm{y}}{ }^{\prime}$ & 17,08 & 13,33 & 9,68 \\
\hline
\end{tabular}

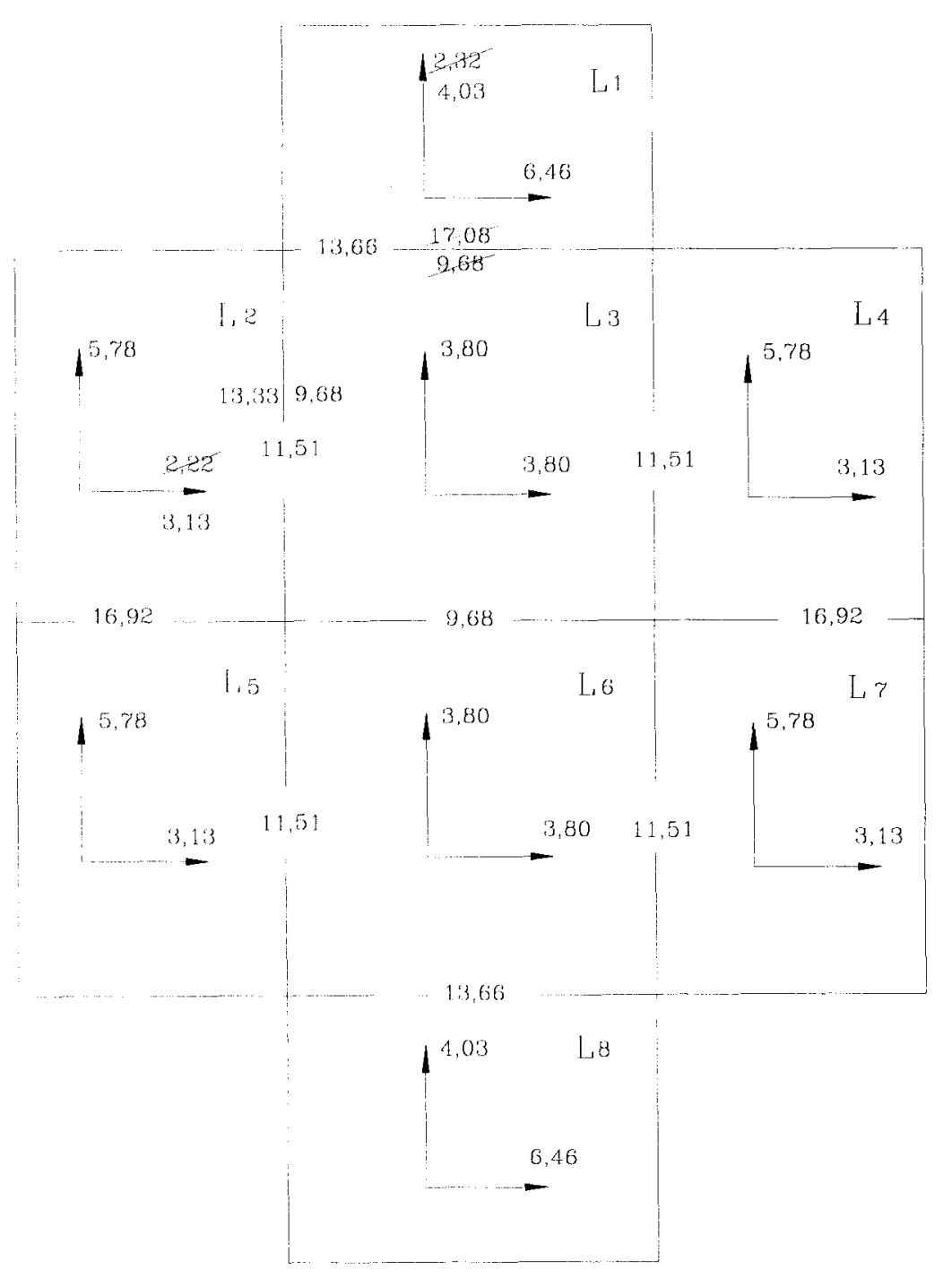

FIGURA 8.4- Momentos elásticos compatibilizados 


\subsubsection{ARMADURAS PARA CÁLCULO ELÁSTICO}

O cálculo para obtenção das armaduras pode ser feito através das tabelas de PINHEIRO (1993), por exemplo.

$$
\begin{aligned}
& k_{c}=\frac{b_{w} d^{2}}{M_{d}} \quad \text { C-20, CA-50A }>\mathrm{k}_{\mathrm{s}} \\
& M_{d}=1,4 M_{k} \\
& A_{s}=\frac{k_{s} M_{d}}{d} \\
& A_{s_{\min }}=0,15 \div\left(b_{w} \cdot h\right)
\end{aligned}
$$

Os momentos, as correspondentes armaduras calculadas e as adotadas estão indicadas nas tabelas 8.3 e 8.4 . A figura 8.5 apresenta o detalhamento da armadura positiva.

\subsubsection{COMPRIMENTO DA ARMADURA SUPERIOR NOS APOIOS}

Para a determinação do comprimento das barras foi utilizada a expressão:

$$
a=\frac{3}{8} \ell+20 \phi+0,75 d
$$

sendo:

$\ell=>$ maior valor entre os menores vãos

$\phi \Rightarrow$ diâmetro das barras

$\mathrm{d}=>$ altura útil da laje

A distribuição das barras é feita alternando $2 \mathrm{a} / 3$ para um lado e $\mathrm{a} / 3$ para o outro, como demonstra a figura 8.6. As tabelas 8.5 e 8.6 indicam respectivamente a quantidade de barras e a massa $(\mathrm{kg})$ do aço das armaduras positiva e negativa. $O$ consumo total de aço para o cálculo elástico é $604 \mathrm{~kg}$. 
Como se trata de um exemplo teórico, não foi calculado o comprimento de ancoragem nas barras positivas e as dobras nas barras negativas, conforme recomenda a NB-1/78 (item 4.1.6.2).

TABELA 8.3- Momentos elásticos positivos e respectivas armaduras.

\begin{tabular}{|c|c|c|c|c|}
\hline \multicolumn{2}{|c|}{ LAJES } & $\mathrm{L}_{1}=\mathrm{L}_{8}$ & $\mathrm{~L}_{2}=\mathrm{L}_{4}=\mathrm{L}_{5}=\mathrm{L}_{7}$ & $L_{3}=L_{5}$ \\
\hline \multirow{3}{*}{$\begin{array}{l}\text { Momento } \\
\mathrm{kNm} / \mathrm{m}\end{array}$} & $m_{x}$ & 6,46 & 5,78 & 3,80 \\
\hline & $\mathrm{m}_{y}$ & 4,03 & 3,13 & 3,80 \\
\hline & $\beta$ & 0,62 & 0,54 & 1,00 \\
\hline \multirow{6}{*}{$\begin{array}{c}\text { Armadura } \\
\mathrm{cm}^{2} / \mathrm{m}\end{array}$} & $a_{\text {sxcal }}$ & 1,97 & 1,77 & 1,16 \\
\hline & $a_{\text {sxadot }}$ & 2,00 & 1,82 * & 1,82 * \\
\hline & adot. & $\phi 5 \mathrm{c} / 10$ & $\phi 5 \mathrm{c} / 11$ & $\phi 5 \mathrm{c} / 11$ \\
\hline & $a_{\text {sycal }}$ & 1,23 & 0,92 & 1,82 \\
\hline & $a_{\text {syadot }}$ & 1,82 * & 1,82 * & $1,82 *$ \\
\hline & adot. & $\phi 5 \mathrm{c} / 11$ & $\phi 5 \mathrm{c} / 11$ & $\phi 5 \mathrm{c} / 11$ \\
\hline
\end{tabular}

TABELA 8.4- Momentos negativos e respectivas armaduras.

\begin{tabular}{|c|c|c|c|c|c|}
\hline \multicolumn{2}{|c|}{ VÍNCULOS } & $\mathrm{L}_{1} \leftrightarrow \mathrm{L}_{3}$ & $\mathrm{~L}_{2} \leftrightarrow \mathrm{L}_{3}$ & $L_{2} \leftrightarrow L_{5}$ & $L_{3} \leftrightarrow L_{6}$ \\
\hline \multirow{2}{*}{$\begin{array}{c}\text { Momentos } \\
\mathrm{kNm} / \mathrm{m}\end{array}$} & $m_{x}{ }^{\prime}$ & - & - & 16,92 & - \\
\hline & $m_{y}^{\prime}$ & 13,66 & 11,51 & - & 9,68 \\
\hline \multirow{6}{*}{$\begin{array}{c}\text { Armadura } \\
\mathrm{cm}^{2} / \mathrm{m}\end{array}$} & $a_{\text {sxcal }}$ & - & - & 5,38 & - \\
\hline & $\mathrm{a}_{\text {sxadot }}$ & - & - & 5,56 & - \\
\hline & adot. & - & - & $\phi 8 \mathrm{c} / 9$ & - \\
\hline & $a_{\text {sycal }}$ & 4,35 & 3,52 & - & 2,96 \\
\hline & $a_{\text {syadot }}$ & 4,55 & 3,57 & - & 3,15 \\
\hline & adot. & $\begin{array}{c}\phi 8 \\
c / 11\end{array}$ & $\begin{array}{c}\phi 8 \\
c / 14\end{array}$ & - & $\begin{array}{l}\phi 6,3 \\
c / 10\end{array}$ \\
\hline
\end{tabular}




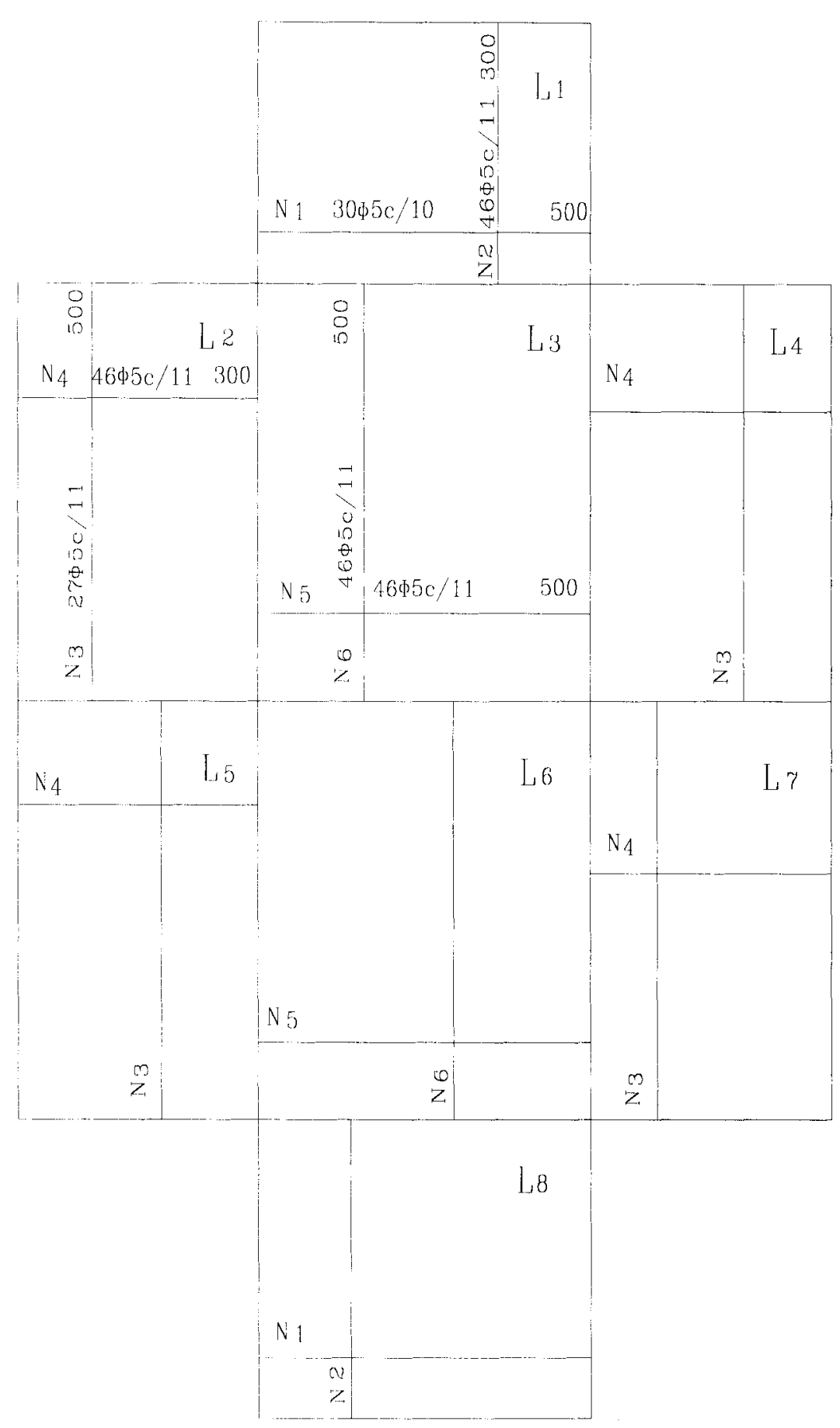

FIGURA 8.5- Detalhamento da armadura inferior (cálculo elástico) 


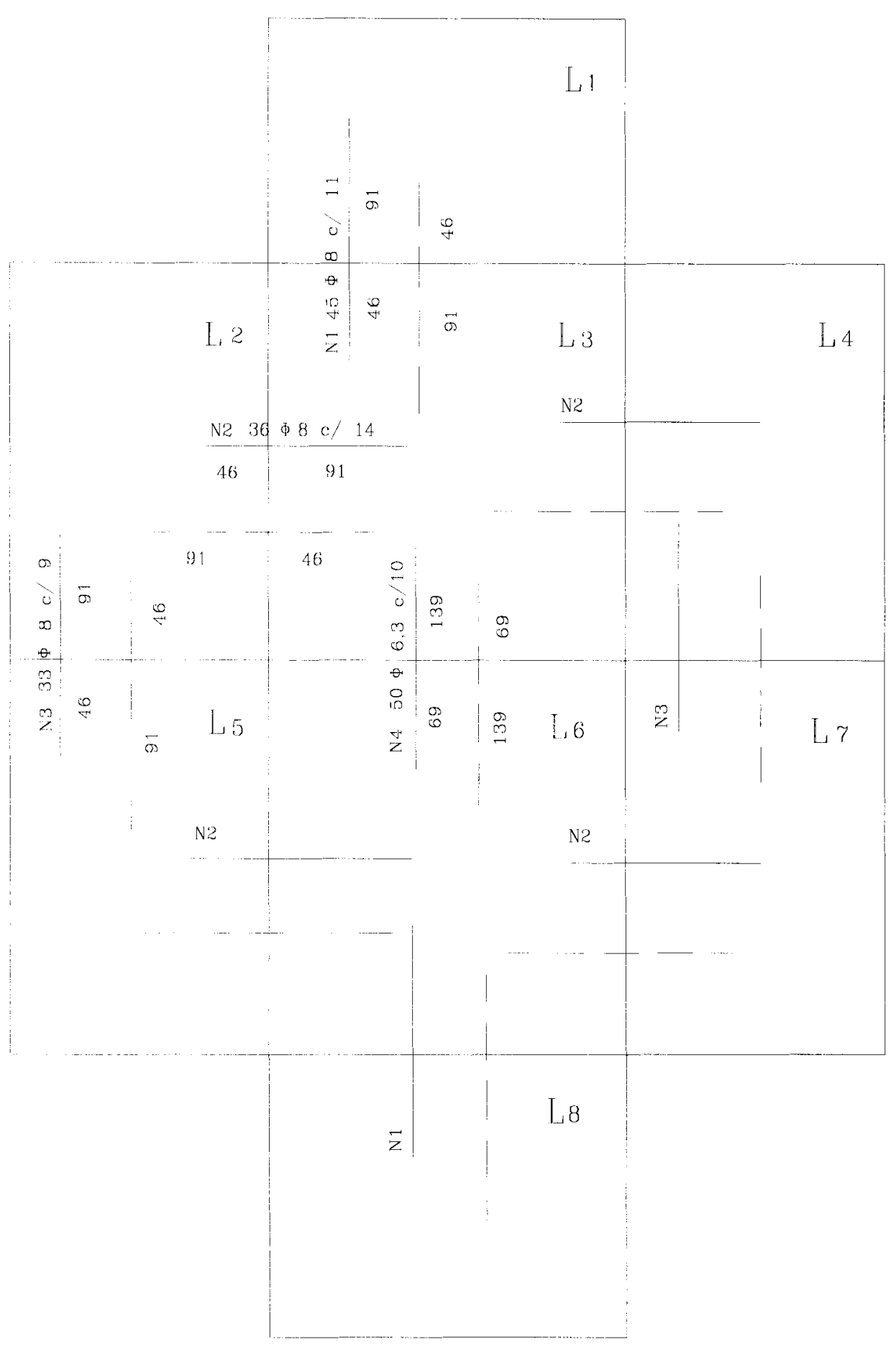

FIGURA 8.6- Detalhamento da armadura superior (cálculo elástico) 
TABELA 8.5- Quantidade de barras (cálculo elástico)

\begin{tabular}{||c|c|c|c|c|c|c||}
\hline ARMADURA & $\mathrm{N}$ & $\mathrm{Q}$ & $\begin{array}{c}\phi \\
(\mathrm{mm})\end{array}$ & $\begin{array}{c}\text { Compr. } \\
(\mathrm{m})\end{array}$ & Quant. & $\begin{array}{c}\text { Compr.Tot. } \\
(\mathrm{m})\end{array}$ \\
\hline \multirow{4}{*}{$\begin{array}{c}\text { ARMADURA } \\
\text { INFERIOR }\end{array}$} & 1 & 2 & 5 & 5,00 & 30 & 300,00 \\
\cline { 2 - 7 } & 2 & 2 & 5 & 3,00 & 46 & 276,00 \\
\cline { 2 - 8 } & 3 & 4 & 5 & 5,00 & 27 & 540,00 \\
\cline { 2 - 8 } & 5 & 2 & 5 & 5,00 & 46 & 552,00 \\
\cline { 2 - 8 } & 7 & 2 & 5 & 5,00 & 46 & 460,00 \\
\hline \multirow{4}{*}{$\begin{array}{c}\text { ARMADURA } \\
\text { SUPERIOR }\end{array}$} & 1 & 2 & 8 & 1,37 & 45 & 123,30 \\
\cline { 2 - 8 } & 3 & 2 & 8 & 1,37 & 33 & 197,28 \\
\cline { 2 - 7 } & 4 & 1 & 6,3 & 2,08 & 50 & 104,00 \\
\hline
\end{tabular}

TABELA 8.6 - Quantidade de aço da armadura (cálculo elástico)

\begin{tabular}{||c|c|c|c||}
\hline \hline ARMADURA & $\phi(\mathrm{mm})$ & Compr.(m) & Massa(kg) \\
\hline ARMADURA INFERIOR & 5 & 2588,00 & 414,08 \\
\hline ARMADURA SUPERIOR & 6,3 & 104,00 & 26,00 \\
\cline { 2 - 5 } & 8 & 411,00 & 164,40 \\
\hline \multicolumn{2}{|c|}{ TOTAL DE AÇO } & $\mathbf{3 1 0 3 , 0 0}$ & $\mathbf{6 0 4 , 4 8}$ \\
\hline
\end{tabular}

\subsubsection{CÁlCULO DOS MOMENTOS PELA TCP}

No pré-dimensionamento utilizam-se os momentos elásticos do item anterior. Os momentos negativos, adotados para o cálculo plástico, são os provenientes do cálculo elástico reduzidos, ou seja, multiplicados por 0,6 (ver item 4.3).

O equacionamento será demonstrado apenas para a laje 1; os resultados estão indicados nas tabelas 8.7 e 8.8 . 


\section{$\underline{\text { LAJE } 1=\text { LAJE } 8}$}

Os valores são retirados das tabelas 8.1, 8.3 e 8.4:

$$
\begin{aligned}
& \mathrm{h}=0,12 \mathrm{~m} \\
& \mathrm{p}=7,50 \mathrm{kN} / \mathrm{m}^{2} \\
& \beta=0,62 \\
& \ell_{\mathrm{x}}=5,00 \mathrm{~m}=\mathrm{b} \\
& \ell_{\mathrm{y}}=3,00 \mathrm{~m}=\mathrm{a} \\
& \mathrm{m}_{\mathrm{y}}^{\prime}=13,66 \mathrm{kNm} / \mathrm{m} \\
& \mathrm{m}_{3}=13,66 \cdot 0,6=8,196 \mathrm{kNm} / \mathrm{m}
\end{aligned}
$$

A laje 1 apresenta a configuração mostrada na fig 8.7.

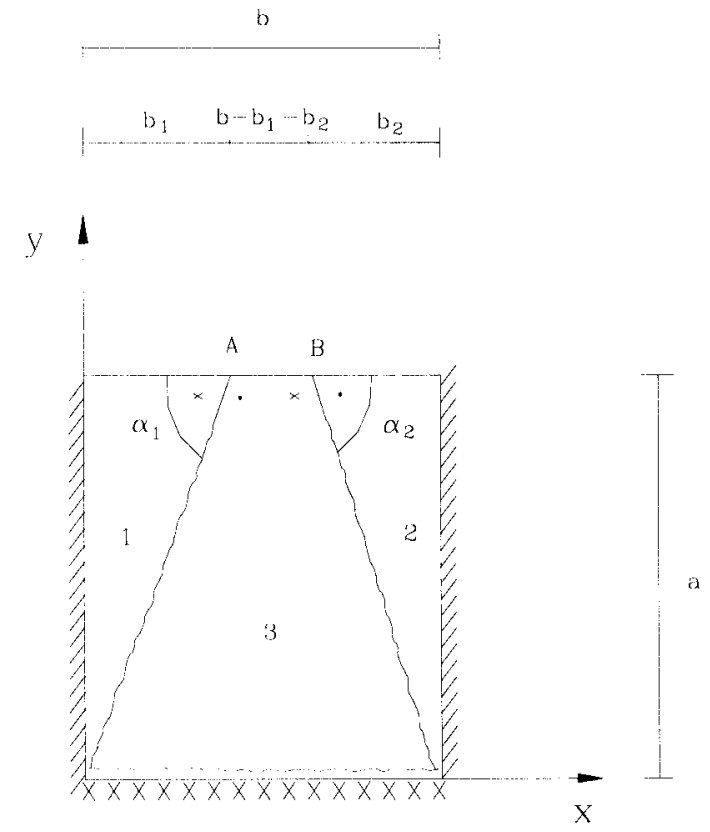

FIGURA 8.7- Laje 1

Determinam-se o valores das forças nodais em função de $\mathrm{m}$, como demonstrado no capítulo 5, tendo-se: 


$$
\begin{aligned}
& K_{A 1}=-m \operatorname{cotg} \alpha_{1}=-\frac{m b_{1}}{a} \\
& K_{A 3}=\frac{m b_{1}}{a} \\
& K_{B 2}=-\frac{m b_{2}}{a} \\
& K_{B 3}=\frac{m b_{2}}{a}
\end{aligned}
$$

\section{Região 1}

$$
\begin{aligned}
& \beta m a-\frac{m b_{1}}{a} \cdot b_{1}=p \cdot\left[\frac{a b_{1}}{2} \cdot \frac{b_{1}}{3}\right] \\
& \beta m a-\frac{m b_{1}^{2}}{a}=p \frac{a b_{1}^{2}}{6}
\end{aligned}
$$

Região 2

$$
\begin{aligned}
& \beta m a-\frac{m b_{2}}{a} b_{2}=p\left[\frac{a b_{2}}{2} \cdot \frac{b_{2}}{3}\right] \\
& \beta m a-\frac{m b_{2}^{2}}{a}=p \frac{a b_{2}^{2}}{6}
\end{aligned}
$$

Região 3

$$
m b_{1}+m b_{2}+m b_{3}+m \frac{b_{1} \cdot a}{a}+m \frac{b_{2} \cdot a}{a}=
$$


$=p \cdot\left[\frac{a b_{1}}{2} \frac{a}{3}+\frac{a b_{2}}{2} \frac{a}{3}+a\left(b-b_{1}-b_{2}\right) \cdot \frac{a}{2}\right]$

$2 m\left(b_{1}+b_{2}\right)+m_{3} b=\frac{p a^{2}}{6}\left[3 b-2\left(b_{1}+b_{2}\right)\right]$

Da equação (8.1), obtém-se:

$b_{1}=\sqrt{\frac{6 a^{2} \beta m}{6 m+p a^{2}}}=b_{2}$

Substituindo os valores de $b_{1}$ e $b_{2}$ na equação (8.3), obtém-se:

$\sqrt{\beta m}+\sqrt{\beta m}=\left(\frac{p a b}{2}-\frac{m_{3} b}{a}\right) \sqrt{\frac{3}{2\left(p a^{2}+6 m\right)}}$

Calcula-se o valor de $m$ por iteração, uma vez que $f_{1}(m)$ é crescente e $f_{2}(m)$ é decrescente, ou seja:

$$
\begin{aligned}
& f_{1}=\sqrt{\beta m+m_{1}}+\sqrt{\beta m+m_{2}} \\
& f_{2}=\left(\frac{p a b}{2}-\frac{m_{3} b}{a}\right) \sqrt{\frac{3}{2\left(p a^{2}+6 m\right)}}
\end{aligned}
$$

Obtém-se um valor limite superior e um inferior para $\mathrm{m}$.

$$
\begin{aligned}
& m_{s}=\frac{1}{\beta}\left[\frac{1,5}{p b^{2}}\left(\frac{p b^{2}}{6}-m_{3}+m_{4}\right)^{2}-m_{4}\right] \\
& m_{i}=\frac{1,5}{p a^{2}}\left(\frac{p a^{2}}{6}-m_{1}+m_{2}\right)^{2}-m_{2}
\end{aligned}
$$


Portanto, $\mathrm{m}_{\mathrm{i}} \leq \mathrm{m} \leq \mathrm{m}_{\mathrm{s}}$, conforme demonstra a figura 8.8.

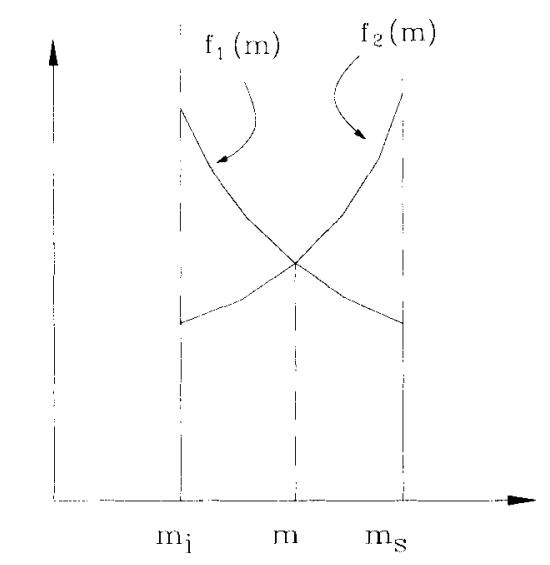

FIGURA 8.8- Momento x Função

Para $\mathrm{m}=9,02 \mathrm{kN} / \mathrm{m}$, tem-se:

$\mathrm{f}_{1}=4,7298$

$\mathrm{f}_{2}=4,7299$

Substituindo na equação (8.4), obtém-se:

$b_{1}=b_{2}=1,58$ metros

Após o cálculo de $m$ devem ser feitas algumas verificações:

$1^{\text {a }}$ verificação: $\mathrm{f}_{2} \geq 0$

$$
\begin{aligned}
& \frac{p a b}{2}-\frac{m_{3} b}{a} \geq 0 \\
& \frac{m_{3} b}{a} \leq \frac{p a b}{2}
\end{aligned}
$$

$m_{3} \leq \frac{p a^{2}}{2}$

$m_{3} \leq 33,75 \mathrm{kNm} / \mathrm{m} \quad$ OK!

$2^{a}$ verificação: $b_{1}+b_{2} \leq b$

$1,58+1,58 \leq 5,00$ OK! 
Como as duas condições são satisfeitas, as hipóteses admitidas estão corretas. Portanto:

$m=9,02 \mathrm{kNm} / \mathrm{m}$

\subsubsection{ARMADURAS PARA O CÁLCULO PLÁSTICO}

O cálculo para obtenção das armaduras é o mesmo utilizado no item 8.1.3 e os resultados estão indicados nas tabelas 8.7 e 8.8. O detalhamento da armadura inferior está demonstrado na figura 8.10 e da armadura superior na figura 8.11.

A quantidade de barras e a massa do aço das armaduras positiva e negativa estão indicados respectivamente nas tabs.8.9 e 8.10.

TABELA 8.7- Momentos positivos e armaduras do cálculo plástico

\begin{tabular}{|c|c|c|c|c|}
\hline \multicolumn{2}{|c|}{ LAJES } & $\mathrm{L}_{1}=\mathrm{L}_{8}$ & $\mathrm{~L}_{2}=\mathrm{L}_{4}=\mathrm{L}_{5}=\mathrm{L}_{7}$ & $\mathrm{~L}_{3}=\mathrm{L}_{6}$ \\
\hline \multirow{3}{*}{$\begin{array}{c}\text { Momentos } \\
\mathrm{kNm} / \mathrm{m}\end{array}$} & $m_{x}$ & 9,02 & 5,81 & 1,00 \\
\hline & $m_{y}$ & 5,59 & 3,14 & 1,00 \\
\hline & $\beta_{\text {adot. }}$ & 0,62 & 0,54 & 1,00 \\
\hline \multirow{6}{*}{$\begin{array}{l}\text { Armadura } \\
\mathrm{cm}^{2} / \mathrm{m}\end{array}$} & $\mathrm{a}_{\mathrm{sxcal}}$ & 2,76 & 1,77 & 0,29 \\
\hline & $\mathrm{a}_{\text {sxadot }}$ & 2,86 & $1,82^{*}$ & $1,82^{*}$ \\
\hline & adot. & $\phi 6,3 \mathrm{c} / 11$ & $\phi 5 \mathrm{c} / 11$ & $\phi 5 \mathrm{c} / 11$ \\
\hline & $a_{\text {sycal }}$ & 1,71 & 0,92 & 0,29 \\
\hline & $a_{\text {syadot }}$ & $1,82^{*}$ & $1,82^{*}$ & $1,82^{*}$ \\
\hline & adot. & $\$ 5 \mathrm{c} / 11$ & $\phi 5 \mathrm{c} / 11$ & $\phi 5 \mathrm{c} / 11$ \\
\hline \multicolumn{2}{|c|}{$\mathrm{m}_{\mathrm{xadot}}$} & 9,35 & 5,79 & 6,02 \\
\hline \multicolumn{2}{|c|}{$\mathrm{m}_{\text {yadot. }}$} & 5,95 & 5,95 & 6,02 \\
\hline \multicolumn{5}{|c|}{$\begin{array}{l}\mathrm{m}_{\text {xadot. }} \text { e } \mathrm{m}_{\text {yadot. }} \text { são os momentos resistentes, obtidos a partir das áreas } \\
\text { efetivas de aço. }\end{array}$} \\
\hline
\end{tabular}


TABELA 8.8- Momentos negativos e armaduras do cálculo plástico

\begin{tabular}{|c|c|c|c|c|c|}
\hline \multicolumn{2}{|c|}{ VÍNCULOS } & $\mathrm{L}_{1}-\mathrm{L}_{3}$ & $\mathrm{~L}_{2} \bullet \mathrm{L}_{3}$ & $\mathrm{~L}_{2}-\mathrm{L}_{5}$ & $\mathrm{~L}_{3}-\mathrm{L}_{6}$ \\
\hline \multirow{2}{*}{$\begin{array}{c}\text { Momentos } \\
\mathrm{kNm} / \mathrm{m}\end{array}$} & $\mathrm{m}_{\mathrm{x}}^{\prime}$ & - & - & 10,15 & - \\
\hline & $\mathrm{m}_{\mathrm{y}}{ }^{\prime}$ & 8,20 & 6,91 & - & 5,81 \\
\hline \multirow{6}{*}{$\begin{array}{c}\text { Armadura } \\
\mathrm{cm}^{2} / \mathrm{m}\end{array}$} & $a_{\text {sxcal }}$ & - & - & 3,10 & - \\
\hline & $a_{\text {sxadot }}$ & - & - & 3,15 & - \\
\hline & adot. & - & - & $\phi 6,3 \mathrm{c} / 10$ & - \\
\hline & $\mathrm{a}_{\text {sycal }}$ & 4,35 & 2,11 & - & 1,77 \\
\hline & $a_{\text {syadot }}$ & 4,55 & 2,11 & - & $1,82 *$ \\
\hline & adot. & $\phi 6,3 \mathrm{c} / 12,5$ & $\phi 5 \mathrm{c} / 9,5$ & - & $\phi 5 \mathrm{c} / 11$ \\
\hline \multicolumn{2}{|c|}{$\mathrm{m}_{\text {xadot. }}$} & - & - & 10,31 & - \\
\hline \multicolumn{2}{|c|}{$\mathrm{m}_{\text {yadot. }}$} & 8,26 & 6,91 & - & 5,97 \\
\hline \multicolumn{6}{|c|}{$\begin{array}{l}\mathrm{m}_{\text {xadot. }} \text { e } \mathrm{m}_{\text {yadot }} \text { são os momentos resistentes, obtidos a partir das áreas } \\
\text { efetivas de aço. }\end{array}$} \\
\hline
\end{tabular}




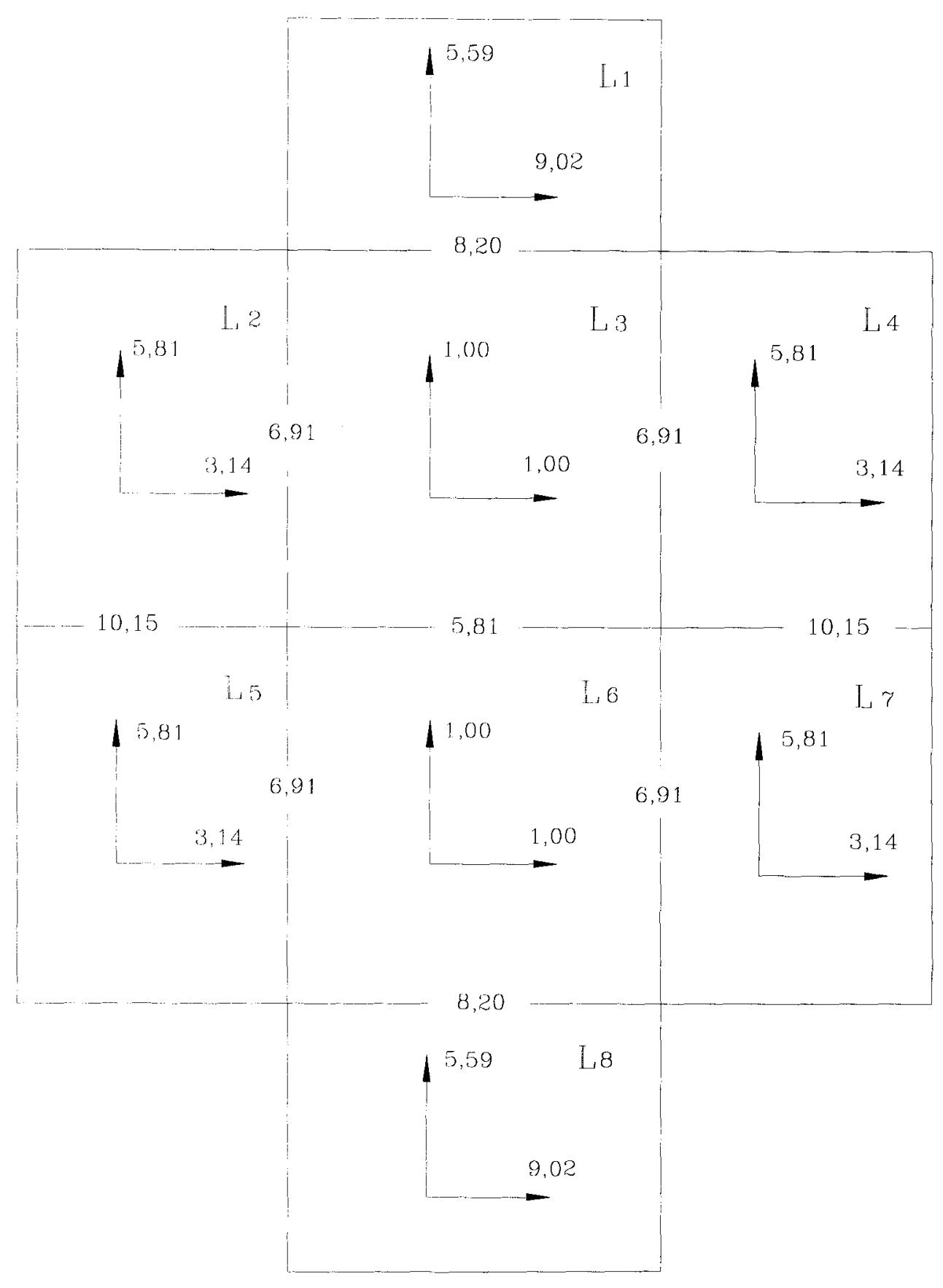

FIGURA 8.9- Momentos plásticos 


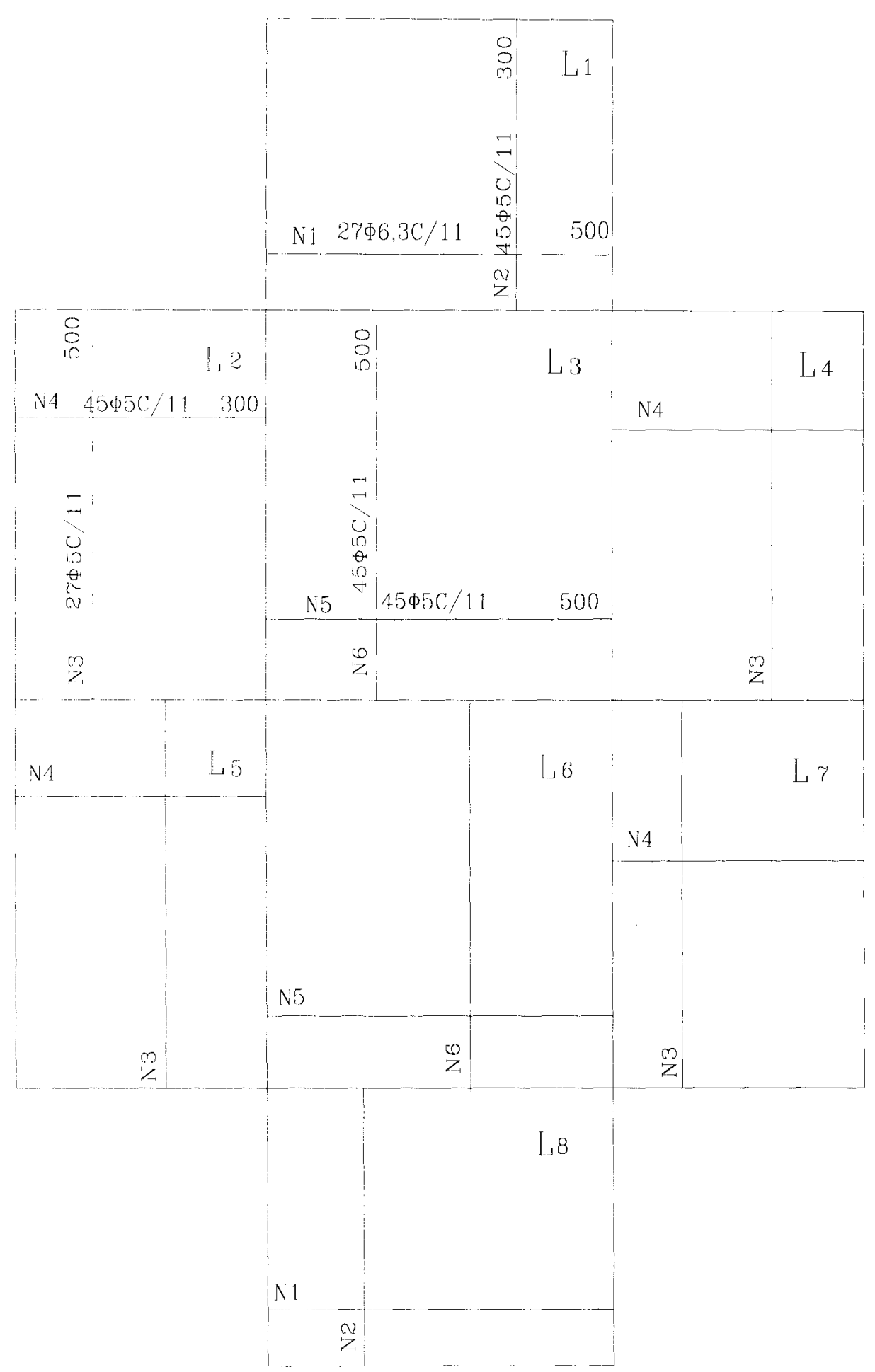

FIGURA 8.10-Detalhamento da armadura inferior (cálculo plástico) 


\subsubsection{COMPRIMENTO DAS BARRAS SOBRE OS APOIOS}

No local onde a armadura é interrompida, como não há mais armadura e a resistência do concreto à tração é desprezada, o momento de plastificação é considerado nulo.

De acordo com a posição do momento, os comprimentos são calculados em função dos lados a e b, ou seja:

$$
\begin{aligned}
& \ell=a-a^{*} \\
& \ell=b-b^{*}
\end{aligned}
$$

Considera-se, conforme demonstrado no capítulo $7, \ell$ o comprimento das barras sobre os apoios. Adota-se o maior $\ell$ encontrado entre as duas configurações.

Tanto para a configuração comum como para a eventual, o lado b é sempre paralelo à charneira central.

Nos casos em que $\ell$ for negativo, as lajes não necessitam de armadura negativa pelo cálculo plástico; basta ancorar a armadura negativa que vem das lajes adjacentes, ou seja, basta adicionar $\mathrm{a}_{\ell}+\ell_{\mathrm{b}}$, sendo:

$$
a_{e}=1,5 d
$$




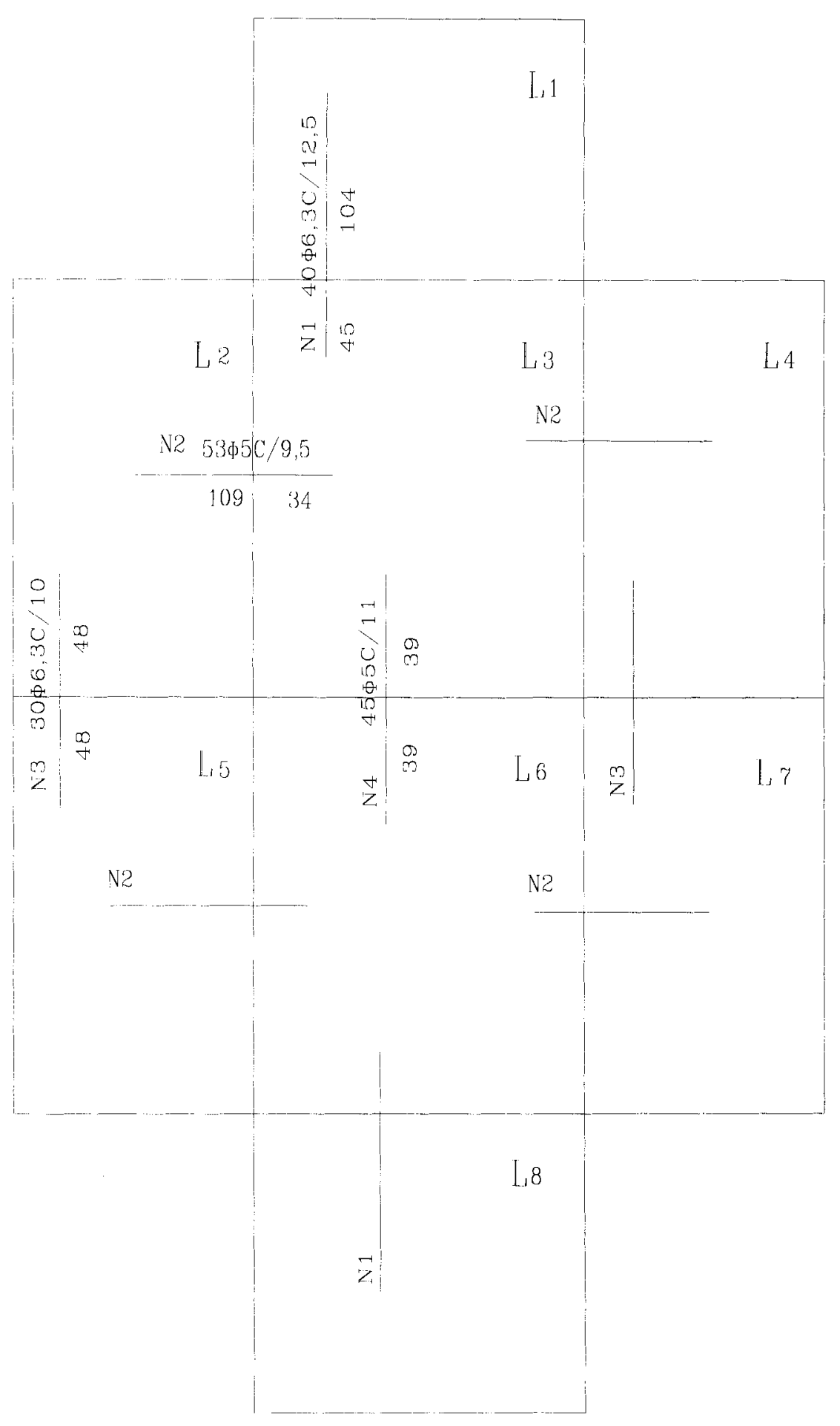

FIGURA 8.11- Detalhamento da armadura superior (cálculo plástico) 
TABELA 8.9- Quantidade de barras (cálculo plástico)

\begin{tabular}{||c|c|c|c|c|c|c||}
\hline ARMADURA & $\mathrm{N}$ & $\mathrm{Q}$ & $\begin{array}{c}\phi \\
(\mathrm{mm})\end{array}$ & $\begin{array}{c}\text { Compr. } \\
(\mathrm{m})\end{array}$ & Quant. & $\begin{array}{c}\text { Compr.Tot. } \\
(\mathrm{m})\end{array}$ \\
\hline \multirow{4}{*}{$\begin{array}{c}\text { ARMADURA } \\
\text { INFERIOR }\end{array}$} & 1 & 2 & 6,3 & 5,00 & 27 & 270,00 \\
\cline { 2 - 7 } & 2 & 2 & 5 & 3,00 & 45 & 270,00 \\
\cline { 2 - 7 } & 4 & 4 & 5 & 3,00 & 45 & 540,00 \\
\cline { 2 - 8 } & 7 & 2 & 5 & 5,00 & 45 & 540,00 \\
\hline \multirow{3}{*}{$\begin{array}{c}\text { ARMADURA } \\
\text { SUPERIOR }\end{array}$} & 2 & 4 & 5 & 1,43 & 53 & 450,00 \\
\cline { 2 - 8 } & 3 & 2 & 6,3 & 0,96 & 30 & 303,16 \\
\cline { 2 - 8 } & 4 & 1 & 5 & 0,78 & 45 & 57,60 \\
\hline
\end{tabular}

TABELA 8.10- Massa do aço da armadura (cálculo plástico)

\begin{tabular}{||c|c|c|c||}
\hline ARMADURA & $\phi(\mathrm{mm})$ & Compr.(m) & Massa(kg) \\
\hline \multirow{2}{*}{ ARMADURA INFERIOR } & 5 & 2250,00 & 360,00 \\
\cline { 2 - 4 } & 6,3 & 270,00 & 67,50 \\
\hline \multirow{2}{*}{ ARMADURA SUPERIOR } & 5 & 338,26 & 54,12 \\
\cline { 2 - 4 } & 6,3 & 176,80 & 44,20 \\
\hline \multicolumn{2}{|c|}{ TOTAL DE·AÇO } & $\mathbf{3 0 3 5 , 0 6}$ & $\mathbf{5 2 5 , 8 2}$ \\
\hline
\end{tabular}

Comparando-se a massa total obtida através do cálculo elástico com a obtida através do cálculo plástico, observa-se que houve uma redução do consumo do aço de $13 \%$. 


\subsubsection{CÁLCULO DAS FLECHAS : VERIFICAÇÃO PARA L1}

a) Momento de fissuração

Segundo a NBR 7197 (1989), para concreto simples o momento de fissuração é obtido da seguinte forma:

$M_{r}=0,25 b_{w} h^{2} f_{t k}$

sendo, para $\mathrm{f}_{\mathrm{ck}} \geq 18 \mathrm{MPa}$ :

$\mathrm{f}_{\mathrm{tk}}=0,06 \mathrm{f}_{\mathrm{ck}}+0,7=1,9 \mathrm{MPa}=0,19 \mathrm{kN} / \mathrm{cm}^{2}$

Portanto:

$\mathrm{M}_{\mathrm{r}}=684 \mathrm{kN} \cdot \mathrm{cm}$

Sendo o momento fletor de serviço dado por:

$\mathrm{M}=646 \mathrm{kN} \cdot \mathrm{cm} / \mathrm{m}$

ou seja:

$\mathrm{M}<\mathrm{M}_{\mathrm{r}}$, a laje se encontra no estádio I.

b) Flecha Imediata

A flecha imediata é dada por: 


$$
a_{i}=\frac{\alpha b}{1200} \cdot \frac{p l_{x}^{4}}{E_{c} I_{e}}
$$

O valor de $\alpha$ é obtido através da tabela 3.13.

$$
\begin{aligned}
& \lambda=\frac{\ell_{y}}{\ell_{x}}=\frac{300}{500}=0,60 \Rightarrow \alpha=2,46 \\
& E_{c}=\text { módulo de elasticidade }=E_{c o} \text { (estádio I) } \\
& E_{c o}=6600 \sqrt{f_{c j}} \\
& f_{c j}=f_{c k}+3,5 \quad(M P a) \\
& f_{c j}=23,50 \mathrm{MPa} \\
& E_{C}=E_{C D}=31995 \mathrm{MPa}=3199,5 \mathrm{kN} / \mathrm{cm}^{2}
\end{aligned}
$$

Através das combinações quase permanentes de utilização, determina-se a solicitação de cálculo:

$$
S_{d, u t i}=S_{g k}+\Psi_{2} S_{q k}
$$

Assim,

$p_{u t i}=g+\Psi_{2} \cdot q$

$p_{\text {uti }}=5,90 \mathrm{kN} / \mathrm{m}^{2} \Rightarrow p=0,00059 \mathrm{kN} / \mathrm{cm}^{2}$

c) Linha neutra

No estádio I tem-se: 
$x_{1}=\frac{0,5 b h^{2}+\alpha_{e}\left(A_{s} d+A^{\prime}{ }_{s} d^{\prime}\right)}{b h+\alpha_{e}\left(A_{s}+A^{\prime}{ }_{s}\right)}$

$\alpha_{e}=\frac{E_{s}}{E_{c}}=\frac{21000}{3199,5}=6,56$

$x_{1}=\frac{0,5 \cdot 100 \cdot 12^{2}+6,56 \cdot 1,82 \cdot 11}{100 \cdot 12+6,56 \cdot 1,82}$

$x_{1}=6,05 \mathrm{~cm}$

d) Momento de inércia

O momento de inércia no estádio I resulta:

$$
\begin{aligned}
& I_{1}=\frac{b h^{3}}{12}+b h\left(x_{1}-\frac{h}{2}\right)^{2}+\alpha_{e} A_{s}\left(d-x_{1}\right)^{2} \\
& I_{1}=14724,47 \mathrm{~cm}^{4}
\end{aligned}
$$

Substituindo esses valores na equação (8.6), obtém-se:

$$
a_{i}=\frac{2,46 \cdot 100}{1200} \cdot \frac{0,00059 \cdot 500^{4}}{3199,5 \cdot 14724,47}
$$

$a_{i}=0,16 \mathrm{~cm}$

e) Flecha decorrente de ações duradouras

$$
a_{1}=a_{i}+a_{l}=\beta a_{i}
$$


$\beta=\frac{2 x+d}{d}$

$\beta=2,09$

$a_{1}=0,33 \mathrm{~cm}$

f) Flecha decorrentes de ações transitórias

$$
\begin{aligned}
& a_{2}=\frac{\alpha b}{1200} \cdot \frac{p_{i} \ell_{x}^{4}}{E_{c} I_{e}} \leq \frac{\ell_{x}}{500} \\
& p_{i}=(1-0,2) \cdot 2=1,6 \mathrm{kN} / \mathrm{m}^{2}=0,00016 \mathrm{kN} / \mathrm{cm}^{2} \\
& a_{2}=\frac{2,46 \cdot 100}{1200} \cdot \frac{0,00016.500^{4}}{3199,5 \cdot 14724,47}
\end{aligned}
$$

$a_{2}=0,04 \mathrm{~cm} \leq 1,00 \quad O K !$

d) Flecha total

$$
\begin{aligned}
& a_{t}=a_{1}+a_{2} \leq \frac{\ell_{x}}{300} \\
& a_{t}=0,37 \mathrm{~cm} \leq 1,67 \mathrm{~cm} \quad \text { OK! }
\end{aligned}
$$




\subsection{EXEMPLO 2}

Este exemplo segue o mesmo critério de cálculo que o primeiro. A figura 8.12 mostra a planta de fôrma do pavimento, que é constituído por 11 lajes. Faz-se, como no exemplo 1, o cálculo do consumo de aço pelo método elástico e pelo método plástico, para fins de comparação. Os vãos, as espessuras e as cargas encontram-se indicados na tab.8.11.

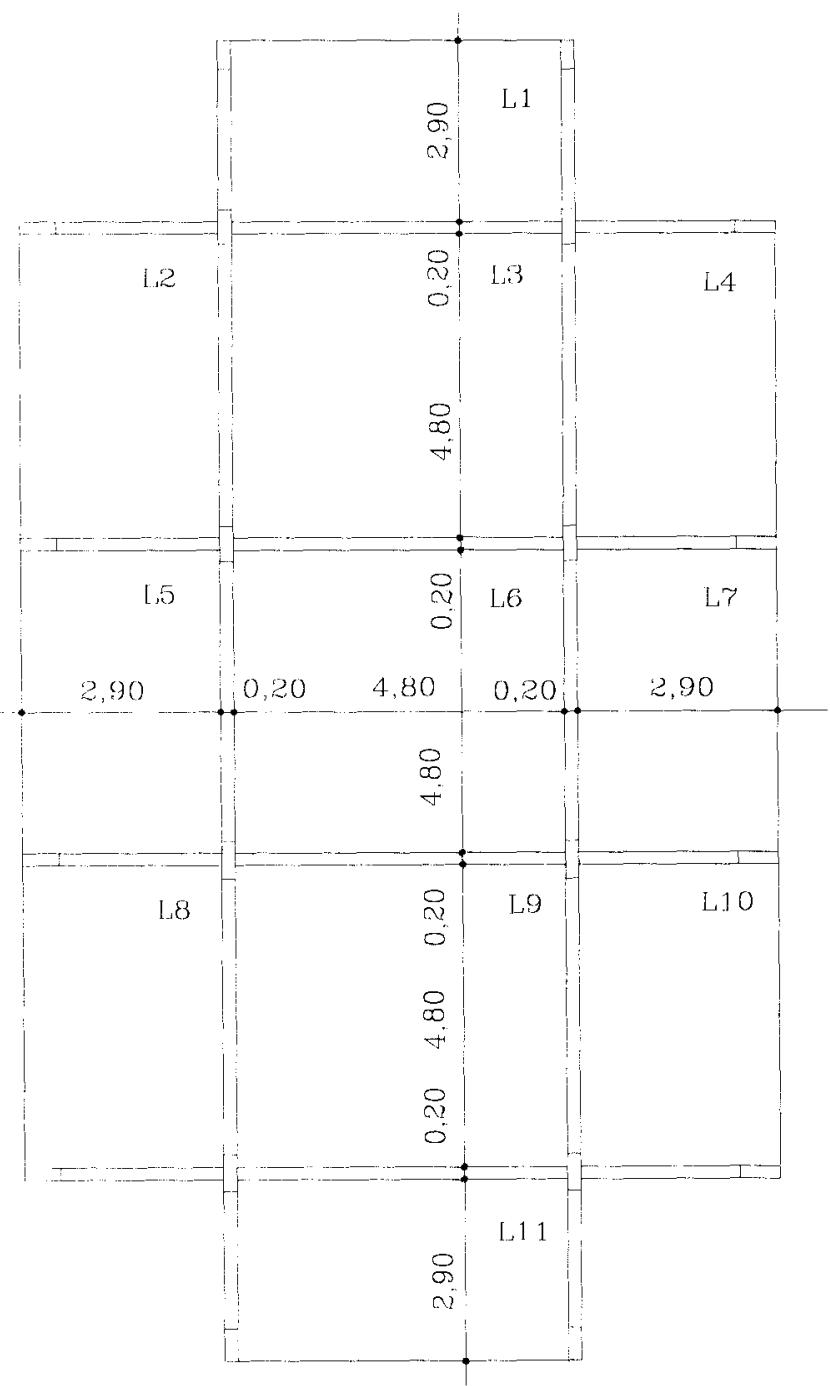

FIGURA 8.12- Planta de fôrma do exemplo 2 
TABELA 8.11- Características e cargas

\begin{tabular}{|c|c|c|c|c|c|}
\hline \multicolumn{2}{|c|}{ LAJES } & $\mathrm{L}_{1}=\mathrm{L}_{11}$ & $\mathrm{~L}_{2}=\mathrm{L}_{4}=\mathrm{L}_{8}=$ & $\mathrm{L}_{5}=\mathrm{L}_{7}$ & $\mathrm{~L}_{3}=\mathrm{L}_{6}=\mathrm{L}_{9}$ \\
\hline \multirow{3}{*}{$\begin{array}{l}\text { CARACTE- } \\
\text { RISTICAS }\end{array}$} & $l_{h}(m)$ & 5,00 & 3,00 & 3,00 & 5,00 \\
\hline & $\ell_{v}(\mathrm{~m})$ & 3,00 & 5,00 & 5,00 & 5,00 \\
\hline & $\mathrm{h}(\mathrm{cm})$ & 12,00 & 12,00 & 12,00 & 12,00 \\
\hline \multirow{6}{*}{$\begin{array}{l}\text { CARGAS } \\
\left(\mathrm{kN} / \mathrm{m}^{2}\right)\end{array}$} & p.p. & 3,00 & 3,00 & 3,00 & 3,00 \\
\hline & piso + revest. & 1,50 & 1,50 & 1,50 & 1,50 \\
\hline & divisórias & 1,00 & 1,00 & 1,00 & 1,00 \\
\hline & $\mathrm{g}$ & 5,50 & 5,50 & 5,50 & 5,50 \\
\hline & $q$ & 2,00 & 2,00 & 2,00 & 2,00 \\
\hline & $p=g+q$ & 7,50 & 7,50 & 7,50 & 7,50 \\
\hline
\end{tabular}

\subsubsection{CÁLCULO DOS MOMENTOS ELÁSTICOS}

Os momentos elásticos foram obtidos seguindo o mesmo critério de cálculo do exemplo 1. Os valores dos momentos estão indicados na tab.8.12 e mostrados na figura 8.13 .

Os momentos elásticos positivos e negativos compatibilizados e as respectivas armaduras estão indicados nas tabelas 8.13 e 8.14 respectivamente.

TABELA 8.12- Momentos elásticos adotados

\begin{tabular}{|c|c|c|c|c||}
\hline LAJES & $\mathrm{L}_{1}=\mathrm{L}_{11}$ & $\mathrm{~L}_{2}=\mathrm{L}_{4}=\mathrm{L}_{8}=\mathrm{L}_{10}$ & $\mathrm{~L}_{5}=\mathrm{L}_{7}$ & $\mathrm{~L}_{3}=\mathrm{L}_{6}=\mathrm{L}_{9}$ \\
\hline $\mathrm{m}_{\mathrm{x}}$ & 6,46 & 5,78 & 4,72 & 3,80 \\
\hline $\mathrm{m}_{\mathrm{x}}{ }^{\prime}$ & - & 16,92 & 13,37 & 9,68 \\
\hline $\mathrm{m}_{\mathrm{y}}$ & 2,32 & 2,22 & 1,57 & 3,80 \\
\hline $\mathrm{m}_{\mathrm{y}}{ }^{\prime}$ & 17,08 & 13,33 & 10,13 & 9,68 \\
\hline
\end{tabular}




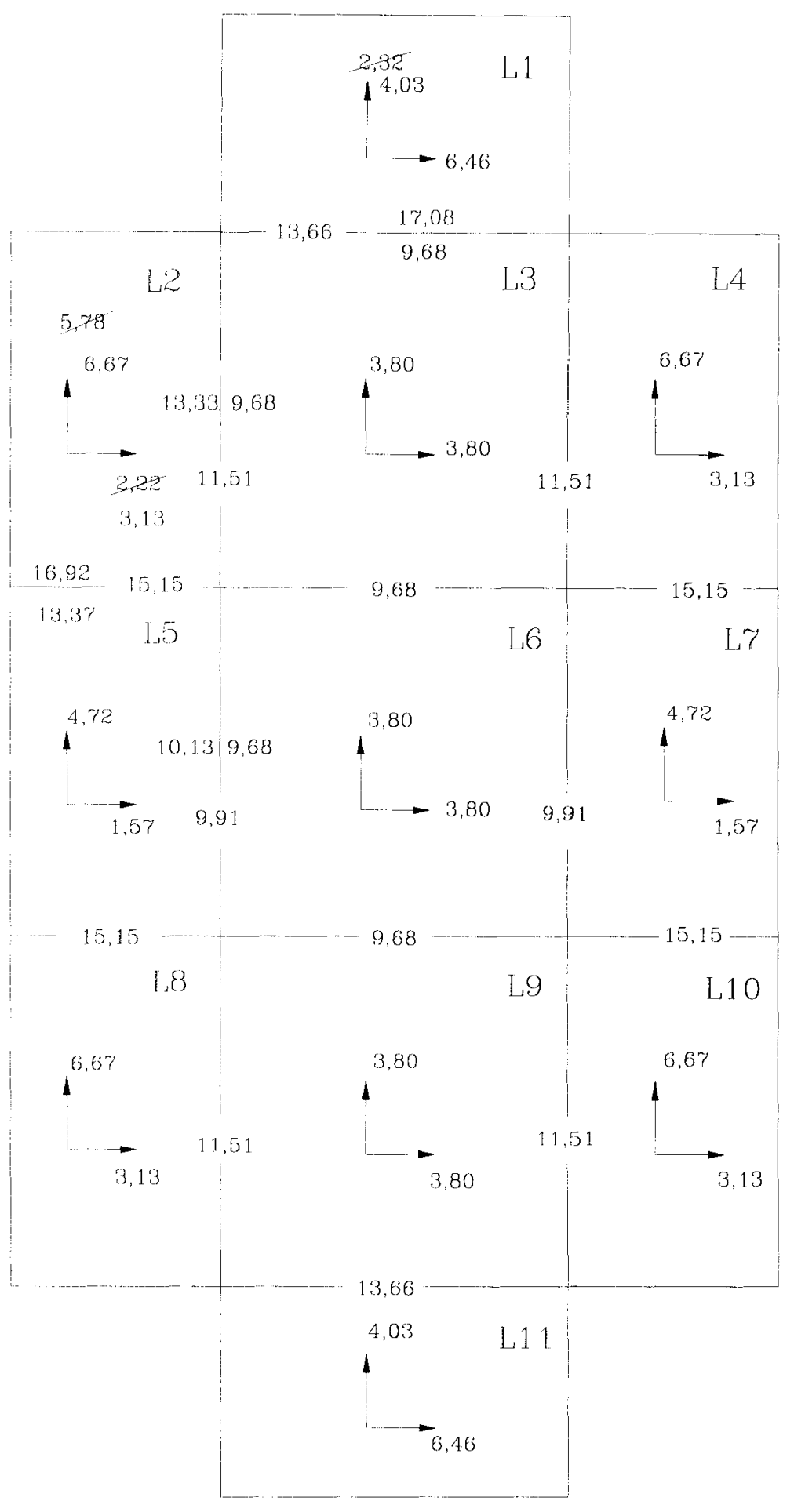

FIGURA 8.13-Momentos elásticos compatibilizados 
TABELA 8.13- Momentos positivos e armaduras do cálculo elástico

\begin{tabular}{|c|c|c|c|c|c|}
\hline \multicolumn{2}{|c|}{ LAJES } & $\mathrm{L}_{1}=\mathrm{L}_{11}$ & $\mathrm{~L}_{2}=\mathrm{L}_{4}=\mathrm{L}_{8}=\mathrm{L}_{10}$ & $\mathrm{~L}_{5}=\mathrm{L}_{7}$ & $\mathrm{~L}_{3}=\mathrm{L}_{6}=\mathrm{L}_{9}$ \\
\hline \multirow{3}{*}{$\begin{array}{c}\text { Momentos } \\
\mathrm{kNm} / \mathrm{m}\end{array}$} & $\mathrm{m}_{\mathrm{x}}$ & 6,46 & 6,67 & 4,72 & 3,80 \\
\hline & $\mathrm{m}_{\mathrm{y}}$ & 4,03 & 3,13 & 1,68 & 3,80 \\
\hline & $\beta$ & 0,62 & 0,47 & 0,36 & 1,00 \\
\hline \multirow{6}{*}{$\begin{array}{c}\text { Armadura } \\
\mathrm{cm}^{2} / \mathrm{m}\end{array}$} & $a_{\text {sxcal }}$ & 1,97 & 2,04 & 1,38 & 1,16 \\
\hline & $\mathbf{a}_{\mathrm{sxadot}}$ & 2,00 & 2,10 & $1,82^{*}$ & $1,82 *$ \\
\hline & adot. & $\phi 5 \mathrm{c} / 10$ & $\phi 6,3 \mathrm{c} / 15$ & $\phi 5 \mathrm{c} / 11$ & $\phi 5 \mathrm{c} / 11$ \\
\hline & $\mathrm{a}_{\text {sycal }}$ & 1,23 & 0,92 & 0,49 & 1,82 \\
\hline & $a_{\text {syadot }}$ & $1,82^{*}$ & $1,82^{*}$ & $1,82^{*}$ & 1,82 \\
\hline & adot. & $\phi 5 \mathrm{c} / 11$ & $\phi 5 \mathrm{c} / 11$ & $\phi 5 \mathrm{c} / 11$ & $\phi 5 \mathrm{c} / 11$ \\
\hline
\end{tabular}

TABELA 8.14- Momentos negativos e armaduras do cálculo elástico

\begin{tabular}{|c|c|c|c|c|c|c|}
\hline \multicolumn{2}{|c|}{ VÍNCULOS } & $\mathrm{L}_{1} \leftrightarrow \mathrm{L}_{3}$ & $\mathrm{~L}_{2} \leftrightarrow \mathrm{L}_{3}$ & $\mathrm{~L}_{2} \leftrightarrow \mathrm{L}_{5}$ & $\mathrm{~L}_{5} \uplus \mathrm{L}_{6}$ & $\mathrm{~L}_{3}-\mathrm{L}_{6}$ \\
\hline \multirow{2}{*}{$\begin{array}{c}\text { Momentos } \\
\mathrm{kNm} / \mathrm{m}\end{array}$} & $m_{x}{ }^{\prime}$ & & & 15,15 & & \\
\hline & $m_{y}^{\prime}$ & 13,66 & 11,51 & & 9,91 & 9,68 \\
\hline \multirow{6}{*}{$\begin{array}{c}\text { Armadura } \\
\mathrm{cm}^{2} / \mathrm{m}\end{array}$} & $\mathrm{a}_{\text {sxcal }}$ & - & - & 4,82 & - & - \\
\hline & $a_{\text {sxadot }}$ & - & - & 5,00 & - & - \\
\hline & adot. & - & - & $\phi 8 \mathrm{c} / 10$ & - & - \\
\hline & $a_{\text {sycal }}$ & 4,35 & 3,52 & - & 3,03 & 2,96 \\
\hline & $\mathrm{a}_{\text {syadot }}$ & 4,55 & 3,57 & - & 3,15 & 3,15 \\
\hline & adot. & $\begin{array}{c}\phi 8 \\
c / 11\end{array}$ & $\begin{array}{c}\phi 8 \\
c / 14\end{array}$ & - & $\begin{array}{l}\phi 6,3 \\
c / 10\end{array}$ & $\begin{array}{l}\phi 6,3 \\
c / 10\end{array}$ \\
\hline
\end{tabular}


As figuras 8.14 e 8.15 demonstram o detalhamento das armaduras inferior e superior respectivamente. A quantidade de aço está indicada na tabela 8.15 e a massa do aço está indicada na tabela 8.16 .

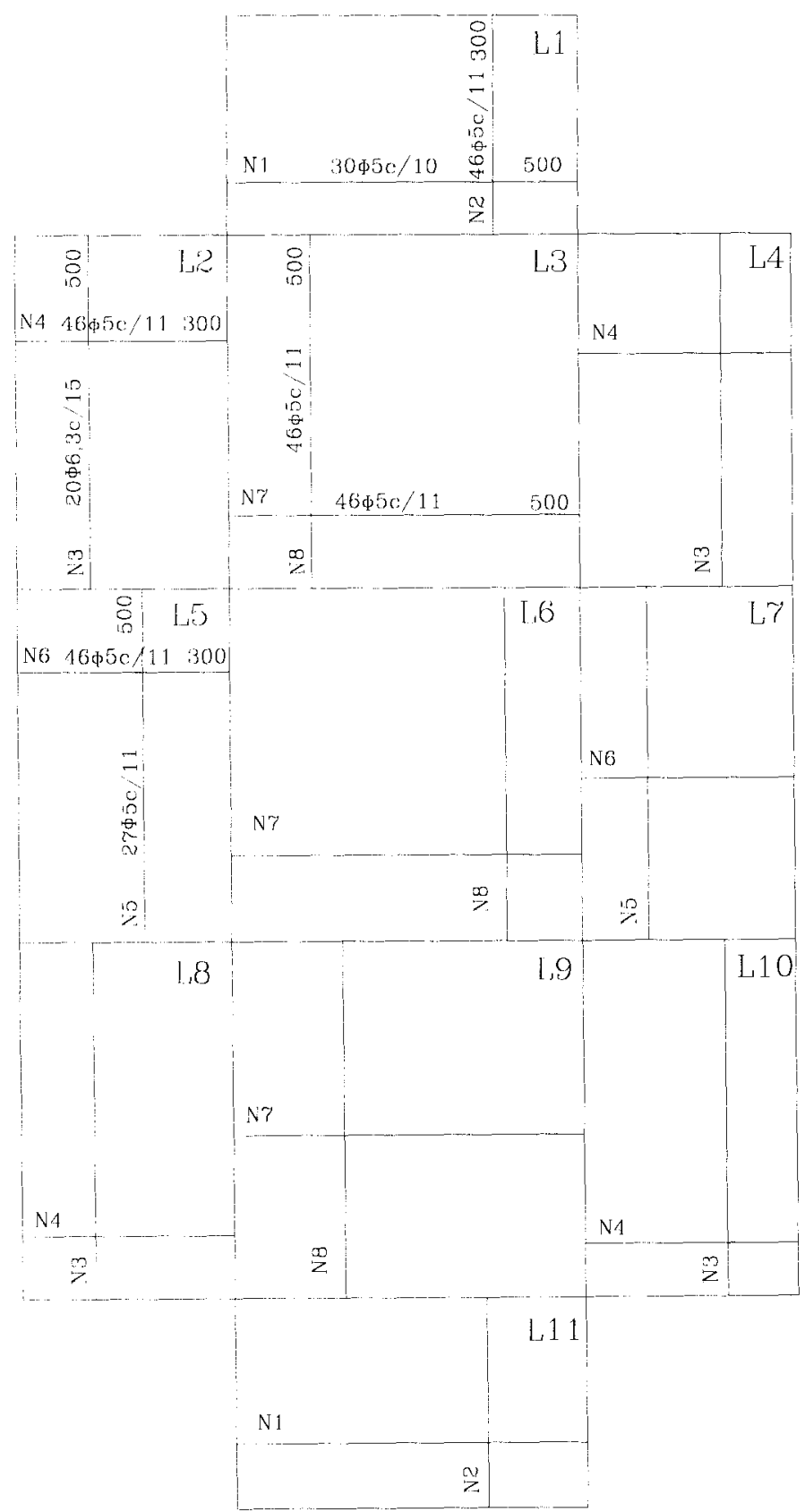

FIGURA 8.14- Detalhamento da armadura inferior (cálculo elástico) 


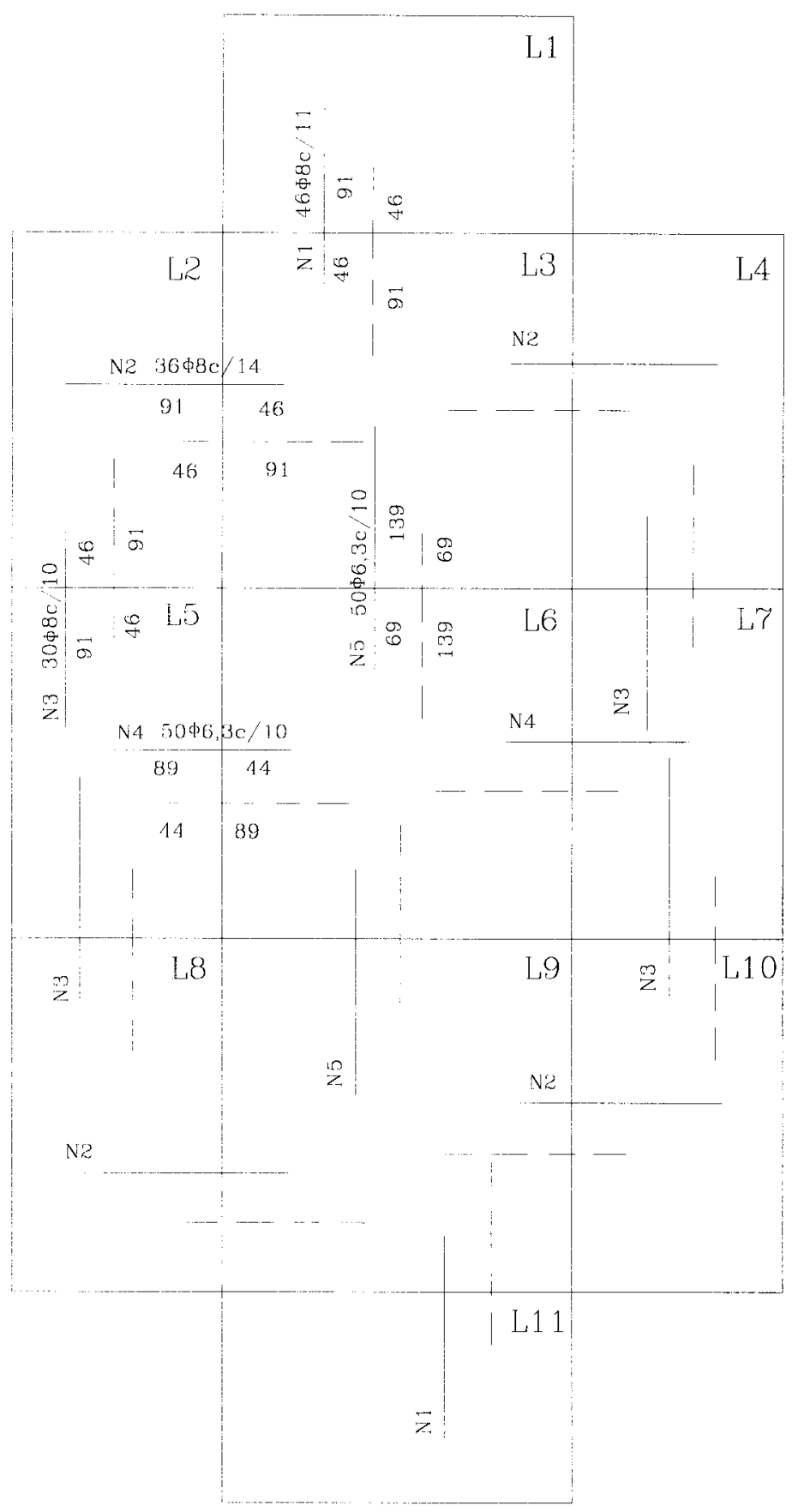

FIGURA 8.15- Detalhamento da armadura superior (cálculo elástico) 
TABELA 8.15- Quantidade de barras (cálculo elástico)

\begin{tabular}{||c|c|c|c|c|c|c||}
\hline ARMADURA & $\mathrm{N}$ & $\mathrm{Q}$ & $\begin{array}{c}\phi \\
(\mathrm{mm})\end{array}$ & $\begin{array}{c}\text { Compr. } \\
(\mathrm{m})\end{array}$ & Quant. & $\begin{array}{c}\text { Compr.Tot. } \\
(\mathrm{m})\end{array}$ \\
\hline & 1 & 2 & 5 & 5,00 & 30 & 300,00 \\
\cline { 2 - 7 } & 2 & 2 & 5 & 3,00 & 46 & 276,00 \\
\cline { 2 - 7 } & 3 & 4 & 6,3 & 5,00 & 20 & 400,00 \\
\cline { 2 - 7 } & 4 & 4 & 5 & 3,00 & 46 & 552,00 \\
\cline { 2 - 7 } ARMADURA & 5 & 2 & 5 & 5,00 & 27 & 270,00 \\
\cline { 2 - 7 } & 6 & 2 & 5 & 3,00 & 46 & 276,00 \\
\cline { 2 - 7 } & 7 & 3 & 5 & 5,00 & 46 & 690,00 \\
\cline { 2 - 7 } & 8 & 3 & 5 & 5,00 & 46 & 690,00 \\
\hline \multirow{5}{*}{\begin{tabular}{c} 
INFERIOR SUPERIOR \\
\cline { 2 - 7 }
\end{tabular}} & 2 & 2 & 8 & 1,37 & 46 & 126,04 \\
\cline { 2 - 7 } & 3 & 2 & 8 & 1,37 & 30 & 197,28 \\
\cline { 2 - 7 } & 4 & 2 & 6,3 & 1,33 & 50 & 136,40 \\
\cline { 2 - 7 } & 5 & 2 & 6,3 & 2,08 & 50 & 208,00 \\
\hline
\end{tabular}

TABELA 8.10- Massa do aço da armadura (cálculo elástico)

\begin{tabular}{||c|c|c|c||}
\hline ARMADURA & $\phi(\mathrm{mm})$ & Compr.(m) & Massa(kg) \\
\hline \multirow{2}{*}{ ARMADURA INFERIOR } & 5 & 3054,00 & 488,64 \\
\cline { 2 - 4 } & 6,3 & 400,00 & 100,00 \\
\hline \multirow{2}{*}{ ARMADURA SUPERIOR } & 6,3 & 341,00 & 85,25 \\
\cline { 2 - 4 } & 8 & 487,72 & 195,09 \\
\hline \multicolumn{2}{|c|}{ TOTAL DE AÇO } & $\mathbf{4 2 8 2 , 7 2}$ & $\mathbf{8 6 8 , 9 8}$ \\
\hline
\end{tabular}




\subsubsection{CÁlCULO PELA TCP}

O critério é o mesmo que o utilizado no exemplo anterior, ou seja, no prédimensionamento utilizam-se os momentos elásticos obtidos anteriormente e os momentos negativos são os provenientes do cálculo elástico, multiplicados por 0,6 . Na fig. 8.16 são mostrados os momentos obtidos pelo cálculo plástico.

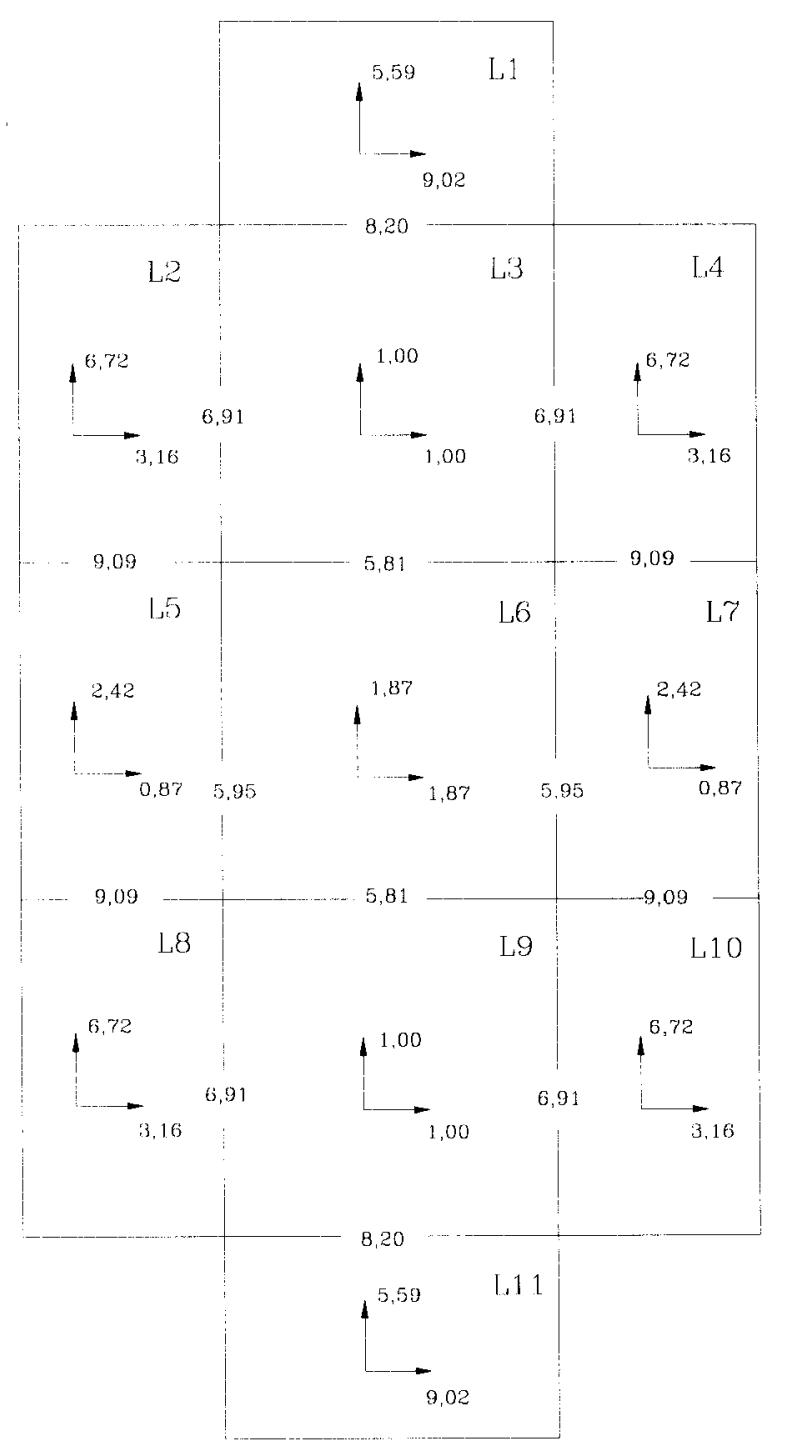

FIGURA 8.16- Momentos do cálculo plástico 
Os momentos positivos e negativos resultantes do cálculo pela TCP e as respectivas armaduras estão indicados nas tabelas 8.17 e 8.18. O detalhamento das armaduras inferior e superior estão demonstrados respectivamente nas figuras 8.17 e 8.18 . As tabelas 8.19 e 8.20 indicam a quantidade e a massa do aço utilizado.

TABELA 8.17- Momentos positivos e armaduras do cálculo plástico

\begin{tabular}{|c|c|c|c|c|c|c|}
\hline \multicolumn{2}{|c|}{ LAJES } & $\mathrm{L}_{1}=\mathrm{L}_{11}$ & $\mathrm{~L}_{2}=\mathrm{L}_{4}=\mathrm{L}_{8}=\mathrm{L}_{10}$ & $\mathrm{~L}_{5}=\mathrm{L}_{7}$ & $\mathrm{~L}_{3}=\mathrm{L}_{9}$ & $\mathrm{~L}_{6}$ \\
\hline \multirow{3}{*}{$\begin{array}{c}\text { Momentos } \\
\mathrm{kNm} / \mathrm{m}\end{array}$} & $m_{x}$ & 9,02 & 6,72 & 2,42 & 1,00 & 1,87 \\
\hline & $m_{y}$ & 5,59 & 3,16 & 0,87 & 1,00 & 1,87 \\
\hline & $\beta$ & 0,62 & 0,47 & 0,36 & 1,00 & 1,00 \\
\hline \multirow{6}{*}{$\begin{array}{c}\text { Armadura } \\
\mathrm{cm}^{2} / \mathrm{m}\end{array}$} & $a_{\text {sxcal }}$ & 2,76 & 2,05 & 0,71 & 0,29 & 0,55 \\
\hline & $a_{\text {sxadot }}$ & 2,86 & 2,11 & $1,82^{*}$ & $1,82 *$ & $1,82 *$ \\
\hline & adot. & $\phi 6,3 \mathrm{c} / 11$ & $\phi 5 \mathrm{c} / 9,5$ & $\phi 5 \mathrm{c} / 11$ & $\phi 5 \mathrm{c} / 11$ & $\phi 5 \mathrm{c} / 11$ \\
\hline & $a_{\text {sycal }}$ & 1,71 & 0,93 & 0,25 & 0,29 & 0,55 \\
\hline & $a_{\text {syadot }}$ & $1,82^{*}$ & $1,82 *$ & $1,82 *$ & 1,82 & $1,82^{*}$ \\
\hline & adot. & $\phi 5 \mathrm{c} / 11$ & $\phi 5 \mathrm{c} / 11$ & $\phi 5 \mathrm{c} / 11$ & $\phi 5 \mathrm{c} / 11$ & $\phi 5 \mathrm{c} / 11$ \\
\hline \multicolumn{2}{|c|}{$\mathrm{m}_{\text {xadot. }}$} & 9,35 & 6,92 & 5,94 & 6,02 & 5,93 \\
\hline \multicolumn{2}{|c|}{$m_{\text {yadot. }}$} & 5,95 & 5,93 & 6,07 & 6,02 & 5,93 \\
\hline
\end{tabular}


TABELA 8.18- Momentos negativos e armaduras do cálculo plástico

\begin{tabular}{|c|c|c|c|c|c|c|}
\hline \multicolumn{2}{|c|}{ VÍNCULOS } & $\mathrm{L}_{1} \leftrightarrow \mathrm{L}_{3}$ & $\mathrm{~L}_{2} \leftrightarrow \mathrm{L}_{3}$ & $\mathrm{~L}_{2} \leftrightarrow \mathrm{L}_{5}$ & $\mathrm{~L}_{5} * \mathrm{~L}_{6}$ & $\mathrm{~L}_{3} \leftrightarrow \mathrm{L}_{6}$ \\
\hline \multirow{2}{*}{$\begin{array}{c}\text { Momentos } \\
\mathrm{kNm} / \mathrm{m}\end{array}$} & $\mathrm{m}_{\mathrm{x}}^{\prime}$ & - & - & 9,09 & - & - \\
\hline & $m_{y}^{\prime}$ & 8,20 & 6,91 & - & 5,95 & 5,81 \\
\hline \multirow{7}{*}{$\begin{array}{l}\text { Armadura } \\
\mathrm{cm}^{2} / \mathrm{m}\end{array}$} & $\mathrm{a}_{\mathrm{sxcal}}$ & - & - & 2,78 & - & - \\
\hline & $\mathbf{a}_{\text {sxadot }}$ & - & - & 2,86 & - & - \\
\hline & adot. & - & - & $\begin{array}{l}\phi 6,3 \\
c / 11\end{array}$ & - & - \\
\hline & $a_{\text {sycal }}$ & 2,50 & 2,11 & - & 1,82 & 1,77 \\
\hline & $a_{\text {syadot }}$ & 2,52 & 2,11 & - & 1,82 & $1,82^{*}$ \\
\hline & adot. & $\phi 6,3$ & $\phi 5$ & - & $\phi 5$ & $\phi 5$ \\
\hline & & $\mathrm{c} / 12,5$ & $\mathrm{c} / 9,5$ & & $\mathrm{c} / 11$ & $\mathrm{c} / 11$ \\
\hline \multicolumn{2}{|c|}{$\mathrm{m}_{\text {xadot. }}$} & - & - & 9,35 & - & - \\
\hline \multicolumn{2}{|c|}{$\mathbf{m}_{\text {yadot. }}$} & 8,26 & 6,91 & - & 5,95 & 5,97 \\
\hline \multicolumn{7}{|c|}{$* \mathrm{~A}_{\mathrm{s} \min }=1,82 \mathrm{~cm}^{2} / \mathrm{m}$} \\
\hline
\end{tabular}




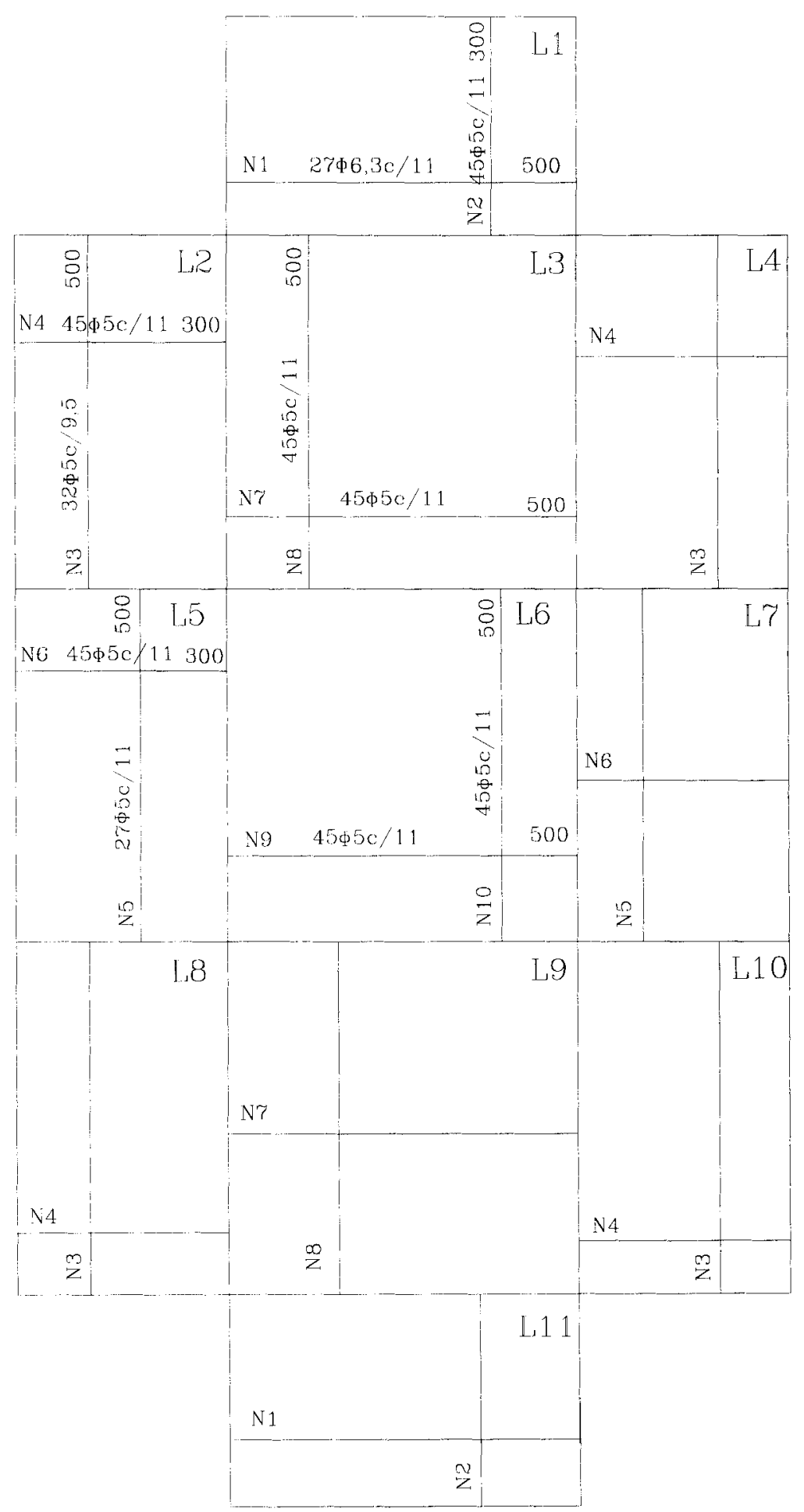

FIGURA 8.17- Detalhamento da armadura inferior (cálculo plástico) 


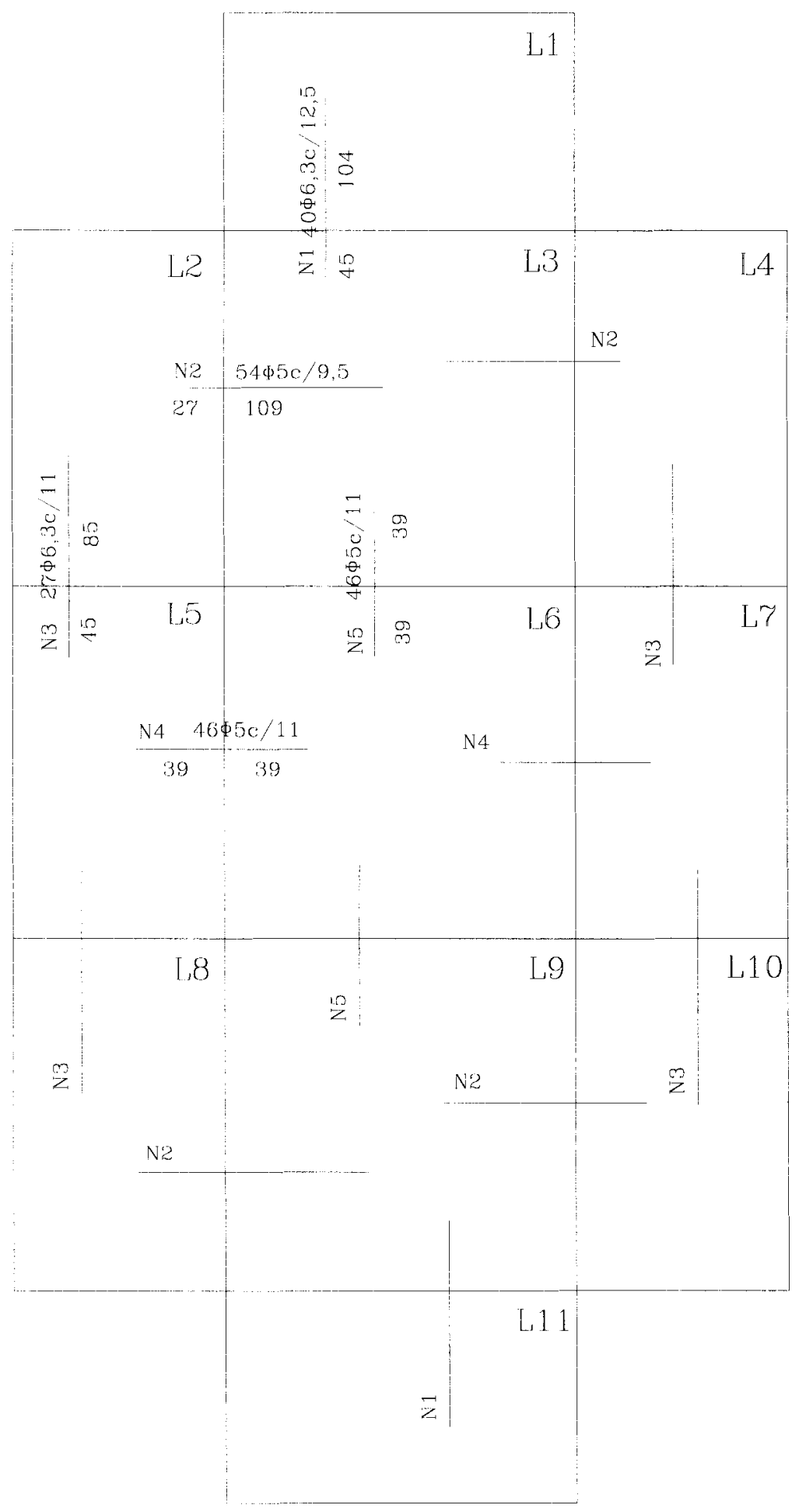

FIGURA 8.18- Detalhamento da armadura superior (cálculo plástico) 
TABELA 8.19- Quantidade de barras (cálculo plástico)

\begin{tabular}{|c|c|c|c|c|c|c|}
\hline ARMADURA & $\mathrm{N}$ & $\mathrm{Q}$ & $\begin{array}{c}\phi \\
(\mathrm{mm}) \\
\end{array}$ & $\begin{array}{c}\text { Compr. } \\
(\mathrm{m})\end{array}$ & Quant. & $\begin{array}{c}\text { Compr.Tot. } \\
\text { (m) }\end{array}$ \\
\hline \multirow{10}{*}{$\begin{array}{l}\text { ARMADURA } \\
\text { INFERIOR }\end{array}$} & 1 & 2 & 6,3 & 5,00 & 27 & 270,00 \\
\hline & 2 & 2 & 5 & 3,00 & 45 & 270,00 \\
\hline & 3 & 4 & 5 & 5,00 & 32 & 640,00 \\
\hline & 4 & 4 & 5 & 3,00 & 45 & 540,00 \\
\hline & 5 & 2 & 5 & 5,00 & 27 & 270,00 \\
\hline & 6 & 2 & 5 & 3,00 & 45 & 270,00 \\
\hline & 7 & 2 & 5 & 5,00 & 45 & 450,00 \\
\hline & 8 & 2 & 5 & 5,00 & 45 & 450,00 \\
\hline & 9 & 1 & 5 & 5,00 & 45 & 225,00 \\
\hline & 10 & 1 & 5 & 5,00 & 45 & 225,00 \\
\hline \multirow{5}{*}{$\begin{array}{c}\text { ARMADURA } \\
\text { SUPERIOR }\end{array}$} & 1 & 2 & 63 & 1,49 & 40 & 119,20 \\
\hline & 2 & 4 & 5 & 1,36 & 54 & 293,76 \\
\hline & 3 & 4 & 63 & 1,30 & 27 & 140,40 \\
\hline & 4 & 2 & 5 & 0,78 & 46 & 71,76 \\
\hline & 5 & 2 & 5 & 0,78 & 46 & 71,76 \\
\hline
\end{tabular}

TABELA 8.20- Massa do aço da armadura (cálculo plástico)

\begin{tabular}{||c|c|c|c|}
\hline ARMADURA & $\phi(\mathrm{mm})$ & Compr.(m) & Massa(kg) \\
\hline \multirow{2}{*}{ ARMADURA INFERIOR } & 5 & 3340,00 & 534,40 \\
\cline { 2 - 4 } & 6,3 & 270,00 & 67,50 \\
\hline \multirow{2}{*}{ ARMADURA SUPERIOR } & 6,3 & 437,28 & 69,96 \\
\cline { 2 - 4 } & 8 & 259,60 & 64,90 \\
\hline \multicolumn{2}{|c|}{ TOTAL DE AÇO } & $\mathbf{4 3 0 6 , 8 8}$ & $\mathbf{7 3 6 , 7 6}$ \\
\hline
\end{tabular}

Fazendo-se uma comparação entre a massa total obtida através do cálculo elástico com a obtida através do cálculo plástico, observa-se que houve uma redução do consumo do aço de $18 \%$. 


\subsubsection{CÁLCULO DAS FLECHAS}

A verificação da flecha foi feita para a laje 1 por ser a mais crítica. Como o momento fletor é o mesmo para as lajes dos dois exemplos, o valor da flecha para a carga total será o mesmo que o obtido no exemplo 1, ou seja:

$$
\begin{aligned}
& a_{t}=0,37 \mathrm{~cm} \leq \frac{\ell_{x}}{300} \\
& a_{t}=0,37 \mathrm{~cm} \leq 1,67 \mathrm{~cm} \quad \text { OK! }
\end{aligned}
$$




\section{CONSIDERAÇÕES FINAIS}

Serão apresentadas as contribuições deste trabalho, uma análise dos resultados, as conclusões e sugestões para novas pesquisas.

\subsection{CONTRIBUIÇÕES DO TRABALHO}

RIOS (1991) apresentou o cálculo das lajes retangulares com uma borda livre pela teoria das charneiras plásticas, considerando carga uniformemente distribuída e carga linear ao longo da borda livre.

Neste trabalho foram incluídas funções aproximadoras dos momentos fletores e das flechas e exemplos considerando a associação dos cálculos elástico e plástico, inclusive com determinação do comprimento das barras negativas com base na TCP e a verificação de flechas, considerando momentos fletores obtidos em regime elástico, coerentes com o comportamento em serviço.

\subsection{ANÁLISE DOS RESULTADOS}

O cálculo pela teoria das charneiras plásticas, sendo fixados os próprios momentos negativos e a relação entre os positivos, é bastante vantajoso para a análise de pavimentos, já que não há necessidade de se usar um processo iterativo entre as lajes 
vizinhas. O cálculo é feito uma única vez para cada laje isoladamente, sendo bastante simples. Analisando-se as tabelas referentes ao consumo de aço, observou-se que há uma economia significativa quando o método plástico é comparado com o elástico. Essa economia se dá também pelo fato de serem utilizados momentos máximos para o cálculo elástico, enquanto que no cálculo plástico os momentos são considerados constantes. A economia foi de $13 \%$ no exemplo 1 e de $18 \%$ no exemplo 2. Poderia ser maior, se não resultasse armadura mínima em tantas lajes.

Mesmo se sabendo que o cálculo de lajes pela TCP geralmente conduz a momentos fletores menores que os resultantes do cálculo elástico, deve-se ter em mente que o cálculo elástico é imprescindivel. A escolha dos momentos negativos e da relação entre os positivos, baseados na teoria da elasticidade, não violenta o comportamento das lajes em serviço, permitindo uma distribuição mais racional das armaduras.

Uma vez que é recomendado que o cálculo elástico seja efetuado previamente, sua automação pode ser feita substituindo-se as tabelas por funções aproximadoras, como fez PINHEIRO (1988) para lajes retangulares com bordas apoiadas ou engastadas Neste trabalho foram acrescentadas lajes com uma borda livre.

Quanto aos momentos negativos, deve-se ressaltar que, no cálculo plástico, recomenda-se que sejam adotados os do cálculo elástico reduzidos, de forma que os momentos positivos finais não resultem muito pequenos. Isto é interessante tanto do ponto de vista econômico como do ponto de vista prático. Sabe-se que, em última instância, as armaduras inferiores são as responsáveis pela segurança da laje, não sendo conveniente que essas armaduras apresentem pequena capacidade resistente, tendo em conta as más condições a que ficam submetidas as barras superiores, durante a execução da laje. Ao mesmo tempo, resultam em armaduras mais balanceadas, o que permite a adoção de espessuras menores.

Nos exemplos ora realizados, os momentos máximos positivos do cálculo plástico resultaram mais próximos dos negativos para fatores de redução dos momentos negativos elásticos da ordem de 0,6 , nos vínculos relativos a pelo menos uma laje com uma borda livre, e em torno de 0,5 nos demais vínculos, adjacentes a lajes com bordas apoiadas ou engastadas. 


\subsection{CONCLUSÕES}

A associação do cálculo elástico com a teoria das charneiras plásticas é bastante adequada para lajes retangulares de edifícios, cada método sendo utilizado na condição em que ele é mais apropriado.

O cálculo elástico pode ser utilizado para pré-dimensionamento, na escolha dos momentos de plastificação negativos e da razão entre os positivos nas duas direções.

O cálculo plástico deve ser usado para dimensionamento da armadura e no cálculo do comprimento das barras sobre os apoios.

Conhecidas as armaduras, os momentos fletores elásticos podem novamente ser empregados para verificação dos estados limites de utilização, pois são mais coerentes com o comportamento das lajes em serviço.

Nos exemplos elaborados, verificou-se que os momentos de plastificação negativos podem ser obtidos dos elásticos multiplicados por 0,5 ou 0,6 , sendo este último fator mais adequado para vínculos adjacentes a pelo menos uma laje com borda livre. Para vínculos referentes a lajes com bordas apoiadas ou engastadas, o fator 0,5 parece ser o mais adequado.

Pôde ser verificada também uma economia do cálculo plástico em relação ao elástico, da ordem de $13 \%$ a $18 \%$, que poderia ser bem maior, se não resultassem tantas lajes com armadura mínima. A economia cresce com o número de vínculos engastados.

Conclui-se, portanto, que a associação proposta é duplamente vantajosa. Além de utilizar o cálculo adequado a cada fase de solicitação da laje, conduz a uma economia significativa em relação ao uso exclusivo do cálculo elástico. 


\subsection{SUGESTÕES PARA NOVAS PESQUISAS}

Sugere-se que sejam feitos outros exemplos, variando o tipo das lajes, considerando inclusive as lajes com mais de uma borda livre.

Pode-se fazer um estudo mais apurado dos estados limites de utilização, incluindo-se a verificação de fissuração. Devem ser analisados os procedimentos que permitam a sistematização do pré-dimensionamento das lajes, no que diz respeito à determinação da espessura. Os valores sugeridos pelas normas são, em geral, exagerados, sobretudo por serem valores que dispensam a verificação das flechas.

As sugestões ora propostas poderão conduzir a um aprimoramento ainda maior do cálculo de lajes de edifícios. 


\section{REFERÊNCIAS}

AMARAL, O.C. Sobre as lajes contínuas. Revista da Escola de Engenharia da UFMG, Belo Horizonte, v.3, n.6, p.133-161, nov. 1964.

AMERICAN CONCRETE INSTITUTE. Building code requirements for reinforced concrete (ACI 318M-83). Detroit, ACI, 1985.

ARMER, G.S.T. The strip method: a new approach to the design of slabs. Concrete, p.358-363, Sept. 1968.

ARMER, G.S.T. Ultimate load tests of slabs designed by the strip method. Proceedings of Institution of Civil Engineers, v.41, p.313-331, Oct. 1968.

ASSOCIAÇÃO BRASILEIRA DE NORMAS TÉCNICAS. NBR 6118 - Projeto e execução de obras de concreto armado. Rio de Janeiro, ABNT, 1978. 76p.

ASSOCIAÇÃO BRASILEIRA DE NORMAS TÉCNICAS. NBR 6120 - Cargas para o cálculo de estruturas de edificações. Rio de Janeiro, ABNT, 1980. 6p.

ASSOCIAÇÃO BRASILEIRA DE NORMAS TÉCNICAS. NBR 8681 - Ações e segurança nas estruturas. Rio de Janeiro, ABNT, 1984.

ASSOCIAÇÃO BRASILEIRA DE NORMAS TÉCNICAS. NBR 7197 - Projeto de estruturas de concreto protendido. Rio de Janeiro, ABNT, 1989. 71p.

BARES, R. Tablas para el calculo de placas y vigas pared. Barcelona, Gustavo Gili, 1972.

CHAMECKI, S. Cálculo de lajes no regime de ruptura. In: ENCICLOPÉDIA Técnica Universal Globo. v.6

CHAMECKI, S. Cálculo no regime de ruptura, das lajes de concreto armadas em cruz. Curitiba, Guaíra, 1948. 106p.

COMITÉ EUROPÉEN DU BÉTON. Dalles et estructures planes: annexes aux recommandations internationales pour le calcul et l'execution des ouvrages en beton. Roma, Associazione Italiana Tecnico-Economica del Cemento (AITEC), 1972. Tome 3, 196p.

CORRÊA, M.R.S. Aplicação do método das faixas finitas na análise de estruturas prismáticas. São Carlos, 1983. Dissertação (Mestrado) - Escola de Engenharia de São Carlos, Universidade de São Paulo. 
CRAWFORD, R.E. Limit design of reinforced concrete slabs. Urbana, 1962. Thesis, University of Illinois.

CRAWFORD, R.E. Limit design of reinforced slabs. Journal of Engineering Mechanics Division, ASCE, v.90, n.5, p.321-342, Oct. 1964.

CZERNY, F. Tafeln fur vierseitig und dreiseitig gelagerte Rechteckplatten (Tabelas para placas retangulares apoiadas em quatro ou três lados). Betonkalender, Berlin, v.65, n.1, p.305-381, 1976.

FERNANDO, J.S.; KEMP, K.O. The strip method of slab design: unique or lowerbound solutions? Magazine of Concrete Research, v.27, n.90, p.23-29, Mar. 1975.

GALILEI, G. Discorsi e dimonstrazioni matematicke: intorno à due nuove scienze. Leida, Elsevirii, 1638. (Tradução em inglês: Two new sciences, by Henry Crew and Alfonso de Savio. New York, The Mackmillan Company, 1933).

GVOZDEV, A.A. Determinación del valor de la carga de rotura para los sistemas estaticamente indeterminados. Proyecto y Norma, n.8, 1934.

GVOZDEV, A.A. Determinación del valor de la carga de rotura para los sistemas estaticamente indeterminados que surgem deformaciones plásticas. Trabajos de las Conferencias sobre Deformaciones Plásticas, Academia de Ciências de la URSS, Departamento de Ciências Técnicas, Moscú, 1938.

GVOZDEV, A.A. Fundamentación del $\delta 33$ de las normas para el proyecto de las estructuras de hormigon armado. Industria de la Construcción, n.3, 1939.

GVOZDEV, A.A. Acerca del equilibrio límite. In: MANUAL del Ingeniero. 1948. v.5

GVOZDEV, A.A. Cálculo de la capacidade portante de las estructuras por el método del equilibrio limite. Moscú, Struzdat, 1949.

GVOZDEV, A.A. Método del equilibrio límite y su aplicación al cálculo de estructuras de hormigón armado. In: MANUAL del Ingeniero. 2.ed. 1949. v.5

HILLERBORG, A. Jamviktsteori for armerade betongplattor (Teoria do equilíbrio para lajes de concreto armado). Betong, v.41, n. 4, p.171-182, 1956.

HILLERBORG, A. A plastic theory for the design of reinforced concrete slabs. In: CONGRESS OF THE INTERNATIONAL ASSOCIATION FOR BRIDGE AND STRUCTURAL ENGINEERING, 6., Stockholm, 1960. Proceedings. p.177-186 
HILLERBORG, A. Strimlemetoden for plattor pa pelare, vin Kelplattor mm.

Stockholm, Utgiven av. SvenskaRiksby ggen, 1959. (Tradução em inglês: Strip method for slabs on columns, L. shaped plates, etc. Melbourne, CSIRO, Division of Building Research, 1964.

HILLERBORG, A. Strip method of design. London, William \& Sons, 1975. 255p.

(A Wiewpoint publication)

INGERSLEV, A. The strength of rectangular slabs. The Institution of Structural Engineers Journal, Jan. 1923

JOHANSEN, K.W. Bruchmomente fur Kreuzweise bewehrten Platten. Mémories, Association Intenationale des Ponts et Charpents, p.277-296, 1932.

JOHANSEN, K.W. Brudlinieteorier. Genoptrykt, Polyteknisk Forening, 1937. $189 \mathrm{p}$.

JOHANSEN, K.W. Pladeformler. 2.ed. Kokenkaun, Polyteknisk Forening, 1949. $172 \mathrm{p}$.

JONES, L.L. The use of nodal forces in yield-line analysis. In: RECENT developments in yield-line theory. London, Cement and Concrete Association, 1965. (M.C.R. Special Publication)

JONES, L.L. Ultimate load analysis of reinforced and prestressed concrete structures. New York, Frederick Ungar Publishing, 1966. 248p.

KEMP, K.O. The evaluation of nodal and edge forces in yield-line theory. In: RECENT developments in yield-line theory. London, Cement and Concrete Association, 1965. (M.C.R. Special Publication)

LANGENDONCK, T. Charneiras plásticas em lajes de edificios. São Paulo, ABCP, 1966. 81p.

LANGENDONCK, T. Teoria elementar das charneiras plásticas. São Paulo, ABCP, 1970. v.1

LANGENDONCK, T. Lajes em forma de T ou L. São Paulo, ABCP, 1972. 89p.

LANGENDOCK, T. Teoria elementar das charneiras plásticas. São Paulo, ABCP, 1975. v. 2

MACHADO, C.P. Sugestões para um aprimoramento do método aproximado de avaliação de flechas de peças de concreto armado da NBR-6118/78. In: SIMPÓSIO EPUSP SOBRE ESTRUTURAS DE CONCRETO, 1., São Paulo, 2224 ago. 1989. Anais. São Paulo, NEP/EPUSP, 1989. v.2, p.659-689 
MANSFIELD, E.H. Studies in collapse analysis of rigid-plastic plates with a square yield diagram. Proceedings of the Royal Society, London, p.211-338, 1957.

MANZOLI, O.L.; PINHEIRO, L.M.; PAIVA, J.B. Elaboração de tabelas para o cálculo de placas elásticas retangulares pelo método dos elementos de contorno. São Carlos, EESC-USP, 1986. (Relatório de Pesquisa, CNPq)

MARCUS, H. Vereinfachte Berechnung biegsamer Platten (Cálculo simplificado de placas fletidas). 2.ed. Berlin, Julius Springer, 1929.

MELGES, J.L.P. Padronização das tabelas para cálculo de lajes retangulares, com carregamento uniforme. Relatório de IC-CNPq, 1993, EESC-USP, Departamento de Estruturas.

MONTOYA, P.J.; MESEGUER, A.G.; CABRE, F.M. Hormigon armado. 7.ed. Barcelona, Gustavo Gili, 1973. v.2

MORLEY, C.T. Equilibrium methods for least upper bounds of rigid-plastic plates. In: RECENT developments in yield-line theory. London, Cement and Concrete Association, 1965. (M.C.R. Special Publication)

NIELSEN, M.P. A new nodal-force theory. In: RECENT developments in yieldline theory. London, Cement and Concrete Association, 1965. (M.C.R. Special Publication)

PINHEIRO, L.M. Análise elástica e plástica de lajes retangulares de edificios. São Carlos, 1988. 303p. Tese (Doutorado) - Escola de Engenharia de São Carlos, Universidade de São Paulo.

PINHEIRO, L.M. Concreto armado: tabelas e ábacos. São Carlos, EESC-USP, 1986. 66p.

POLILLO, A. Dimensionamento de concreto armado. 2.ed. Rio de Janeiro, Científica, 1974. v.2

RIOS, P.M. Lajes retangulares de edificios: associação do cálculo elástico com a teoria das charneiras plásticas. São Carlos, 1991. 246p. Dissertação (Mestrado) Escola de Engenharia de São Carlos, Universidade de São Paulo.

ROCHA, A.M. Novo curso prático de concreto armado. 12.ed. Rio de Janeiro, Científica, 1971. v.1

SANTOS, L.M. Edificios de concreto armado: generalidades, lajes. São Paulo, FDTE-EPUSP-IPT, 1984. (mimeografado) 
SANTOS, L.M. Cálculo plástico de lajes contínuas de edifícios de concreto armado. In: SIMPÓSIO EPUSP SOBRE ESTRUTURAS DE CONCRETO, 1., São Paulo, 22-24 ago. 1989. Anais. São Paulo, NEP/EPUSP, 1989. v.2, p.577-608

SILVA, R.C.; GIONGO, J.S. Concreto armado: estados limites de utilização. São Carlos, EESC-USP, 1994.

WOOD, R.H. Plastic and elastic design of slabs and plates. London, Thames \& Hudson, 1961.

WOOD, R.H. New techniques in nodal-force theory for slabs. In: RECENT developments in yield-line theory. London, Cement and Concrete Association, 1965. (M.C.R. Special Publication)

WOOD, R.H. ; ARMER, G.S.T. The theory of the strip method for design of slabs. Proceedings of Institution of Civil Engineers, v.41, p. 285-311, Oct. 1968. 